UNIVERSIDADE DE SÃO PAULO

FACULDADE DE ARQUITETURA E URBANISMO

Roselene de Araujo Motta Ferreira Nogueira

\title{
Arquitetura escolar estadual paulista: o desafio do Conforto Ambiental
}


Roselene de Araujo Motta Ferreira Nogueira

\section{Arquitetura escolar estadual paulista: o desafio do Conforto Ambiental}

Dissertação apresentada à Faculdade de Arquitetura e Urbanismo da Universidade de São Paulo, para obtenção do título de Mestre em Arquitetura e Urbanismo

Área de Concentração: Tecnologia da Arquitetura Orientadora: Prof $^{a}{ }^{-} r^{a}$ Anésia Barros Frota

EXEMPLAR REVISADO E ALTERADO EM RELAÇÃO À VERSÃO ORIGINAL, SOB RESPONSABILIDADE DO AUTOR E ANUEENCIA DO ORIENTADOR. $O$ original se encontra disponível na sede do programa.

São Paulo, 17 de agosto de 2011

São Paulo 
AUTORIZO A REPRODUÇÃO E DIVULGAÇÃO TOTAL OU PARCIAL DESTE TRABALHO, POR QUALQUER MEIO CONVENCIONAL OU ELETRÔNICO, PARA FINS DE ESTUDO E PESQUISA, DESDE QUE CITADA A FONTE.

e-MAIL roselene@usp.br

roselene.nogueira@fde.sp.gov.br

roselene.motta@gmail.com

Nogueira, Roselene de Araujo Motta Ferreira

N778a Arquitetura escolar estadual paulista: o desafio do conforto ambiental / Roselene de Araujo Motta Ferreira Nogueira. -- São Paulo, 2011.

XXX p. : il.

Dissertação (Mestrado - Área de Concentração: Tecnologia da Arquitetura) - FAUUSP.

Orientadora: Anésia Barros Frota

1.Escolas (Arquitetura) 2.Conforto ambiental I.Título

CDU 727.1 
NOGUEIRA, Roselene de Araujo Motta Ferreira

Arquitetura escolar estadual paulista: o desafio do Conforto Ambiental

Dissertação apresentada à Faculdade de Arquitetura e Urbanismo da Universidade de São Paulo, para obtenção do título de Mestre em Conforto Ambiental

Área de Concentração: Tecnologia da Arquitetura

Orientadora: Prof ${ }^{a}$ Dr$^{a}$ Anésia Barros Frota

Aprovada em:

Banca Examinadora

Prof Dr : Instituição

Julgamento Assinatura

Prof Dr : Instituição

Julgamento Assinatura

Prof Dr: Instituição

Julgamento Assinatura 


\section{Agradecimentos}

A Beatriz, Heloísa, Isabela e Moacyr pelo Amor que tudo espera e jamais acaba.

À Suely Teresinha, minha mãe, ao Alberto, meu pai na Terra, e à Luciana, minha irmãzinha, pelo apoio, incentivo, e pela confiança irrestrita que em mim depositam.

Ao Samuel, meu pai no céu, pelo legado em livros e valor à Educação.

À Nonô e ao Vovô - Leonor e Francisco, meus avós maternos, porque sempre acreditaram; e também aos avós paternos Francisca e Rosalvo, e Diamantina e Manoel, no tempo que lhes coube.

À Prof ${ }^{a}$ Anésia Barros Frota, minha orientadora e meu ideal acadêmico, pelo apoio ilimitado e pela infinita paciência.

Aos Profs Ualfrido Del Carlo e Júlio Roberto Katinsky pela Iniciação Científica, e ao Prof Luis Carlos Chichierchio pelas aulas na Ambiental sobre o livro do LNEC, fundamentos das convicções que construí.

Aos Profs João Gualberto de Azevedo Baring e Maria Lucia Refinetti Rodrigues Martins pelos comentários preciosos durante a banca de Qualificação.

Aos colegas do LABAUT Leonardo Marques Monteiro, Alessandra Prata e Bruna Luz pelos comentários a este trabalho.

A Roberta Kehdy pelo apoio multidisciplinar.

À FDE, na pessoa do seu então Presidente dr Fabio Bonini, por ratificar a pertinência deste curso às minhas atividades como funcionária da FDE, quando o conforto ambiental ainda não era objeto das diretrizes do projeto escolar.

Às amigas e colegas Avany de Francisco Ferreira e Mirela Geiger de Mello, respectivamente Gerente e Chefe de Projetos na FDE, pelo aprendizado diário com as autoras das mais citadas referências bibliográficas em Arquitetura Escolar, e pela disponibilização de material para esta pesquisa.

À amiga e colega Nanci Saraiva Moreira, pelo apoio, incentivo, aprendizado, e parceria.

A todos os amigos e colegas da FDE, que em diversos momentos e intensidades acreditaram e curtiram comigo a realização deste trabalho, sobretudo: Ana Claudia Souza de Oliveira, Claudia Del Negro Tayer, Cristina Machado, Cristina Tosta, Dimas Bertolotti, Emico Matsumoto, Fabiana Frota de Albuquerque Landi, Fernanda Sene Prado Uegama, Flavio Hadlich, Ivanir Reis Neves Abreu, Marcela Jimenez Rodrigues, Maria Laura Fogaça Zei, Marjorie Morad, Naide Patapas Cotrim Correia, Nancy Hitomi Suzuki, Rita Beatriz Enge, Sandra Tiemi Canashiro, Sílvia Regina Fernandes Morales e Siméia de Carvalho Pinto. 


\section{RESUMO}

As escolas estaduais paulistas são objeto de atuação da Fundação para o Desenvolvimento da Educação (FDE) e contam hoje 5.247 unidades $^{1}$ em todo o Estado. Os projetos de adequação e ampliação das escolas existentes, bem como das novas edificações, são terceirizados a escritórios de Arquitetura que coordenam a elaboração do projeto completo, cabendo à equipe da Gerência de Projetos da FDE analisar o produto para verificar o atendimento às Normas de Apresentação de Projetos e aos Catálogos Técnicos - que contêm especificações de Ambientes, Mobiliário, Layout, Componentes e Serviços - às Normas Técnicas Brasileiras e à Legislação interveniente. Tais Normas de Apresentação de Projetos e Catálogos Técnicos são desenvolvidos e atualizados continuamente pela equipe técnica da FDE, também em conformidade às Normas Técnicas e à legislação, e consonantes às políticas públicas da Secretaria de Estado da Educação (SEE) que a FDE tem por missão executar. Neste contexto, as diretrizes e parâmetros que guardam alguma relação com as disciplinas de conforto ambiental, introduzidas neste conjunto até 2.008, aproximadamente, o foram de forma indireta e não sistemática ao longo da história da arquitetura escolar. Paralelamente, a premência em todo o planeta por tornar sustentáveis as ações humanas gerou dispositivos legais que obrigam à inserção destas disciplinas ao conjunto de referências para projeto. A FDE encontrase atualmente nesta transição; diretrizes de sustentabilidade vêm sendo elaboradas para implantação a curto, médio e longo prazo e serão parte integrante dos Catálogos Técnicos ao projeto, preponderantemente por imposição legal, mas também por iniciativas pontuais internas. Desta forma, o objeto deste trabalho são os insumos de conforto ambiental como elemento para a formulação de diretrizes de projeto e de instrumentos para sua análise. O objetivo é verificar as questões de conforto ambiental que já incorporadas a projetos de escolas estaduais, estabelecendo um panorama atual como base para a futura formulação de diretrizes e sistematização de instrumentos. Como contribuição, descrevem-se as convicções acerca dos conhecimentos expostos ao longo do texto sobre a necessidade, a premência, a pertinência, a possibilidade e a viabilidade de, enfim, projetar a escola estadual paulista sob a lente do conforto ambiental.

Palavras-chave: Escolas (Arquitetura); Conforto ambiental.

\footnotetext{
${ }^{1}$ Fevereiro 2011 fonte: CIE
} 


\section{ABSTRACT}

State schools in São Paulo are objects of action by the Foundation for the Development of Education (FDE) and comprise today $5.247^{2}$ units throughout the State of São Paulo. Designs aiming at adjusting and enlarging the existing schools, as well as those intended to build new ones are outsourced to architecture firms in charge of coordinating the production of the whole drafting, the staff of Design Management from FDE being responsible for analyzing the product so as to verify compliance with the Design Presentation Standards and the Technical Catalogues- which contain specifications as regards Rooms, Furniture, Layout, Components and Services- with Brazilian Technical Standards and with the intervening Legislation. Such Design Presentation Standards and Technical Catalogues are constantly developed and updated by FDE's technical staff, also in accordance with the Technical Standard and the legislation, and pursuant to the public policies of the State Secretariat of Education (SEE), the performance of which stands as FDE's purpose. In this context, the guidelines and parameters which bear any relation to the discipline of environmental comfort, introduced in this ensemble at about 2.008, were so introduced in an indirect way and not systematically along the history of school architecture. In much the same direction, the urge all over the planet to make human actions sustainable, has engendered legal provisions which require the insertion of these disciplines in the ensemble of design criteria. FDE stands at this moment in this transition; sustainability guidelines are being developed for implementation in the short, medium and long runs, and will be included in the Technical Catalogues to the design, predominantly for legal imposition, but also owing to internal punctual initiatives. Thus, the object of this study are the inputs of environmental comfort as constitutive elements for the creation of design guidelines and of instruments to analyze the same. The study aims at examining the issues of environmental comfort already incorporated in the design of state schools, establishing a current view as a ground for the future formulation of guidelines and systematization of instruments. As a contribution, the study describes the beliefs, through the awareness displayed throughout the text, on the need, the urge, the relevance, the possibility and the feasibility of, ultimately, designing state schools in São Paulo under the perspective of environmental comfort.

Key words: Schools (Architecture); environmental comfort.

\footnotetext{
${ }^{2}$ CIE data / February, 2011
} 


\section{LISTA DE ABREVIATURAS E SIGLAS}

CDHU Companhia de Desenvolvimento Habitacional e Urbano do Estado de São Paulo

CIE Centro de Informações Educacionais da FDE

CONESP Companhia de Construções Escolares do Estado de São Paulo

CPOS Companhia Paulista de Obras e Serviços

DOP Diretoria de Obras Públicas

EE Escola Estadual

FDE Fundação para o Desenvolvimento da Educação

FECE Fundo Estadual de Construções Escolares

IPESP Instituto de Previdência do Estado de São Paulo

OECD Organização para o Desenvolvimento Econômico

SEE Secretaria de Estado da Educação 
Figura 1 - Mapa de 1877 à esquerda, com ampliação do detalhe em que aparece a Escola de Primeiras Letras do Arouche, à direita; fonte: site do arquivo público do Estado de São Paulo, acesso $2010 .$.

Figura 2 - Escola de Primeiras Letras, acesso pela atual Rua Aguiar de Barros, 160 - fonte: arquivos da FDE

Figura 3 - Escola de Primeiras Letras - Elevações que ilustram as dimensões das aberturas - fonte: arquivos da FDE....

Figura 4 - Localização da Escola de Primeiras Letras, inaugurada em 1879 junto à Estrada para Santo Amaro. A legenda aponta para o isolamento dos ambientes, ilustrando a separação entre alunos e alunas. O lote contíguo presumivelmente utilizado para acesso da banda aqui chamada " $A$ ", fazia parte da área maior doada pela Baronesa de Limeira; no entanto, este lote não encontra-se atualmente sob a posse do Governo do Estado. Desenho: NOGUEIRA, Roselene ...........................17 Figura 5 - Grupo Escolar Rodrigues Alves, do arquiteto Ramos de Azevedo, na Avenida Paulista imagem: arquivo FAUUSP, in (FERREIRA, CORREAA e MELLO, 1998); texto sobre imagem pela

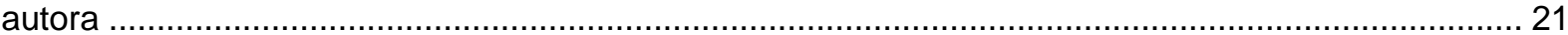
Figura 6 - Escola Normal de Botucatu, do arquiteto Victor Dubugras - iluminação do interior da sala de aula - imagem: João Musa, in (FERREIRA, CORRÊA e MELLO, 1998); texto sobre imagem pela autora

Figura 7 - Grupo Escolar Padre Manoel da Nóbrega, do arquiteto Hernani do Val Penteado, bairro da Freguesia do Ó, São Paulo - imagem: arquivo DOP-CPOS in (FERREIRA, CORREA e MELLO, 1998); texto sobre imagem pela autora

Figura 8 - EE Prof ${ }^{a}$ Marina Cintra, bairro da Consolação, São Paulo, do arquiteto José Maria da Silva Neves - abertura para ventilação cruzada acima da porta e lousa dupla para driblar ofuscamento; imagem: arquivo DOP-CPOS in (FERREIRA, CORRÊA e MELLO, 1998) Figura 9 - EE Prof ${ }^{a}$ Marina Cintra, bairro da Consolação, São Paulo, do arquiteto José Maria da Silva Neves - - iluminação natural nas circulações - imagem: Carlos Kipnis, in (FERREIRA, CORRÊA e MELLO, 1998)

Figura 10 - EE Princesa Isabel, bairro da Saúde, São Paulo, do arquiteto José Maria da Silva Neves iluminação natural na circulação - imagem: Carlos Kipnis in (FERREIRA, CORRÊA e MELLO, 1998)

Figura 11 - escola no bairro do Tatuapé, São Paulo, do arquiteto José Maria da Silva Neves - a implantação da escola volta-se para a melhor orientação solar ao invés de seguir a ortogonalidade das vias públicas - imagem: Revista Acrópole ..................................................................... 25 Figura 12 - croquis de Hélio Duarte - Revista Habitat 4 in (FERREIRA, CORRÊA e MELLO, 1998); texto sobre imagem pela autora .................................................................................... 27 Figura 13 - EE Brasílio Machado, bairro da Vila Mariana, São Paulo - imagem: acervo FDE in (FERREIRA, CORRÊA e MELLO, 1998) .......................................................................... 28 Figura 14 - EE Brasílio Machado, bairro da Vila Mariana, São Paulo - imagem: Carlos Kipnis in (FERREIRA, CORRÊA e MELLO, 1998) ............................................................................ 28 Figura 15 - Ginásio de Itanhaém, do arquiteto Vilanova Artigas - imagem: Fundação Vilanova Artigas in (FERREIRA, CORRÊA e MELLO, 1998); texto sobre imagem pela autora ................................... 31 Figura 16 Ginásio de Guarulhos, do arquiteto Vilanova Artigas - imagem: Carlos Kipnis, arquivos da

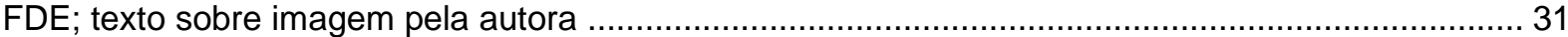
Figura 17 - EE Doutor Telêmaco Paioli Melges, Campinas, do escritório UNA Arquitetos, 2004; imagem: Nelson Kon in (FERREIRA e MELLO, 2006) ......................................................... 34 Figura 18 - EE Conjunto Habitacional Campinas E1B de André Vainer e Guilherme Paoliello, 2004; imagem: Carlos Kipnis in (FERREIRA e MELLO, 2006) ............................................................ 34 Figura 19 - EE Jornalista Roberto Marinho / CHB F2, em Campinas, do escritório Andrade Morettin, 2004; imagem: Nelson Kon in (FERREIRA e MELLO, 2006) ................................................... 35 Figura 20 EE Conjunto Habitacional Campinas F1, do escritório MMBB, 2004; imagem: Nelson Kon in (FERREIRA e MELLO, 2006)...................................................................................... 35 Figura 21 - Software Climaticus: telas de classificação de Mahoney e zonas climáticas segundo

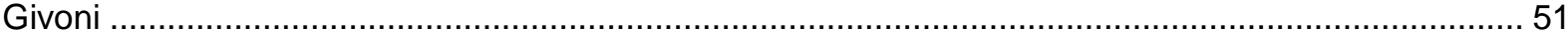

Figura 22 - Software Fachada: tela de entrada de dados .................................................... 52 Figura 23 - Software Chaminé: tela de entrada de dados e resultados.........................................5 52 Figura 24 - Software Humano: telas de seleção da cidade e de opções relativas ao usuário e

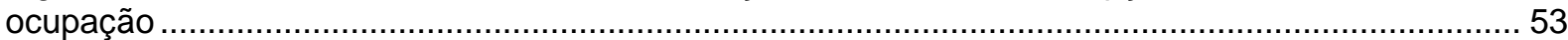
Figura 25 - Software Obstrução: tela de resultados para ar-condicionado, aquecimento e iluminação

Figura 26 - Software Lux: tela de entrada de dados do ambiente a ser avaliado. 
Figura 27 - Software Acústico: tela de entrada de dados da via, da barreira e da fachada ................55 Figura 28 - Software BD Acústica: tela de índice de isolamento de lajes/coberturas e de coeficiente

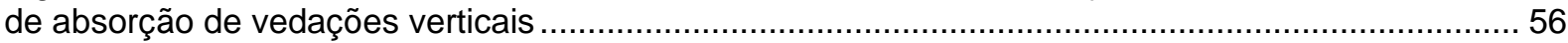
Figura 29 - Software Urbanus: tela de resultados de perda de calor por evaporação e trocas térmicas

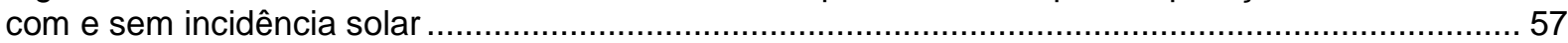

Figura 30 - Software Tensil: telas de resultados de conforto térmico e níveis de iluminância .............57

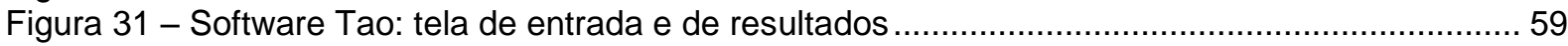

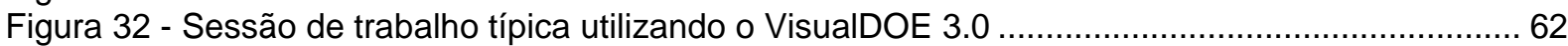

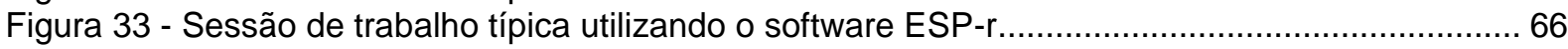

Figura 34 - Sessão de trabalho típica utilizando o software Ecotect ...............................................68

Figura 35 - Modelo no SketchUp com estudo de sombras e penetração solar ....................................69

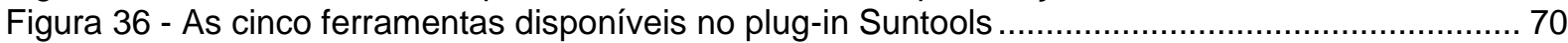

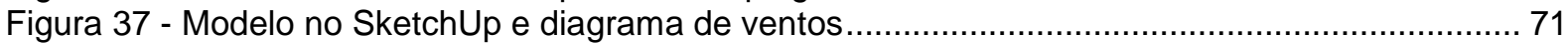

Figura 38 - Modelo no SketchUp e estudo de iluminação natural ................................................... 71

Figura 39 - Sessão de trabalho típica utilizando o Tas 3D Modeller ................................................ 73

Figura 40 - Zoneamento de um pavimento de um modelo gerado no Tas ....................................... 74

Figura 41 - Camadas com as informações necessárias para os materiais de uma parede externa ... 74

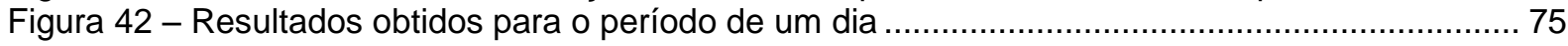

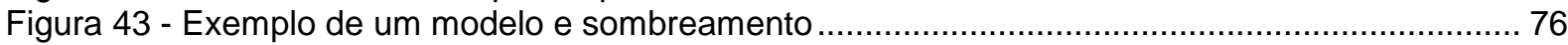

Figura 44 - Temperatura e radiação global para 14 dias de verão .................................................. 76

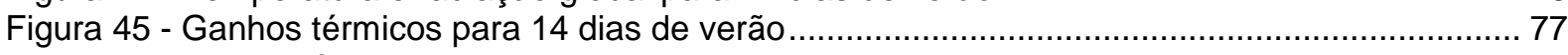

Figura 46 - Perdas térmicas para 14 dias de verão ............................................................... 77

Figura 47 - Esquema de ventilação cruzada e ventilação unilateral e esquema de ventilação cruzada

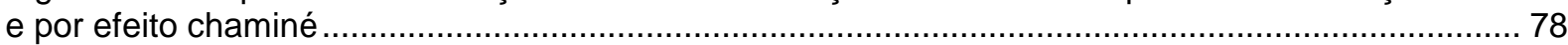

Figura 48 - Esquema de ventilação através de fachada dupla e esquema de regime múltiplo de

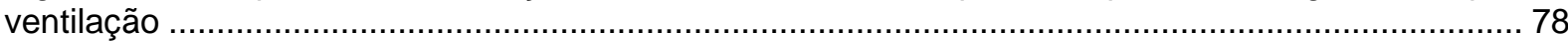

Figura 49 - Resultados em Temperatura Resultante ................................................................. 79

Figura 50 - Visualização "foto-realística" e por "intensidade" (iluminâncias) ….................................... 80

Figura 51 - Esquema de exportação de projeto desenvolvido no Tas............................................... 81

Figura 52 - Esquema de projeto no módulo Tas Systems ......................................................... 82

Figura 53 - Esquema de Plotagem de temperatura resultante de conforto e de resultados de PPD... 83

Figura 54 - Simulação de uma sala de escritório usando o CFD 3D e outra simulação para o mesmo

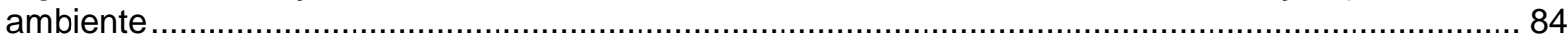

Figura 55 - Escolas estaduais existentes no entorno do Aeroporto de Viracopos, Campinas - imagem

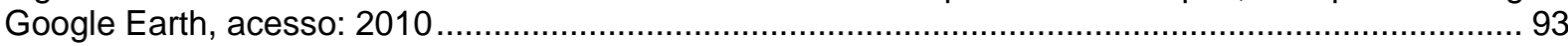

Figura 56 - Adensamento ocorrido no entorno da EE Paul Eugéne Charbonneau entre 2002 e 2009,

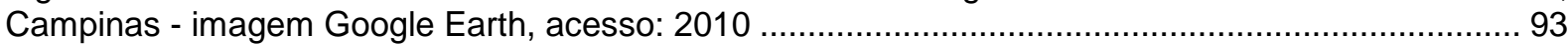

Figura 57 - Adensamento ocorrido no Jardim Marisa entre 2002 e 2009, Campinas - imagem Google

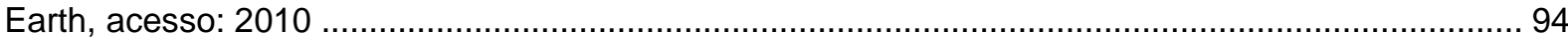

Figura 58 - Adensamento ocorrido no entorno da EE Celeste Palandi de Mello, EE Francisco de Assis

e Terreno Jd Marisa entre 2002 e 2009, Campinas - imagem Google Earth, acesso: 2010 ............... 94

Figura 60 - Plano Específico de Zoneamento de Ruído, arquivo FDE ............................................ 95

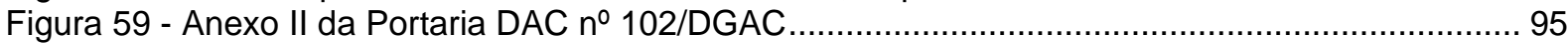

Figura 61- Esquema ilustrativo do sistema de geotermia ............................................................ 97

Figura 62 - Exemplo de medição: "Limites de zonas de ruído aeronáutico em alguns países" ........ 102

Figura 63 - Exemplo de medição de ruído aeronáutico; fonte: INFRAERO ….................................. 102

Figura 64 - Evolução da curva de ruído do Aeroporto de Chicago - fonte: site do Aeroporto O'Hare,

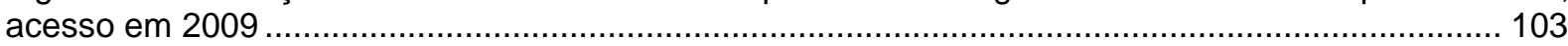

Figura 65 - Certificado de Alta Qualidade Ambiental - AQUA obtido pela FDE para a fase Programa

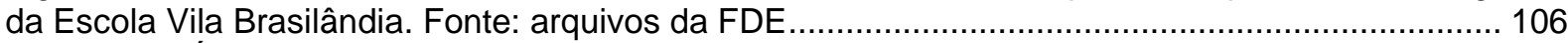
Figura 66 - Área do site da FDE para acesso aos catálogos técnicos, manuais técnicos e normas de projetos. 
SUMÁRIO

$\begin{array}{ll}\text { INTRODUÇÃO } & 10\end{array}$

Objeto 11

Objetivo 11

$\begin{array}{ll}\text { Estrutura } & 12\end{array}$

1. Panorama histórico da arquitetura escolar estadual paulista 13

$1.1 \quad$ O período imperial 13

1.2. Escolas pioneiras da República 1890-1920 19

1.3. Escolas sem representatividade arquitetônica do período 1920-1950 22

1.4. Comissão escolar 1936-1937 22

1.5 Convênio escolar: os efervescentes anos 1948-1959 26

1.6 IPESP 1957-1966 e FECE 1966-1976 29

1.7 CONESP 1977-1987 32

1.8 FDE 1987-2003 32

1.9 FDE 2003 até hoje: Escolas em sistema estrutural pré-fabricado 32

2. Produção científica voltada à arquitetura escolar pública 36

$\begin{array}{ll}3 . & \text { Instrumentos para projeto }\end{array}$

3.1 Normas Técnicas Brasileiras $\quad 48$

3.2 Softwares 50

3.2.1 Softwares do LABAUT 50

3.2.2 Outros softwares para avaliação de desempenho ambiental 59

3.3 Avaliação Pós-Ocupação: o convênio OECD + USP + SEE 85

4. Projetos da FDE 87

4.1 Projetos da FDE que incorporaram conhecimentos de conforto $\begin{array}{ll}\text { ambiental } & 87\end{array}$

4.2 Escolas em zona aeroportuária: o exemplo de Viracopos 91

$\begin{array}{lll}4.3 & \text { Projetos submetidos à certificação AQUA } & 104\end{array}$

5. Conceitos de conforto ambiental, incorporados e a incorporar $\begin{array}{ll}\text { ao projeto da FDE } & 107\end{array}$

$\begin{array}{lll}5.1 & \text { Conceitos incorporados } & 107\end{array}$

5.2 Roteiro para análise de relatórios de consultoria em conforto ambiental110

5.2.1 Conforto térmico 110

5.2.2 Conforto acústico 112

5.3 Catálogos técnicos da FDE: aspectos incorporados 114

5.4 Catálogos técnicos da FDE: aspectos a incorporar 134

$\begin{array}{ll}\text { CONSIDERAÇÕES FINAIS } & 141\end{array}$

REFERÊNCIAS BIBLIOGRÁFICAS 142 


\section{INTRODUÇÃO}

As escolas estaduais paulistas estão subordinadas à Secretaria de Estado da Educação (SEE), sendo sua construção, adequação, ampliação e manutenção da responsabilidade da Fundação para o Desenvolvimento da Educação (FDE).

A FDE foi criada em $1987^{3}$ e tem entre seus objetivos, fornecer recursos físicos para a educação, em especial em cumprimento ou como complementação às políticas definidas pela SEE para executar as políticas públicas da SEE.

A FDE tem sob sua responsabilidade $5.247^{4}$ unidades escolares existentes, além dos prédios administrativos, bem como a construção de obras novas. Os projetos são terceirizados a escritórios de Arquitetura que coordenam a elaboração do projeto completo, cabendo à equipe da Gerência de Projetos da FDE analisar o produto para verificar 0 atendimento às exigências da SEE, às Normas de Apresentação de Projetos e aos Catálogos Técnicos FDE, às Normas Técnicas Brasileiras e à Legislação interveniente.

As Normas de Apresentação de Projetos e os Catálogos Técnicos de especificações de Ambientes, Mobiliário, Layout, Componentes e Serviços, são desenvolvidos e atualizados continuamente pela equipe técnica da FDE, não só em conformidade às Normas Técnicas e à legislação vigente mas consonantes às políticas públicas da Secretaria de Estado da Educação (SEE) que a FDE tem por missão executar - e estão disponíveis para consulta no site (FDE, 2.011).

Neste contexto, as diretrizes e parâmetros que guardam alguma relação com as disciplinas de conforto ambiental, introduzidas neste conjunto até 2.008, aproximadamente, o foram de forma indireta e não sistemática ao longo da história da arquitetura escolar. Paralelamente, a premência em todo o planeta por tornar sustentáveis as ações humanas gerou dispositivos legais que vêm sendo

\footnotetext{
${ }^{3}$ Decreto no 27.102 de 23 de Junho de 1987

Nova redação do Estatuto Decreto № 51.925, de 22 de junho de 2007

${ }^{4}$ Centro de Informações Educacionais - CIE - relatório fevereiro/2011 cf Portaria FDE n 075/2008
} 
determinantes pela inserção destas disciplinas ao conjunto de referências para projeto.

A FDE encontra-se atualmente nesta transição; diretrizes de sustentabilidade vêm sendo elaboradas para implantação a curto, médio e longo prazo e serão parte integrante dos Catálogos Técnicos, preponderantemente por imposição legal, mas também por iniciativas pontuais internas.

Tais diretrizes abrangem desde medidas mais complexas como o estudo de fontes de energia renováveis para escolas isoladas e sem acesso à energia elétrica, como sistemas de energia solar fotovoltaicos autônomos, a equipamentos como bicicletários e cestos para coleta seletiva de lixo.

Assim, este trabalho acontece num momento em que as políticas públicas da SEE que a FDE tem por missão executar - estão alinhadas às questões ambientais, o que se constitui em vetor fundamental e decisivo para que esta pesquisa cumpra de imediato a função de referência para o projeto escolar sustentável ou verde.

\section{Objeto}

O objeto deste trabalho são os insumos de conforto ambiental como elemento para a formulação de diretrizes de projeto e de instrumentos para sua análise.

\section{Objetivo}

O objetivo é estabelecer o panorama atual das questões de conforto ambiental no projeto de escolas estaduais como base para a futura formulação de diretrizes e sistematização de instrumentos. Como contribuição, descrevem-se as convicções acerca dos conhecimentos expostos ao longo do texto sobre a necessidade, a premência, a pertinência, a possibilidade e a viabilidade de, enfim, projetar a escola estadual paulista sob a lente do conforto ambiental. 


\section{Estrutura}

Para atingir o objetivo da pesquisa, este texto encontra-se estruturado em cinco capítulos.

No primeiro capítulo tem-se um histórico da arquitetura escolar estadual paulista sob a lente do conforto ambiental, da influência dos higienistas à certificação de qualidade ambiental, considerando itens construtivos que, intencionalmente ou não, modulam as condições de conforto.

No segundo capítulo considera-se a produção científica voltada à arquitetura escolar pública, apresentando-se uma compilação dos trabalhos acadêmicos, com título, autores, resumo, visando o panorama do que já foi desenvolvido em pesquisas na área.

No terceiro capítulo são considerados instrumentos para projeto. Inicialmente lista-se as Normas Técnicas Brasileiras de interesse, considerando-se as relativas aos confortos térmico, acústico, de iluminação e desempenho. Na sequência discorre-se sobre softwares para desenvolvimento e avaliação de desempenho de projetos de ambiente construído. Por fim, considera-se a avaliação pós-ocupação, mencionando-se em específico o caso da parceria entre a Organisation for Economics Co-operation and Development (OECD), a SEE e a própria FDE.

No quarto capítulo consideram-se projetos da FDE que incorporaram questões de conforto. São listados projetos que receberam consultorias na área de conforto ambiental. Avalia-se detidamente um estudo de caso de implantação de escola em zona aeroportuária. Por fim, são considerados projetos de escolas estaduais paulistas submetidos à certificação AQUA.

No quinto capítulo são apresentadas as questões de conforto ambiental incorporadas, e propostas de questões a incorporar ao projeto das escolas estaduais paulistas.

Nas considerações finais descrevem-se as convicções acerca dos conhecimentos expostos ao longo do texto sobre a necessidade, a premência, a pertinência, a possibilidade e a viabilidade de, enfim, projetar a escola estadual paulista sob a lente do conforto ambiental. 


\section{Panorama histórico da arquitetura escolar estadual paulista}

\subsection{Período Imperial}

A construção escolar paulista tem seu marco legal em 1.834 através do Ato Adicional à Constituição de 1824, pela delegação às províncias da competência de promover a instrução pública e para tanto, "criar estabelecimentos próprios às escolas de primeiras letras para meninos e meninas em todas as cidades, vilas e lugares mais populosos".

No entanto, apesar dos dispositivos constitucionais instituídos ao longo da primeira metade do século XIX, na prática, pouco se fez pela educação pública. As crianças alfabetizadas durante o Império em sua maioria aprenderam com a família ou com preceptores contratados. Havia professores que faziam de suas casas escolas, oferecendo um ensino precário.

Paralelamente, a conquista das novas terras a partir dos descobrimentos do século $\mathrm{XVI}$ desencadeou especulações e estudos sobre as diferenças geográficas e humanas encontradas pelos europeus. Tais estudos, em conjunto a outras inquietações pré-existentes concernentes à saúde, potencializadas pelo encontro das doenças tropicais, trouxe ao século XIX a consolidação da disciplina de Higiene como fator civilizatório. (SEGAWA, 2003)

Em 1867 a Sorbonne promoveu Conferências sobre Higiene durante a Exposição Universal de Paris, as quais foram traduzidas para o português por Machado de Assis sob a supervisão do Dr. Homem de Mello, à época Inspetor Geral da Instrução Primária e Secundária da Corte.

Em 1873 houve a publicação de "Hygiene para uso dos mestres-escola", destinado "às administrações das escolas do Império" e que visava a ensinar aos professores primários alguns dos princípios elementares da doutrina que reivindicava para si o estatuto de ciência-mestra, via de acesso aos segredos da civilização. 
Tais diretrizes se faziam sentir pela sua ausência, conforme registrado pelos mestres de primeiras letras, bem como os presidentes das províncias, em relatórios dos fatos ligados à instrução pública, o que permite:

\begin{abstract}
"reconstituir o que era o ensino básico brasileiro no final do Império. Primeira constatação: não havia prédios escolares. As aulas de primeiras letras funcionavam num cômodo da casa do professor (...). As escolas públicas da província permanecem, na generalidade, funcionando em local impróprio, muitas vezes sem condições higiênicas e desprovidas de tudo quanto Ihes é indispensável".
\end{abstract}

Em relatório de 1878 um "conceituado professor de Bragança, no interior paulista, descrevia (...) o estabelecimento onde ensinava as primeiras letras. Ele reclamava da 'falta de um edifício apropriado para as escolas onde possa o professor desenvolver todos os preceitos da ciência pedagógica ${ }^{5 ! ”}$. (MARCILIO)

A carência de prédios era conhecida pelo governo de São Paulo, que estabeleceu no último quarto do século XIX, uma ação para promover a criação de escolas públicas na Província.

Há registro de três Escolas de Primeiras Letras construídas nesse período, sendo duas em área urbana - uma no Arouche e outra no Bairro da Luz - ambas já demolidas, e uma terceira escola em área ainda não urbanizada junto à então Estrada para Santo Amaro, hoje Rua Santo Amaro, no bairro da Bela Vista, e que se constitui em raro remanescente de prédio edificado especificamente para o uso escolar durante o Império, quiçá o único exemplar que se tem registro na cidade de São Paulo.

A Escola de Primeiras Letras do Arouche foi inaugurada em 1877, construída conforme projeto de autoria do inspetor de Obras Públicas eng ${ }^{\circ}$ Elias Fausto Pacheco Jordão, diplomado e doutorado nos EUA, tendo por isto reproduzido o estilo das escolas americanas que conheceu.

\footnotetext{
${ }^{5}$ Referência do trabalho não consultado
} 
Esta Escola aparece em planta da cidade datada de 1877 e intitulada Mapa da Capital da Província de São Paulo - Museus, Edifícios Públicos, Hotéis, Linhas Férreas, Bondes, Passeios, etc; publicado por Fr. ${ }^{\text {do }}$ de Albuquerque e Jules Martin, e reproduzido abaixo:
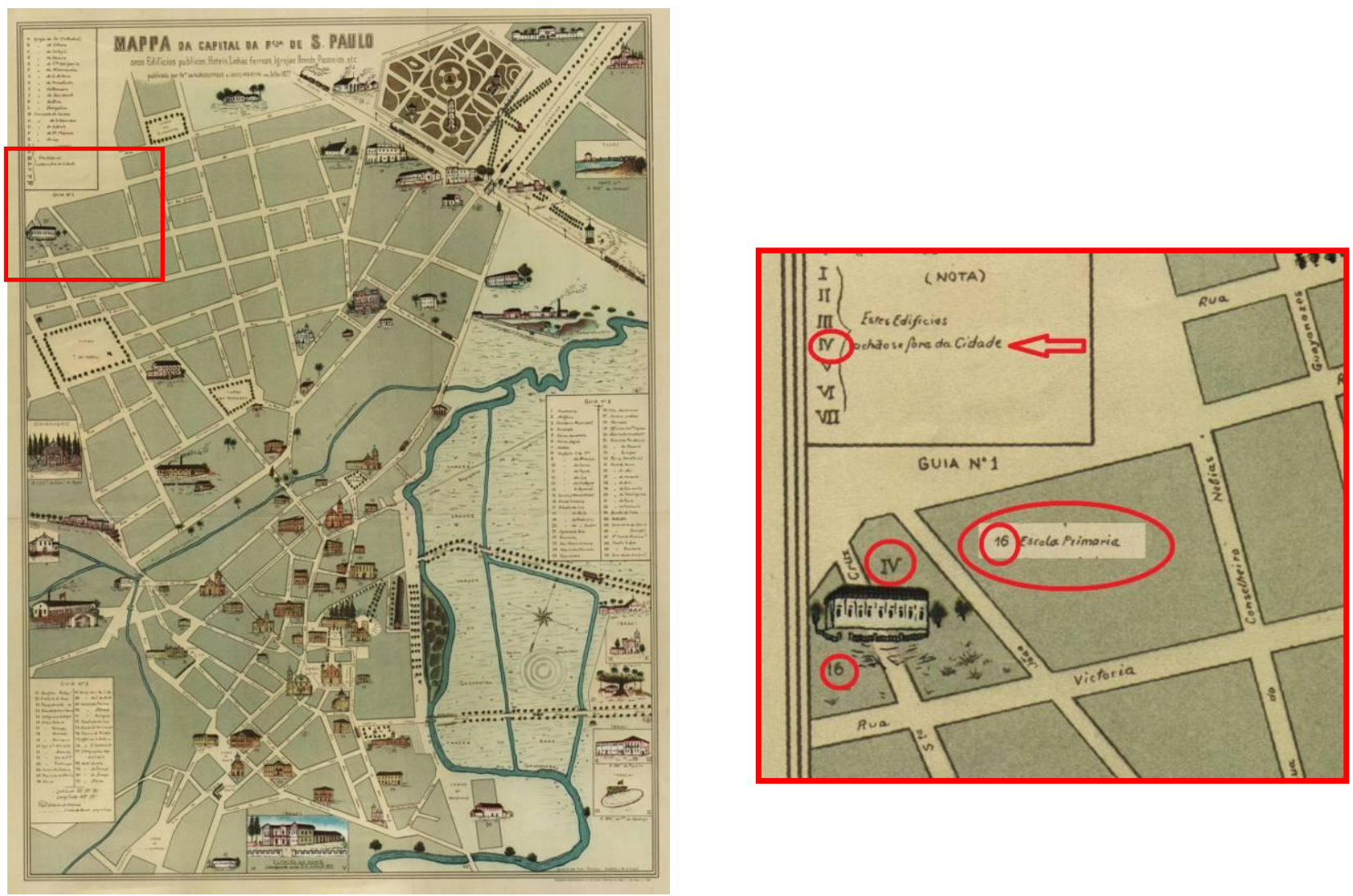

Figura 1 - Mapa de 1877 à esquerda, com ampliação do detalhe em que aparece a Escola de Primeiras Letras do Arouche, à direita; fonte: site do arquivo público do Estado de São Paulo, acesso 2010

Nesse mesmo ano, em atenção a apelo do Presidente da Província, a Baronesa de Limeira doou um terreno de $22 \mathrm{~m}$ x $40 \mathrm{~m}$ junto à Estrada para Santo Amaro, para a finalidade específica de construção de uma Escola de Primeiras Letras. Em 1879 foi concluída a construção do edifício, de alvenaria de tijolos, com duas salas de aula de $6 \mathrm{~m} \times 9 \mathrm{~m}$ e acessos independentes para cada sexo - segundo determinações da época e que perdurariam até os anos 30 do século $X X$. A cobertura é em quatro águas que terminam junto a calhas contíguas a uma platibanda, com descida de águas pluviais por tubulação embutida na alvenaria.

Este prédio conta hoje 132 anos e abriga a EE Paulo Machado de Carvalho, com entrada pela Rua Aguiar de Barros, 160, na Bela Vista. 


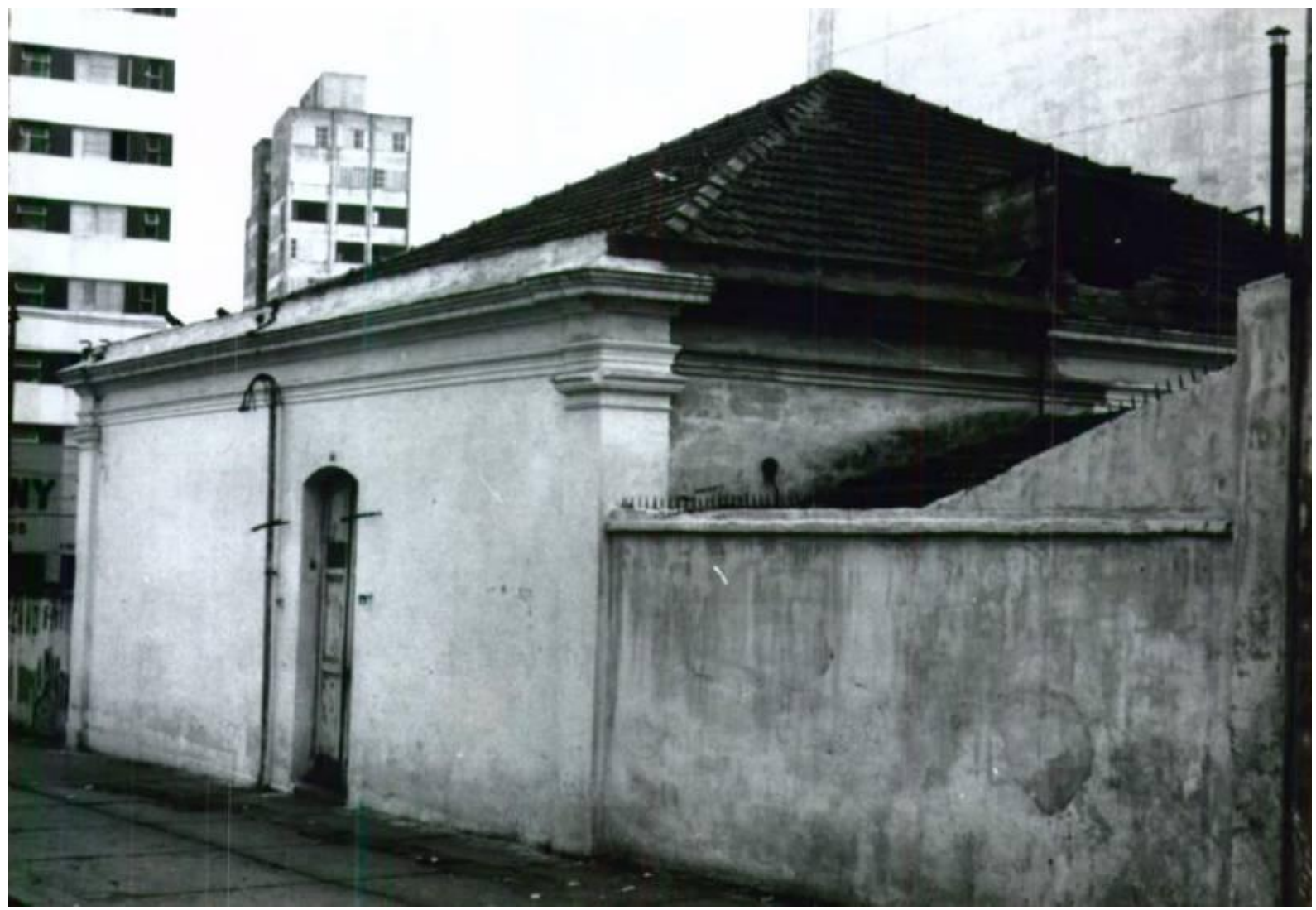

Figura 2 - Escola de Primeiras Letras, acesso pela atual Rua Aguiar de Barros, 160 - fonte: arquivos da FDE
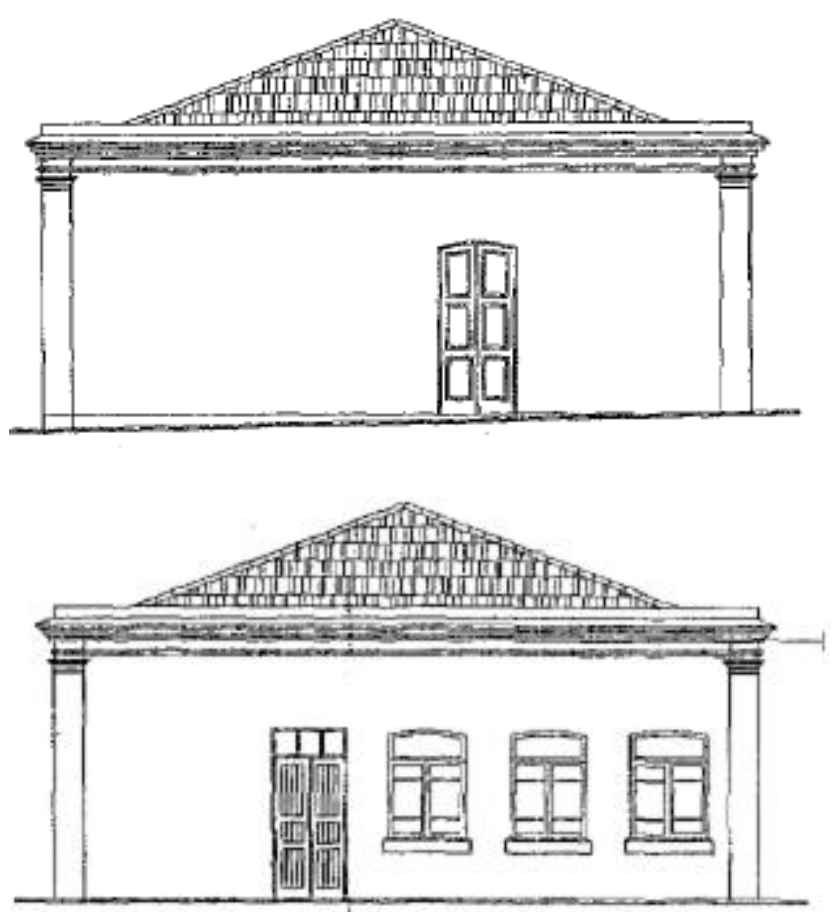

Figura 3 - Escola de Primeiras Letras - Elevações que ilustram as dimensões das aberturas - fonte: arquivos da FDE 


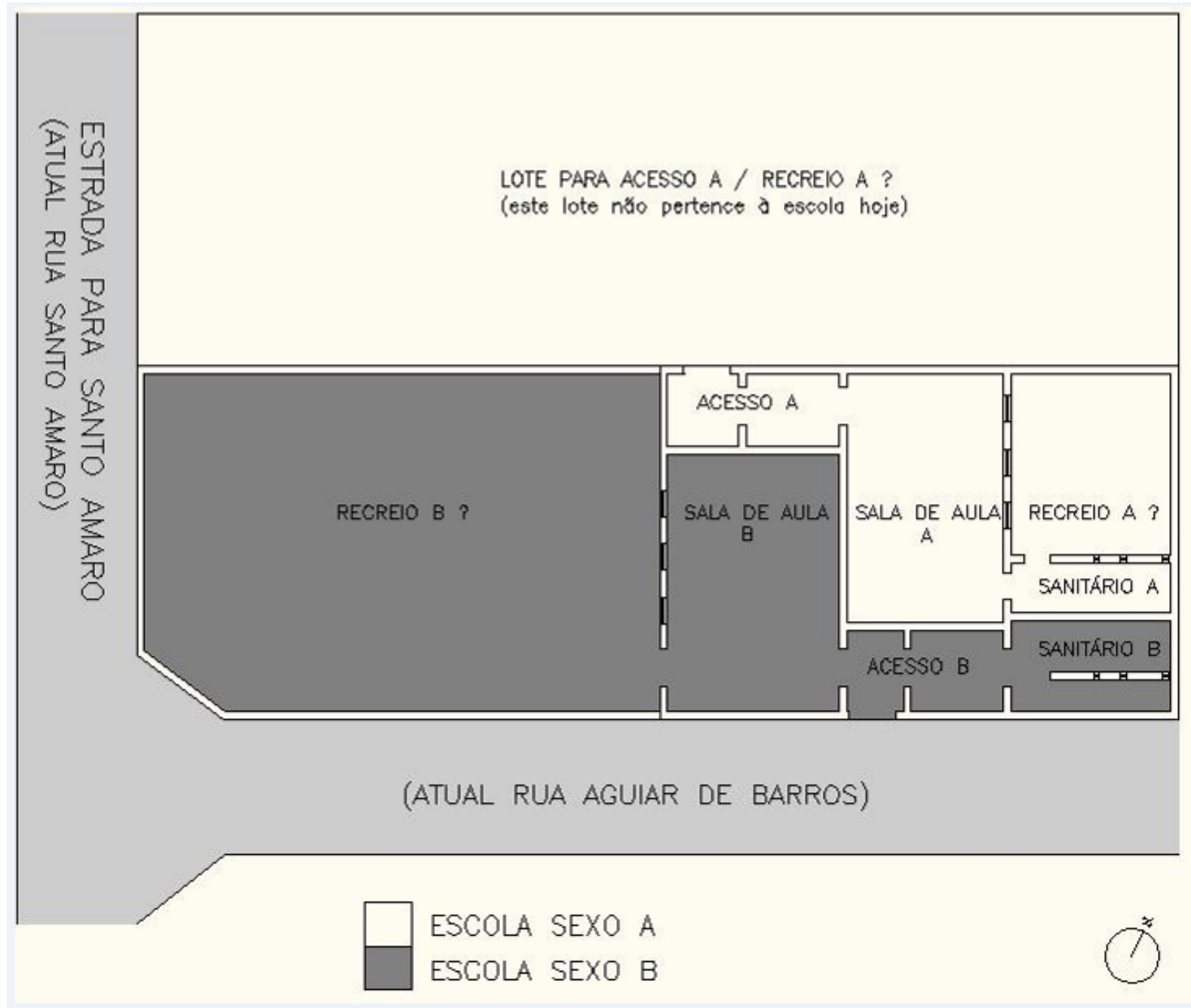

Figura 4 - Localização da Escola de Primeiras Letras, inaugurada em 1879 junto à Estrada para Santo Amaro. A legenda aponta para o isolamento dos ambientes, ilustrando a separação entre alunos e alunas. O lote contíguo presumivelmente utilizado para acesso da banda aqui chamada "A", fazia parte da área maior doada pela Baronesa de Limeira; no entanto, este lote não encontra-se atualmente sob a posse do Governo do Estado. Desenho: NOGUEIRA, Roselene

As dimensões das janelas desta edificação - que permitem iluminação e ventilação generosas; o pé direito alto, os sanitários com instalações apropriadas e contíguo ao prédio principal, assim como a qualidade construtiva que mantém íntegro o prédio passados 132 anos, a presença das cimalhas e as pinturas descobertas em intervenção de restauro ocorrida em 2.009, tudo sugere compromisso com os conceitos técnicos então vigentes.

No texto a seguir (SEGAWA, 2003) pode-se compreender o pensamento da época que esta escola parece refletir, e para o caso de sua implantação ter acontecido por motivações diversas destas - e mais profundamente não investigamos por não ser este o objeto da pesquisa -, ainda assim o texto é pertinente no sentido de ilustrar o 
processo intelectual que traz às disciplinas que hoje chamamos de Conforto Ambiental.

Teses contaminadas de determinismo geográfico ou climático declinaram para interpretações racistas, como que a estabelecer uma etnoclimatologia firmando uma tênue fronteira entre clima e civilização. Esta civilização que, no contexto do colonialismo do século 19, deparou-se com o enfrentamento dos trópicos como fator integrante do processo civilizatório e de dominação promovidos pelas potências europeias. Tal ideário se manifestava na introdução de uma obra que se pode considerar um dos primeiros manuais de conforto ambiental, sintomaticamente editada não na metrópole, mas na colônia. Em 1882 publicava-se na Argélia, então partição francesa, o livro $L$ 'habitation dans les pays chauds - contribution a l'art de l'acclimatation, de autoria de H. Dessoliers, de $1882^{6}$, "ingénieur dês arts et manufactures". Considerando-se os limites dos conhecimentos físicos e médicos do último quartel do oitocentos, tratava-se de um formidável compêndio, no qual questões de clima (temperatura, umidade, vento) e luminosidade eram confrontadas com a fisiologia humana; processos de transformação das condições ambientais (ventilação, refrigeração, evaporação, dissecação) eram especificados conforme recomendações considerando sistemas construtivos e dispositivos mecânicos.

"Não é suficiente atenuar pela drenagem e pelo cultivo as influências telúricas de sítios pantanosos, de torná-los habitáveis; é necessário também modificar as condições térmicas e higrométricas do meio no qual viveremos",

fundamentava Dessoliers, porque

"em todos os países quentes, a casa deve ser um sanitarium no qual o homem, cada dia, retempera suas forças. Então ele resistirá mais energicamente aos princípios mórbidos do lugar e logrará mais decididamente a obra-mãe da colonização: o saneamento da terra". ${ }^{7}$

Todo esse esforço tinha uma finalidade maior. A introdução do compêndio de Dessoliers intitula-se "A colonização é para a França uma questão de primeira ordem". Citando Paul Leroy-Beaulieu na obra De la Colonisation chez les Peuples Modernas, o engenheiro justifica a aclimação como um processo vital para a continuidade e disseminação do domínio francês no mundo:

"No começo do século 20 os russos ocuparão enormes espaços, alemães e austríacos dominarão a Europa Central, anglo-saxões ocuparão os melhores recantos do globo impondo ao mundo civilizado a sua língua, e o que será da França? [...]

\footnotetext{
${ }^{6}$ DESSOLIERS, H. L'habitation dans les pays chauds: contribution à l'art de l'acclimatation. Alger, Imprimerie P. Bienvenu, 1882.
}

${ }^{7}$ id 
Nosso país tem uma maneira de evitar essa irremediável decadência - é colonizar. Se não colonizarmos, dentro de dois ou três séculos estaremos abaixo dos espanhóis e dos portugueses, que tiveram a rara felicidade de implantar suas raças e suas línguas nos imensos espaços da América do Sul". 8

\section{Sob o signo do salubrismo}

A colonização como vetor de investigação climática e a aclimação como processo para aliviar a inserção humana em latitudes julgadas críticas pelo ideário civilizador europeu, conformou parte das preocupações que fomentaram especulações sobre o que muito mais tarde seria conhecido como uma disciplina pelo conforto ambiental. No século 19, a interpretação da ação do ambiente sobre o homem ganha outros contornos: o determinismo climático não mais constituía uma perspectiva incondicional, mas enxergava-se um viés "possibilista" $(10)^{9}$, no qual se vislumbrava uma interação menos absoluta e submissa entre o ambiente e os humanos. A consciência do ambiente como uma totalidade ampla e complexa ganha força com o desenvolvimento da medicina de inspiração científica surgida com a Revolução Francesa, pelo esquadrinhamento do médico, sob o signo da salubridade.

\section{(...)}

No final do século 19 e até a terceira década do século seguinte, a ventilação e a insolação - nem sempre numa perspectiva conjunta - estarão fundamentalmente relacionados com a salubridade.

SEGAWA, Hugo "Clave de Sol", grifos nossos

O ensino como um todo, só entrou em processo de franco desenvolvimento com a Proclamação da República, que marca o início da Arquitetura Escolar propriamente dita. (GONDRA, 2007)

\subsection{Escolas pioneiras da República 1890-1920}

A partir da Proclamação da República e durante aproximadamente 40 anos, no Estado de São Paulo, a construção dos prédios escolares deu-se com as seguintes características:

\footnotetext{
${ }^{8}$ DESSOLIERS, H. L'habitation dans les pays chauds: contribution à l'art de l'acclimatation. Alger, Imprimerie P. Bienvenu, 1882. ${ }^{9}$ id
} 
- $\quad$ o órgão responsável pela implantação era a Diretoria de Obras Públicas (DOP), atrelada ao governo estadual;

- $\quad$ localização estratégica na malha urbana, acompanhando as áreas ocupadas pela cultura do café e ferrovias, na Capital e no Interior;

- $\quad$ autores dos projetos: na maioria engenheiros e arquitetos estrangeiros ou brasileiros formados no exterior - como é o caso de Ramos de Azevedo;

- $\quad$ utilização de projetos-tipo fortemente inspirados em projetos estrangeiros;

- $\quad$ características construtivas: refletem o conhecimento e disponibilidade de materiais, bem como os princípios de higiene em voga ${ }^{10}$, sobretudo no que diz respeito às janelas e pés direito bastante altos, pelo favorecimento à então valorizada cubagem de ar - posteriormente preterida pela ventilação cruzada:

- pés direitos altos;

- coberturas sem beiral;

- duas lousas de forma a ter opção de uso nos momentos em que o sol estivesse incidindo sobre uma das lousas e assim lidando com o ofuscamento;

- porões idealizados para compensar o desnível do terreno ao implantar projetos-padrão, acabavam por favorecer a ventilação sob o piso e assim evitar umidade e perda de calor pelo contato com o solo;

○ forro de madeira;

- pisos em madeira nas áreas secas;

- pisos em ladrilho hidráulico sobre abobadilhas de tijolos nas áreas molhadas;

- assoalhos de madeira entre pavimentos, com encaixes de marcenaria de forma a diminuir o ruído de impacto de um pavimento sobre o outro.

${ }^{10}$ Em 1894 foi decretado o primeiro Código Sanitário do Estado com 520 artigos de normas de higiene e saúde pública, atualizado em 1916 e novamente em 1925. (CAMPOS, 2002) 


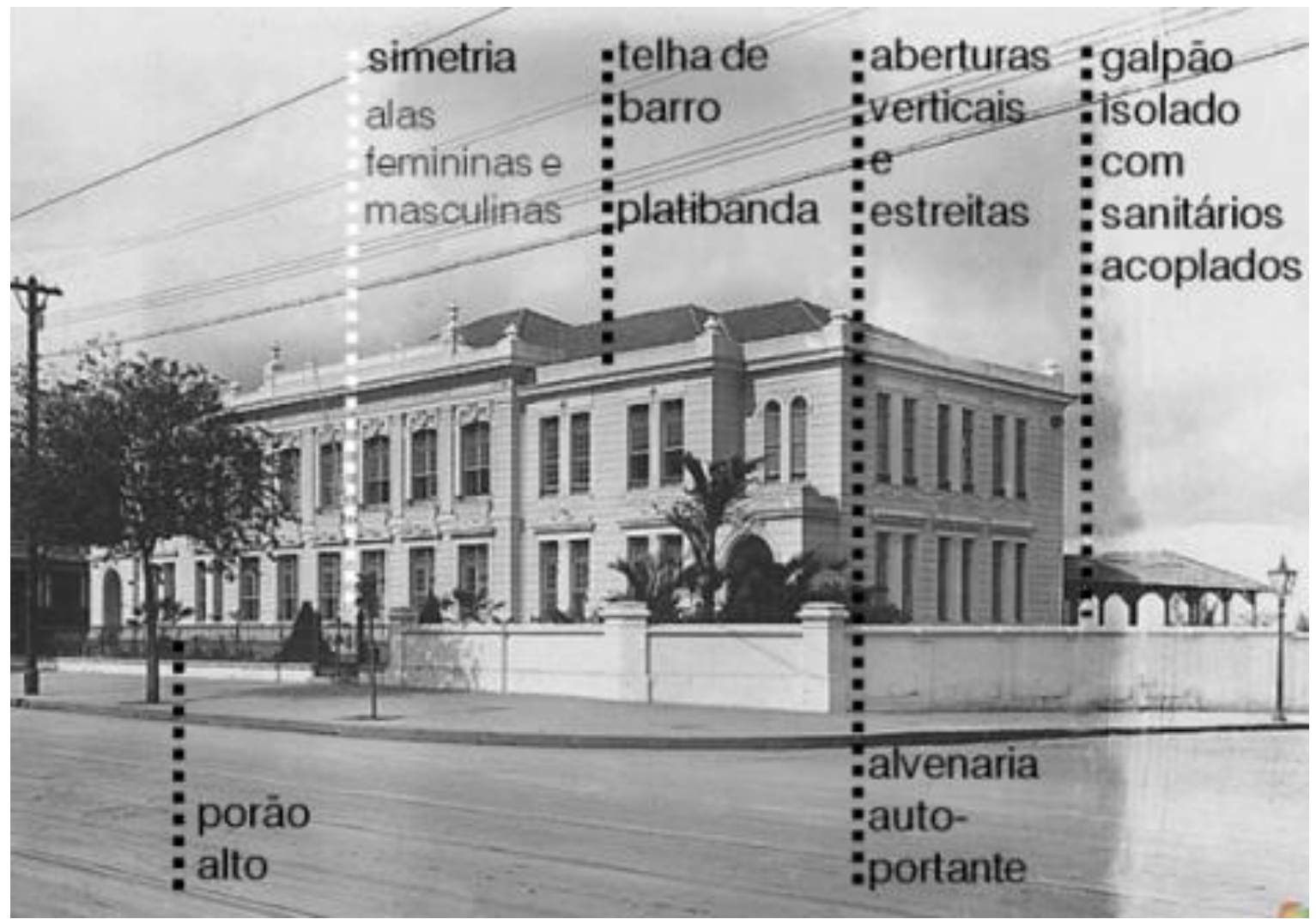

Figura 5 - Grupo Escolar Rodrigues Alves, do arquiteto Ramos de Azevedo, na Avenida Paulista - imagem: arquivo FAUUSP, in (FERREIRA, CORRÊA e MELLO, 1998); texto sobre imagem pela autora

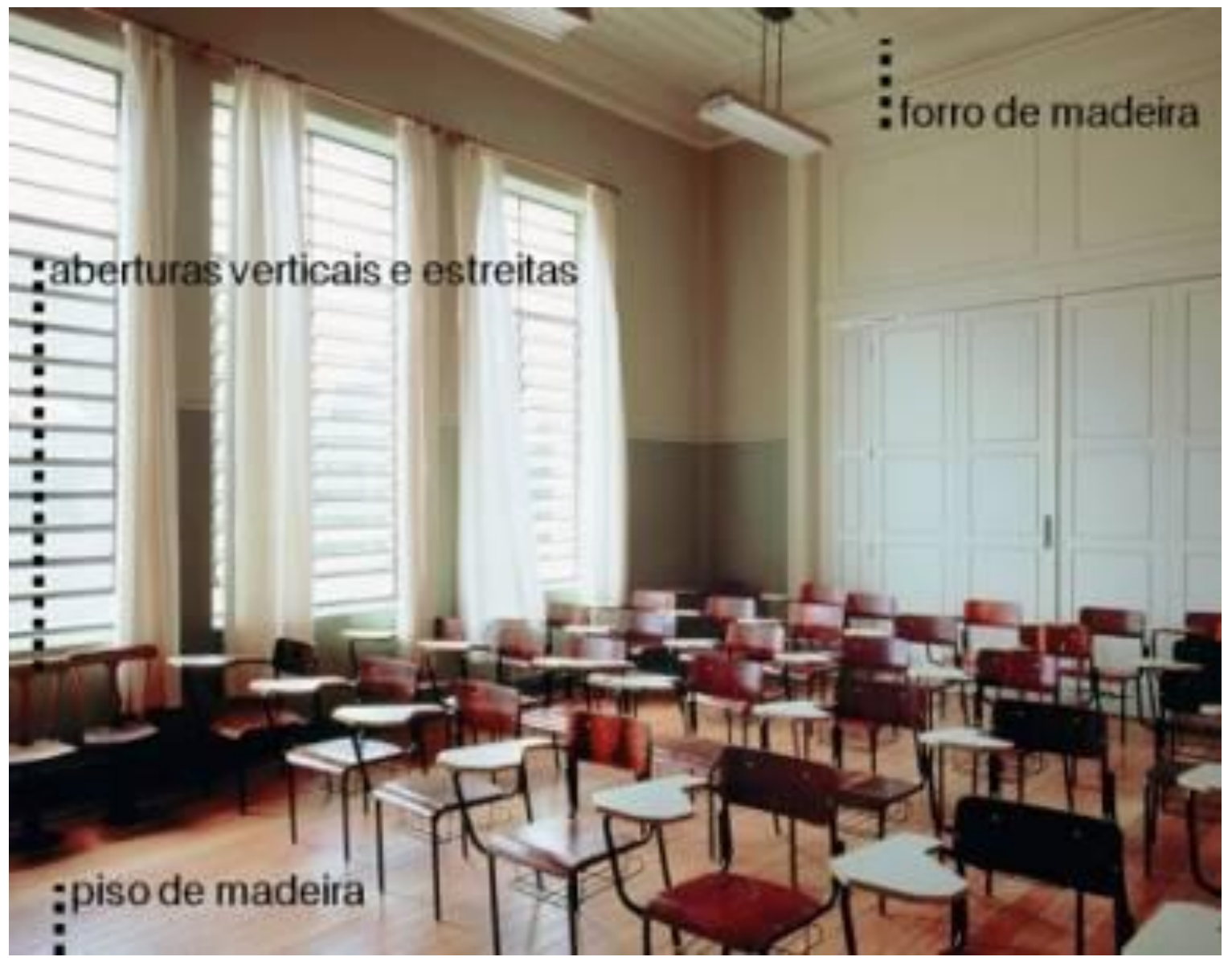

Figura 6 - Escola Normal de Botucatu, do arquiteto Victor Dubugras - iluminação do interior da sala de aula imagem: João Musa, in (FERREIRA, CORRÊA e MELLO, 1998); texto sobre imagem pela autora 


\subsection{Escolas sem representatividade arquitetônica do período 1920 - 1950}

O período entre 1920 e 1950 caracteriza-se por edifícios mais simples, implantados pelo DOP, a maior parte deles no interior, térreos, destinados a Grupos Escolares, cujo programa era mais simples que o dos Ginásios.

$\mathrm{Na}$ Capital, o pico construtivo desse período acontece nos anos 1936 - 1937, num movimento bastante diferenciado do trabalho desenvolvido no DOP.

\subsection{Comissão Escolar: $1936-1937$}

Em 1936, uma equipe multidisciplinar publica o livro Novos Prédios para Grupo Escolar e estabelecem novas diretrizes para a construção escolar.

- acréscimo ao programa dos ambientes vinculados à Higiene e Saúde: Gabinete Dentário, Sala para Educação Sanitária, Vestiários para Banho, Salas de Leitura, Auditório-Ginásio;

- destacam-se as determinações de Prestes Maia para que fosse adotada a melhor orientação solar

- estrutura de concreto armado

- o concreto armado libera o térreo através do uso de pilotis

- as vergas vencem vãos maiores, as janelas das salas de aula se ampliam e tornam-se horizontais

- técnica de impermeabilização permite levar o piso dos ambientes ao solo

- recreio coberto deixa de ser volume à parte do prédio escolar e passa a ser incorporado ao mesmo na área em pilotis

- projetos apropriam-se da declividade do terreno.

- a cubagem de ar antes propiciada por pés direitos altos é superada pelo conceito de ventilação cruzada

○ iluminação natural nas circulações 
Exemplificam esta fase as seguintes escolas:

- de autoria de José Maria da Silva Neves:

Grupo Escolar Professor Gomes Cardim Aclimação

Grupo Escolar Marina Cintra Consolação

Grupo Escolar Professor José Escobar Ipiranga

Grupo Escolar Godofredo Furtado Pinheiros

Grupo Escolar Princesa Isabel Saúde

Grupo Escolar Silva Jardim Tucuruvi

Grupo Escolar Visconde de Congonhas do Campo Tatuapé

- de autoria de Hernani do Val Penteado:

Grupo Escolar Padre Manoel da Nóbrega Freguesia do Ó

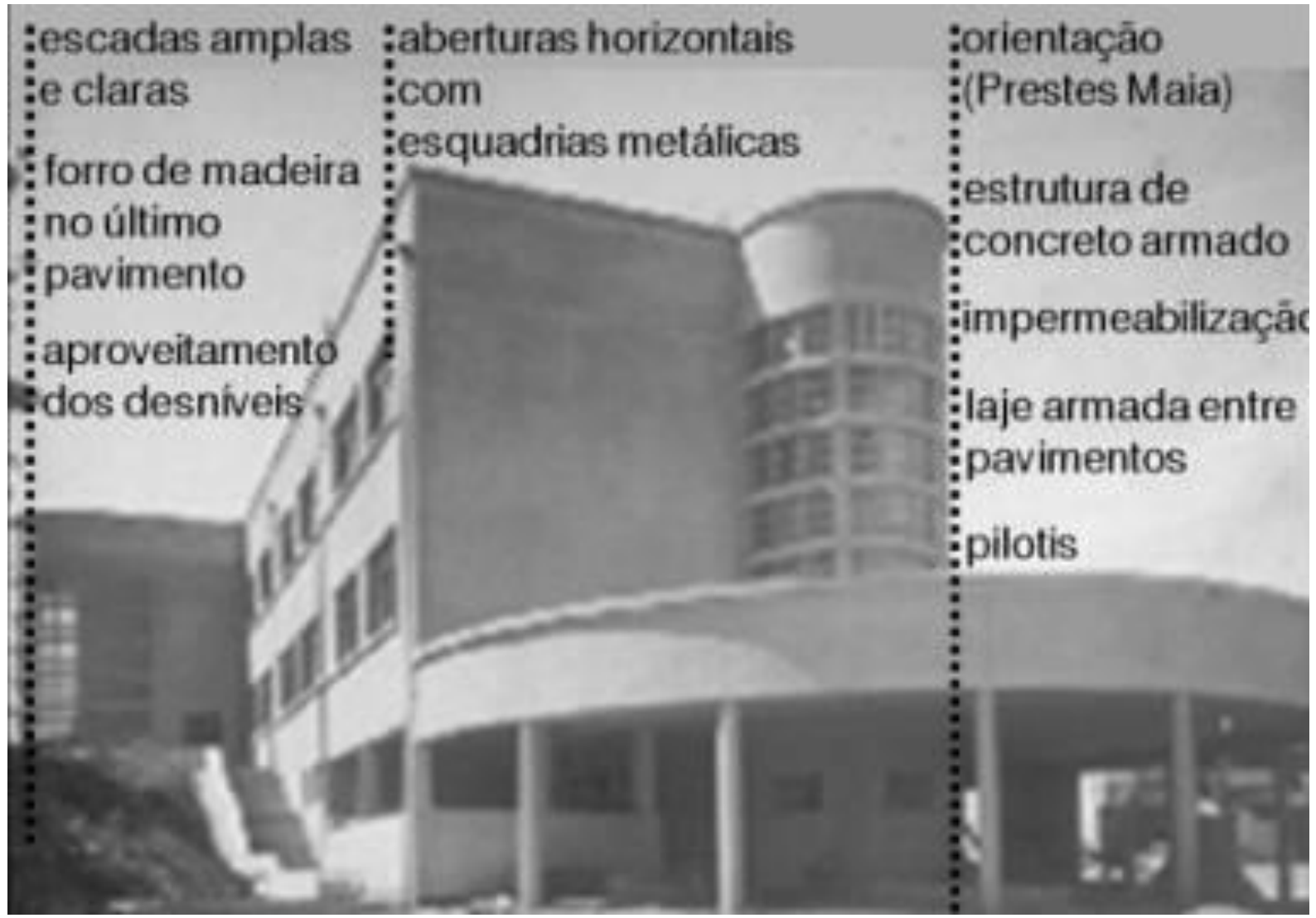

Figura 7 - Grupo Escolar Padre Manoel da Nóbrega, do arquiteto Hernani do Val Penteado, bairro da Freguesia do Ó, São Paulo - imagem: arquivo DOP-CPOS in (FERREIRA, CORRÊA e MELLO, 1998); texto sobre imagem pela autora 


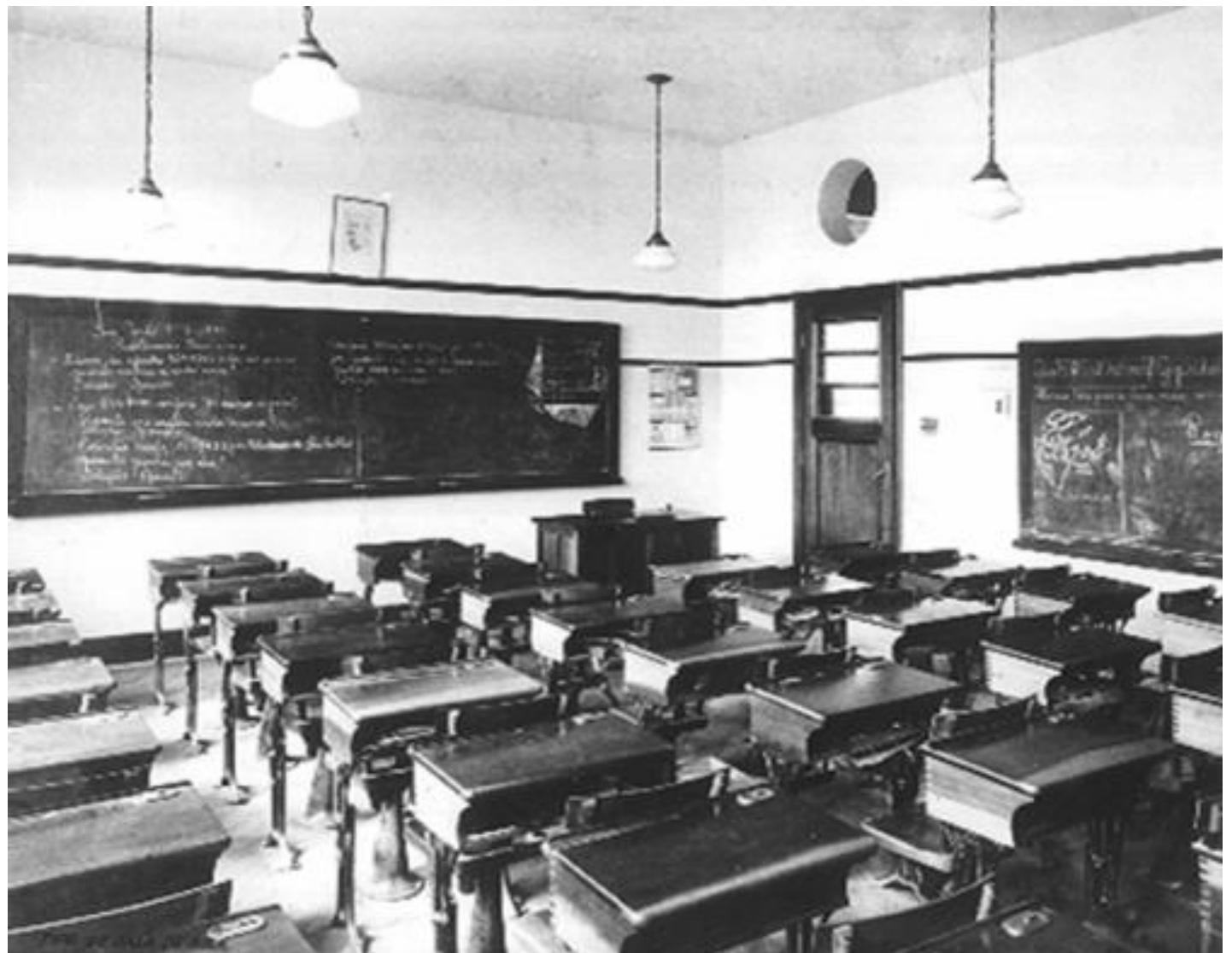

Figura 8 - EE Prof ${ }^{a}$ Marina Cintra, bairro da Consolação, São Paulo, do arquiteto José Maria da Silva Neves - abertura para ventilação cruzada acima da porta e lousa dupla para driblar ofuscamento; imagem: arquivo DOP-CPOS in (FERREIRA, CORRÊA e MELLO, 1998)

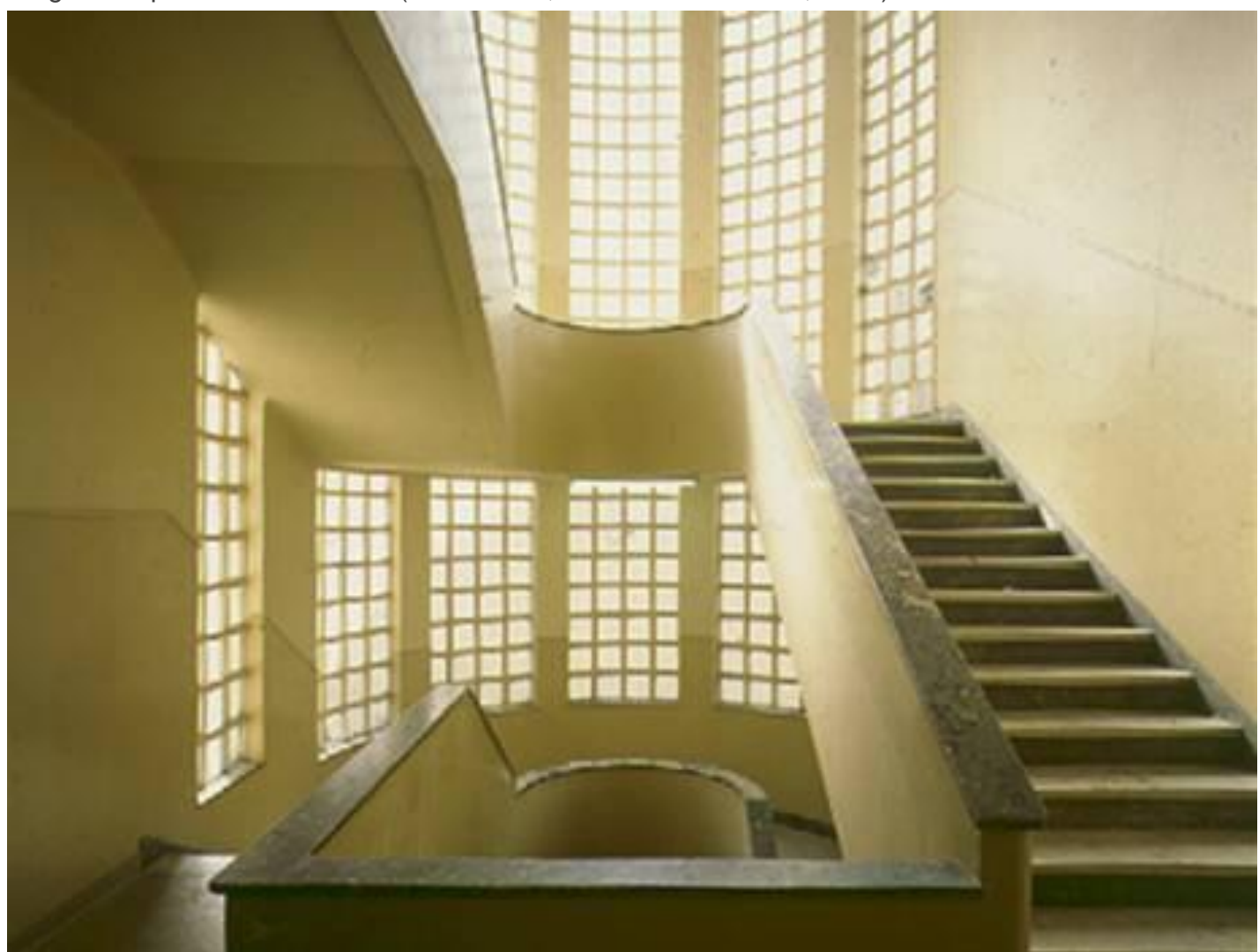

Figura 9 - EE Prof - Marina Cintra, bairro da Consolação, São Paulo, do arquiteto José Maria da Silva Neves - - iluminação natural nas circulações - imagem: Carlos Kipnis, in (FERREIRA, CORRÊA e MELLO, 1998) 


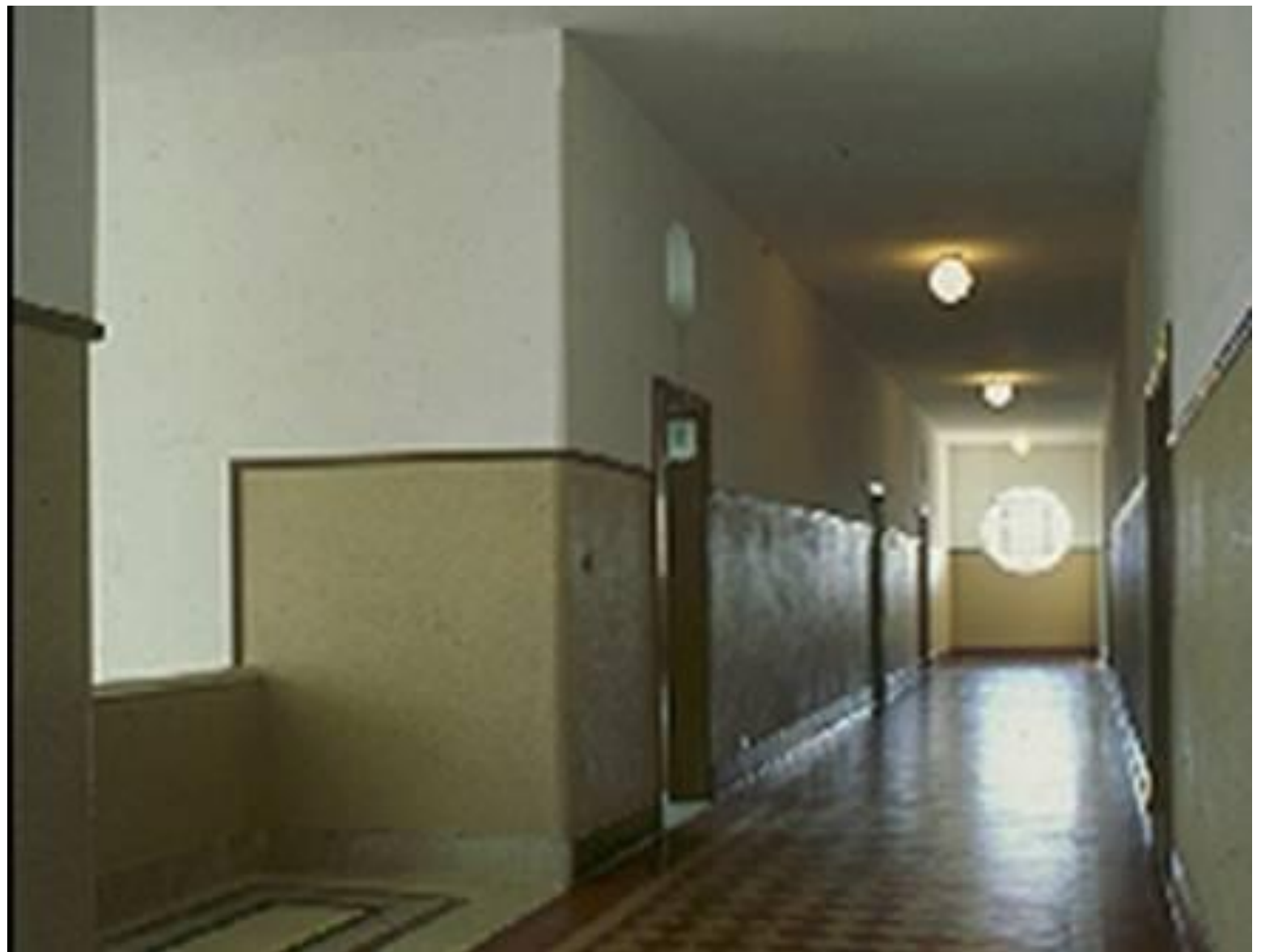

Figura 10 - EE Princesa Isabel, bairro da Saúde, São Paulo, do arquiteto José Maria da Silva Neves - iluminação natural na circulação - imagem: Carlos Kipnis in (FERREIRA, CORRÊA e MELLO, 1998)

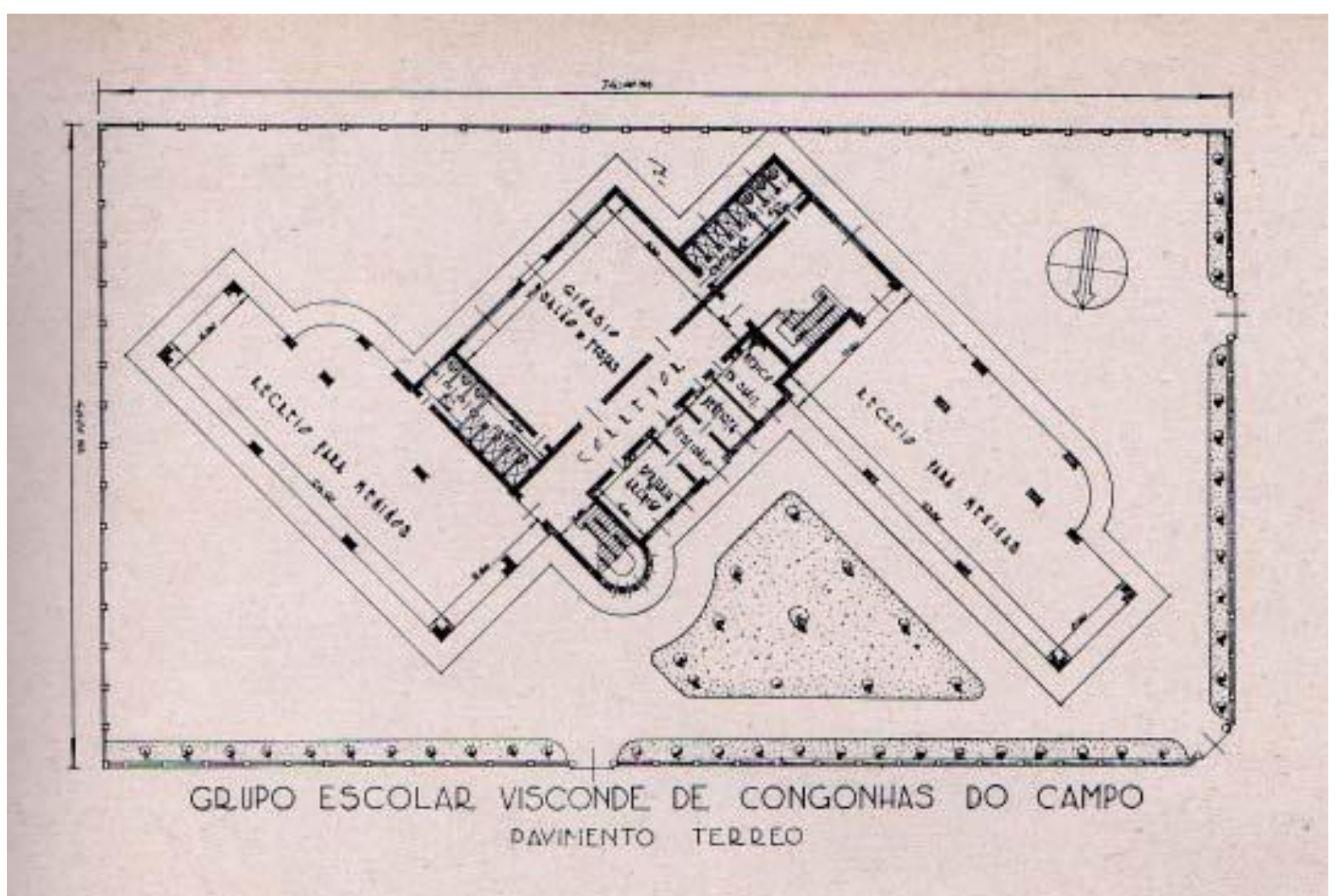

Figura 11 - escola no bairro do Tatuapé, São Paulo, do arquiteto José Maria da Silva Neves - a implantação da escola volta-se para a melhor orientação solar ao invés de seguir a ortogonalidade das vias públicas - imagem: Revista Acrópole 


\subsection{Convênio Escolar: os efervescentes anos 1948 - 1959}

Também de forma paralela à atividade do DOP acontece o período conhecido como Convênio Escolar, pela decisão política de construir em larga escala na Capital e equacionar a demanda por vagas no ensino público em curto prazo até a comemoração do IV Centenário em 1954.

O Convênio Escolar foi um acordo firmado entre a Prefeitura de São Paulo e o Estado em 1948, no qual o Município se encarregaria de viabilizar o planejamento, projeto e construção de escolas, e o Estado ficaria responsável por ministrar o ensino. Através do Convênio Escolar são construídas cerca de 70 escolas na Capital, no período entre 1949 e 1954.

O arquiteto Hélio Duarte lidera a equipe de profissionais que irá imprimir conceitos e procedimentos distintos daqueles adotados pelo DOP, fundamentados na proposta do educador Anísio Teixeira, pioneiro na proposta da escola em período integral e aberta ao uso comunidade, bem como seus equipamentos complementares, como as bibliotecas, os parques infantis, os teatros, etc.

Os autores da maioria dos projetos são de formação carioca, e trazem como proposta a arquitetura moderna que vinha sendo feita no Rio de Janeiro sob liderança de Oscar Niemeyer, Lúcio Costa e Reidy.

São arquitetos e/ou engenheiros atuantes neste período, sob a concepção pedagógica do Prof. Anísio Teixeira: Hélio Duarte, Eduardo Corona, Roberto Tibau, Oswaldo Corrêa Gonçalves, Ernest Mange, Antônio Carlos Pitombo, Paulo José Rodrigues Rosa, Rubens Freitas Azevedo, Rubens Cardieri, Aluísio da Rocha Leão e Juvenal Waetge Júnior. O partido dos projetos contempla:

- os princípios da Arquitetura Moderna

- a adaptação do prédio à escala da criança

- a integração com a natureza

- abundância de ar e luz

- espaços são generosos 
- jardins incorporados ao edifício

- grandes caixilhos de ferro ocupando quase todo o pé direito

- ventilação cruzada feita através de tubos incrustados na alvenaria

- elementos vazados cerâmicos

- lajes de forro

- piso em cerâmica vermelha

- portas de madeira

- pérgolas

- marquises

- esbeltos pilares em "V"

- telha de fibrocimento

- volumes em forma de "asa de borboleta"

- recreio coberto em arco pré-moldado de concreto;

- blocos volumetricamente independentes: pedagógico, administrativo, de recreação, interligados por circulações cobertas;

- projetos específicos a cada terreno, com repetições pontuais;

- o programa dos Ginásios e das Escolas Normais previa piscina, auditório e quadra esportiva coberta.

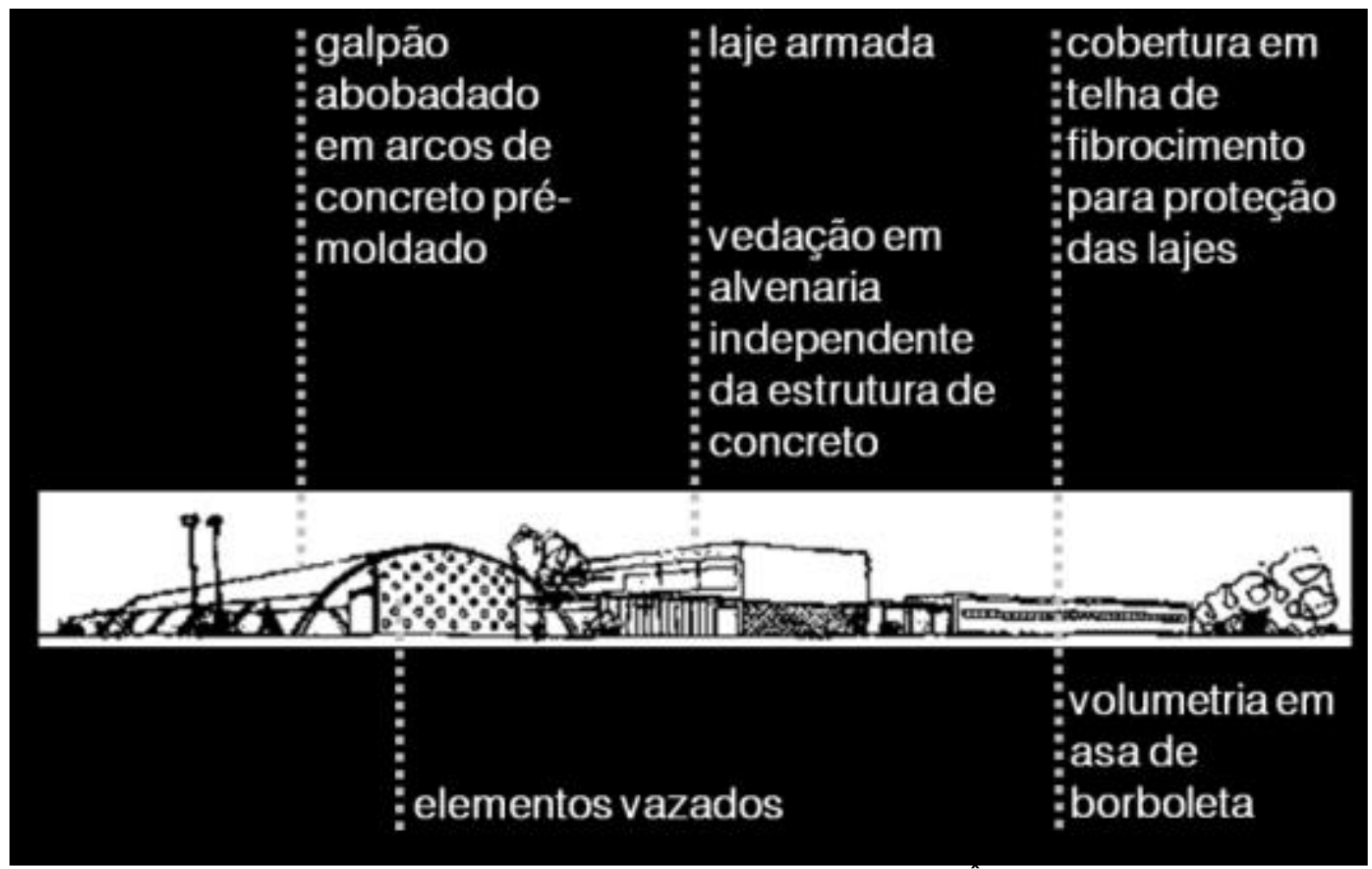

Figura 12 - croquis de Hélio Duarte - Revista Habitat 4 in (FERREIRA, CORRÊA e MELLO, 1998); texto sobre imagem pela autora 


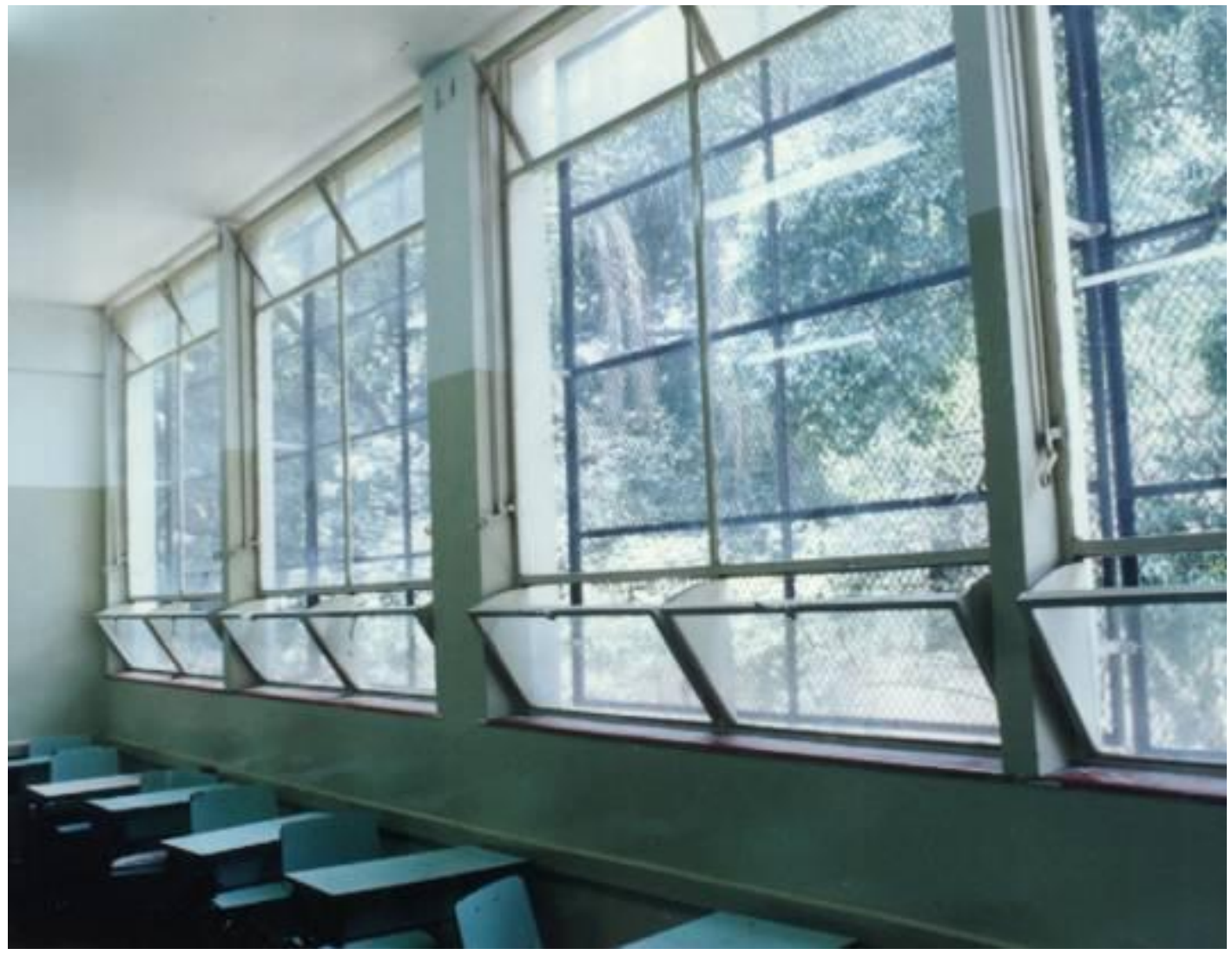

Figura 13 - EE Brasílio Machado, bairro da Vila Mariana, São Paulo - imagem: acervo FDE in (FERREIRA, CORRÊA e MELLO, 1998)

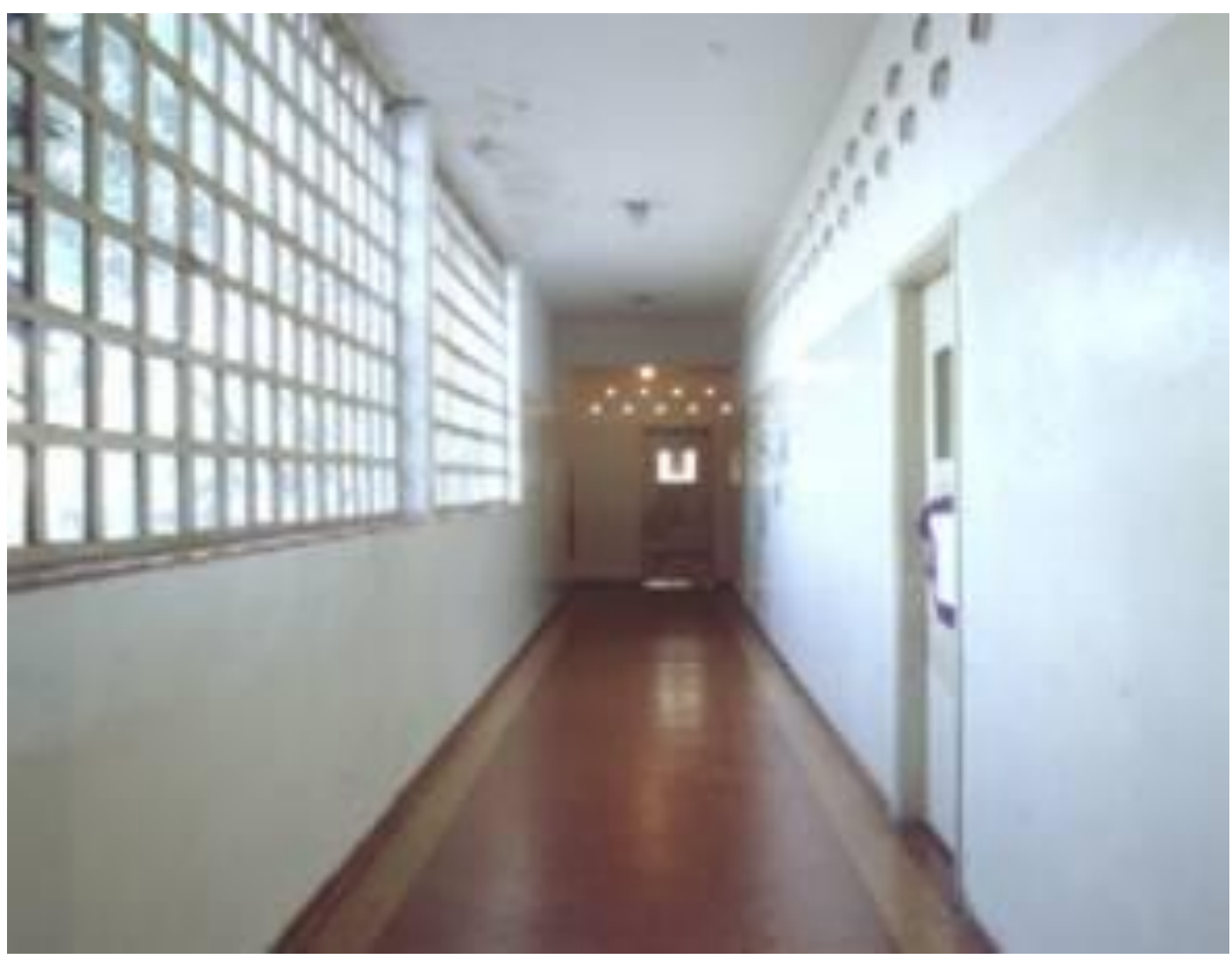

Figura 14 - EE Brasílio Machado, bairro da Vila Mariana, São Paulo - imagem: Carlos Kipnis in (FERREIRA, CORRÊA e MELLO, 1998) 


\subsection{IPESP: $1957-1966$ \\ FECE: $1966-1976$}

A principal característica deste período é o fato das escolas serem financiadas pelo Instituto da Previdência do Estado de São Paulo, e também ocorre paralelamente às atividades normais do DOP.

O período tem início com Jânio Quadros em 1957 mas é com o Plano de Ação do governo de Carvalho Pinto que é criado o Fundo Estadual da Construção Escolar (FECE), em 1959, para atender à construção, ampliação e equipamento de prédios destinados a escolas de ensino público primário e médio do Estado, no entanto inicialmente este órgão desempenha apenas a função de planejar, ficando a incumbência ao IPESP de elaborar os projetos e executar as construções escolares.

Fazem parte do Grupo de Planejamento do Plano de Ação, entre muitos outros: Paulo Menezes Mendes da Rocha, Celso Monteiro Lamparelli Francisco Whitaker Ferreira e Vilanova Artigas, sendo que este último em reunião no IAB assim incentiva os arquitetos a participarem da elaboração dos projetos a despeito dos honorários considerados injustos, como consta em ata (FERREIRA e MELLO, 2006):

"considera que as últimas administrações do governo desorganizaram seus quadros técnicos, ficando os mesmos impossibilitados de dar continuidade ao planejamento de suas obras e que o convite feito recentemente do IPESP a diversos arquitetos paulistas na base de honorários injustos, ainda significa um passo a frente no processo de reconhecimento do arquiteto como profissional, devendo o IAB adotar, nessa oportunidade atitude tática adequando a uma evolução desse processo no sentido do interesse da classe".

É então selado um acordo entre o governo e o IAB para que os prédios executados na gestão Carvalho Pinto fossem feitos com projetos elaborados pelos escritórios paulistas de arquitetura.

Este modelo de terceirização dos projetos a diferentes escritórios de arquitetura feita pelo IPESP foi mantido pelos órgãos pelo FECE, pela Conesp e pela FDE, pela 
contribuição à diversidade arquitetônica e pela economia de recursos humanos na entidade pública.

Das aproximadamente 600 escolas construídas pelo IPESP destacam-se os Ginásios de Itanhaém e Guarulhos, de Vilanova Artigas em que o recreio coberto passa a ser o espaço central.

O partido dos projetos assim caracteriza-se:

- lajes de concreto impermeabilizadas sustentadas por pórticos de geometria marcantes

- grandes vãos

- níveis que se interpenetram através de ambientes

- pés-direito duplos

- dimensões generosas

- luminosidade

- circulações com bancos

- jardins internos

- caixilhos em todo o pé-direito cuidadosamente projetados para liberar as visuais na altura do olho do aluno

- o espaço, a estrutura e a técnica construtiva são privilegiados em detrimento da sofisticação dos acabamentos

Em meados de 1970 o número de prédios construído chega a 7.000, o ápice da história da construção escolar. 


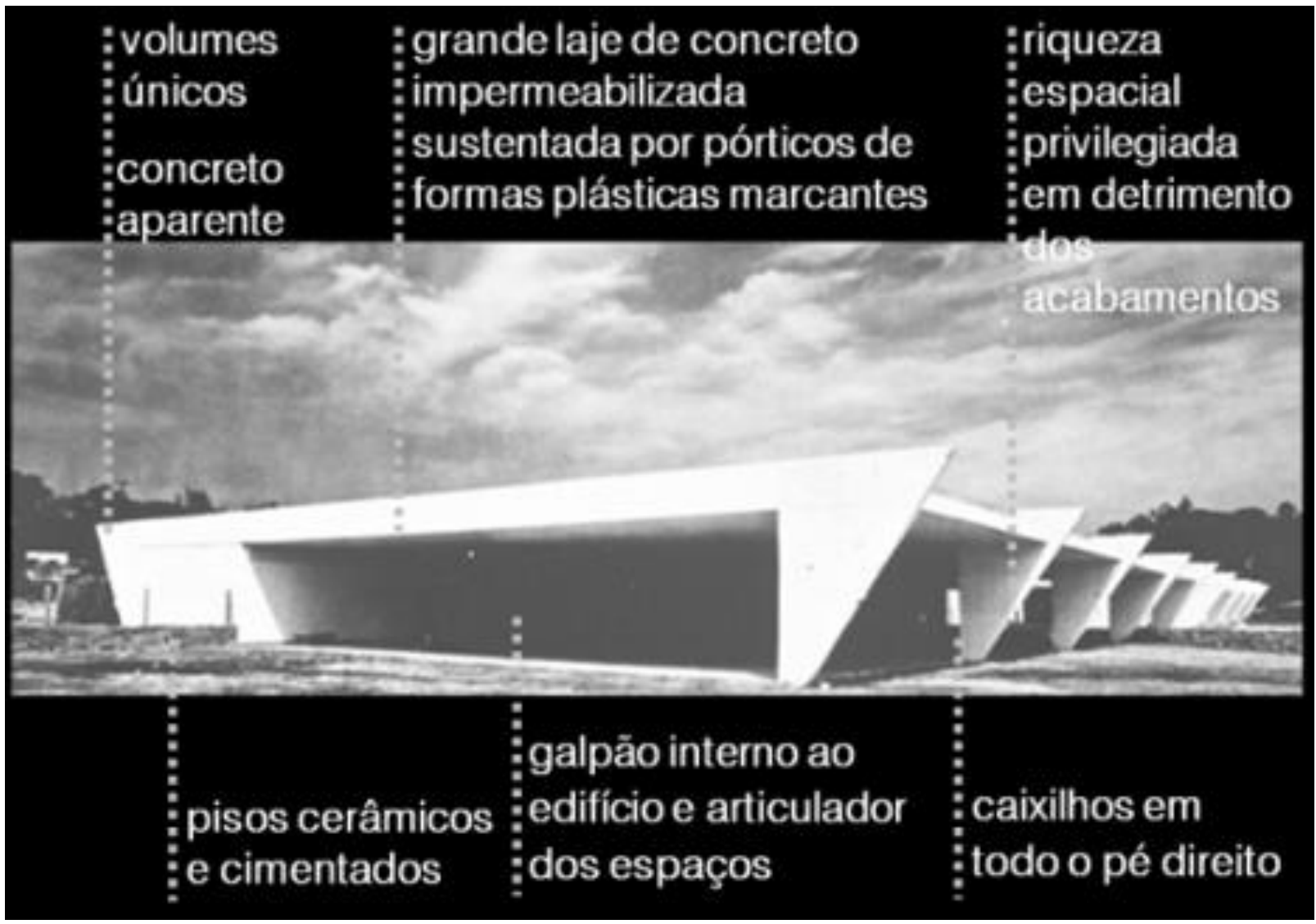

Figura 15 - Ginásio de Itanhaém, do arquiteto Vilanova Artigas - imagem: Fundação Vilanova Artigas in (FERREIRA, CORRÊA e MELLO, 1998); texto sobre imagem pela autora

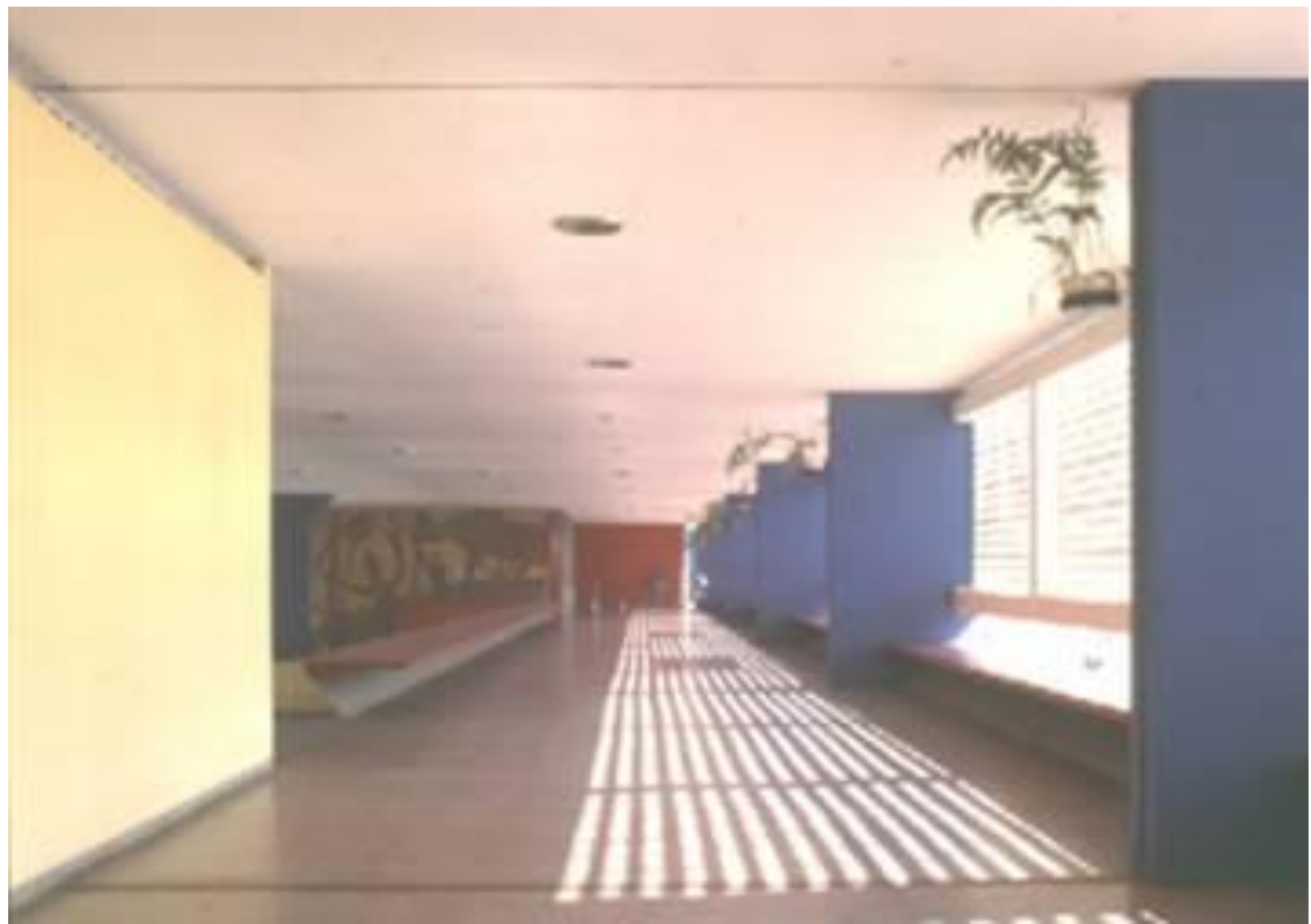

Figura 16 Ginásio de Guarulhos, do arquiteto Vilanova Artigas - imagem: Carlos Kipnis, arquivos da FDE; texto sobre imagem pela autora 


\subsection{CONESP 1977 - 1987}

Os anos 70 intensificam e sistematizam a catalogação dos componentes construtivos e sua industrialização, fundamentados na coordenação modular, objetivando maior rapidez no atendimento à demanda ao conceber o edifício escolar como um jogo de montar através da racionalização da construção. São então elaborados os cadernos de especificações dos componentes e serviços da construção escolar e a listagem de preços, nos aos quais estão atrelados o projeto, a especificação, os preços, os elementos necessários ao recebimento e o pagamento dos serviços.

Ao final deste período a arquiteta Mayumi de Souza Lima empreende uma Avaliação pós-ocupação com o intuito de inserir diretrizes de Conforto Ambiental aos projetos, no entanto esta iniciativa não tem continuidade.

\subsection{FDE $1987-2003$}

Período marcado pela implantação de projetos-padrão para a grande maioria das novas escolas, sendo raros os projetos especiais.

Os mesmos projetos foram implantados nos mais diversos tipos de terreno, em todo tipo de orientação e características climáticas.

\subsection{FDE 2003 até hoje: Escolas em sistema estrutural pré-fabricado}

Diversos fatores contribuíram para que a FDE adotasse o sistema pré-fabricado como solução estrutural para os edifícios escolares, como a indisponibilidade de terrenos nos grandes centros urbanos quer pela implantação de projetos-padrão existentes, seja pela exiguidade de área, seja pela topografia complexa dos terrenos remanescentes, e isto paralelamente à crescente demanda em algumas regiões, levando à adoção pela FDE pela construção das escolas estaduais em sistema préfabricado de concreto e em estrutura metálica, com solução estrutural padronizada, resultando em prédios de representativa qualidade espacial expressa numa grande diversidade de soluções arquitetônicas, pela parceria do órgão público e os escritórios de arquitetura.

Em muitos casos, é demolida a escola existente para construção de uma nova escola, ampliada, pela indisponibilidade de terrenos para abrigar o crescimento da demanda. 
A opção por este sistema construtivo foi motivada pela qualidade, possibilidade de controle tecnológico da produção, menor prazo de execução e otimização da relação custo $\mathrm{x}$ benefício e representou um salto qualitativo nas soluções espaciais $\mathrm{e}$ funcionais, com diversidade de soluções arquitetônicas mesmo tendo a estrutura padronizada, com projetos específicos para cada terreno e programa arquitetônico.

Foram incluídos ou reintroduzidos novos ambientes nesse período: quadras poliesportivas cobertas, salas de uso múltiplo e de reforço, depósitos de material pedagógico e de educação física, cantina.

O parâmetro acessibilidade foi definitivamente incorporado, possibilitando o acesso ao maior número possível de indivíduos independente de suas necessidades especiais.

O controle tecnológico sobre o processo de produção trouxe maior qualidade à obra e consequentemente melhor desempenho da estrutura, otimização dos prazos envolvidos no processo entre identificar a demanda e ocupar o edifício, a um custo equivalente ao custo das obras moldadas in loco e com aumento da satisfação do usuário, apresentando portando a melhor relação custo/benefício.

As questões de conforto ambiental foram tratadas pela iniciativa de cada escritório, não tendo sido premissas explícitas da FDE, que começou a sistematizar as solicitações de Conforto Ambiental a partir de 2007.

Com a adoção da quadra coberta para terrenos diminutos, tornou-se tipologia predominante nos grandes centros urbanos aquela com a quadra na cobertura sobre as salas de aula, em geral ocupando um ou dos pavimentos mais abaixo. Assim, ao longo dos últimos 115 anos, houve ações nas diversas esferas do poder público, isoladas ou em forma de convênio, para providenciar os meios de construção dos edifícios escolares, tendo-se acumulado experiências que ao mesmo tempo refletiram e influenciaram as técnicas construtivas de seu tempo, dada a representatividade quantitativa que a construção escolar sempre teve na construção civil brasileira. 


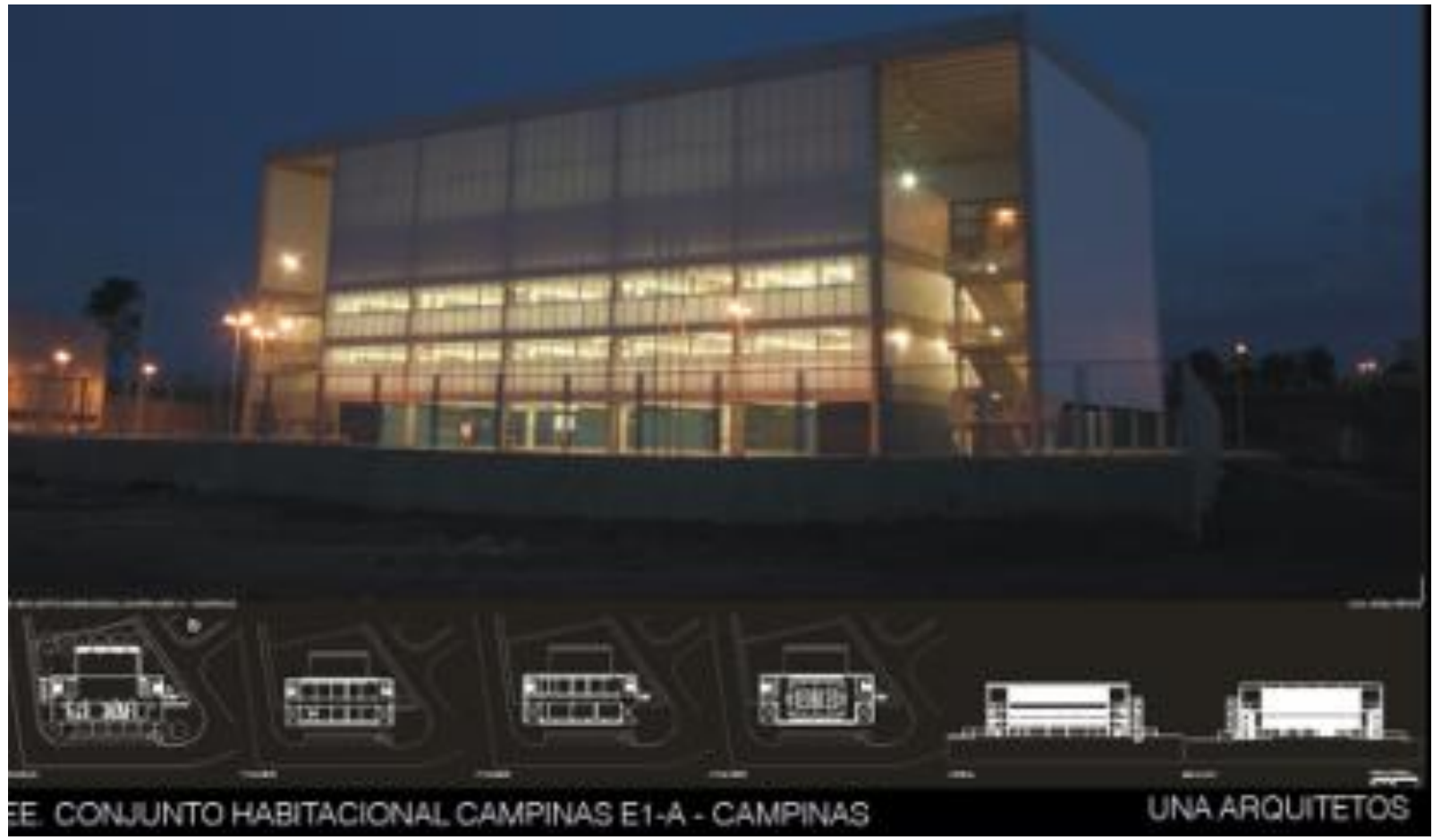

Figura 17 - EE Doutor Telêmaco Paioli Melges, Campinas, do escritório UNA Arquitetos, 2004; imagem: Nelson Kon in (FERREIRA e MELLO, 2006)

A linguagem de conforto ambiental aparece em determinados momentos, mas de forma não sistematizada.

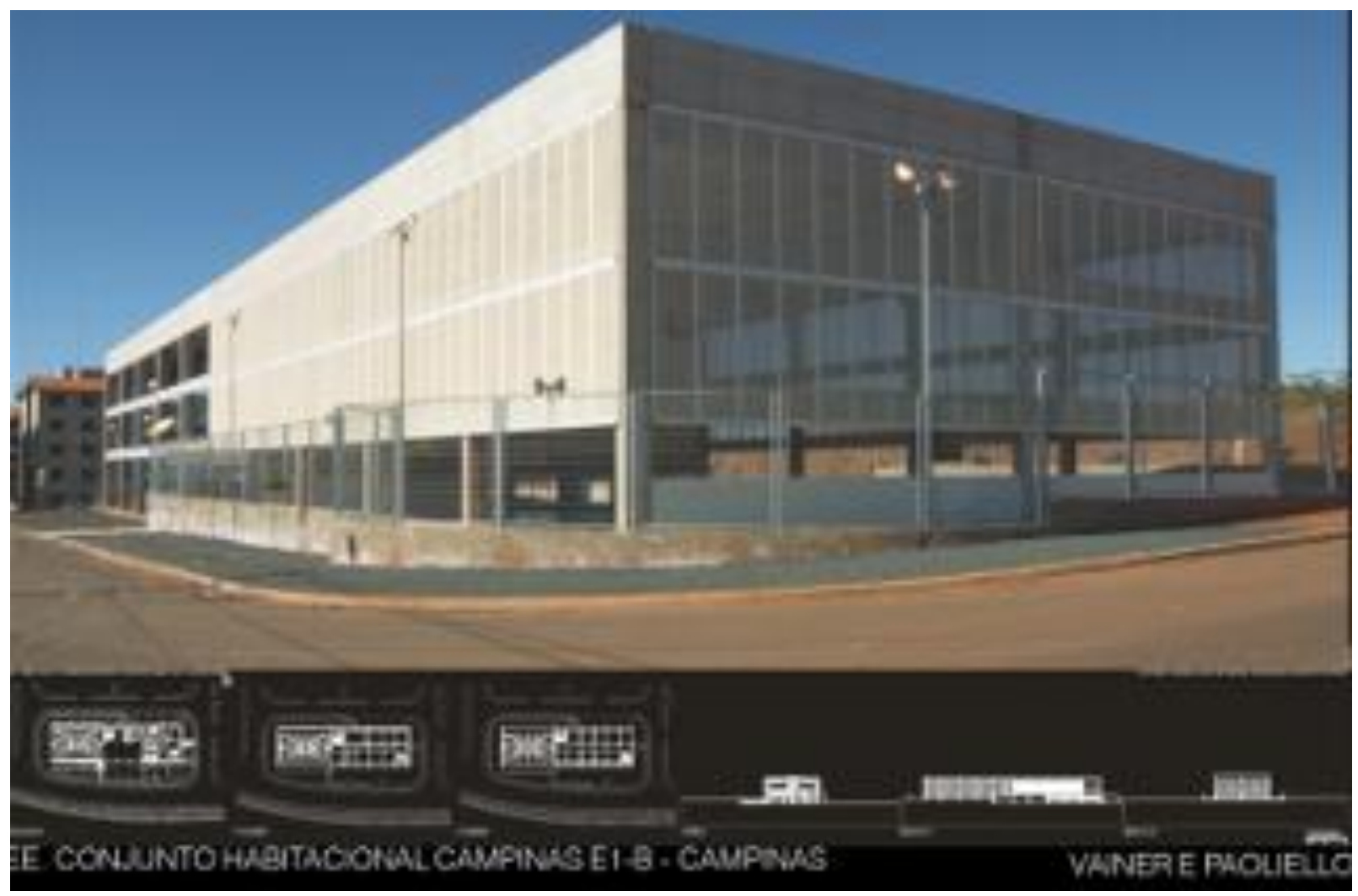

Figura 18 - EE Conjunto Habitacional Campinas E1B de André Vainer e Guilherme Paoliello, 2004; imagem: Carlos Kipnis in (FERREIRA e MELLO, 2006) 


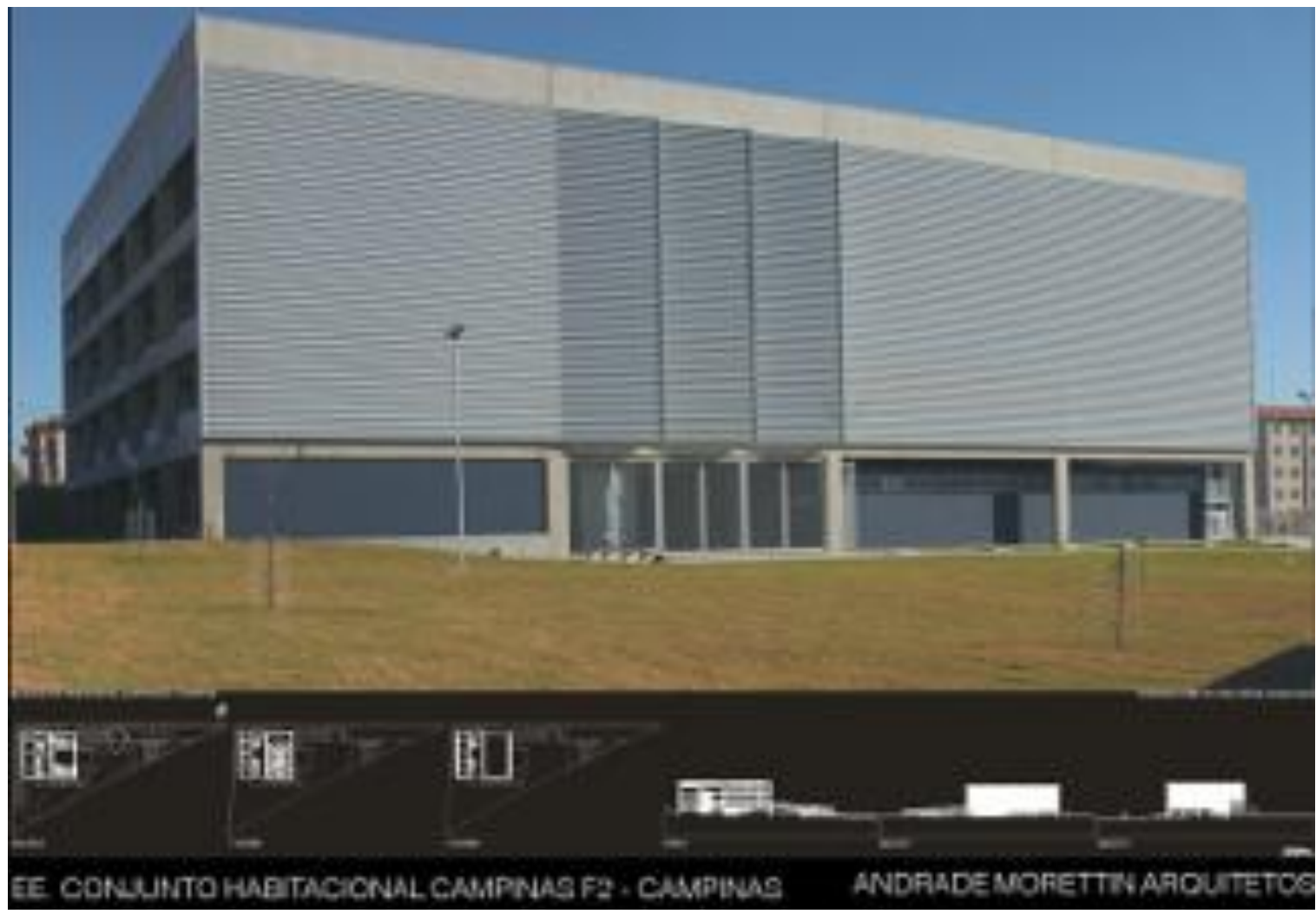

Figura 19 - EE Jornalista Roberto Marinho / CHB F2, em Campinas, do escritório Andrade Morettin, 2004; imagem: Nelson Kon in (FERREIRA e MELLO, 2006)

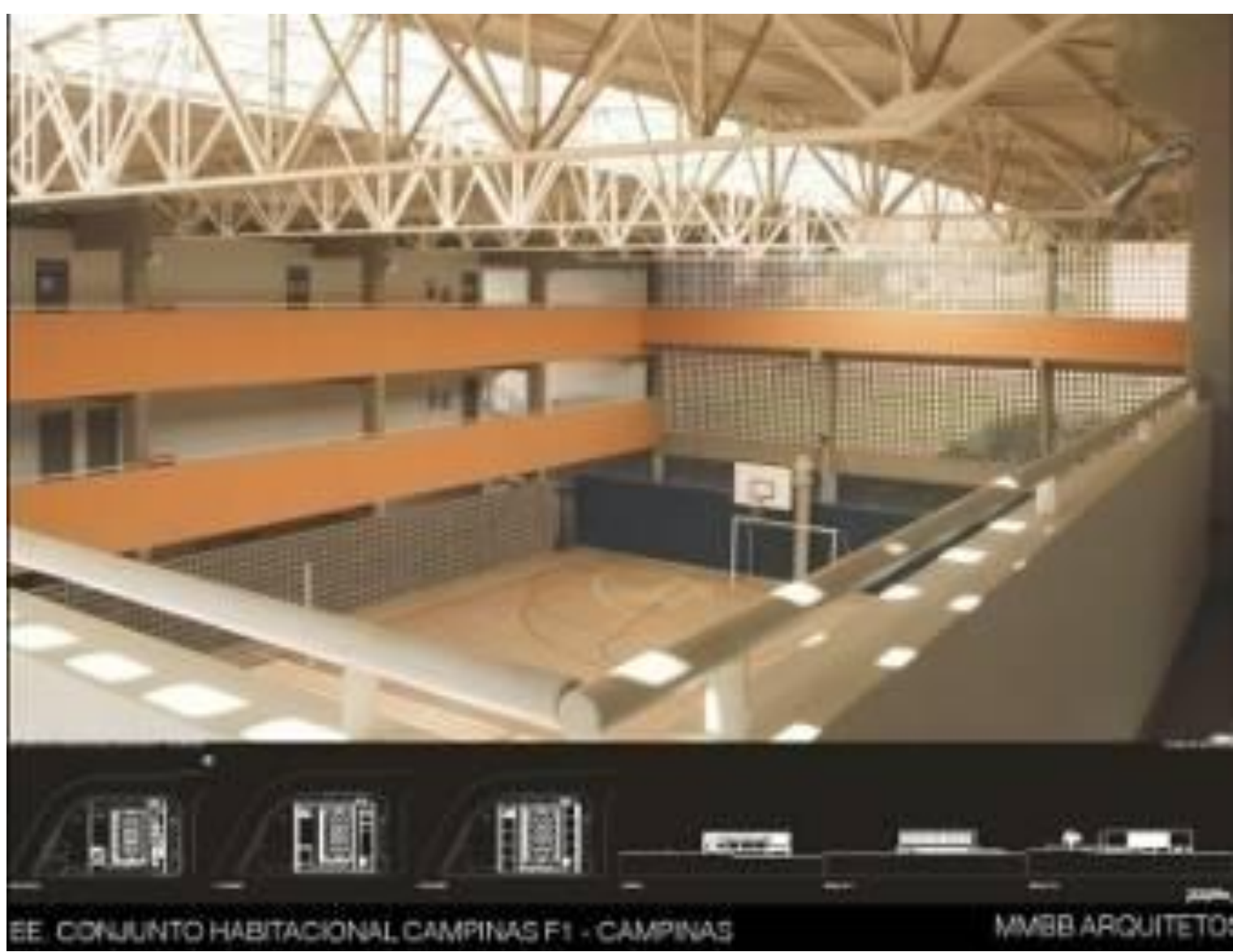

Figura 20 EE Conjunto Habitacional Campinas F1, do escritório MMBB, 2004; imagem: Nelson Kon in (FERREIRA e MELLO, 2006) 


\section{Produção científica voltada à arquitetura escolar estadual}

Seguem-se produtos que resultam de investigação científica relacionada à arquitetura escolar e questões de conforto. É preciso criar um canal de comunicação entre a Universidade e a FDE de forma que as produções possam retroalimentaremse com ganhos para todos os setores envolvidos.

\section{Anésia Barros Frota.}

Estudos de proteção solar com brise-soleil, para escolas localizadas no Estado de São Paulo - para o Manual de Projeto.

1993. Virgínia Dantas de Araújo.

Parâmetros de Conforto Térmico para Usuários de Edificações Escolares no Litoral Nordestino.

Tese (Doutorado em Arquitetura e Urbanismo) - Universidade de São Paulo. Orientador: Anésia Barros Frota.

1997. Sheila Walbe Ornstein; C. A. Martins.

Arquitetura Manutenção e Segurança de Ambientes Escolares: Um Estudo Aplicativo de APO.

Ambiente Construído (São Paulo), v. 1, p. 7-18.

1997. Renata Faccin Camargo; Doris C.C.K. Kowaltowski.

Melhorias de Conforto ao ambiente educacional por meio da avaliação do edifício escolar: estudo de caso em duas escolas de primeiro grau em São Carlos - SP.

ENCAC.

RESUMO

Este trabalho apresenta um estudo direcionado à melhoria de edifícios escolares em uso e realimentação de novos projetos arquitetônicos, com participação do usuário. 0 objetivo principal foi despertar o interesse dos usuários pelo ambiente que ocupam. Assim, foram analisadas duas escolas de primeiro grau distintas na cidade de São Carlos - SP. Concluiu-se que o usuário possui uma relação mecanizada com o ambiente que trabalha, compreendendo mais facilmente questões funcionais. Embora existam diferenças básicas entre as duas escolas, os resultados apresentaram pouca variação. A participação do usuário demonstrouse válida a partir da uniformidade de percepção. Pode-se destacar recomendações de aumento de conforto ambiental dessas escolas, através de modificações de uso e alterações arquitetônicas simples.

1999. Maurício Roriz; Edenir Ghisi; Roberto Lamberts.

Uma proposta de Norma Técnica Brasileira sobre desempenho térmico de habitações populares.

V Encontro Nacional de Conforto no Ambiente Construído e II Encontro Latino-Americano de Conforto no Ambiente Construído - ENCAC.

Este trabalho resume uma proposta de Norma Técnica Brasileira que define requisitos mínimos aceitáveis de desempenho térmico para habitações de interesse social. O território brasileiro é dividido em 8 zonas bioclimáticas e, para cada zona, são indicadas estratégias de condicionamento térmico passivo que contribuam para elevar os níveis de conforto térmico. 
1999. Doris C.C.K. Kowaltowski; Francisco Borges Filho; Lucila C. Labaki; Regina C. Ruschel; Stelamaris R. Bertoli; Silvia A. M. G. Pina; Renata F. de Camargo; Núbia Bernardes Melhoria do Conforto Ambiental em edificaç;cões escolares na região de Campinas.

V Encontro Nacional de Conforto no Ambiente Construído e II Encontro Latino-Americano de Conforto no Ambiente Construído - ENCAC.

RESUMO

O conforto ambiental de edificações escolares afeta o ambiente escolar e a qualidade do ensino. Os prédios escolares no país apresentam falhas no aspecto de conforto, muitas vezes relacionadas às modificações de uso, problemas derivados do projeto e obra original, bem como o desgaste natural de uma construção. Existem problemas simples cujas soluções oferecem possibilidade de ganhos qualitativos com custo reduzido. Este trabalho descreve uma pesquisa junto às escolas estaduais da região de Campinas cujo objetivo é detectar problemas relacionados ao conforto e propor um acervo de soluções para que a própria escola tenha possibilidade de introduzir melhorias no ambiente construído. A pesquisa conta com o apoio da FAPESP, no programa "Ensino Público".

2001.Valéria A. C. da Graça; Doris C. C. K. Kowaltowski; João R. D. Petreche; Cheng Liang Yee. Otimização de projetos das escolas da Rede Estadual de São Ppaulo considerando Conforto Ambiental.

VI Encontro Nacional e III Encontro Latino-Americano sobre Conforto no Ambiente Construído. São Pedro, SP, Brasil. 11 a 14 de novembro, 2001 - Promoção ANTAC.

RESUMO

Muitos prédios escolares possuem falhas relacionadas a questões de conforto ambiental, o que permite considerar que os parâmetros atuais de projeto e sua avaliação necessitam de uma visão mais criteriosa. Esta pesquisa contribui para a avaliação/otimização de projeto escolar da rede estadual de ensino, na fase de anteprojeto, considerando parâmetros de conforto ambiental. O objetivo da avaliação/otimização de projeto é maximizar e qualificar diversas soluções de projeto em relação a diferentes aspectos do conforto ambiental. Foram considerados para cada aspecto de conforto parâmetros específicos. Os parâmetros de conforto ambiental são conflitantes, ou seja, não é possível maximizar todos os confortos ao mesmo tempo, mas sim encontrar um conjunto de soluções de projeto onde alterando-se parâmetros de um conforto para melhor prejudica-se o outro. A metodologia desenvolvida foi aplicada a vários projetos de escolas da rede pública estadual de São Paulo. Os resultados mostram que não existe um projeto ideal/otimizado, mas um conjunto de soluções de compromisso de conforto ambiental. A aplicação desta metodologia na fase de anteprojeto possibilitará o aumento de conscientização em relação a importância dos parâmetros de conforto ambiental.

2001.Valéria A. C. da Graça; Paulo Scarazzato; Doris C. C. K. Kowaltowski.

Método simplificado para a avaliação de iluminação natural em anteprojetos de escolas de ensino Estadual de São Paulo.

VI Encontro Nacional e III Encontro Latino-Americano sobre Conforto no Ambiente Construído. São Pedro, SP, Brasil. 11 a 14 de novembro, 2001 - Promoção ANTAC.

RESUMO

Este trabalho visou àa compreensão de alguns métodos de avaliação de iluminação natural verificando-se a possibilidade da utilização destes para qualificar e avaliar os projetos arquitetônicos de escolas de ensino fundamental e médio do estado de São Paulo. Foi feito um quadro comparativo dos principais métodos de avaliação, o que possibilitou o entendimento dos parâmetros necessários para aplicação de cada modelo, bem como a pertinência destes parâmetros na fase de anteprojeto. Através desta análise foi constatadao a necessidade de desenvolvimento de método simplificado de avaliação para a iluminação natural das salas de aula considerando-se especificamente os dados existentes no anteprojeto.

2001. Núbia Bernardi; Doris C. C. K. Kowaltowski.

Avaliação da interferência comportamental do usuário para a melhoria do conforto ambiental em espaços escolares: estudo de caso em Campinas - SP. 
VI Encontro Nacional e III Encontro Latino-Americano sobre Conforto no Ambiente Construído. São Pedro, SP, Brasil. 11 a 14 de novembro, 2001 - Promoção ANTAC.

RESUMO

O objeto desta pesquisa recai sobre o comportamento de indivíduos no ambiente escolar, detectando as suas reações e participações em relação ao conforto ambiental nos seus aspectos térmicos, lumínicos, sonoros e funcionais. A metodologia adotada utilizou a observação em campo com o mapeamento das interferências do usuário, medições técnicas de níveis de conforto ambiental e a aplicação de questionários. A pesquisa observou poucas ações dos usuários a favor do próprio conforto. As interferências observadas ocorrem após uma situação de estímulo. Destaca-se a necessidade de conscientização do usuário no controle do ambiente e conforto. A satisfação individual e coletiva no arranjo do ambiente e o papel participativo de controle do conforto deve ser abordado através do preparo pedagógico na própria escola.

2002. Giselle A. N. Azevedo

Arquitetura Escolar e Educação: Um Modelo Conceitual de Abordagem Interacionista.

Tese de Doutorado. Rio de Janeiro, RJ.

RESUMO

Este trabalho se propõe a analisar a adequação dos ambientes escolares a partir de uma abordagem interacionista, reconhecendo-se a relevância das relações usuário-ambiente, para a consolidação de um compromisso entre arquitetura, educação e meio-ambiente. A construção de um Modelo Conceitual propõe recomendações que têm em vista a produção de uma arquitetura mais representativa dos valores e necessidades dos usuários, considerando a concepção do edifício escolar como um processo coletivo e interdisciplinar. O contexto atual - em que novos conceitos sobre educação são discutidos - e quando se implementa uma conscientização ecológica mundial, vai exigir uma maior reflexão sobre os significados do ambiente no processo de construção do conhecimento, e consequentemente, o estabelecimento de novas estratégias projetuais que incorporem essa visão interacionista.

2002. Nelson S. Vianna; Marcelo de A. Romero.

Procedimentos metodológicos para a avaliação pós-ocupação em conjuntos habitacionais de baixa renda com ênfase no conforto ambiental.

ANTAC.

RESUMO

Este artigo apresenta parte dos resultados de estudos desenvolvidos na área de Conforto Ambiental, com ênfase na insolação dos edifícios, cujo objetivo de estudo foi um conjunto habitacional da periferia da cidade de São Paulo, construído pela Companhia de Desenvolvimento Habitacional e Urbano do Estado de São Paulo. Discutem-se os critérios adotados na avaliação da variável insolação, os critérios de desempenho para cada um dos ambientes da habitação, assim como os principais resultados da análise comportamental e técnica.

2003. Valéria Azzi Collet da Graça; Doris C.C.K. Kowaltowski

Metodologia de avaliação de conforto ambiental com o conceito de otimização multicritério pra projetos escolares

ENCAC-COTEDI, Curitiba, PR, Brasil; 5 - 7 novembro.

RESUMO

Avaliações pós-ocupação realizadas em prédios de escolas do Estado de São Paulo mostraram que os edifícios possuem uma série de problemas relacionados ao conforto ambiental, o que permite considerar que os parâmetros atuais de projeto necessitam de uma revisão criteriosa. Esta pesquisa apresenta um método de avaliação e otimização de projetos arquitetônicos de escolas para a rede pública estadual de São Paulo, considerando a formulação dos parâmetros de conforto ambiental que são utilizados na fase de anteprojeto. O objetivo da avaliação/otimização do projeto foi maximizar diversos aspectos de conforto ambiental e qualificar as diversas soluções de projeto existentes. O método de avaliação foi aplicado em 35 projetos de escolas. Os resultados mostraram a existência de conflito entre os diferentes parâmetros de conforto ambiental e a importância do uso da otimização para a 
avaliação de projetos. Observou-se que não é possível maximizar os quatro confortos ao mesmo tempo, mas sim encontrar um conjunto de soluções de compromisso. A aplicação mostrou, também, a relevância do método como um importante instrumento de avaliação e de processo de decisão.

2004. Valéria Azzi Collet da Graça; Doris C.C.K. Kowaltowski

Metodologia de avaliação de conforto ambiental de projetos escolares usando o conceito de otimização multicritério.

Ambiente Construído, Porto Alegre, v. 4; n. 3; pp 19-35, jul/set.

RESUMO

Avaliações pós-ocupação realizadas em prédios de escolas do Estado de São Paulo mostraram que os edifícios possuem uma série de problemas relacionados ao conforto ambiental, o que permite considerar que os parâmetros atuais de projeto necessitam de uma revisão criteriosa. Esta pesquisa apresenta um método de avaliação e otimização de projetos arquitetônicos de escolas para a rede pública estadual de São Paulo, considerando a formulação dos parâmetros de conforto ambiental que são utilizados na fase de anteprojeto. O objetivo da avaliação/otimização do projeto foi maximizar diversos aspectos de conforto ambiental e qualificar as diversas soluções de projeto existentes. O método de avaliação foi aplicado em 35 projetos de escolas. Os resultados mostraram a existência de conflito entre os diferentes parâmetros de conforto ambiental e a importância do uso da otimização para a avaliação de projetos. Observou-se que não é possível maximizar os quatro confortos (térmico, luminoso, acústico e funcional) ao mesmo tempo, mas sim encontrar um conjunto de soluções de compromisso. A aplicação mostrou, também, a relevância do método como um importante instrumento de avaliação e de processo de decisão.

2005. Teresa B. S. Funari; Doris C.C.K. Kowaltowski.

Arquitetura escolar e avaliação pós-ocupação.

ENCAC - ELACAC 2005, Maceió, Alagoas, Brasil. 5- 7 out.

RESUMO

Esta comunicação visa apresentar uma pesquisa documental em andamento de estudo da qualidade do ambiente escolar no Brasil. O estudo analisa avaliações da arquitetura escolar com organização dos métodos utilizados e dos resultados obtidos. Essas informações devem fornecer subsídio para uma discussão da arquitetura escolar no Brasil e proporcionar diretrizes projetuais para novas edificações, com ênfase no conforto ambiental e na relação entre forma e metodologia de ensino.

2005. Doris C.C.K. Kowaltowski; Lucila C. Labaki; Marlei G. do Nascimento; Suzana N. P. de Oliveira e Sousa; Francisco Borges Filho; Daniel da Rocha C. Silva; Silvia A. Mikami G. Pina. Manual de Conforto Ambiental: Texto didático para o ensino fundamental São Paulo.

Fundação Carlos Chagas.

2006. Núbia, Bernardi; Doris C.C.K. Kowaltowski.

Environmental Comfort in School Buildings: A Case Study of Awareness and Participation of Users: Environment and Behavior.

Environment and Behavior, v. 38, n. 2, p. 155-172.

2006. Núbia, Bernardi; Doris C.C.K. Kowaltowski.

Universal Design in Architectural Education: A Teaching Experience.

IAPS 2006 - 19th IAPS Conference, International Association for People-Environment Studies, Alexandria, Egypt. p. 1-6.

2006. Lívia Marina Lopez; Doris C.C.K. Kowaltowski

Arquitetura Escolar e sua Iconografia: Análise e Propostas para o Projeto do Ambiente de Ensino

XIV Congresso Interno de Iniciação Científica, UNICAMP. 
A discussão da arquitetura escolar se faz necessária devido às condições muitas vezes inadequadas do ambiente de ensino, principalmente em relação ao conforto ambiental. Este trabalho foi centrado na ilustração de livro sobre arquitetura escolar ("Melhorias do Conforto Ambiental em Edificações Escolares Municipais de Campinas, SP") a ser publicado e no desenvolvimento de conceitos e técnicas iconográficas. $O$ objetivo principal deste projeto de pesquisa foi reunir uma iconografia representativa da arquitetura escolar. A pesquisa bibliográfica indicou as melhores técnicas de desenho e a seleção de exemplos iconográficos representativos. A metodologia adotada consistiu na análise do texto do livro na busca de desenhos apropriados. Foram definidas as melhores técnicas de representação gráfica para a formação de um banco de imagens com posterior inserção no texto. Desenhos foram elaborados e transformados em arquivos digitais. A divulgação do resultado desta pesquisa, através de um novo livro sobre arquitetura escolar, disponibilizará dados e informações mais precisos, servindo como referência de suma importância às futuras construções, intervenções e melhorias arquitetônicas no espaço escolar. A obra prevista também é vista como apoio importante ao ensino de projeto.

2007. Fabiana Valeck de Oliveira.

Arquitetura Escolar Paulista nos Anos 30.

Dissertação de mestrado FAU USP. Orientador: Prof. Maria Lucia Bressan Pinheiro.

2007. L. C. Labaki; V. G. Silva; Adriana P.A.S. Castro; F. E.A.R. Nogueira; Grace C.R. Gutierrez;

Paula R. Pizarro; S. Delbin; Valéria A. C. da Graça; D. C.C.K. Kowaltowski; S. A. M. G. Pina. Indicadores de Eficiência Energética e Conforto Ambiental em Escolas da Rede Pública de Campinas, $S P$.

ENCAC 2007 IX Encontro Nacional e V Encontro Latino Americano de conforto no ambiente construído, Ouro Preto, MG. 2007. p. 2112-2113.

2007. Doris C. C. K. Kowaltowski; Lucila C. Labaki; Valéria de Paiva; Giovana Bianchi; Michael Mösch.

The Creative Design Process Supported by the Restrictions Imposed by Bioclimatic and School Architecture: A Teaching Experience.

PALENC 2007 - 2nd PALENC Conference, and 28th AIVC Conference: Building low energy cooling and advanced ventilation technologies in the 21st century, Creta, Grécia. p. 577 - 581.

2007. Valéria A. C. da Graça; D. C.C.K. Kowaltowski.

Aspectos de Conforto Ambiental, Escritórios de Arquitetura e Projetos de Escolas.

ENCAC 2007 IX Encontro Nacional e V Encontro Latino Americano de conforto no ambiente construído, Ouro Preto, MG. p. 835-844.

2007. Valéria A. C. da Graça; D. C.C.K. Kowaltowski; J. R. D. Petreche.

O Uso de Metodologia de Projeto Axiomático para a Integração de Aspectos de Conforto Ambiental no Desenvolvimento de Projetos para a Tipologia Escolar no Estado de São Paulo.

ENCAC 2007 IX Encontro Nacional e V Encontro Latino Americano de conforto no ambiente construído, Ouro Preto, MG. p. 845-854.

2007. Valéria A. C. da Graça; D. C.C.K. Kowaltowski; J. R. D. Petreche.

An Evaluation Method for School Building Design at the Preliminary Phase with Optimization of Aspects of Environmental Comfort for the School System of the State of São Paulo in Brazil: Building and Environment.

Building and Environment, v. 42, n. 2, p. 984 - 999, ISBN ISSN 0360-1323.

2007. Valéria A. C. da Graça; D. C.C.K. Kowaltowski.

Using Solution Examples and Axiomatic Design to Support Sustainable School Projects in the State of São Paulo / Brazil: A Teaching Experience.

CISBAT 2007, International Scientific Conference, Lausanne, Switzerland. 2007. p. 347 - 352.

2007. D. C. C. K. Kowaltowski; Valéria de Paiva; L. C. Labaki; S. A. M. G. Pina. 
Restrictions As Stimuli For Creative Thought In Architectural Education.

EP 2007 - 7th Biennal Conference on Environmental Psychology, Bayreuth, Germany. p. 133.

2007. Dimas Bertolotti

lluminação natural em projetos de escolas: uma proposta de metodologia para melhorar a qualidade da iluminação e conservar energia

Dissertação de Mestrado; Faculdade de Arquitetura e Urbanismo (FAU); Tecnologia da Arquitetura, USP. Orientador: Paulo Sergio Scarazzato.

RESUMO

Este trabalho tem como objetivo analisar estratégias de iluminação natural utilizadas nos estágios iniciais do projeto de arquitetura capazes de aumentar a qualidade da iluminação e a conservação de energia nos edifícios escolares. Essas estratégias têm sido aplicadas com sucesso em edifícios escolares em vários países, melhorando o desempenho e o bem-estar dos estudantes e conservando energia. Entre essas estratégias, o autor selecionou um dispositivo zenital para iluminação natural com seleção angular e difusores opacos, realizou um ensaio experimental em um modelo físico reduzido de uma sala de aula padrão, sob condições de céu real e analisou comparativamente os resultados. O estudo mostrou que a adoção de uma metodologia para utilizar estratégias como a analisada neste trabalho pode conseguir um adequado controle da radiação solar para evitar a incidência direta da luz do Sol, evitar o ofuscamento e o aquecimento excessivo de ambientes de salas de aula em climas quentes e, ao mesmo tempo, aproveitar a iluminação natural, tanto difusa quanto direta refletida, para obter maior conforto visual e economizar energia.

2008. Maíra Piccolotto Issa.

Avaliação Pós-Ocupação: procedimentos para a aplicação em escolas do ensino fundamental e médio.

Iniciação Científica. (Graduando em Arquitetura e Urbanismo) - Faculdade de Arquitetura e Urbanismo da USP, Fundação de Amparo à Pesquisa do Estado de São Paulo. Orientador: Sheila Walbe Ornstein.

2008. Julyane Pereira Poltronieri.

Procedimentos para a Avaliação de Desempenho das Etapas de Planejamento e de Projeto de Escolas do Ensino Fundamental e Médio.

Iniciação Científica. (Graduando em Arquitetura e Urbanismo) - Faculdade de Arquitetura e Urbanismo da USP, Conselho Nacional de Desenvolvimento Científico e Tecnológico. Orientador: Sheila Walbe Ornstein.

2008. Valéria Azzi Collet da Graça.

Otimização de Projetos de Escolas através de metodologia de indicadores de Especialistas em Conforto Ambiental.

FEC/UNICAMP, Campinas. Orientador (es): KOWALTOWSKI, DORIS C.C.K.

RESUMO

Avaliações de Pós-Ocupação de prédios escolares no Estado de São Paulo, Brasil, têm mostrado que muitas escolas apresentam uma série de problemas especialmente relacionados ao conforto ambiental. Uma revisão dos parâmetros de projeto de escolas é portanto necessária. Esta pesquisa apresenta um método para avaliar e otimizar projetos escolares para o sistema de escolas do Estado de São Paulo considerando parâmetros de conforto ambiental a serem aplicados num estágio preliminar do projeto. A aplicação do método em 35 projetos mostrou a existência de conflitos entre parâmetros, não sendo possível maximizar os 4 parâmetros ao mesmo tempo, sendo necessário priorizar parâmetros. O teste aplicado mostrou que o método de otimização é um instrumento importante de projeto e avaliação.

2008. V. C. da Graça; D. C. C. K. Kowaltowski; L. C. Labaki; J. R. D. Petreche.

With Comfort in Mind: Using Expert Evaluated Examples in A School Design Discipline of A Building Technology Course. 
PLEA 2008 - 25th PLEA International Conference on Passive and Low Energy Architecture, Dublin, Ireland. p. 1-6.

2008. Cecília Matos Mueller; Anésia Barros Frota.

O processo metodológico para elaboração de projetos com qualidade ambiental: exemplificação por meio de um anteprojeto de escola em São Paulo, Partes 1 e 2.

NUTAU $20087^{0}$ Seminário Internacional Espaço Sustentável Inovações em Edifícios e Cidades, São Paulo.

RESUMO

A parte 1 deste artigo apresenta uma proposta de etapas que configuram um processo metodológico para elaboração de projetos com qualidade ambiental, com base na tecnologia hoje disponível. O objetivo não é ser um roteiro de caráter conclusivo, mas sim um roteiro que apresenta etapas complementares (como a caracterização físico-climática do terreno e do entorno, os ruídos no local, a aplicação da bioclimatologia à arquitetura e a avaliação do desempenho do edifício) àquelas já utilizadas no processo projetual convencional de um escritório de arquitetura.

A parte 2 deste artigo exemplifica o processo metodológico para elaboração de projetos com qualidade ambiental por meio de estudos preliminares para um anteprojeto de uma escola pública de $1^{\circ} \mathrm{grau}$. O resultado mostrou a viabilidade da aplicação dessa metodologia, dentro da rotina habitual dos escritórios de arquitetura, para alcançar a relação ótima entre forma, estética, racionalidade construtiva, custo, conforto ambiental e eficiência energética.

2009. Thaís Molon Grotti.

Aferição de instrumentos para Avaliação Pós-Ocupação: O Caso das Escolas de Ensino Fundamental e a satisfação dos Alunos de menor Faixa Etária.

Iniciação Científica. (Graduando em Arquitetura e Urbanismo) - Faculdade de Arquitetura e Urbanismo da USP, Fundação de Amparo à Pesquisa do Estado de São Paulo. Orientador: Sheila Walbe Ornstein.

2009. Flávio Hadlich.

As escolas do Ipesp: projetos de edifícios escolares produzidos para o Instituto de Previdência do Estado de São Paulo de 1959 a 1962.

Dissertação de mestrado FAU/USP. Orientador: Prof. Dr. Adilson Costa Macedo.

2009. Vanessa Gomes da Silva; D. C. C. K. Kowaltowski; Paula P.R Pereira; Luciano Minette; Marcella S. Deliberador.

Analysis of the Building Process and of Energy Efficiency of Public Schools in the State of São Paulo, Brazil.

CSAAR 2009 International conference: Sustainable Archiecture and urban Development, Tripoli, Lybia. p. 255 - 270.

2009. Vanessa Gomes da Silva; D. C. C. K. Kowaltowski; Maristela G. da Silva.

Education Challenges for Sustainable Design and Construction.

Engineering Sustainability 2009: Innovations that Span Boundaries, Pittsburgh, USA. p. 1-2.

2009. D. C. C. K. Kowaltowski; Vanessa Gomes da Silva; Valéria C. da Graça; Paula P.R Pereira; Marcella S. Deliberador; Francisco G. de Figueiredo.

Desafios e Realidades: O Processo de Projeto Escolar no Estado de São Paulo.

ENCAC 2009 X Encontro Nacional e VI Encontro Latino Americano de Conforto no Ambiente Construído, Natal, RN. p. 1526-1535.

2009. Michael Mösch.

O Processo Projetivo na Arquitetura: O Ensino do Projeto de Escolas.

FEC/Departamento de Arquitetura e Construção. Orientador(es): Doris C.C.K. Kowaltowski. 
2009. Doris C.C.K. Kowaltowski; Giovana Bianchi; Valéria T. De Paiva

Methods that may stimulate creativity and their use in architectural design.

Int. Journal Technol Des Educ. - Springer Science+Business Media B.V. 2009.

RESUMO

The architectural design process is based on a creative phase where creativity is highly valued. Although the literature on creativity is rich in ways to stimulate the decision-making process, these tools are rarely formally present in the building design process. To further the discussion on creativity and design education this paper presents a study on methods that may enhance the creative process and their application in architecture courses around the world. The results of this inquiry indicate that design instructors apply methods that may stimulate creativity mostly informally, with some positive results. To explore more fully the richness of the literature on the enhancement of creativity, structured applications of methods are recommended in controlled experiments to analyze results.

2010. Núbia, Bernardi; Doris C.C.K. Kowaltowski.

When Role Playing is not Enough: Improved Universal Design Education

ArchNet - Special Special Volume: Design Education: Explorations and Prospects for a Better Built Environment. Ashraf M. Salama and Michael J. Crosbie (editors), v. 4, Issues 2-3, Jul/Nov. p. 376-390.)

RESUMO

In this paper the principles of Universal Design (UD) are discussed in the context of design education. The application of the concepts of UD to building and urban design has ensured a better quality of life for users with disabilities, however, to create na accessible environment the design profession needs to adopt new attitudes and the design process and its teaching strategies must change. Design education is discussed in relation to role-playing and participatory design activities. A teaching experience is presented, with the goal to develop student awareness of users with special needs. New design communication instruments were developed, such as tactile maps, to enable user participation of the visually impaired. Design is primarily based on visual communication and visually impaired users were included in the teaching experience in view of their inability to evaluate typical design documentation, such as drawings and models. Role-playing, as a means of bringing students closer to the issues of users with disabilities, was shown to be insufficient and the creation of a collaborative design process was important to increase student's sensitivity. The active participation of users with disabilities ensured that future professionals gained a deeper understanding of user needs and were able to create appropriate and quality environment. The inclusion of visually impaired users in the design process is seen as original in design pedagogies. The use of tactile maps for design documentation was shown to be an important contribution to research in the area of design methods. Some research questions arose from the teaching experience, relating to technical details of tactile map production, as well as pedagogical and ethical issues involved in participatory design.

2010. Liliane Cristine Nambu.

Aferição de Instrumentos para Avaliação de Desempenho de Edifícios Escolares de Ensino Fundamental: do programa de necessidades à pós-ocupação.

Iniciação Científica. (Graduando em Arquitetura e Urbanismo) - Faculdade de Arquitetura e Urbanismo da USP, Conselho Nacional de Desenvolvimento Científico e Tecnológico. Orientador: Sheila Walbe Ornstein.

\section{Francisco Varejão Manara.}

Avaliação do mobiliário de edifícios escolares do ensino fundamental: do programa de necessidades à usabilidade.

Iniciação Científica. (Graduando em Design) - Faculdade de Arquitetura e Urbanismo da Universidade de São Paulo, Fundação para a Pesquisa Ambiental. Orientador: Sheila Walbe Ornstein

2010. Liliane Cristine Nambu; Sheila Walbe Orstein.

O Lugar do Pátio nos edifícios escolares públicos: avaliação de estudos de caso na região metropolitana de São Paulo. 
I Workshop GAE-PROLUGAR-SEL. Rio de Janeiro: Faculdade de Arquitetura e Urbanismo da UFRJ/ProArq, v. 1. p. 128-140.

CASSIA SHROEDER BUITONI DISSERTAÇÃO DE MESTRADO à FAUUSP: MAYUMI WATANABE SOUZA LIMA: A CONSTRUÇÃO DO ESPAÇO PARA A EDUCAÇÃO. ORIENTADORA VERA MARIA PALLAMIN 2009 ()

2010. D.C.C.K. Kowaltowski; M. S. Deliberador.

O processo de projeto de arquitetura escolar no Estado de São Paulo: caracterização e possibilidades de intervenção.

1ํ. Workshop GAE-PROLUGAR-SEL - O LUGAR DO PÁáTIO ESCOLAR NO SISTEMA DE ESPAÇçOS LIVRES, 2010, Rio de Janeiro.

RESUMO

A qualidade da educação vem sendo constantemente questionada através das avaliações de desempenho aplicadas junto aos alunos das escolas públicas. Observa-se a necessidade de uma atuação multidisciplinar que vislumbre a melhoria da qualidade de ensino de forma geral, - que significa incluir a participação do profissional de arquitetura, responsável pelas definições das características físicas do ambiente escolar. O objetivo desse trabalho é abordar aspectos relativos à qualidade do espaço escolar e das questões inerentes ao processo de projeto das escolas públicas do Estado de São Paulo. A metodologia utilizada envolveu a sistematização das informações disponíveis na literaturae relativas à qualidade do espaço escolar com ênfase nas áreas livres. Observou-se que na prática de projeto as relações entre espaços internos e externos são ignoradas, desde o programa de necessidades, onde os ambientes aparecem apenas descritos com relação às suas dimensões físicas. Descreve-se o pátio como um espaço limitado às suas dimensões físicas e não entendido como um conceito ampliado de uso educacional das áreas livres. Esses pátios são áreas que incorporam as atividades de lazer, além das atividades pedagógicas que impliquem na necessidade de espaços externos, dada a ausência da relação desses com os espaços das salas de aula. A partir do estudo bibliográfico, propôs-se o esquema do processo de projeto de referência. Propôs-se também esquema do processo de projeto da Fundação para o Desenvolvimento Escolar, a partir da metodologia que a Fundação promove. Realizou-se uma pesquisa de campo que fundamentou o desenvolvimento de um terceiro esquema chamado de processo de projeto enriquecido, que incorpora as etapas do processo de referência consideradas possíveis de serem aplicadas na realidade atual da FDE. Esse estudo também demonstrou a pouca discussão existente acerca dos espaços livres, ou mesmo do típico pátio escolar. As implantações das escolas são desenvolvidas enfocando a acomodação dos ambientes do programa dentro dos terrenos exíguos e da promoção de um acesso adequado que traz uma mínima relação urbana ao projeto, dando pouca atenção às relações dos espaços internos e externos. Faltam atuações direcionadas à qualidade da paisagem e o projeto de espaços de apoio e lazer, que enriqueçam a experiência educacional.

2010. D. C. C. K. Kowaltowski; G. Bianchi; V. T. Paiva.

Methods that may stimulate creativity and their use in architectural education.

International Journal of Technology and Design Education, vol. 20, No. 4 pp 453 - 476, ISSN 0957-7572.

2010. Coordenação Dóris C.C.K. Kowaltowski.

O processo de projeto em arquitetura: da teoria a tecnologia.

Ed. Oficina de Textos, Livro no prelo dez.

2010. Vanessa Gomes da Silva; F. R. M. Oliveira; M. G. Silva; D. C. C. K. Kowaltowski.

Education challenges for sustainable design and construction.

CIB World Building Congress, 2010, Salford Quays.

2011. M. S. Deliberador; D.C.C.K. Kowaltowski.

Improving School Building Quality in the State of São Paulo, Brazil. 
Anais do PLEA2011: Architecture and sustainable development, Louvain-la-Neuve, Bélgica, Julho.

2011. D. C. C. K. KOWALTOWSKI; M. DELIBERADOR; VANESSA G. SILVA; FRANCISCO B. FILHO.

The school building design process in the State of São Paulo, Brazil: is sustainability an issue

Engineering Sustainability 2011: Innovation and the Triple Bottom Line, April 10-12.

RESUMO/EXTENDED ABSTRACT

This paper presents the results of an investigation conducted in the State of São Paulo, Brazil with 44 of the architects who are responsible for the design of school buildings for the public sector. The study was based on structured interviews with the goal of characterizing the specific design process. Results showed that this process is strongly influenced by the government agency responsible for public school buildings (FDE) in the State, with only very little leeway for innovation and individual flair. In relation to aspects of thermal comfort and sustainability the professionals mentioned few items as guiding principles, like cross ventilation, solar window protectors and orientation of building blocks. In relation to sustainability the results showed that designers are not as yet prepared to assess the wide range of items found in certifications such as LEED. The design process was compared to recommendations found in the literature on high performance school buildings. Some opportunities for change could be identified, such as awareness of risk situations that demand special attentions especially with regard to difficult sites. Although the results are not encouraging in bringing about immediate improvements in the school building design process, there are signs of change that should be explored. These signs are in the form of new types of contracts and the inclusion of quality control processes. Finally, the characterization of the local school design process indicates the need for better assessment tools and access to technical information directly applicable to the local design issues.

1996 - 1999. Coordenador da Pesquisa: Prof. Dr. Marcelo de Andrade Roméro / Sheila Walbe Ornstein - Coordenador. ()

Pesquisa Habitare Procedimentos Metodológicos para Aplicação da Avaliação Pós-Ocupação em Conjuntos Habitacionais para População de Baixa Renda: do Desenho à Unidade Habitacional. Conjunto Habitacional

RESUMO

A pesquisa em questão foi desenvolvida utilizando-se como estudo de caso o Conjunto Habitacional Jardim São Luís, ocupado a partir de 1993, situado na região sudoeste do município de São Paulo (Administração Regional do Campo Limpo) e executado pela Companhia de Desenvolvimento Habitacional e Urbano do Estado de São Paulo (CDHU), com unidades habitacionais em edifícios iguais, modelo "H", com quatro pavimentos com oito apartamentos cada. Especificamente, foram considerados não somente as unidades habitacionais e seus edifícios, mas também sua circunvizinhança, a infra-estrutura, os serviços, a escola e as áreas livres do conjunto. Este trabalho desenvolveu, então, uma pesquisa teórico-prática, com a aplicação dos conceitos e dos procedimentos metodológicos de avaliação pós-ocupação, com o objetivo de aperfeiçoar esses procedimentos e de experimentar técnicas pouco empregadas nas APOs já desenvolvidas, o que possibilita a obtenção de resultados mais precisos e abrangentes. Tais procedimentos levaram sempre em consideração, além da avaliação de desempenho técnico dos edifícios eleitos, a satisfação de seus usuários em relação aos aspectos priorizados.

2007 - 2008. Rosaria Ono; Nanci Saraiva Moreira; Richard Yelland; Hannah Von Ahlefeld; Henry Sanoff; Teresa Heitor; Sheila Walbe Ornstein.

Pesquisa International Facility Performance Evaluation Pilot Project (FPEPP). Conselho Nacional de Desenvolvimento Científico e Tecnológico - Cooperação / Organisation for Economic Cooperation and Development - Cooperação.

RESUMO

Esta pesquisa piloto é parte dos projetos coordenados pelo Programme on Educational Building (PEB) da Organisation for Economic and Co-Operation Development (OECD) para o biênio 2007-2008 [www.oecd.org/edu/facilities/evaluatingquality]. A OECD tem sede em Paris, e desenvolve os indicadores educacionais sob a sigla PISA - Programme for International 
Student Assessment [www.oecd.org/edu]. Esta pesquisa foi estruturada nas reuniões com especialistas internacionais em avaliação de desempenho, avaliação da qualidade arquitetônica e avaliação pós-ocupação ocorridas no biênio 2005-2006 em Portugal, no México e na França, nas quais tive participação. Serão escolhidos edifícios escolares em países como Brasil, Portugal, EUA, Inglaterra, Áustria, Suiça, dentre outros, para aferição de diferentes métodos, técnicas e ferramentas, para avaliação de desempenho, desde a etapa de pré-projeto até a pós-ocupação. A ideia é gerar procedimentos amigáveis para avaliação de equipamentos escolares que possam ser aplicados - observadas as diferenças sócioeconômicas e culturais, geográficas e climáticas - em diferentes países, visando incrementar a qualidade do processo de projeto do equipamento escolar, seu planejamento, projeto, uso, operação, manutenção e gerenciamento. Pretende-se definir padrões de desempenho e de qualidade de equipamentos educacionais e auxiliar na definição das chamadas "melhores práticas de espaços para o aprendizado". No caso do Brasil, coordeno esta pesquisa, com a parceria da Secretaria de Educação do Estado de São Paulo e a Fundação para o Desenvolvimento da Educação (SEE-FDE). Também pretende elaborar um manual contemplando procedimentos e tipos de instrumentos/ferramentas para APO em distintos países, como por exemplo, questionários, entrevistas, grupos focais, observações, walkthrougs, dentre outros). Coordenação geral: a cargo de Richard Yelland (Coordenador PEB-OECD) e Hannah Von Ahlefeld, analista (PEB-OECD). Consultar: [www.oecd.org].

2009 - Atual. Sheila Walbe Ornstein - Coordenador; Rosaria Ono; Nanci Saraiva Moreira; Liliane Cristine Nambu; Caroline Akemi Makiyama Maeda.

Projeto de pesquisa Qualidade Arquitetônica dos Ambientes Educacionais para o Ensino Fundamental e Médio. Procedimentos para a Avaliação de Desempenho: do Pré-Projeto à Pós-Ocupação.

Finaciador(es): Conselho Nacional de Desenvolvimento Científico e Tecnológico - Bolsa / Fundação de Amparo à Pesquisa do Estado de São Paulo - Bolsa. RESUMO

Esta pesquisa tem como objetivo: (1) à luz das exigêencias determinadas pelos projetos pedagógicos contemporâneos, contribuir com as redes públicas de equipamentos escolares para o ensino fundamental e médio no sentido da adequação do edifício - escola e vizinhança - à flexibilidade de uso dos seus ambientes, inserção da tecnologia da informação, acessibilidade às pessoas com deficiência, ergonomia, mobiliário e segurança contra incêndio e patrimonial; (2) contribuir para a implantação de um sistema de gestão do processo de projeto, abrangendo procedimentos amigáveis passíveis de aplicação nas etapas de préprojeto, projeto e pós-ocupação, considerando tanto os pontos de vista da comunidade na qual o edifício escolar está (será) inserido, dos alunos, dos professores, dos funcionários e dos especialistas;(3) contribuir para a qualidade arquitetônica face às efetivas demandas dos usuários e das especificações dos projetos pedagógicos; (4) dar continuidade à parceria acadêmica entre a FAUUSP-Grupo de Pesquisa CNPq Qualidade e Desempenho no Ambiente Construído e a Fundação para o Desenvolvimento Educacional / Secretaria de Estado da Educação.

2009 - Atual. Sheila Walbe Ornstein - Coordenador; Rosaria Ono; Nanci Saraiva Moreira; Ana Judite G. França; Liliane Cristine Nambu; Caroline Akemi Makiyama Maeda. International Pilot Study on the Evaluation of Quality in Educational Spaces (EQES).

Finaciador(es): Conselho Nacional de Desenvolvimento Científico e Tecnológico - Bolsa / Fundação de Amparo à Pesquisa do Estado de São Paulo - Bolsa.

RESUMO

Projeto de pesquisa internacional e piloto sob a organização geral do Centre for Effective Learning Environments (CELE) da Organisation for Economic Co-Operation and Development (OECD) cujo objetivo é aferir métodos e técnicas para avaliação de desempenho de edifícios escolares em uso tais como: questionários, grupos focais, walkthroughs e outros. Tem a participação de vários países associados a OECD dentre eles Portugal, México, Brasil e Reino Unido dentre outros. A partir das conclusões desta aplicação piloto a OECD pretende elaborar uma publicação contemplando os procedimentos gerais para este tipo de avaliação de desempenho em uso ou avaliação pós-ocupação (APO). Esta pesquisa piloto está sendo realizada junto com a pesquisa sobre o mesmo tema relativa 
à bolsa produtividade (APO/edifícios escolares) e conta com a parceria da Secretaria de educação do Governo do Estado de São Paulo /Fundação para o Desenvolvimento da Educação (FDE).

2009 - Flávio Hadlich.

As escolas do Ipesp: projetos de edifícios escolares produzidos para o Instituto de Previdência do Estado de São Paulo de 1959 a 1962.

Dissertação de Mestrado. Curso de Pós-Graduação da Faculdade de Arquitetura e Urbanismo da Universidade de São Paulo. São Paulo. p. 163, 2009.

\begin{abstract}
RESUMO
Esta dissertação teve por objetivo realizar uma análise dos projetos escolares encomendados pelo Instituto de Previdência do Estado de São Paulo (IPESP) junto aos escritórios paulistas de arquitetura durante a vigência do Plano de Ação do então governador do Estado, Carlos Alberto Alves de Carvalho Pinto. Foram realizados levantamentos dos projetos selecionados, caracterizando construtivamente a produção em estudo e comparando com as diretrizes de projeto elaboradas pelo Fundo Estadual de Construções Escolares (FECE) criado pelo governo do Estado para o planejamento da rede escolar. Também foram analisados os fatores que possibilitaram uma nova forma de elaboração de projetos para obras públicas - até então realizados por funcionários públicos - através de contratos com os escritórios de arquitetura, e sua repercussão junto à classe arquitetônica. Para o melhor entendimento e verificação da diversidade de projetos elaborados, foram criados grupos com projetos selecionados por similaridade conceitual através de critérios embasados na espacialidade e forma das edificações. Esses grupos foram representados por esquemas gráficos que sintetizaram as suas características mais expressivas. Por fim, considerações foram feitas sobre as realizações do Plano de Ação, a produção da arquitetura escolar do Ipesp e sua repercussão na arquitetura escolar paulista posterior.
\end{abstract}

2009 - Cássia S. Buitoni

Mayumi Watanabe Souza Lima: a construção do espaço para a educação.

Dissertação de Mestrado. Curso de Pós-Graduação da Faculdade de Arquitetura e Urbanismo da Universidade de São Paulo. São Paulo. 2009.

(). Carlos Roberto Godoi Cintra; Luiz Gonzaga Mariano de Souza.

A utilização da ISO 6241 na avaliação de edificações escolares, através dos métodos e técnicas da APO - Avaliação Pós Ocupação. O caso das Escolas de Cara Nova de Mogi das Cruzes - SP.

RESUMO

This article uses the ISO 6241 to evaluate the state median education school buildings of Mogi das Cruzes, that are called Cara Nova (New Face), that were generated by the bireciprocal association between the architecture and the pedagogy based on the last generation design, issued by the improvement of the study of the evolution of the paulista (from the State of São Paulo) architecture of school building. The ISO 6241 - Normalization and Performance in Buildings, is part of the whole group of norms directed toward the quality management in contractor companies, and was used, in this case study applying the POE Post-Occupancy Evaluation, a group of methods and techniques, in which a technical approach of building is done, prioritizing the final user satisfaction as a predominant factor of the product performance. The physical evaluation was done in relation to: the social convenience; the building itself; and the functionality and environmental comfort, in confront to the observations of the users with the technician focus, pointing to the main qualities and deficiencies. In conclusion this article evaluates the adequacy of the ISO 6241 to be applied in this type of building, as a tool to measure its physical performance. 


\section{INSTRUMENTOS PARA PROJETO}

Neste capítulo serão considerados instrumentos utilizados como recursos de projetos. Assim, em primeiro lugar serão arroladas as normas técnicas brasileiras. Na sequência, serão apresentados os principais softwares de informação do projeto e avaliação de desempenho. Por fim, será considerada a avaliação pós-ocupação de um caso específico.

\subsection{Normas Técnicas Brasileiras}

Com relação às Normas Técnicas Brasileiras, agrupam-se aqui em quatro categorias: Conforto Térmico, Conforto Acústico, Conforto Luminoso e Desempenho. Elas servem de referência para os procedimentos a serem adotados para organização, dimensionamento e verificação dos espaços e sistemas projetados, bem como apresentam critérios para as avaliações a serem realizadas.

\section{Conforto Térmico}

NBR 15.220-1:2005Desempenho térmico de edificações - Parte 1

Definições, símbolos e unidades

NBR 15.220-2:2005Desempenho térmico de edificações - Parte 2

Métodos de cálculo da transmitância térmica, da capacidade térmica, do atraso térmico e do fator solar de elementos e componentes de edificações (+ errata)

NBR 15.220-3:2005Desempenho térmico de edificações - Parte 3

Zoneamento bioclimático brasileiro e diretrizes construtivas para habitações unifamiliares de interesse social

NBR 15.220-4:2005Desempenho térmico de edificações - Parte 4

Medição da resistência térmica e da condutividade térmica pelo princípio da placa quente protegida

NBR 15.220-5:2005Desempenho térmico de edificações - Parte 5

Medição da resistência térmica e da condutividade térmica pelo método fluximétrico

Conforto Acústico 
NBRISO 31-7:2006 Grandezas e unidades - Parte 7: Acústica

NBR 8.572:1984 Fixação de valores de redução de nível de ruído para tratamento acústico de edificações expostas ao ruído aeronáutico Procedimento

NBR 10.151:2000 Acústica: Avaliação do ruído em áreas habitadas, visando o conforto da comunidade

NBR 10.152:1987 Níveis de ruído para conforto acústico

NBR 12.179:1992 Tratamento acústico em recintos fechados - Procedimento

Conforto Luminoso

NBR 5.382:1985 Verificação de iluminância de interiores

NBR 5.413:1992 Iluminância de interiores

NBR 5.461:1991 Iluminação

NBR 15.215-1:2005Iluminação natural - Parte 1

Conceitos básicos e definições

NBR 15.215-2:2005Iluminação natural - Parte 2

Procedimentos de cálculo para a estimativa da disponibilidade de luz natural

NBR 15.215-3:2005lluminação natural - Parte 3

Procedimento de cálculo para a determinação da iluminação natural em ambientes internos

NBR 15.215-4:2005lluminação natural - Parte 4

Verificação experimental das condições de iluminação interna de edificações - Método de medição

Desempenho

NBR 15.575-1:2010Edifícios habitacionais de até cinco pavimentos - Desempenho Parte 1

Requisitos gerais

NBR 15.575-2:2010Edifícios habitacionais de até cinco pavimentos - Desempenho Parte 2 
Requisitos para os sistemas estruturais

NBR 15.575-3:2010Edifícios habitacionais de até cinco pavimentos - Desempenho -

Parte 3

Requisitos para os sistemas de pisos internos

NBR 15.575-4:2010Edifícios habitacionais de até cinco pavimentos - Desempenho -

Parte 4

Sistemas de vedações verticais externas e internas

NBR 15.575-5:2010Edifícios habitacionais de até cinco pavimentos - Desempenho -

Parte 5

Requisitos para sistemas de coberturas

NBR 15.575-6:2010Edifícios habitacionais de até cinco pavimentos - Desempenho -

Parte 6

Sistemas hidrossanitários

\subsection{Softwares}

Serão considerados aqui softwares utilizados como instrumentos para desenvolvimento de projeto e avaliação de desempenho.

Em um primeiro momento, serão apresentados e descritas as características básicas dos softwares desenvolvidos pelo Laboratório de Conforto Ambiental e Eficiência Energética (LABAUT) do Departamento de Tecnologia (AUT) da Faculdade de Arquitetura e Urbanismo da Universidade de São Paulo (FAUUSP). $\mathrm{Na}$ sequência, serão considerados outros softwares comumente utilizados por consultores brasileiros na área de conforto ambiental para informar o projeto arquitetônico e auxiliar no dimensionamento de espaços e sistemas.

\subsubsection{Softwares do LABAUT}

Ao longo dos últimos anos, o LABAUT vem trabalhando no desenvolvimento de aplicativos computacionais que auxiliam nos cálculos de conforto ambiental para o projeto de arquitetura e urbanismo. São utilizados como base o MS-Excel e o Visual Basic for Applications para elaborar planilhas de cálculos de fácil utilização. São apresentados na sequência os softwares disponíveis no site da FAU. 
Climaticus 4.1

O Climaticus 4.1 é um software que oferece acesso a um banco de dados climáticos para 58 cidades brasileiras, de forma rápida, direta e organizada. 0 programa também oferece ferramentas para o diagnóstico climático, tais como a Carta Bioclimática de Givoni, a classificação do clima segundo Mahoney e diagramas de geometria ótima.

A versão 1.0 foi desenvolvida inicialmente em 2003, pela aluna Gabriela Audi Ferreira, com Bolsa de Iniciação Científica, sob orientação da Prof ${ }^{\underline{a}}$ Dr $^{\underline{a}}$ Marcia Peinado Alucci, a qual vem trabalhando desde então no desenvolvimento de novas versões.

Este software vem sendo utilizado por diversos consultores dos projetos da fDE, sobretudo aqueles certificados pelo AQUA.
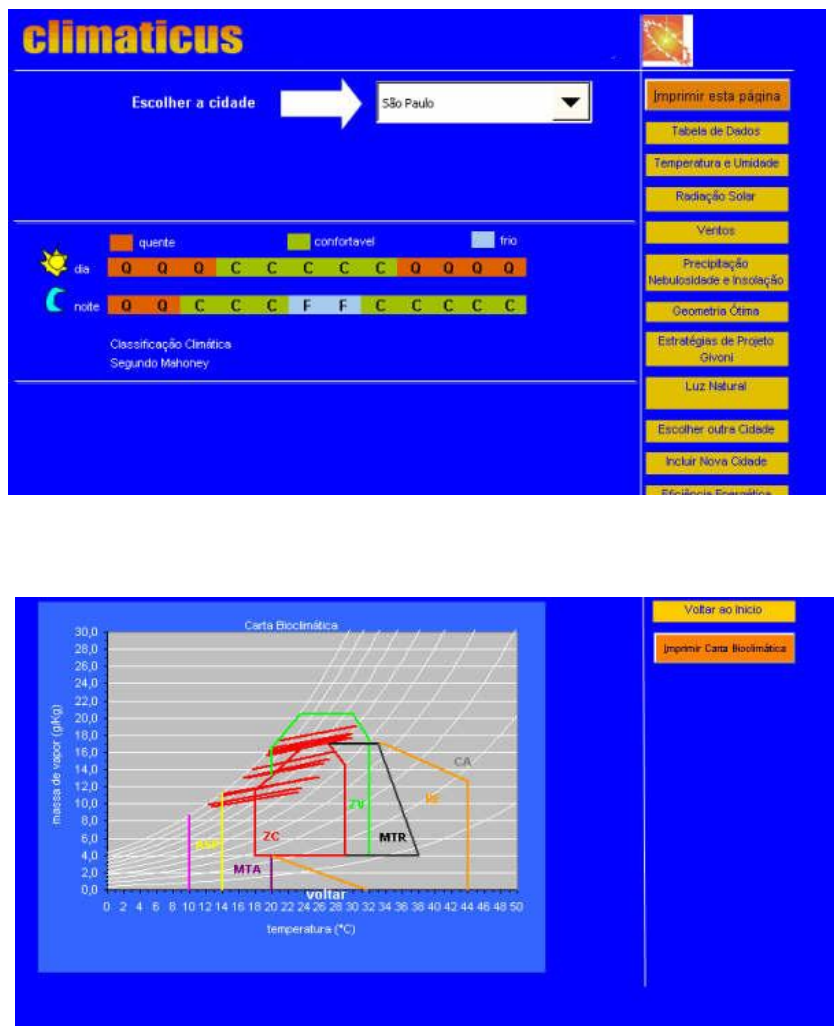

Figura 21 - Software Climaticus: telas de classificação de Mahoney e zonas climáticas segundo Givoni 
Fachada 2.0

O fachada 2.0 calcula temperatura do ar interna sem condicionamento artificial, as condições de conforto térmico dos ambientes e o consumo de energia elétrica pelo sistema de ar condicionado, para o horário crítico em termos térmicos: 15 horas. Foi desenvolvido pela Prof $\stackrel{a}{\text { D }} r^{\mathrm{a}}$ Marcia Peinado Alucci em 2003.

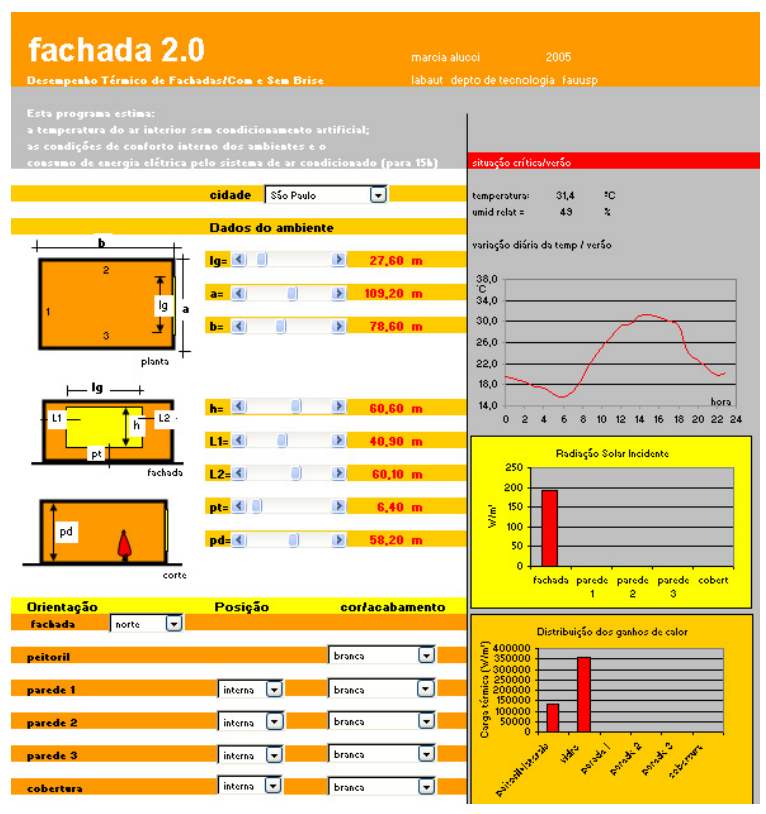

Figura 22 - Software Fachada: tela de entrada de dados

Chaminé 2.5

O software Chaminé 2.5 calcula a vazão de ar, em metros cúbicos por hora, por efeito chaminé para ambientes com diferentes aberturas laterais e zenitais. $O$ software foi desenvolvido pela Prof ${ }^{\mathrm{a}} \mathrm{Dr}^{\mathrm{a}}$ Marcia Peinado Alucci em 2002.
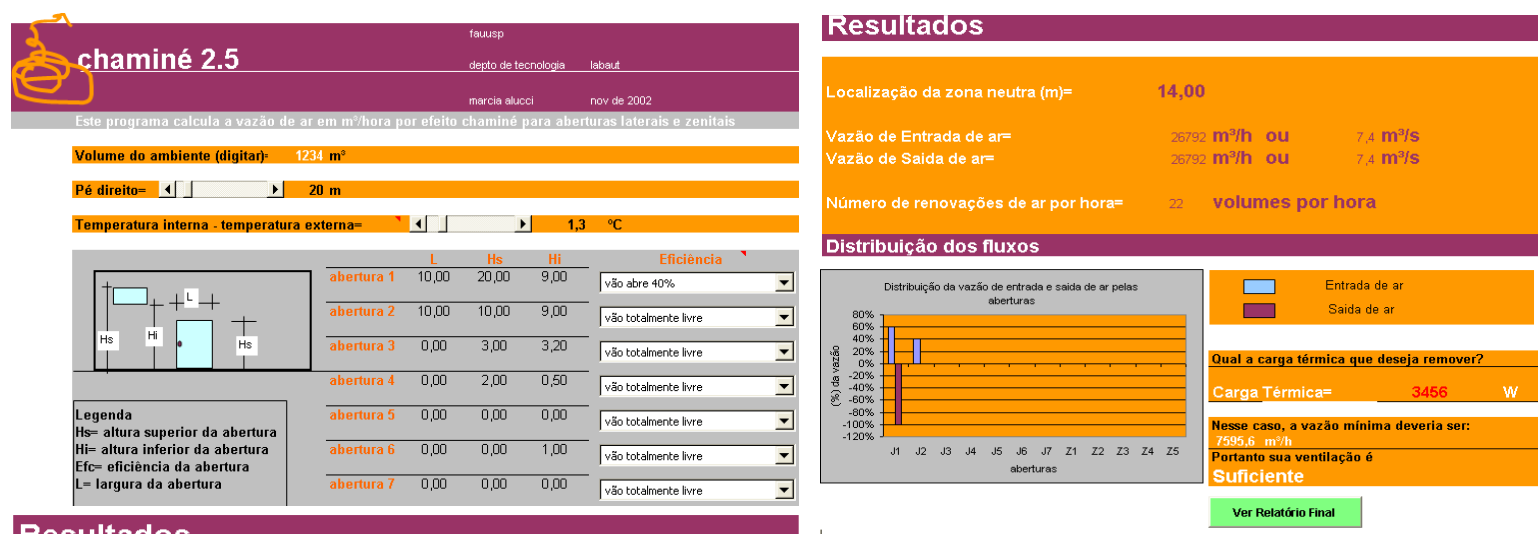

Figura 23 - Software Chaminé: tela de entrada de dados e resultados 
Humano 1.1

O Humano 1.1 possibilita a simulação do desempenho térmico de um recinto pelo método do CSTB - Centre Scientifique et Tecnique du Bâtiment. A partir da descrição das características construtivas do ambiente em questão, o software calcula os níveis de conforto em dias típicos de inverno e de verão. São diferenciais do programa o cálculo do desempenho de brises assim como da ventilação natural por efeito chaminé. O aplicativo foi desenvolvido como Trabalho Final de Graduação pelo aluno Daniel Cóstola, sob orientação da $\operatorname{Prof}^{a}{ }^{a} r^{a}$ Marcia Peinado Alucci, em 2002.
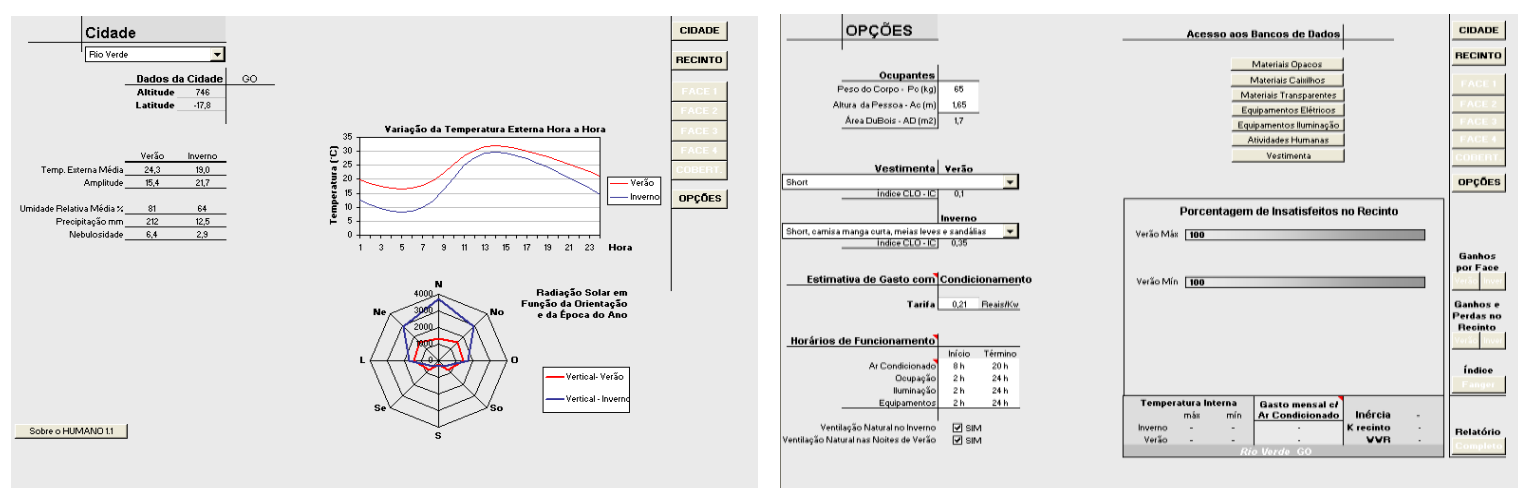

Figura 24 - Software Humano: telas de seleção da cidade e de opções relativas ao usuário e ocupação

Obstrução 1.0

O software obstrução 1.0 calcula o impacto que uma nova edificação terá no consumo energético anual do entorno. O software possibilita seu uso em dois níveis: avançado, para consultores, e restrito, para usuários em geral. Foi desenvolvido pelo aluno Rafael Silva Brandão, ao longo do curso de mestrado, orientado pela Prof $^{\text {a }}$ Dr $^{\text {a }}$ Marcia Peinado Alucci, em 2004. 


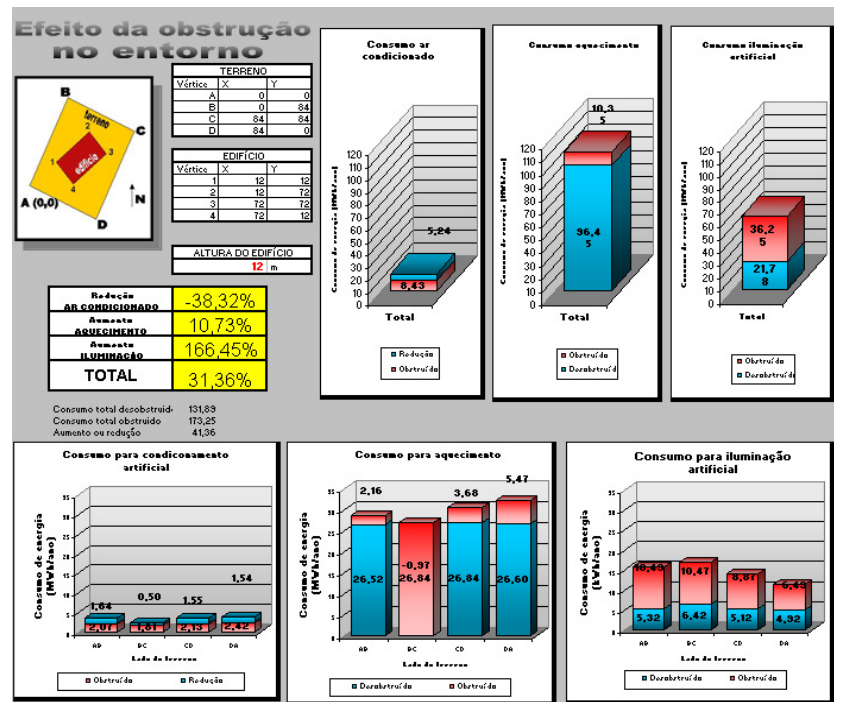

Figura 25 - Software Obstrução: tela de resultados para ar-condicionado, aquecimento e iluminação

$\operatorname{Lux} 1.1$

O software Lux 1.1 calcula a distribuição, em porcentagem do Fator de Luz Diurna (FLD), no ambiente e faz a estimativa do consumo de energia elétrica para complementar a iluminação natural. O software foi desenvolvido pela $\operatorname{Prof}^{\mathrm{a}} \mathrm{Dr}^{\mathrm{a}}$ Marcia Peinado Alucci em 2002.

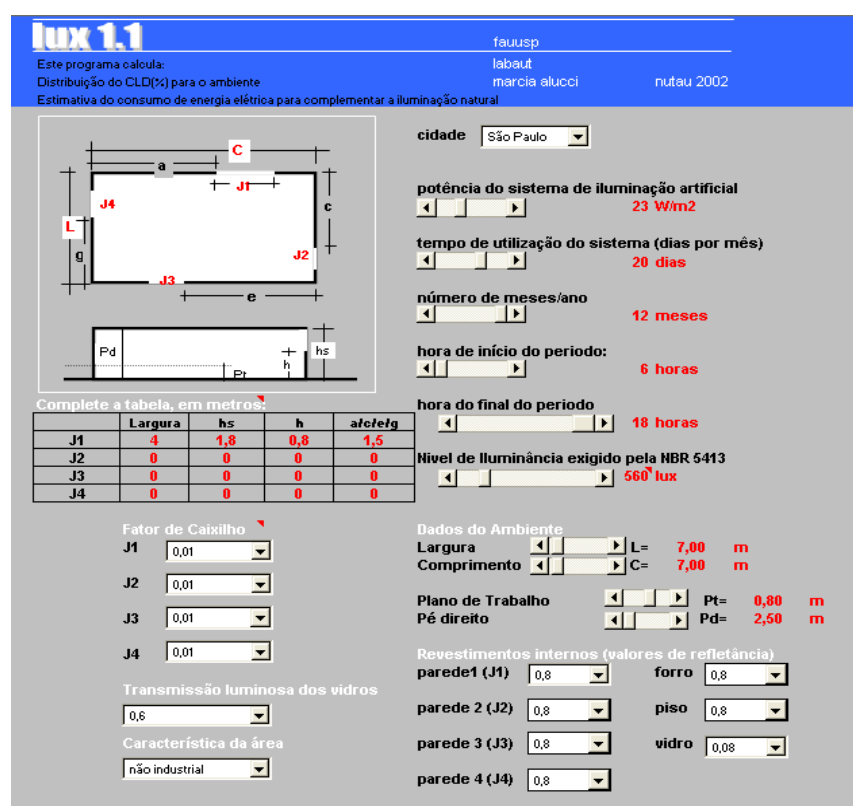

Figura 26 - Software Lux: tela de entrada de dados do ambiente a ser avaliado 
Acústico 2.0

O software Acústico 2.0 calcula o efeito das barreiras acústicas, o isolamento acústico nas fachadas e o tempo de reverberação dos ambientes, considerando o ruído de tráfego. Foi desenvolvido pela $\operatorname{Prof}^{\mathrm{a}} \mathrm{Dr}^{\mathrm{a}}$ Marcia Peinado Alucci em 2002.

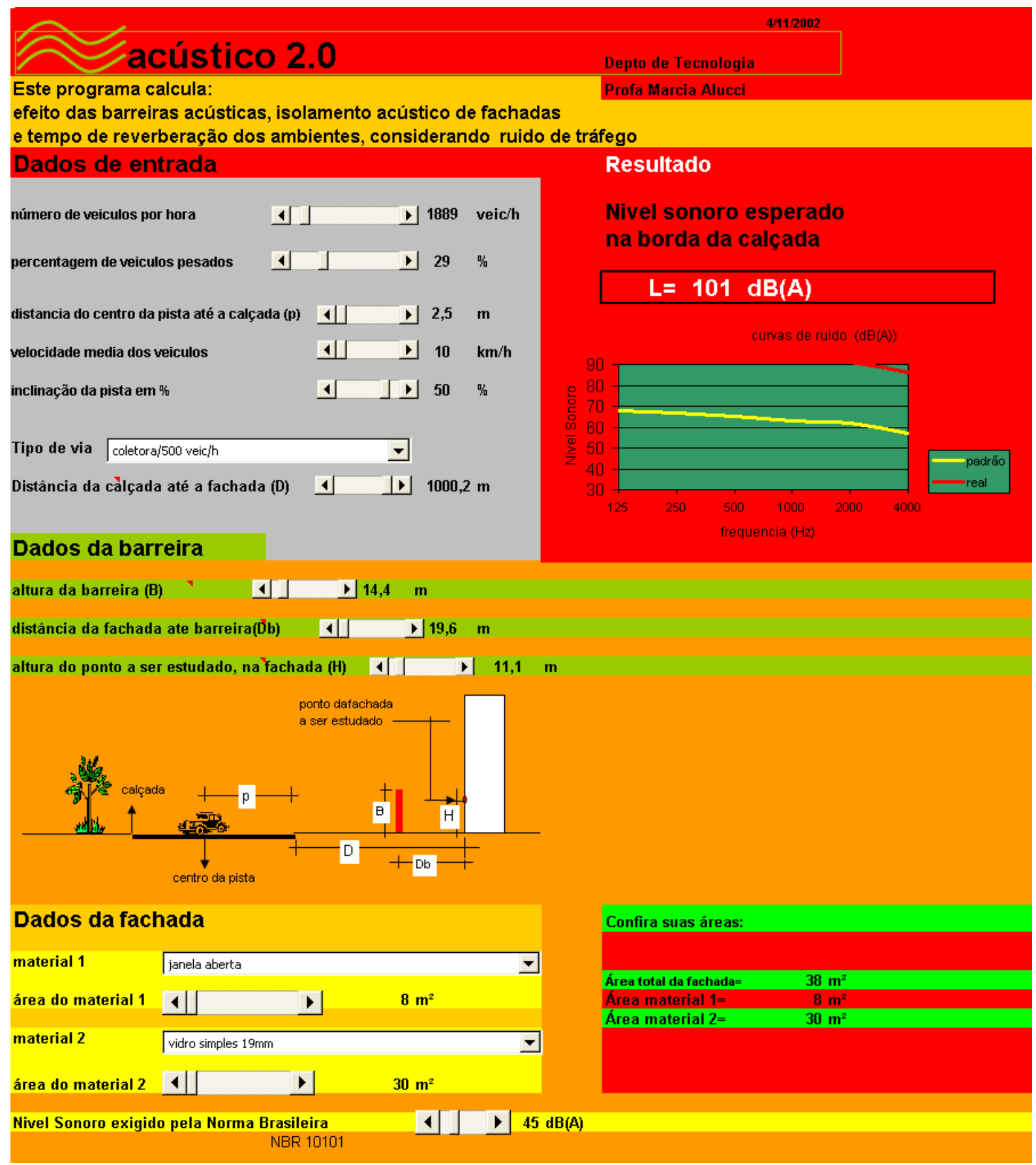

Figura 27 - Software Acústico: tela de entrada de dados da via, da barreira e da fachada 
BD Acústica 1.2

O Banco de Dados de Características Acústicas dos Materiais 1.2 apresenta, por meio de gráficos, os coeficientes de absorção e o índice de isolamentos acústicos por faixa de frequência, para inúmeros materiais utilizados na construção civil. O programa traz também exemplos de cálculos de acústica arquitetônica.

Foi desenvolvido por meio de Bolsa de Iniciação Científica financiada pela Fundação de Apoio à Pesquisa do Estado de São Paulo, pela aluna Paula Constante Santos, sob orientação da Prof ${ }^{\underline{a}}$ Drª Marcia Peinado Alucci, em 2003.
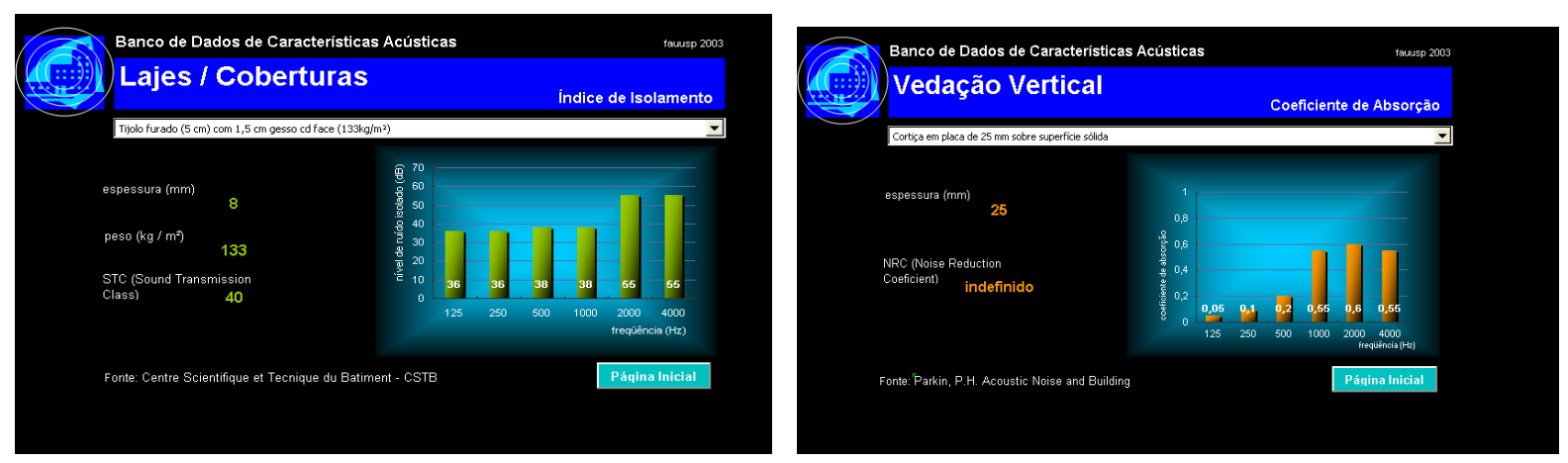

Figura 28 - Software BD Acústica: tela de índice de isolamento de lajes/coberturas e de coeficiente de absorção de vedações verticais

Urbanus 2.0

O aplicativo Urbanus 2.0 permite correlacionar o clima com a situação térmica de usuários de espaços abertos, através de balanço termo-fisiológico e índices de esforço fisiológico e estresse térmico. O programa apresenta banco de dados de 58 cidades brasileiras, verificando as condições de estresse térmico em espaços abertos e/ou sombreados, através do reconhecimento das limitações impostas pelas condições climáticas e da avaliação comparativa de diferentes soluções de tratamento desses espaços. O software foi desenvolvido pela Prof ${ }^{a}$ Dr $^{-}$Marcia Peinado Alucci, com colaboração do aluno de pós-graduação Leonardo Marques Monteiro, em 2004. 


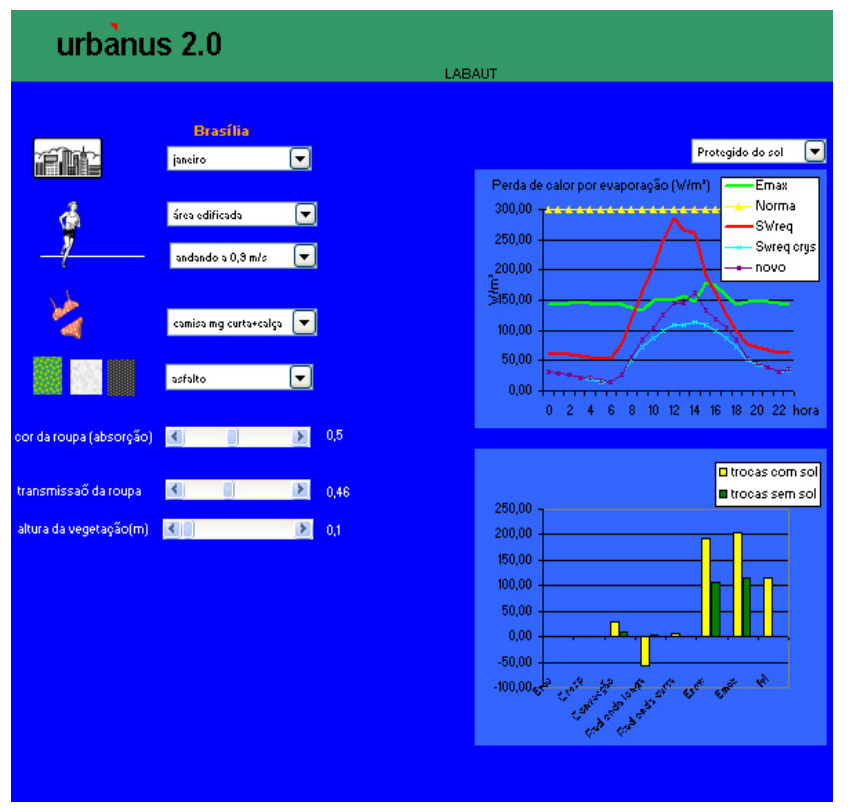

Figura 29 - Software Urbanus: tela de resultados de perda de calor por evaporação e trocas térmicas com e sem incidência solar

Tensil 1.2

O aplicativo Tensil 1.2 permite escolha da membrana têxtil mais adequada ao conforto térmico e luminoso do usuário levando em consideração as características climáticas de cada cidade brasileira e as características do piso sob a membrana. $O$ aplicativo possui banco de dados de características termo-luminosas de 27 diferentes tipos de membranas. Estes dados foram obtidos em medidas de laboratório e de campo realizados por pesquisadores do LABAUT. A validação do software foi realizada a partir de medidas realizadas sob a estrutura tensionada com membrana têxtil construída no Canteiro Experimental da FAUUSP. O software foi

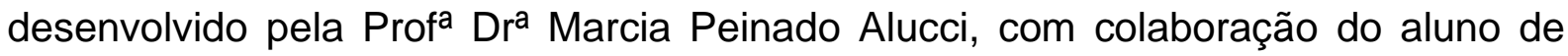
pós-graduação Leonardo Marques Monteiro, em 2005.
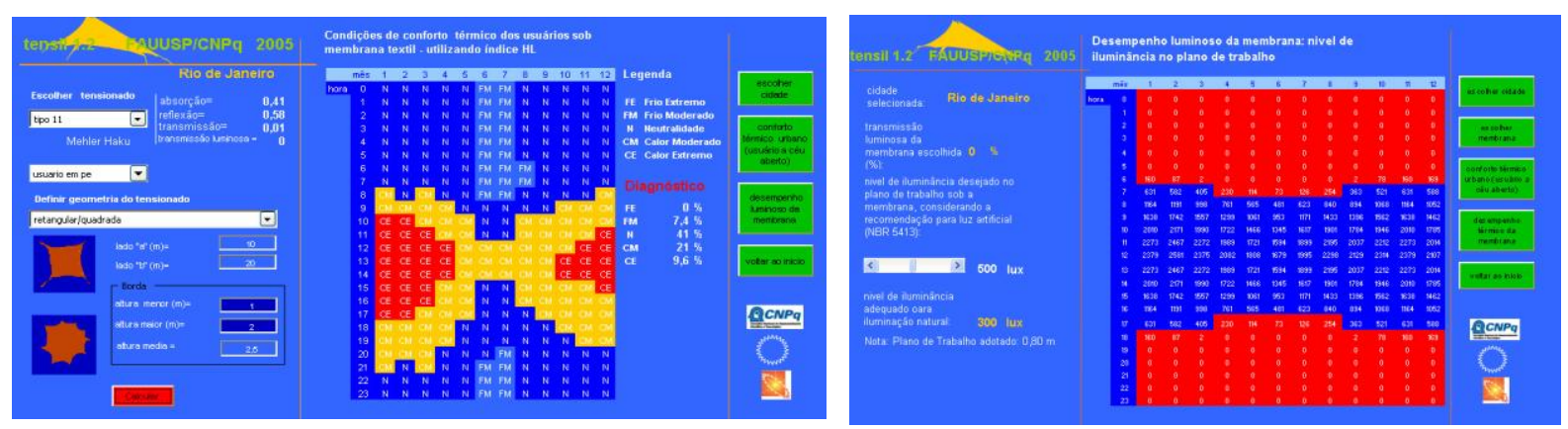

Figura 30 - Software Tensil: telas de resultados de conforto térmico e níveis de iluminância 
Tao

Tao é um software para aplicação nas etapas conceituais e iniciais de projeto de novas edificações. Tem por objetivo identificar as alternativas de implantação em um determinado terreno, de forma a otimizar o desempenho térmico, luminoso, acústico e energético da edificação.

Para a utilização do aplicativo são necessários os seguintes dados de entrada: a cidade, dados do terreno, dados das obstruções do entorno imediato, sistema viário e características do tráfego local, dimensões e características da edificação, características do pavimento tipo e do programa de uso.

São avaliados dois ambientes típicos de cada uma das quatro fachadas, sendo um no primeiro pavimento e outro no último pavimento tipo.

Com relação ao desempenho térmico, a verificação é realizada para situações de verão e inverno, sendo adotados os seguintes parâmetros:

- a temperatura do ar às $15 \mathrm{~h}$ e

- a variação horária da temperatura do ar interior.

Para o desempenho luminoso, os parâmetros adotados são:

- a profundidade do ambiente, que permite dispensar a iluminação artificial durante $80 \%$ das horas do ano, e

- a porcentagem da área do piso, por fachada, que pode ser atendida com iluminação natural.

Considerando o desempenho acústico, o parâmetro adotado para a identificação das alternativas para implantação da edificação no terreno é o nível sonoro que atinge suas fachadas.

Por fim, com relação ao desempenho energético os parâmetros adotados são:

- o consumo de energia elétrica decorrente do uso do sistema de condicionamento artificial, 
- o consumo de energia elétrica decorrente do uso do sistema de iluminação artificial e

- o consumo total de energia elétrica decorrente de ambos os sistemas.

A aplicação do programa permite obter, como resultados, informações sobre o impacto de alterações no projeto arquitetônico sobre o desempenho da edificação. Permite ainda verificar o conjunto de orientações que otimizam, simultaneamente, o desempenho térmico, luminoso, acústico e energético da edificação.

Finalmente, verificam-se ainda, para cada alternativa de implantação, os diversos critérios que são ou não atendidos.

Esta ferramenta computacional é de fácil utilização e visa a diversos profissionais, especialmente àqueles que têm poder de decisão nas etapas iniciais e conceituais de projeto de edificações. A ferramenta visa ainda aos estudantes da área, pois possibilita uma forma simples e rápida de verificar de forma integrada as consequências de diferentes opções projetuais de implantação em termos de desempenho térmico, luminoso, acústico e energético da edificação.

O software Tao foi desenvolvido pela Profa. Dra. Márcia Alucci, coordenadora do LABAUT, como requisito parcial para obtenção de título de Livre Docência junto a FAUUSP.
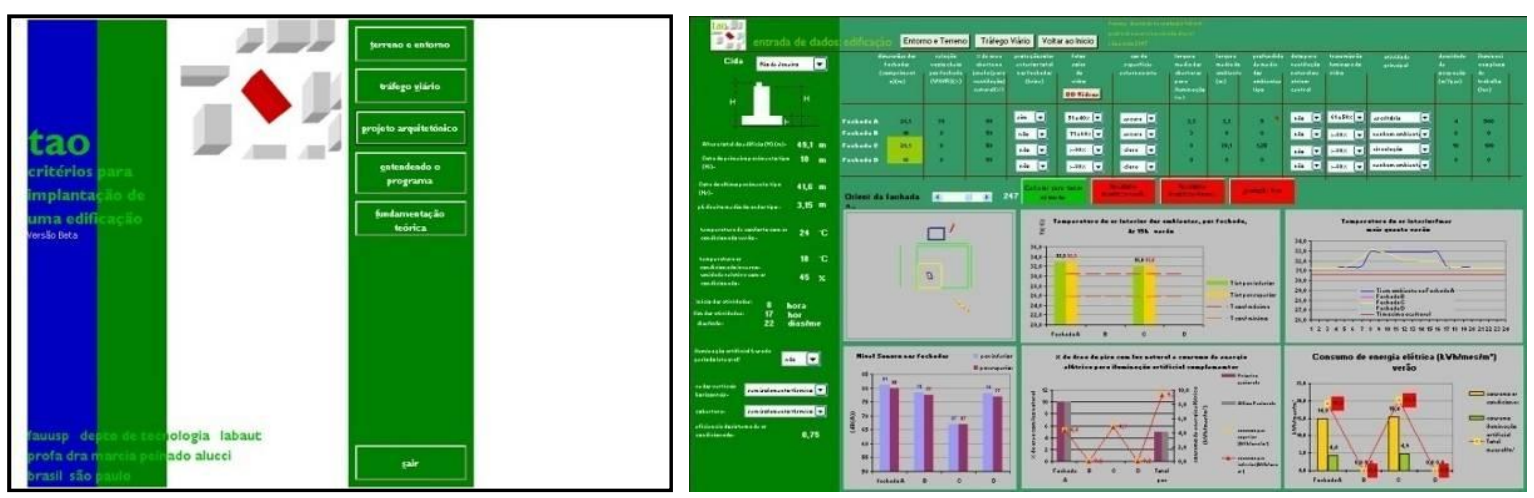

Figura 31 - Software Tao: tela de entrada e de resultados

3.2.2 Outros softwares para avaliação de desempenho ambiental

São apresentados na sequência softwares de avaliação de desempenho ambiental comumente utilizados por consultores brasileiros na área para 0 
desenvolvimento do projeto arquitetônico e auxílio no dimensionamento de espaços e sistemas passivos e ativos.

DOE-2

Em 1976, o U.S. Energy Research and Development Administration (ERDA) e California Energy Commission (CEC) concluíram que os programas de simulação eram inadequados para o meio não acadêmico. Decidiram pelo desenvolvimento de um programa de domínio público e o projeto foi estabelecido entre vários laboratórios: Lawrence Berkeley Laboratory $(\mathrm{LBL})$ da Universidade da Califórnia, Argonne National Laboratory e Los Alamos National Laboratory e a empresa Consultants Computation Bureau. O projeto foi gerenciado pelo LBL. O primeiro resultado do programa foi apresentado em 1977.

Porém, com o fim dos recursos dos patrocinadores, o U.S. Department of Energy (DOE) assumiu o suporte do desenvolvimento e apresentou a versão DOE-1, em 1978. Desde então, as versões do DOE têm sido continuamente revisadas e aprimoradas através dos esforços do Simulation Research Group do LBL, e de vários outros pesquisadores associados.

O programa passou a ser largamente usado como ferramenta de projeto de edificações, em projetos de conservação de energia e desenvolvimento de padrões de uso de energia.

O DOE-2.1E11 é composto de cinco módulos: um decodificador do arquivo de entrada e quatro subprogramas. Estes são executados sequencialmente, com relatórios subdivididos por módulos, sendo que a saída de um se torna a entrada do próximo. Estes módulos são:

A) BDL. Analisa o arquivo compilado pelo usuário empregando biblioteca do próprio programa e o traduz para o código do computador.

B) LOADS. Calcula as cargas térmicas horárias internas e externas do edifício e das zonas. Os cálculos são baseados em aproximações de condições dinâmicas de regimes estacionários: cada espaço é considerado a uma temperatura constante declarada no modelo.

\footnotetext{
${ }^{11}$ Maiores informações sobre o software e versões de demonstração podem ser encontradas no Simulation Research Group do Lawrence Berkeley National Laboratory (LBNL) em http://simulationresearch.lbl.gov
} 
C) SYSTEMS. É composto pelo sistema secundário de climatização artificial. Compreende a caracterização de dutos, climatizadores do tipo fan-coil, do tipo gabinete ou "self-contained", perdas em tubulação de água gelada, controles de temperatura e umidade, e rotinas de funcionamento.

D) PLANT. Reproduz o sistema primário de climatização artificial, composto por resfriadores de líquido (conhecidos no jargão como chillers), caldeiras, bombas hidráulicas e torre de arrefecimento.

E) ECONOMICS. É o quarto e último subprograma: calcula a conta de energia segundo os procedimentos tarifários em vigor, ditados pela concessionária de energia elétrica.

O Laboratório de Eficiência Energética em Edificações (Labeee) da Universidade Federal de Santa Catarina (UFSC) vêm utilizando o VisualDOE2.6, que é uma versão do DOE-2.1E para sistema operacional Windows. O DOE-2.1E simula o consumo de energia da edificação a partir de informações climáticas horárias da região, descrição arquitetônica e construtiva do prédio, padrões de uso e ocupação, potência instalada em iluminação, equipamentos, características do sistema de condicionamento de ar e estrutura tarifária.

Através de uma interface gráfica e compatível com 0 Windows, 0 VisualDOE2.6 ampliou o leque de aplicações do DOE-2.1E, que é compatível apenas com sistema operacional UNIX. Dentre as inúmeras vantagens, recursos e aplicações do programa, o coordenador deste laboratório, Lamberts (s.d.) destaca:

- simulação da evolução de variáveis ambientais no interior da edificação,

- identificação de alternativas de melhoria na eficiência energética da edificação,

- estimativa de redução de consumo e demanda de energia a partir da implementação de medidas de conservação

- rapidez, baixo custo e precisão dos resultados de simulações se comparado aos outros métodos disponíveis. 


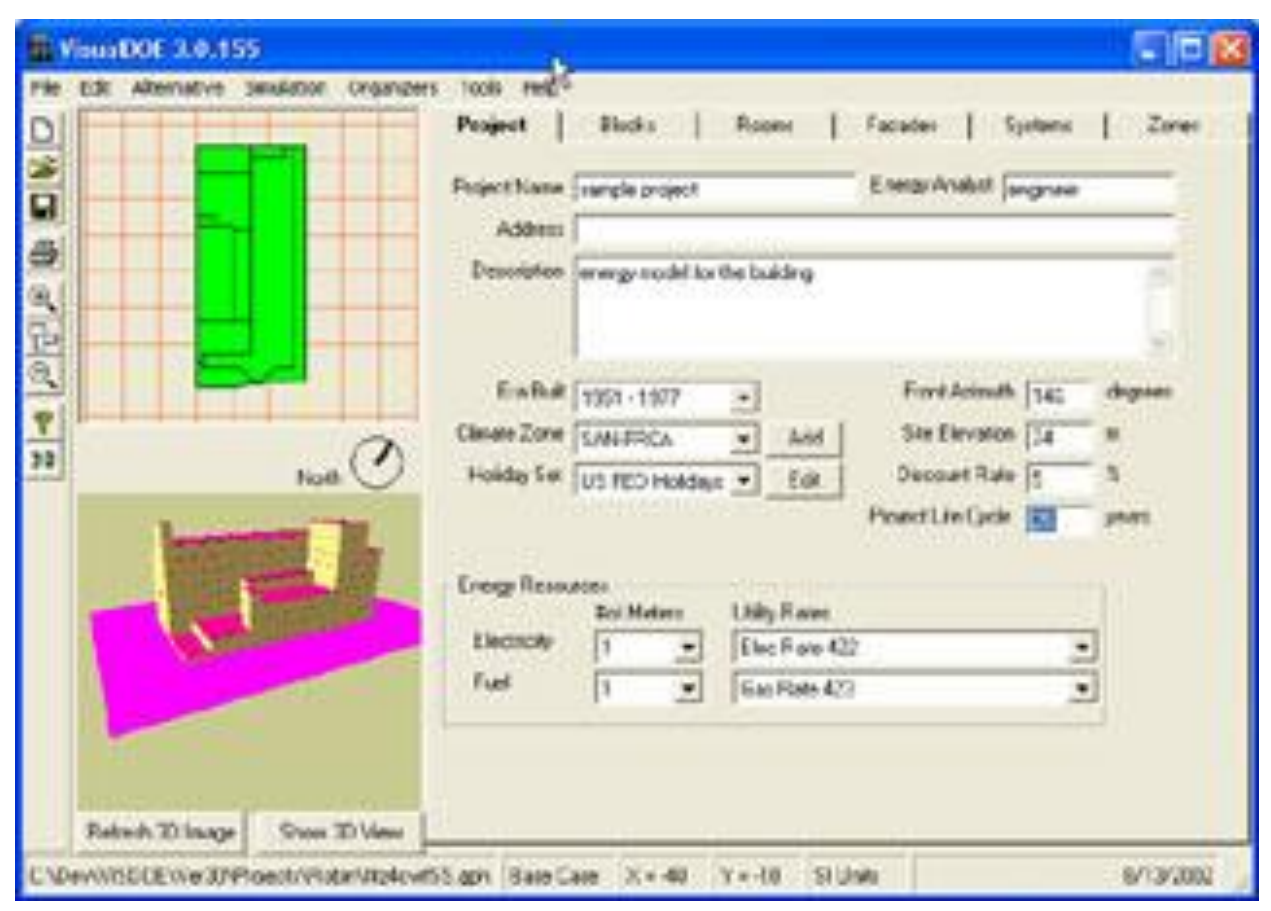

Figura 32 - Sessão de trabalho típica utilizando o VisualDOE 3.0

Sob a orientação de Roberto Lamberts, quatro dissertações de mestrado foram desenvolvidas utilizando-se os recursos do DOE-2.1E, ou posteriormente do VisualDOE2.6, para realização de simulações.

BULLA (1995) parametriza a avaliação do desempenho energético da envolvente de edifícios comerciais para a cidade de Florianópolis. Os parâmetros trabalhados são obtidos a partir da definição da forma do edifício típico e dos materiais usados na construção do mesmo. São eles: coeficiente de sombreamento das janelas, razão entre áreas de janelas e paredes, absortividade das paredes e telhado e transmitância térmica das paredes e telhado. Para analisar estes parâmetros foram usados três elementos: uma ferramenta simuladora, para analisar o desempenho térmico e energético do edifício (DOE-2.1E), um arquivo de dados climáticos horários compatíveis com a ferramenta simuladora (formato TRY, para a cidade de Florianópolis) e um modelo simplificado para o edifício típico (caso base), o qual representa a prática construtiva da região em estudo. Não se tem maiores informações sobre os resultados conseguidos com esta pesquisa pois até o presente momento não se conseguiu ter acesso ao trabalho na íntegra.

PEDRINI (1997) desenvolve uma metodologia para calibração do programa DOE-2.1E. Testa-se a fidelidade de vários modelos desenvolvidos utilizando o programa de simulação frente a dados reais de um edifício de Florianópolis, o 
edifício sede da Eletrosul. Os modelos são obtidos através de vários níveis de detalhamento do edifício. A calibração, principal elemento discutido no trabalho, consiste na correção ou ajuste dos valores atribuídos às características da edificação representadas no modelo, identificadas como variáveis de entrada. As técnicas usadas são reunidas em cinco grupos de abordagens e classificadas segundo a complexidade do modelo. No trabalho fica evidenciada a importância da monitoração de cargas de consumo por uso final e a influência da eficiência do sistema de condicionamento de ar. Com base nos resultados, recomenda-se uma planilha de coleta de dados a distância, e rotinas de abordagem que otimizem a modelagem. Com relação ao uso específico do software, o autor desenvolve uma série de considerações relativas ao processo de modelagem, uma vez que utilizouse de modelos simplificados, fazendo-se assim uma discussão sobre os cuidados a serem tomados e as implicações deste processo.

SIGNOR (1999) desenvolve equações de correlação entre consumo de energia elétrica e variáveis arquitetônicas para climas de 14 capitais brasileiras, utilizando simulações computacionais efetuadas no programa Visual DOE. Segundo as conclusões do autor, as equações encontradas mostraram-se bastante simples e confiáveis, retornando com precisão o consumo anual previsto de edifícios comerciais climatizados artificialmente frente a nove parâmetros construtivos e de utilização. O estudo pretende servir de auxílio para o desenvolvimento da norma brasileira de eficiência energética em edificações.

CARLO (2000) avalia as diferenças de consumo de edificações simuladas em sítios distintos em uma mesma cidade e em diferentes anos através do uso de arquivos climáticos horários cujos dados foram medidos em mais de um ano nas estações climáticas localizadas nestes sítios. Para simular os protótipos foi utilizado - VisualDOE 2.61. O resultado dos consumos indicou diferenças entre sítios que variam em função do tipo de dado climático. Em sítios onde houve diferenças de radiação solar entre os arquivos climáticos provenientes de diferentes estações, a diferença de consumo dos protótipos entre sítios foi alta, chegando a $18 \%$. Em sítios onde não houve diferenças de radiação solar entre os arquivos climáticos, as diferenças de consumo entre sítios dependeram da diferença dos graus hora entre os arquivos climáticos: quando esta foi da ordem de $50 \%$, a diferença no consumo foi significativa, chegando a $8 \%$; quando a diferença dos graus hora foi menor que $10 \%$, não houve diferenças significativas no consumo entre sítios. Os consumos 
dos protótipos menos sensíveis às variações do ambiente externo apresentaram diferenças entre sítios somente relacionadas aos graus hora. Já a comparação do consumo de um arquivo TRY com os demais sítios e anos simulados apresentou diferenças significativas entre sítios de até $10 \%$, não apresentando variação entre os anos.

ESP-r

O software de simulação ESP-r - "Environment System Perfomance research" foi desenvolvido pela Unidade de Pesquisa Energética da Divisão de Termo Fluido e Engenharia Ambiental do Departamento de Engenharia Mecânica da Universidade de Strathclyde12, na Escócia. Trata-se de um programa de simulação energética que objetiva analisar o comportamento térmico de edifícios em regime dinâmico e desta forma integra um grande número de equações algébricas. O ESP-r utiliza o método das diferenças finitas que contempla os edifícios e os sistemas energéticos auxiliares, onde se verifiquem processos de transferência de calor em regime transiente.

O programa permite calcular os balanços de massa e de energia em todos os volumes finitos e o modo como evoluem, sujeitos não só à influência de condições de fronteira (clima e regime de controle), mas também a ligações existentes entre os diferentes volumes. A ação da radiação solar sobre os elementos opacos e transparentes de um edifício é determinante no seu balanço energético pelo que, no programa ESP-r, encontram-se implementados algoritmos que permitem prever a posição da superfície relativamente à incidência dos raios solares, em função da latitude e longitude do local, hora do dia, ano e geometria da superfície, e prever ainda, o seu sombreamento e o modo como a insolação das superfícies exteriores e interiores se processa. A energia absorvida é transmitida para o exterior e interior por processos condutivos, convectivos e emissão da radiação de longo comprimento de onda. Tais fenômenos são analisados detalhadamente pelo programa por determinarem grande parte dos ganhos de calor existentes no edifício.

A primeira versão do ESP-r foi desenvolvida por Joe Clark da Universidade de Strathclyde entre 1974 e 1977. Posteriormente, foi promovida a sua validação, e

\footnotetext{
12 Uma versão de demonstração do software ESP-r e seus tutoriais podem ser encontrados em http://www.esru.strath.ac.uk/Programs/ESP-r_tut/intro.htm.
} 
diversas alterações e aprimoramentos vêm sendo implantados desde então, tais como a introdução de novas variáveis, os processos multizona e principalmente a interface com os usuários, que na versão 8 já é bastante amigável e interativa. Em 1986, o ESP-r foi escolhido pela CEE (Comunidade Econômica Europeia) para ser o Modelo Europeu de Referência para a simulação de edifícios e foi utilizado em diversos projetos comunitários e financiados com recursos comunitários, entre eles, o PASSYS e o PASCOOL.

Com relação à estrutura do programa, o ESP-r é constituído por três grandes módulos interligados que constituem, na fase inicial, a descrição do edifício no que diz respeito à geometria, aspectos construtivos, uso e operação com vistas à simulação. Numa segunda fase, processa-se a simulação propriamente dita e, por fim, a análise dos resultados. A figura a seguir, indica as principais etapas de uso e operação do programa, com os seus arquivos e extensões. O módulo PRJ "Project Manager Program" é o responsável por toda a etapa de entrada de dados dos edifícios, de suas zonas, de seus materiais, formas de uso e operação. O módulo BPS "Building Plant Simulation" é responsável pelas simulações e variações paramétricas e necessita fundamentalmente de uma base de dados climáticos no formato utilizado pelo ESP-r (arquivos TRY-test reference year). Finalmente, o módulo RES "Results" emite os arquivos com os resultados das simulações. 


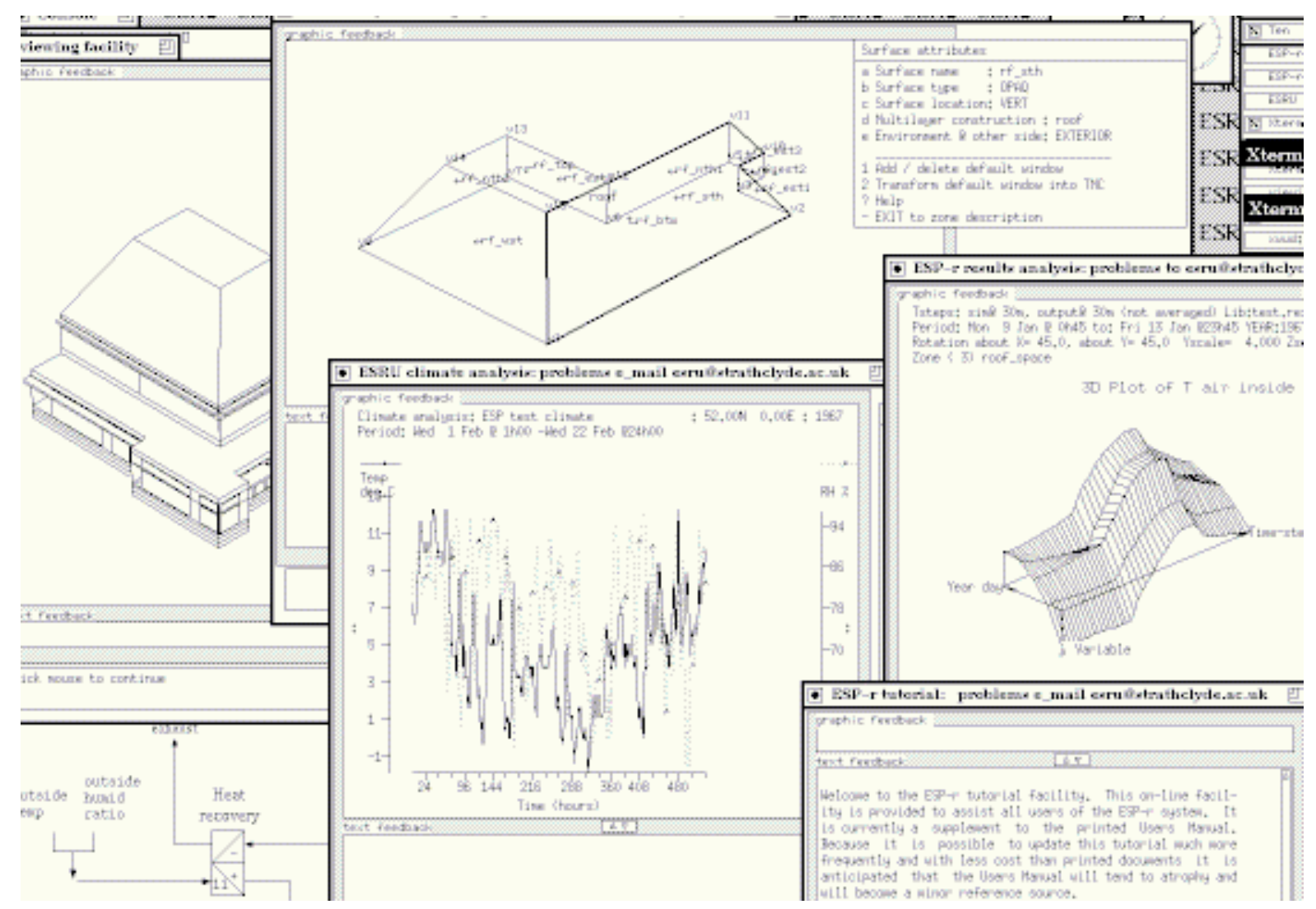

Figura 33 - Sessão de trabalho típica utilizando o software ESP-r

Em setembro de 1995, o Professor Marcelo Romero, da Faculdade de Arquitetura e Urbanismo da Universidade de São Paulo recebeu no Brasil um treinamento sobre o programa e em maio de 1996, recebeu uma nova fase de treinamento no Projeto ESURE - Energias Solares Renováveis, do Departamento de Energias Renováveis do INETI- Instituto Nacional de Engenharia e Tecnologia Industrial de Portugal, sediado em Lisboa, onde foram simuladas e efetuadas as variações paramétricas dos estudos de caso de sua tese de livre-docência. O INETI é hoje um dos centros de referência em simulação por computador, atuando como um "Research Center" para o ESP-r e para o DOE-2 que é o programa de simulação de referência para os EUA.

DILONARDO (2001) realizou sua dissertação avaliando o uso de tecnologias passivas visando a eficiência energética em edifícios de escritórios. Para as simulações dos modelos, utilizou o software ESP-r. Com relação a este, a autora coloca que o mesmo já foi "testado e comparado com medições em estudos de caso reais, em diversos projetos de pesquisa financiados pela CEE (...) e pela AIE" (2001, p. 6.12). Desta forma a autora conclui que em termos de algoritmos e de modelagem 
matemático do programa não há dúvidas de que os mesmos se encontram adequados e refletem muito próximo do real, as condições ambientais. Contudo, considerando os dados de saída, a autora pondera que apesar da enorme quantidade de dados que permitem análises as mais variadas, a resolução gráfica destes é bastante inapropriada, obrigando o usuário a lançar mão dos dados matemáticos informados para conceber gráficos de maior qualidade.

Cabe ressaltar que as versões novas do programa possuem um módulo específico de tratamento e geração gráfica, módulo o qual não está disponível na versão do programa cedida à FAUUSP pela Universidade de Glasgow.

\section{Ecotect}

O software Ecotect foi desenvolvido pela Square 1 Research Pty Ltd., da Welsh School of Architecture da Cardiff University, na Austrália. O software foi desenvolvido por Andrew Marsh and Caroline Raines, tendo sido adquirido pela Autodesk.13

Enquanto o DOE e o ESP-r apresentam-se como soluções sofisticadas para a simulação termo-energética, com possibilidade de grande ênfase para sistemas artificiais, conforme se verificou na apresentação dos trabalhos que os utilizaram, o Ecotect propõe-se a uma atuação um pouco diferenciada. Seguindo o preceito de que uma solução sustentável deve ser atingida desde os primórdios do projeto, o software pretende abranger todas as áreas de análise referentes ao conforto no ambiente construído.

O Ecotect realiza análise de sombreamento, cálculo de radiação solar incidente, análise de iluminação natural e artificial, análise de performance térmica, análise acústica, gerenciamento de custos e recursos e ainda importa e exporta modelos. Todos estes recursos estão disponíveis de forma interativa, com uma interface bastante amigável se comparada ao DOE e ao ESP-r, de modo que cada decisão de mudança projetual possa ser acompanhada das suas respectivas implicações.

\footnotetext{
13 http://www.autodesk.com
} 


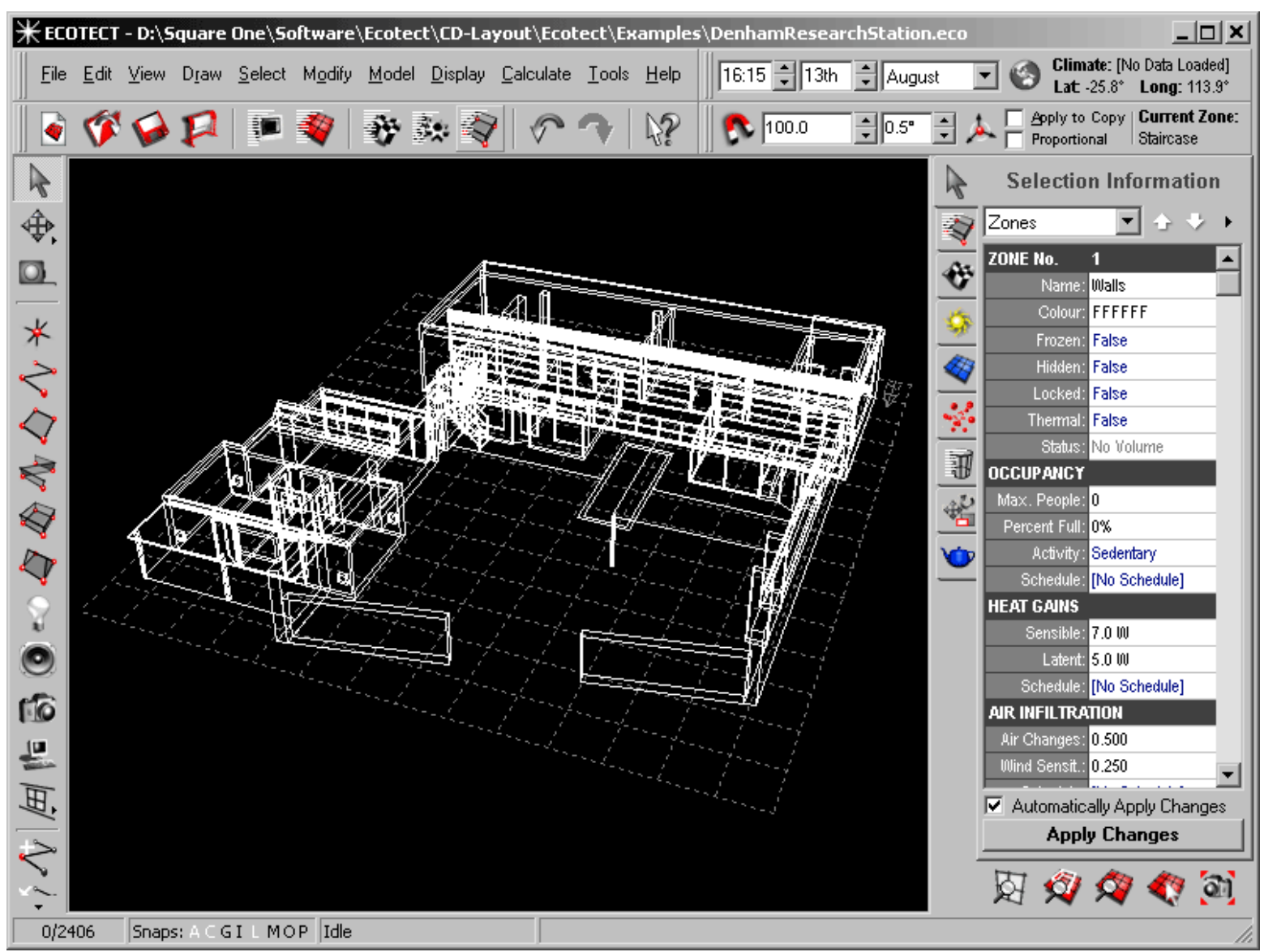

Figura 34 - Sessão de trabalho típica utilizando o software Ecotect

Contudo, embora apresente esta interface gráfica amigável e facilidade para experimentar diversas decisões projetuais no estágio de conceituação do projeto, obtendo-se análises razoáveis para modelos bastante simples, deve-se alertar que, como o software é capaz de executar análises diversas, o usuário deve ter conhecimento das variáveis necessárias para determinada análise antes de modelar ou importar a geometria específica.

A Welsh School of Architecture tem utilizado o software continuamente desde a sua criação. No site da Square 1 tem-se a apresentação detalhada de 38 projetos recentes, a maioria na Austrália, mas também na Inglaterra e no País de Gales, onde durante o processo de desenvolvimento foi utilizado o software Ecotect. No site da Autodesk encontram-se tutoriais e trabalhos desenvolvidos com o software.

Não se localizou, aqui no país, trabalho de pesquisa ou artigo científico utilizando o software em questão. Sabe-se que a Faculdade de Arquitetura da Universidade de São Paulo possui cópia do referido e que os alunos do Curso de Especialização em Conforto Ambiental e Conservação de Energia da Fundação de 
Amparo a Pesquisa Ambiental (CECACE-FUPAM/USP) já o utilizaram para execução de seus respectivos trabalhos de conclusão de curso.

\section{SketchUp}

O Google SketchUp é um software gratuito de modelagem 3D, cujo principal apelo é o de ser fácil e intuitivo, permitindo que qualquer pessoa modele em 3D com rapidez e precisão. Propõe-se a gerar modelos em 3D para que os projetistas possam tomar decisões mais informadas, comunicando detalhes do projeto e compartilhando informações.

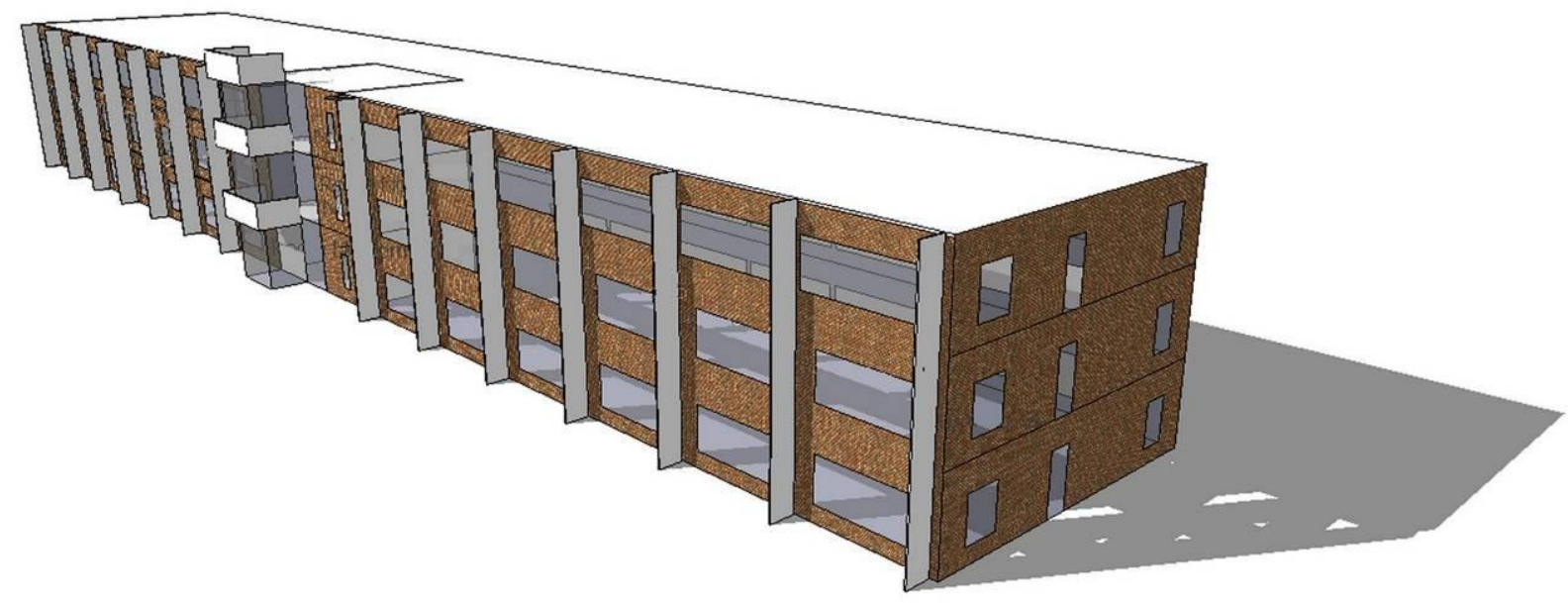

Figura 35 - Modelo no SketchUp com estudo de sombras e penetração solar

A versão SketchUp Pro, versão paga, inclui o LayOut, uma ferramenta de documentação e apresentação em 2D para profissionais. O LayOut combina modelos em 3D com texto e elementos de desenho em 2D para criar documentos de design, desenhos de construção e apresentações digitais.

Com a popularização do software, vários plug-ins foram desenvolvidos para utilização do software para avaliações ambientais. Destacam-se dois: o Suntools e o IES VE.

O Plugin Suntools foi desenvolvido na Technion, Israel Institiute of Technology. E apresenta cinco ferramentas básicas, que permitem:

- visualização da trajetória solar (mês a mês ou todos os meses) 
- posição solar para uma data e horário

- vistas axonométricas da posição solar

- penetração solar / acesso solar em pontos específicos de análise

- cálculo e visualização de céu visível e obstruído a partir de qualquer ponto do projeto.

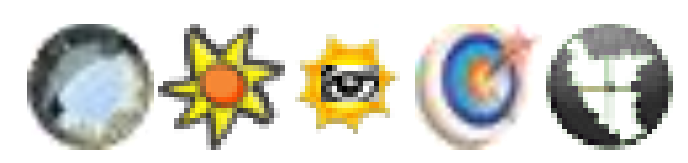

Figura 36 - As cinco ferramentas disponíveis no plug-in Suntools

O plug-in IES VE (Virtual Environment) permite uma interface de uso entre o Sketchup e ferramentas de análise de desempenho e energia, com variedade de profundidade de capacidades de avaliação.

As figuras a seguir ilustram, respectivamente, um modelo no Sketchup com diagrama de ventos e uma simulação realizada para verificação das condições de iluminação natural no ambiente interno.

O plug-in realiza ainda estudos de insolação e de desempenho térmico e acústico de ambientes internos. Trabalha também com exportação de modelos para simulação nos softwares da IES Virtual Environment. 

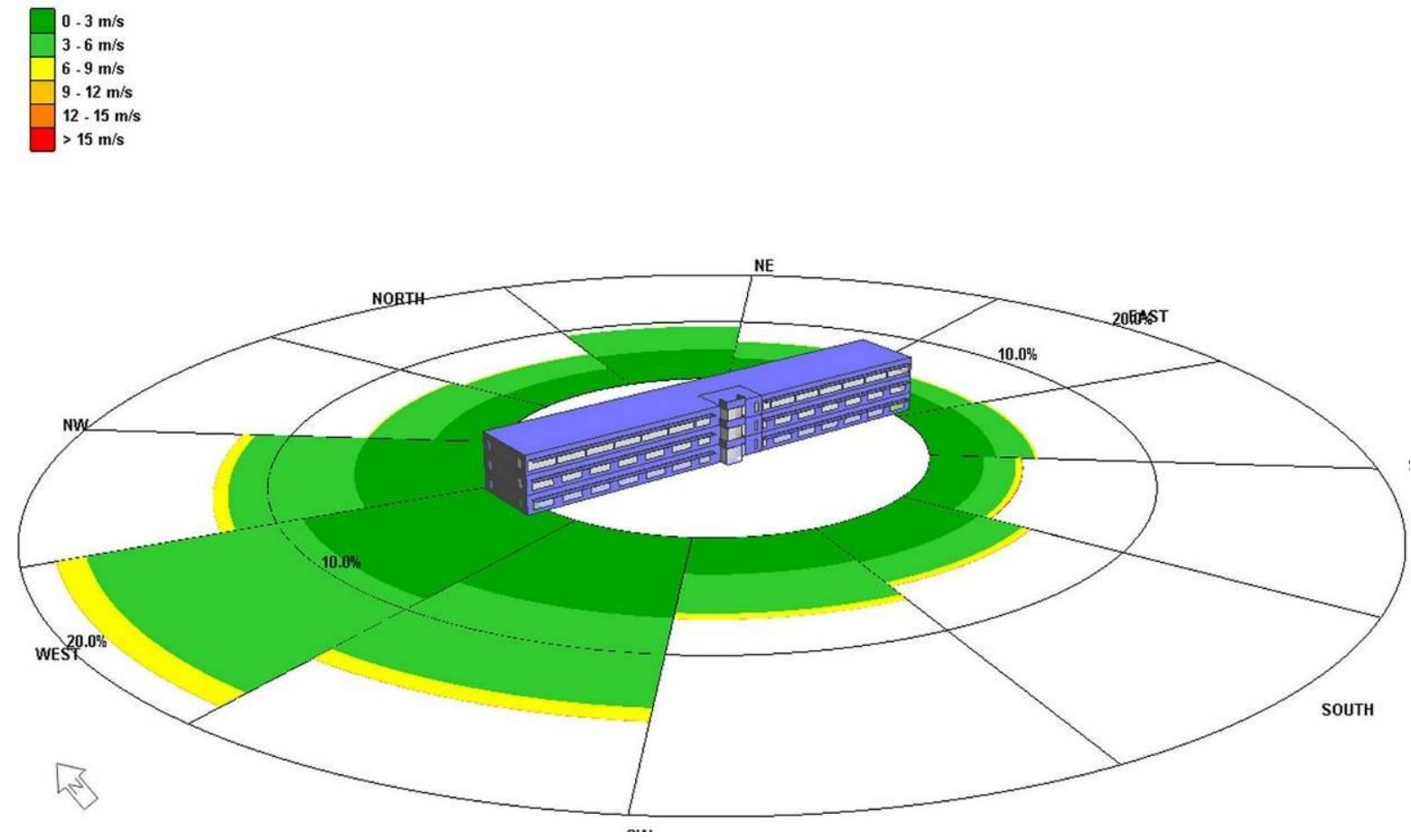

Figura 37 - Modelo no SketchUp e diagrama de ventos

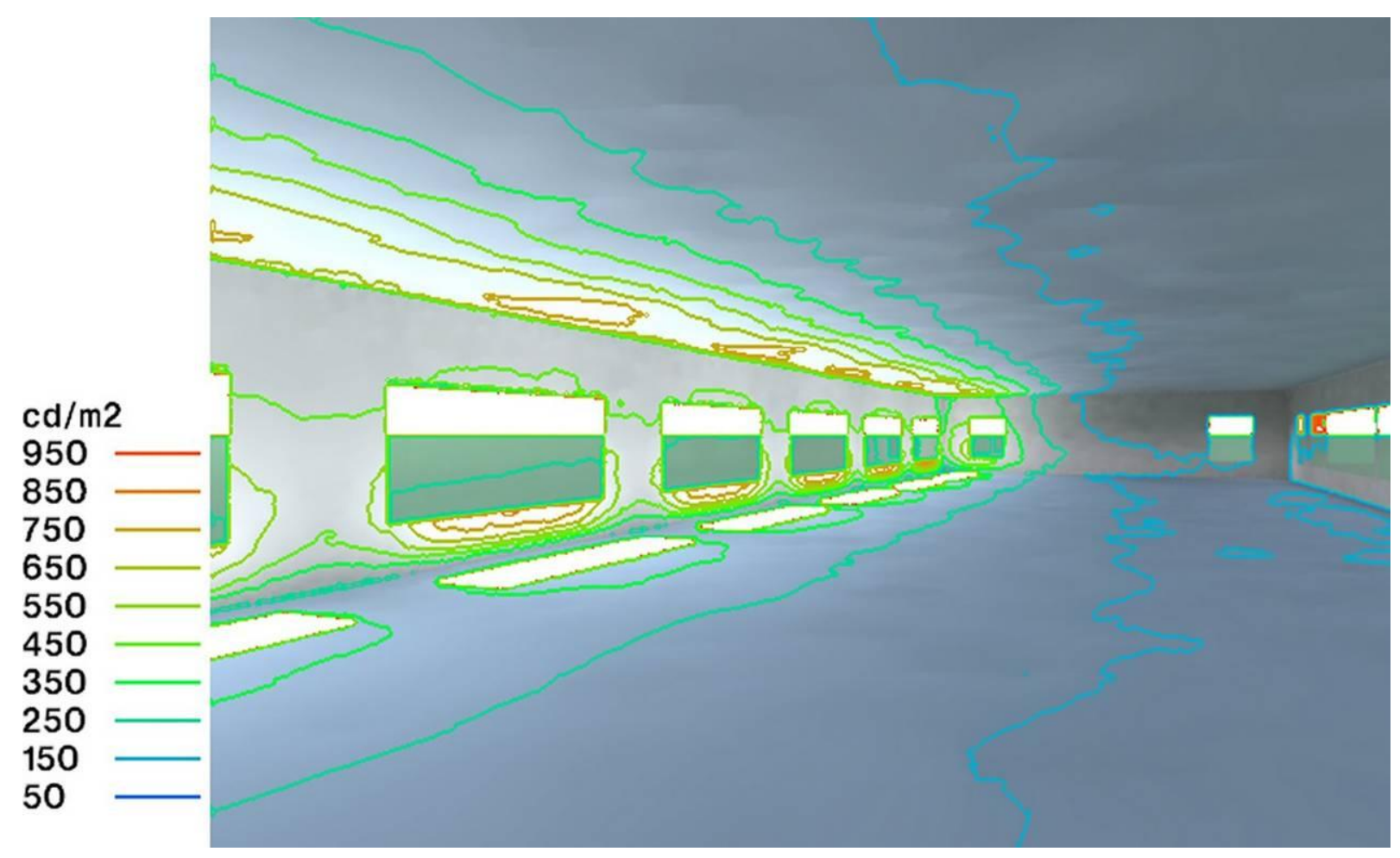

Figura 38 - Modelo no SketchUp e estudo de iluminação natural 
A primeira versão do software Tas foi desenvolvida em 1989 pela Environmental Design Solutions Limited (EDSL). Desde o início a equipe simultaneamente comercializava o produto e prestava serviços de consultoria com os recursos de simulação do mesmo. A empresa acredita que a qualidade do produto é garantida pelo seu constante desenvolvimento simultâneo aos serviços de consultoria externa e suporte aos usuários do software.

O módulo específico de dinâmica dos fluidos computacional surgiu no pacote Tas a partir de 1999, a partir das necessidades de análise micro-climáticas de ambientes específicos verificadas ao longo dos serviços de consultoria prestadas pela empresa.

Assim, hoje, o Tas é um conjunto de softwares que visa a simulação dinâmica da performance térmica de edifícios e de seus sistemas, sendo composto por três módulos integrados: Tas Building Designer (3D), Tas Systems (HVAC), Tas Ambiens (CFD 2D/3D).

O Tas Bulding Designer (Tas-BD) permite simulação dinâmica térmica do edifício integrando ventilação natural e forçada, através de geometria baseada em gráficos tridimensionais.

A entrada de dados no software pode ser sistematizada em quatro etapas.

A primeira etapa é a criação do modelo a ser simulado. Possui ainda um recurso chamado "CADlink", para importar arquivos dwg e dwf. Estes arquivos podem ser 2D ou 3D. No caso de arquivos bidimensionais, estes são usados como base para a modelagem com recursos do próprio software.

A seguir, tem-se um modelo gerado a partir do modelador do software, o Tas 3D Modeller. 


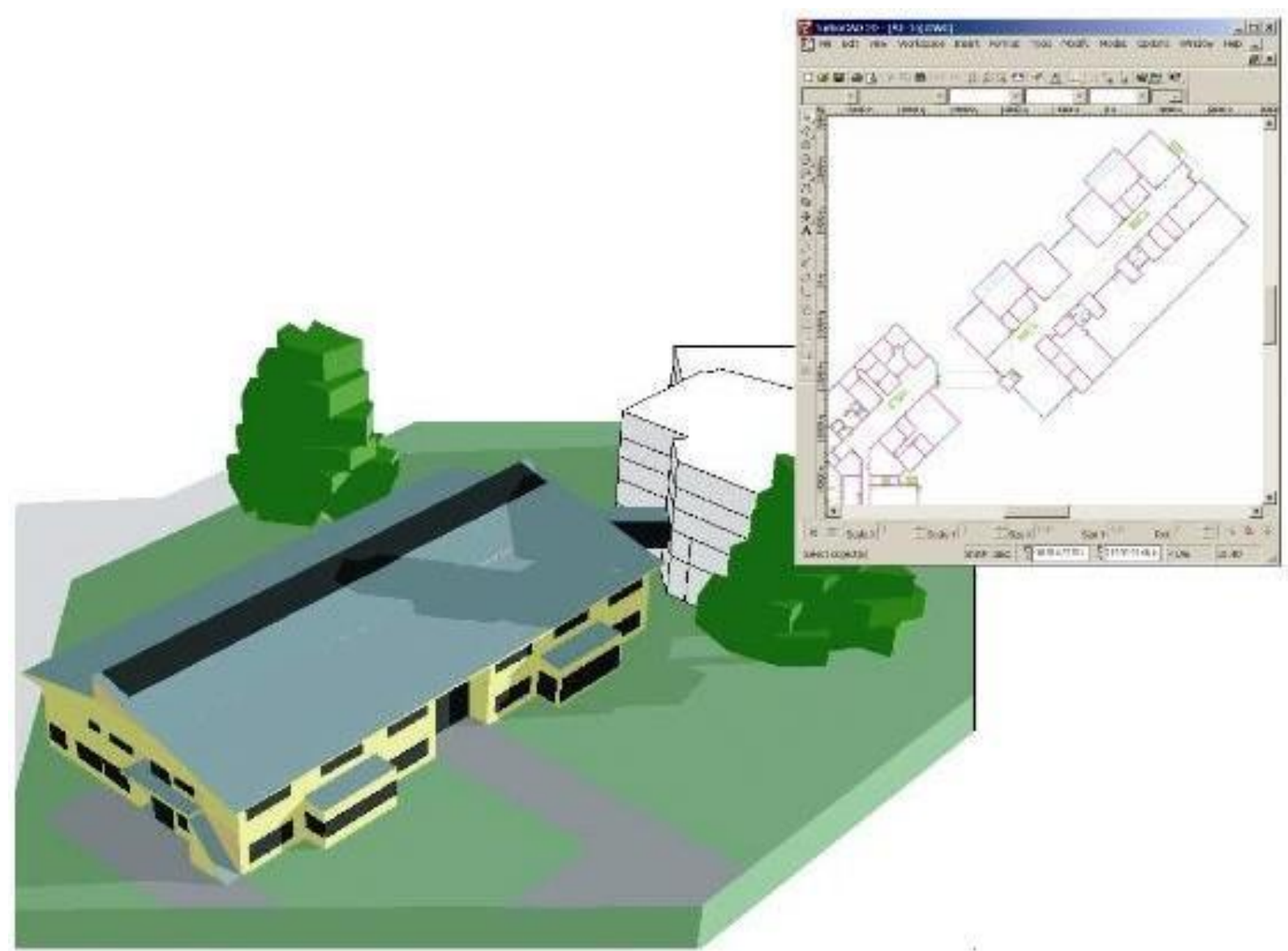

Figura 39 - Sessão de trabalho típica utilizando o Tas 3D Modeller

A segunda etapa é o zoneamento do modelo, possibilitando a criação de um calendário de ocupação para realização das análises posteriores. O zoneamento é um procedimento flexível que permite que posteriores mudanças nestas zonas ou no calendário de ocupação sejam automaticamente atualizados para os resultados da simulação. A figura a seguir ilustra o zoneamento de um pavimento do modelo. 


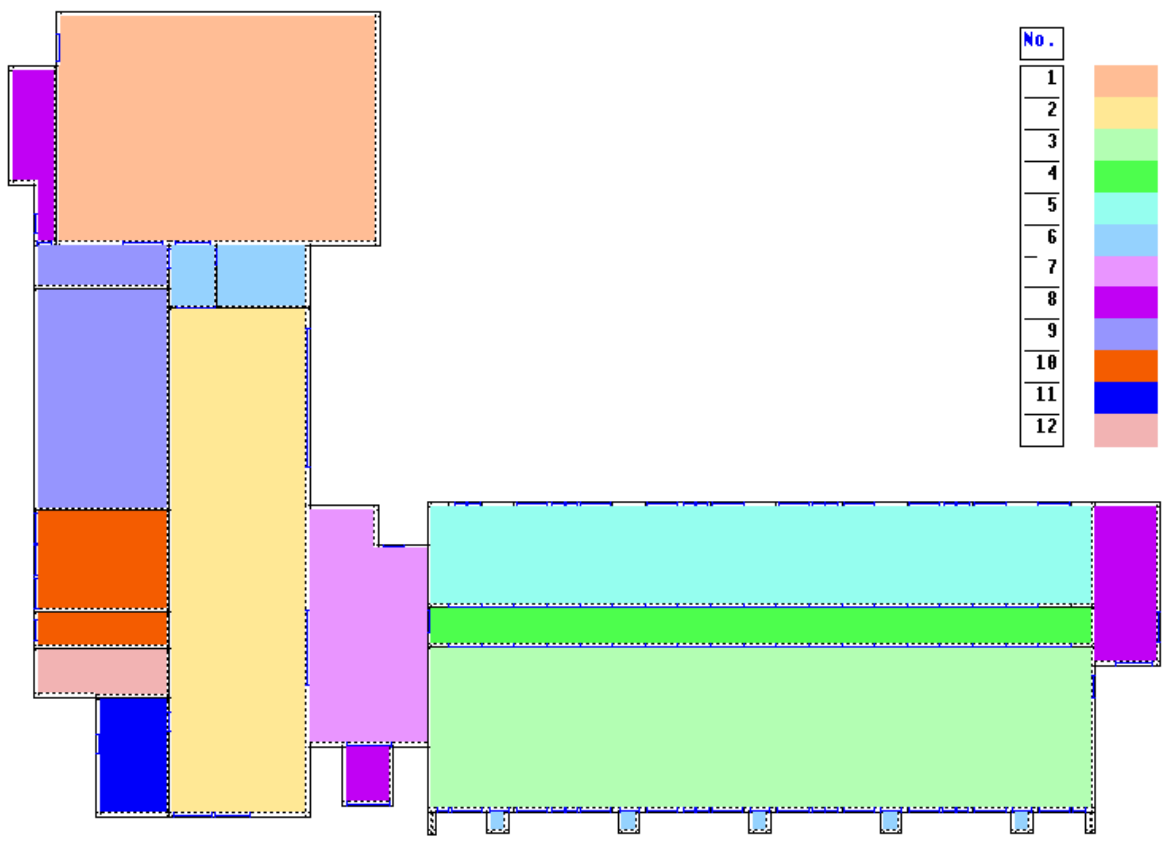

Figura 40 - Zoneamento de um pavimento de um modelo gerado no Tas

A terceira etapa é a descrição das propriedades termo-físicas dos materiais. Para a realização da simulação dinâmica do modelo, é preciso que as características de todos os materiais de construção utilizados sejam inseridas no modelo, através da criação de camadas (layers) específicos, que contém o material e as características deste.

A figura a seguir ilustra a criação das camadas com as informações necessárias para os materiais de uma parede externa.

\begin{tabular}{|c|c|c|c|c|c|c|c|c|}
\hline \begin{tabular}{|l|} 
Layer \\
\end{tabular} & M-Code & $\begin{array}{l}\text { Width } \\
\text { (mm) }\end{array}$ & $\begin{array}{l}\text { Conductivity } \\
(W / m C)\end{array}$ & $\begin{array}{l}\text { Density } \\
(\mathrm{kg} / \mathrm{m} 3)\end{array}$ & $\begin{array}{l}\text { Specific } \\
\text { Heat } \\
\text { (J/kg C) }\end{array}$ & $\begin{array}{l}\text { Convection } \\
\text { Coefficient } \\
\text { (w/m2 C) }\end{array}$ & $\begin{array}{l}\text { Vapour } \\
\text { Diffusion } \\
\text { Factor }\end{array}$ & Material Name \\
\hline Inside & am1plast/1 & 12.00 & .079 & 400.0 & 837.0 & - & 11.000 & \begin{tabular}{|l} 
LIGHTWEIGHT PLASTER \\
$1 * 4$
\end{tabular} \\
\hline 2 & am1block/2 & 150.00 & .200 & 950.0 & 1060.0 & - & 6.800 & 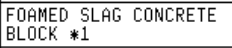 \\
\hline 3 & am1ins/7 & 100.00 & .048 & 240.0 & 1050.0 & - & 2.700 & MINERAL WOOL BOARD *4 \\
\hline 4 & am1cav/5 & 50.00 & - & - & - & 1.010 & 1.000 & $\begin{array}{l}\text { 50MMM AIR (HORIZONTAL } \\
\text { FLOW) }\end{array}$ \\
\hline 5 & am1brick/1 & 105.00 & .700 & 1700.0 & 800.0 & - & 8.000 & BRICKWORK *4 \\
\hline 6 & & & & & & & & \\
\hline 7 & & & & & & & & \\
\hline 8 & & & & & & & & \\
\hline 9 & & & & & & & & \\
\hline 10 & & & & & & & & \\
\hline 11 & & & & & & & & \\
\hline 12 & & & & & & & & \\
\hline
\end{tabular}

Figura 41 - Camadas com as informações necessárias para os materiais de uma parede externa 
A quarta e última etapa de inserção de dados é relativa aos dados de clima. modelo será submetido às informações climáticas fornecidas (intensidades solares, temperatura, umidade e velocidade do vento).

O software possui módulo específico (Tas CFD), com arquivos climáticos de 2.500 localidades no mundo.

Contudo, existe também um módulo para importação de dados no formato TMY2 (do METEONORM da Meteotest14).

Em qualquer um dos casos, o resultado é uma simulação hora a hora da performance ambiental e do uso de energia para cada zona do modelo, para um período de um dia até um ano.

A figura a seguir ilustra um resultado hipotético obtido.

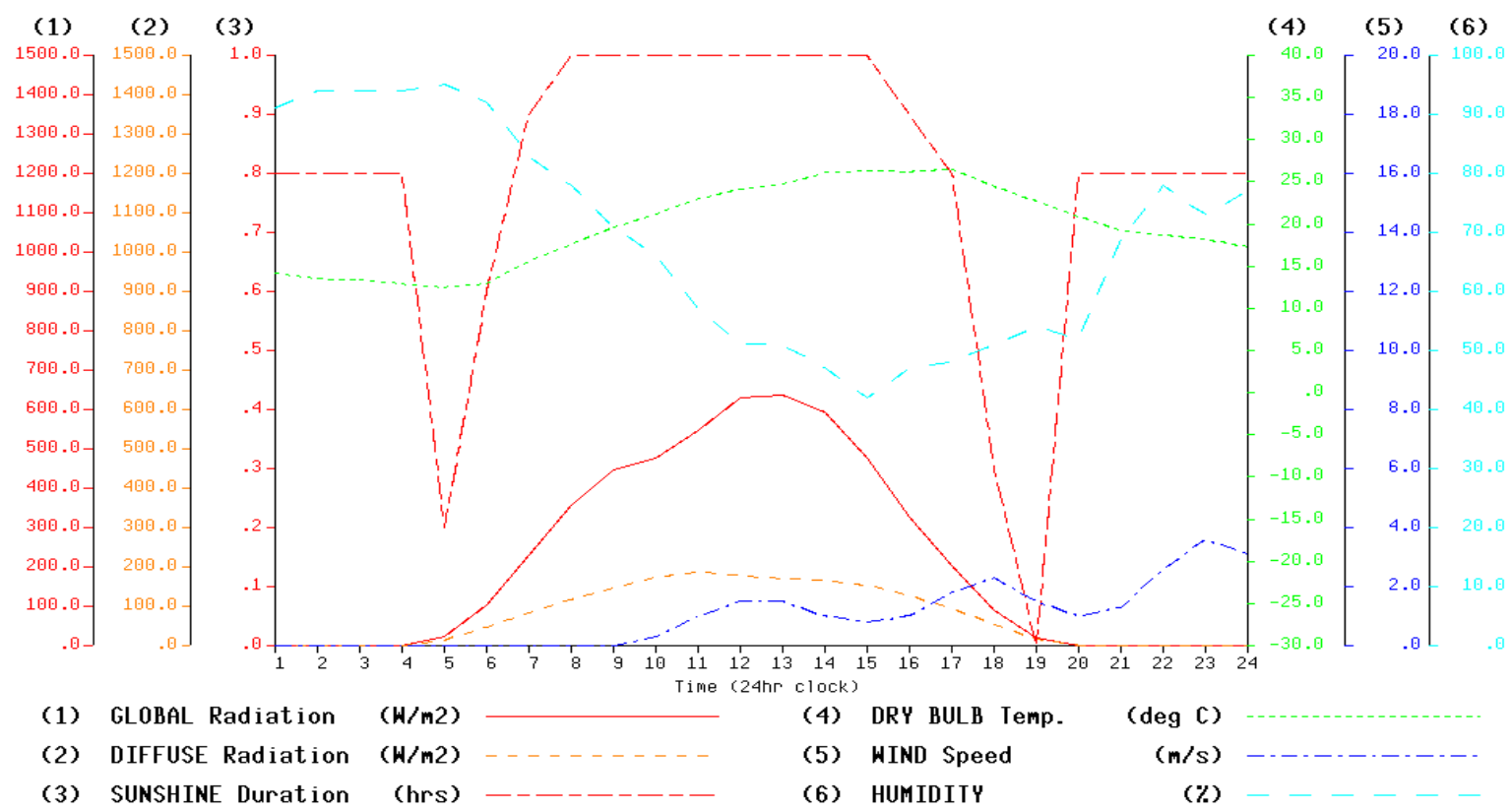

Figura 42 - Resultados obtidos para o período de um dia

É fornecido, também em forma gráfica, o resultado do cálculo das sombras externas, inclusive sombra da luz solar difusa nas aberturas. Também de sombras e luz solar difusa no interior da edificação, para o cálculo de átrios, por exemplo. A figura a seguir ilustra um modelo e seu sombreamento.

\footnotetext{
${ }^{14} \mathrm{O}$ endereço da empresa é http://www.meteotest.ch. Uma versão de demonstração do software específico pode ser encontrado em http:/www.meteotest.ch/products/meteonorm/download/info.html
} 


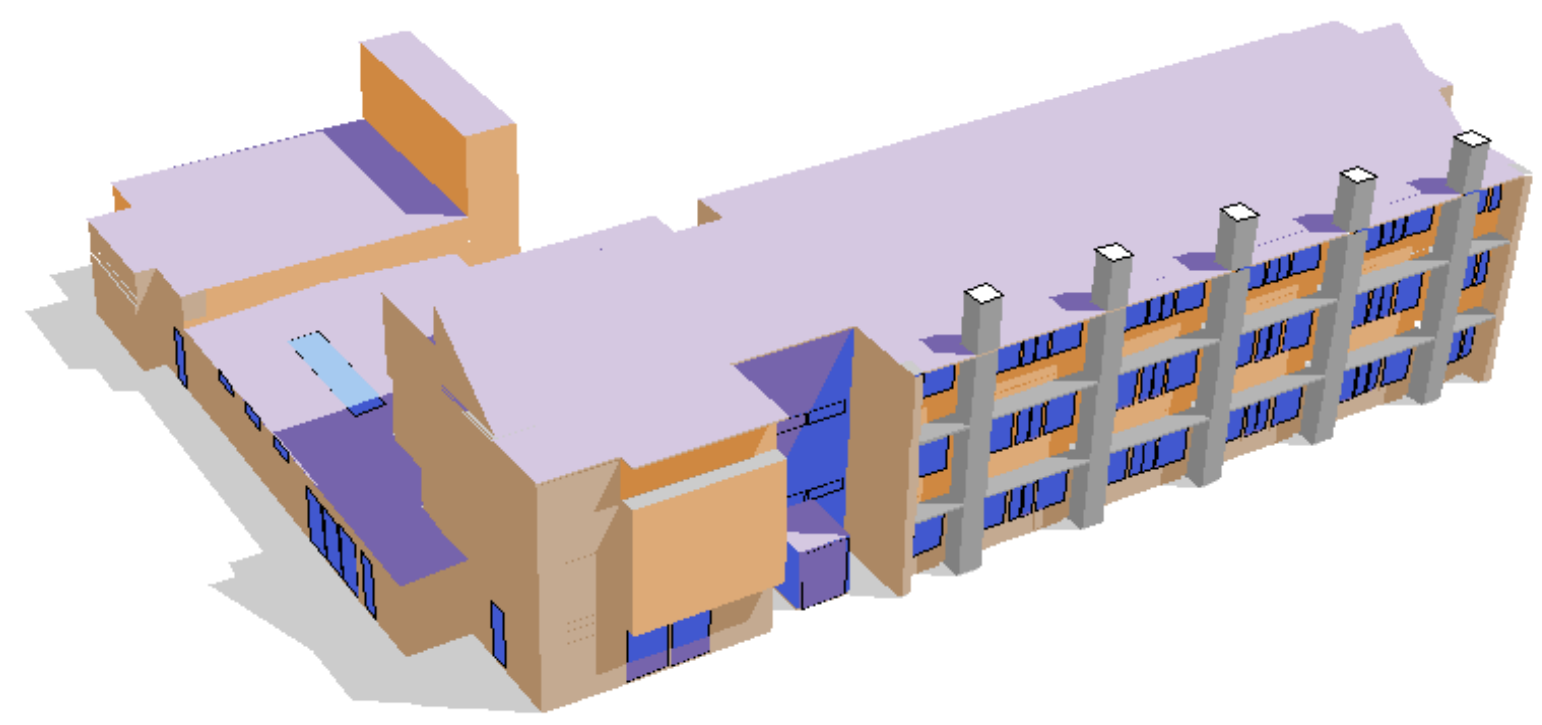

Figura 43 - Exemplo de um modelo e sombreamento

Utilizando os dados horários de clima contendo radiação solar, temperatura do ar, velocidade e direção dos ventos; e as variáveis aberturas e proteção solar (quanto e quando) e edifícios do entorno, calcula o balanço de energia e fluxo de ventos.

O software avalia ainda sistemas e dimensiona cargas também de sistemas artificiais usuais e ainda de: Displacement ventilation, Chilled Beams/Ceilings, Fancoil e Vav, quando integrado ao módulo Tas Systems.

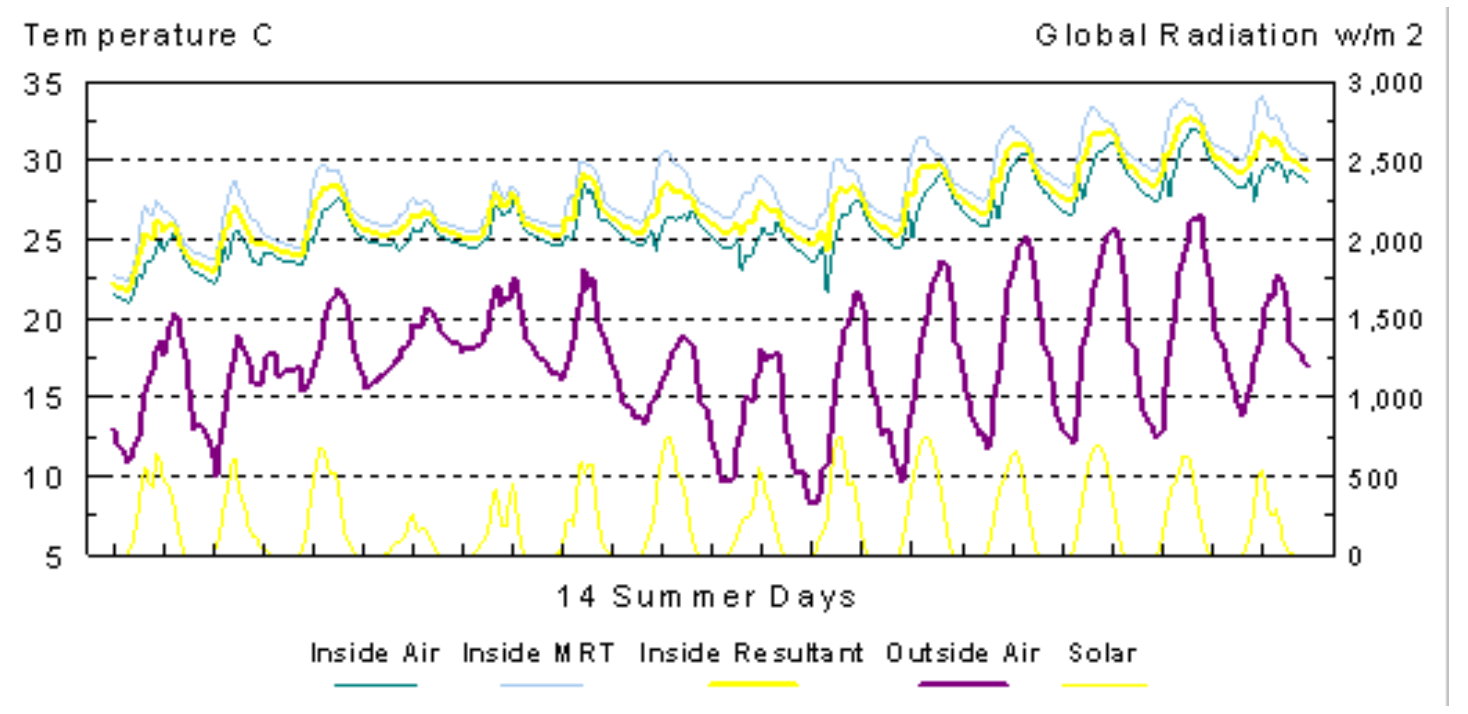

Figura 44 - Temperatura e radiação global para 14 dias de verão 


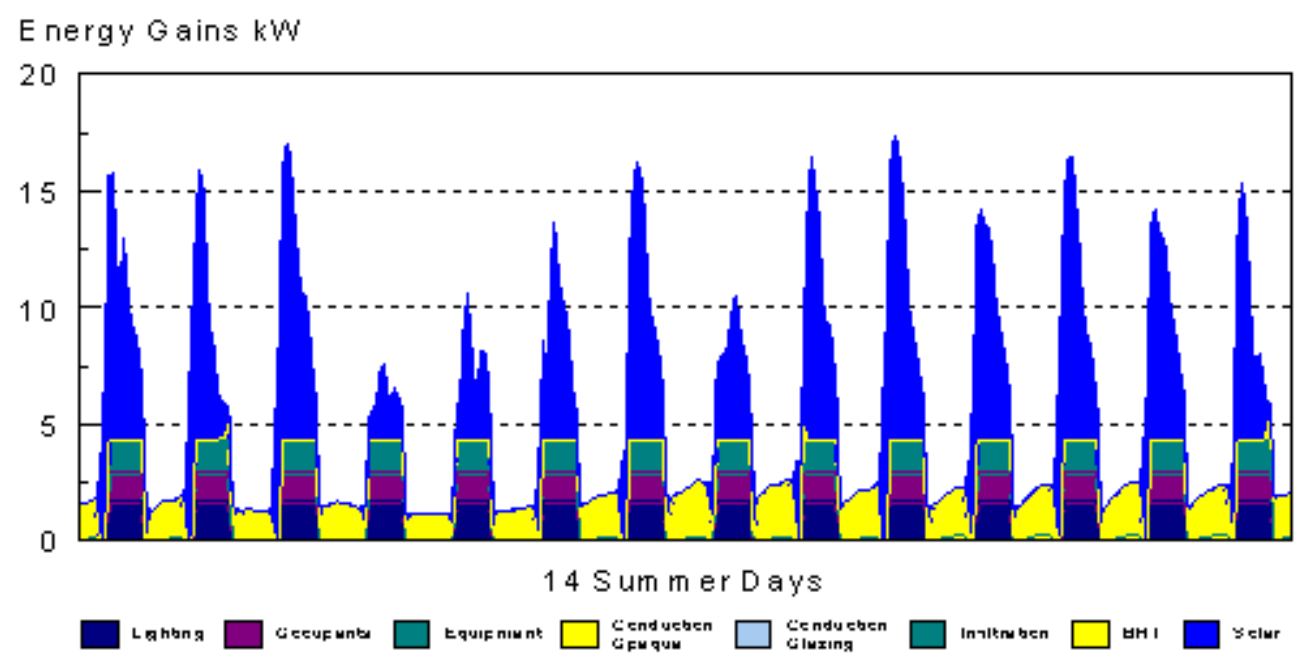

Figura 45 - Ganhos térmicos para 14 dias de verão

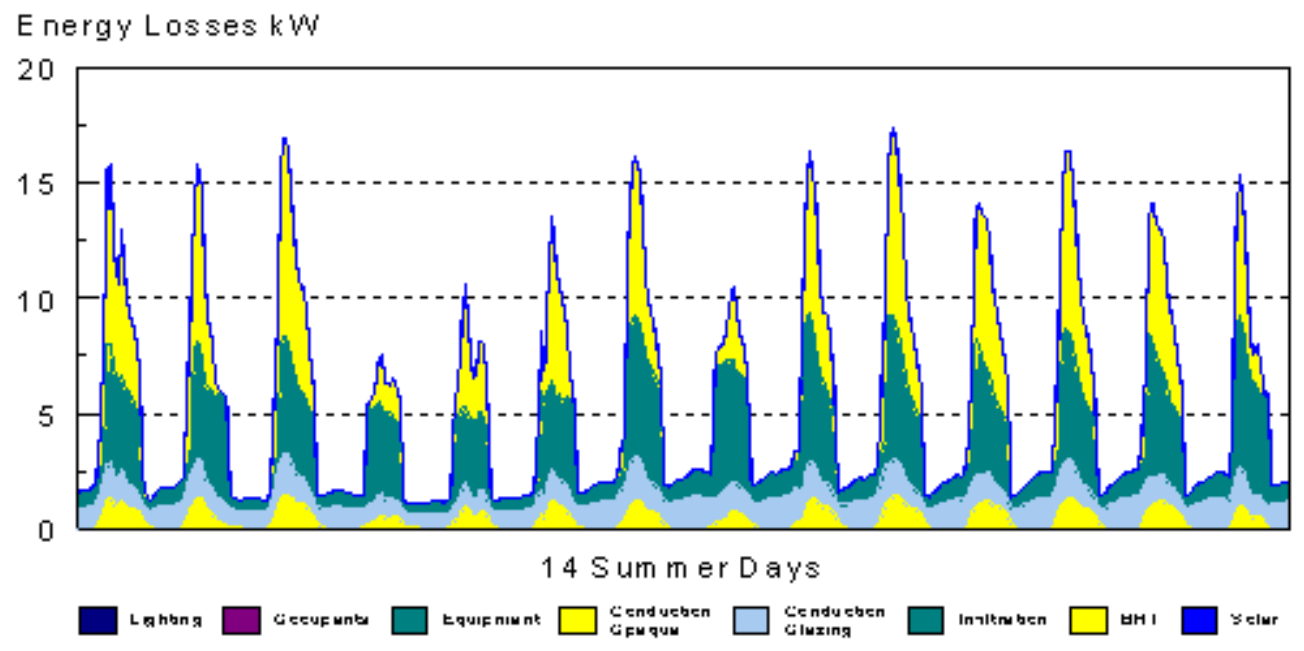

Figura 46 - Perdas térmicas para 14 dias de verão

O módulo integrado Tas-Flows avalia ventilação unilateral, cruzada, por "efeito chaminé" (stack ventilation), unilateral por fachada dupla e por regimes múltiplos. Usando os dados de clima, o balanço de energia e o fluxo de ar são calculados em intervalos de uma hora.

A ventilação cruzada simples é analisada considerando-se a velocidade e a direção do vento, modificados pela altura relativa das aberturas e pelos edifícios do entorno. A ventilação unilteral é baseada na diferença de temperatura interna e externa e na diferença de altura das aberturas.

A ventilação cruzada e por efeito chaminé podem ser calculados simultaneamente. O fluxo de ar é calculado para cada abertura em conjunto com o fluxo dos espaços internos. O balanço de energia e o fluxo de ar são realizado para 
todos os ambientes hora a hora, permitindo o efeito acumulativo de ganhos e perdas internos.
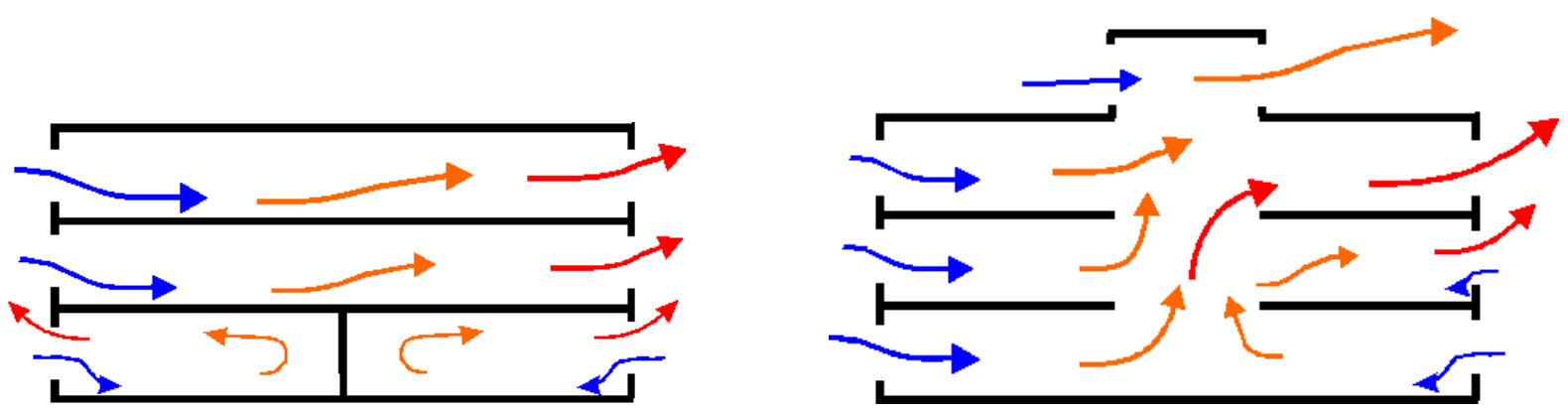

Figura 47 - Esquema de ventilação cruzada e ventilação unilateral e esquema de ventilação cruzada e por efeito chaminé

Quando o ruído externo é fator condicionante, a ventilação natural pode ser conseguida através de fachada dupla. O vento e a diferença de pressão direcionam o fluxo de ar pelo vazio da fachada dupla. O fluxo de ar é calculado considerando-se fatores que incluem a velocidade do vento e a altura da fachada dupla ou, em condições de calmaria, a temperatura dentro do vão. Ventilação unilateral acontece então entre os ambientes internos e o vão da fachada dupla.

Qualquer combinação de regimes de ventilação pode ser incluída em um mesmo modelo. O controle das aberturas pode ser colocado sob influência das variáveis internas e dos parâmetros de clima. As aberturas podem ainda ser controladas individualmente ou em conjunto, através da perfomance de um dado ambiente ou grupo de ambientes. Os mecanismos de controle solar também podem ser operados de maneira dinâmica em combinação com o controle das aberturas.
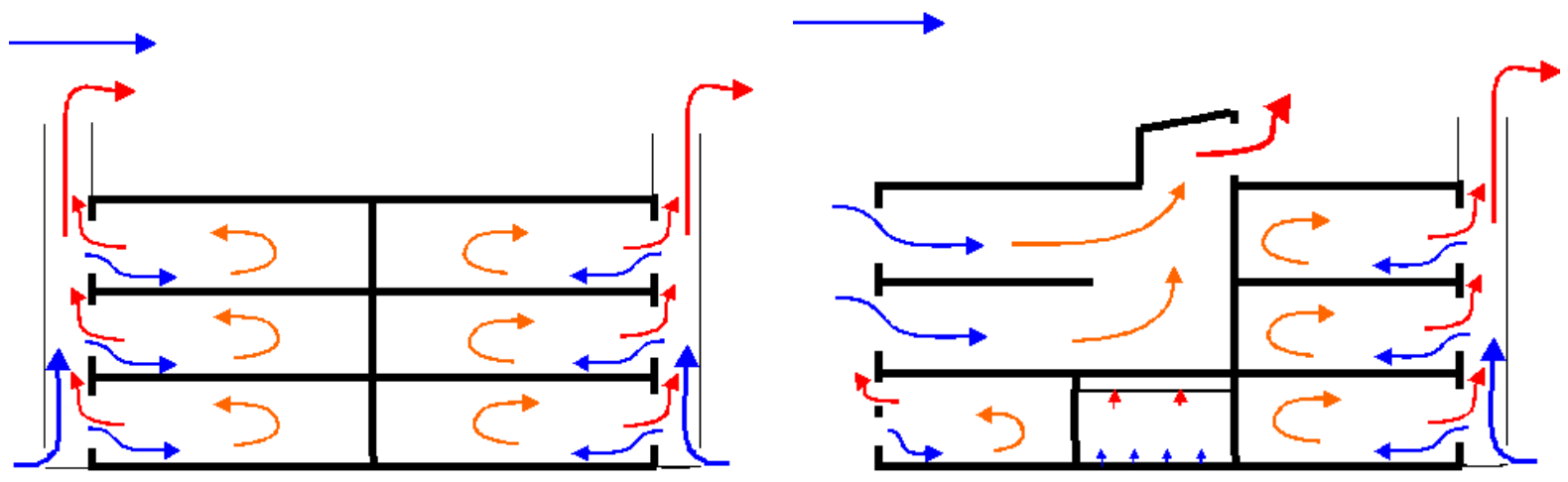

Figura 48 - Esquema de ventilação através de fachada dupla e esquema de regime múltiplo de ventilação 
O software possui módulo integrado para cálculo dos níveis de carbono emitidos anualmente pelos sistemas do edifício, em acordo com o Document L2 Conservation of Fuel and Power, 2001 Edition. O módulo permite ainda comparação do método de emissão de carbono com os métodos dos elementos e método do edifício como um todo.

O Tas Bulding Designer gera também automaticamente valores de ganho e perda de carga muito similares aos previstos no Guide A Section 5 do Chartered Institution of Building Services Engineers.15

Os dados obtidos com a simulação podem ser exportados para a confecção de relatórios e apresentações. Podem ainda ser exportados arquivos para outros softwares, para que outras análises e decisões projetuais possam ser tomadas de forma integrada. Capacidade de exportar dados no formato .xls, tendo como destino o editor de planilhas Excel, da Microsoft. Este software pode ser utilizado para obtenção automática de gráficos específicos, com dados e rótulos de texto fornecidos automaticamente pelo Tas, como o apresentado abaixo, que informa a distribuição da frequência das temperaturas internas.

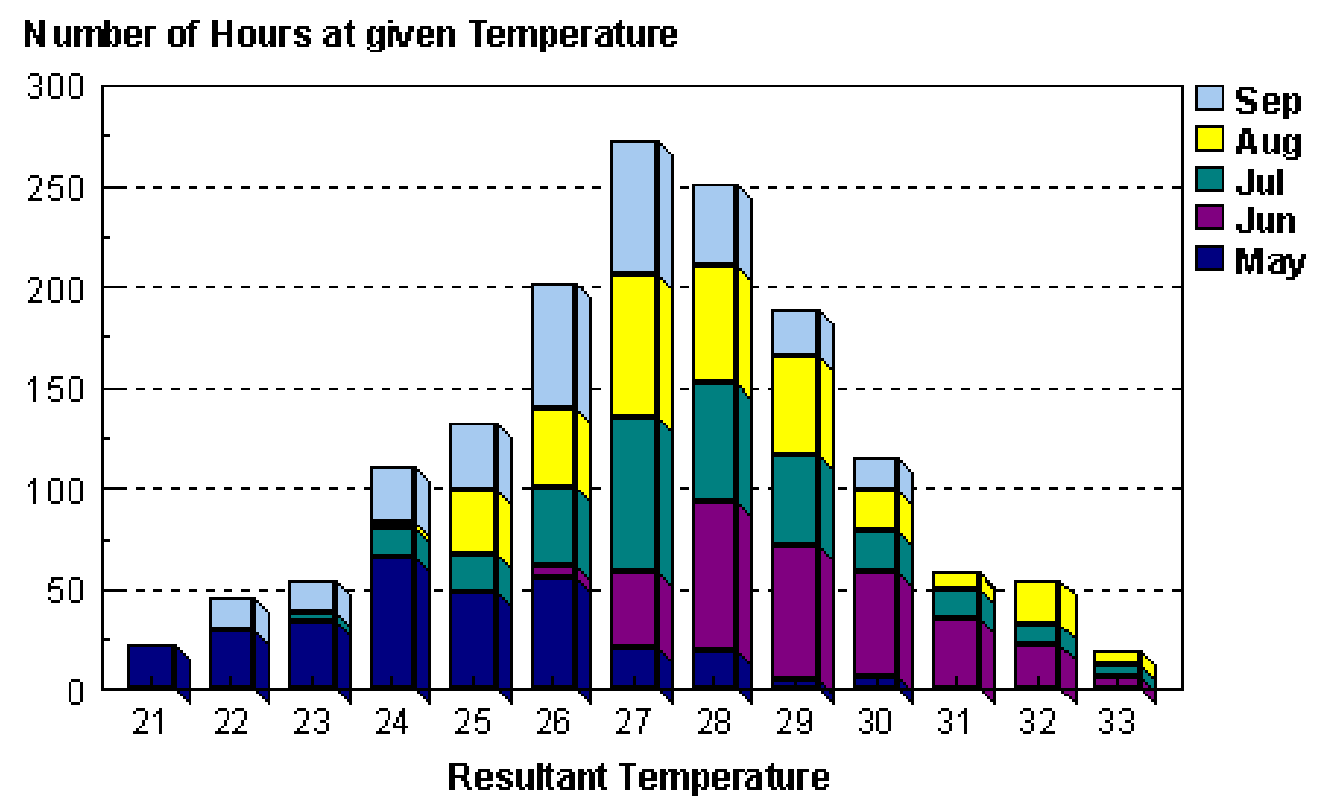

Figura 49 - Resultados em Temperatura Resultante

\footnotetext{
${ }^{15} \mathrm{O}$ endereço da CIBSE é http://www.cibse.org. O Guide A: Environmental Design pode ser encontrado na rede em: http://www.cibse.org/index.cfm?action=PubDetails\&PubID=1\&TopSecID=4\&L1=56
} 
O modelo geométrico tri-dimensional simulado no Tas pode ser exportado para o Lightscape da Autodesk para animaçao "fly-through" e estudos de iluminação, com visualização "foto-realística" e por "intensidade".
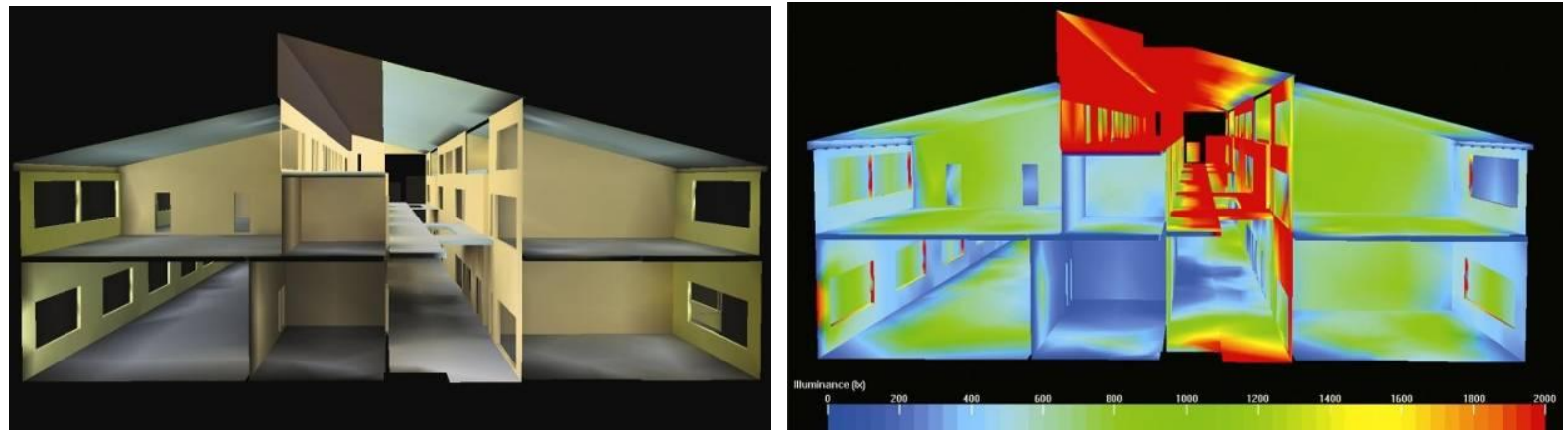

Figura 50 - Visualização "foto-realística" e por "intensidade" (iluminâncias)

O modelo geométrico tridimensional pode ser também exportado para o Cymap da Building Services Design Software (http://www.cymap.com), para o desenvolvimento de projetos elétricos, mecânicos e hidráulicos. Os dados originais do Tas, depois de tratados também pelo Lightscape, podem ser usados para a análise e criação de layout de iluminação artificial no Cymap's Lighting Design Module, que trabalha com os padrões CIBSE, DIN e ASHRAE. O esquema a seguir ilustra a exportação do projeto desenvolvido no Tas para a análise nesse módulo. 


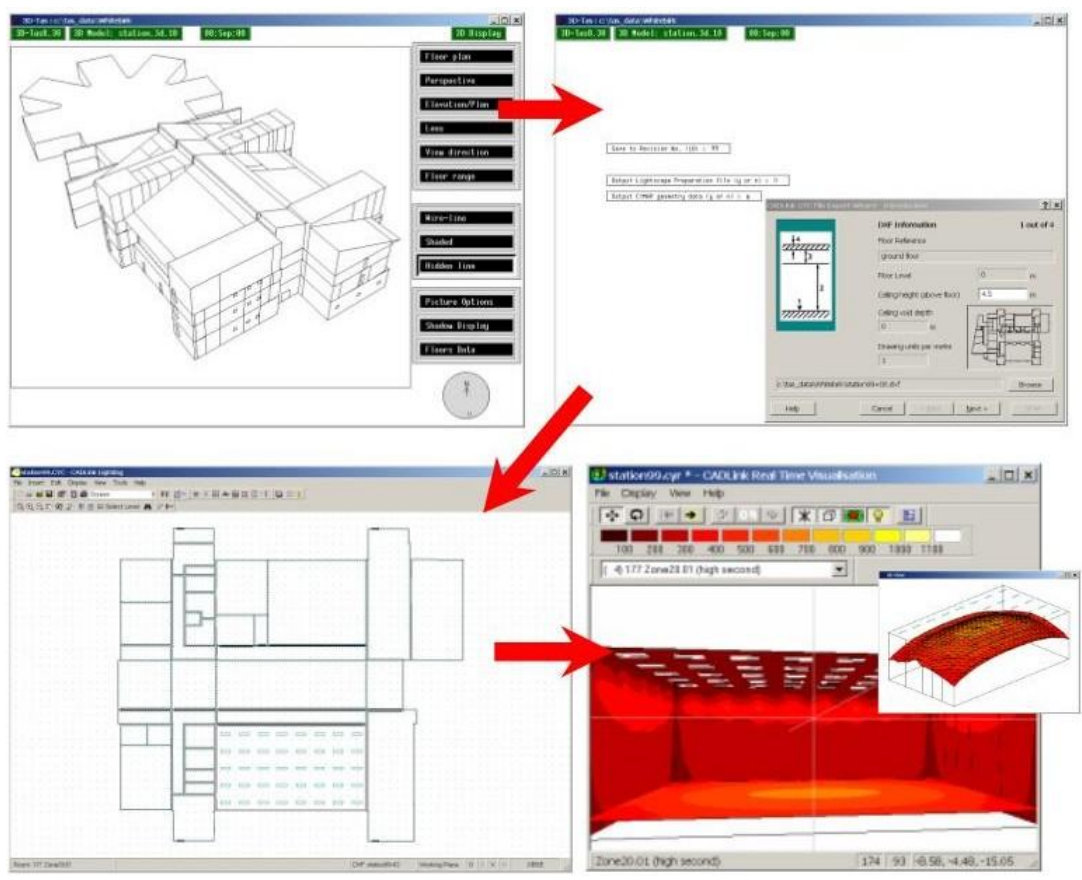

Figura 51 - Esquema de exportação de projeto desenvolvido no Tas

O Tas systems é um simulador de sistemas e controles HVAC integrado ao Tas Bulding Designer. Realiza automaticamente o dimensionamento da ventilação, dimensionamento dos componentes e demanda total de energia.

O módulo possui biblioteca de ícones para localização em planta e criação de modelo de simulação (sistemas e controles).

Os sistemas são baseados em componentes (fans, chillers, boilers...) e permite comparação entre: capacidade relativa, uso de energia, condição de conforto para sistemas diversos como: fan-coil, VAV, displacement ventilation, chilled beams (passiva e ativa), radiant chilled ceiling, etc 


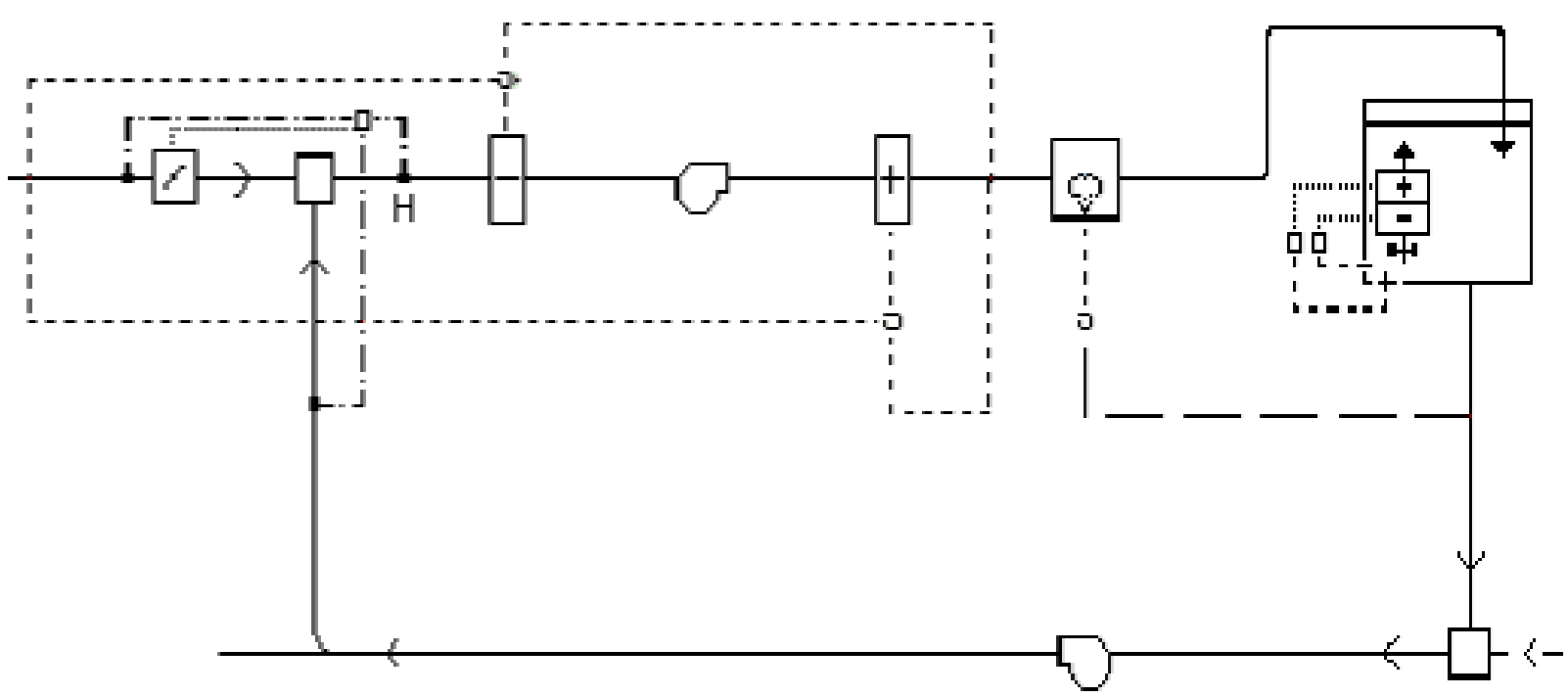

Figura 52 - Esquema de projeto no módulo Tas Systems

O Tas Ambiens é um módulo de simulação baseado na dinâmica dos fluidos computacional (CFD), que trabalha de forma integrada ao Tas Building Designer.

Produz seção com as variações do micro-clima em um dado ambiente/edifício, possibilitando solução para condições específicas da envoltória e das fontes de calor internas.

É um dos únicos software CFD desenvolvido especificamente para estes tipos de análise em ambientes de edificações. O módulo permite plotagem de gráficos de: Temperatura Radiante, Temperatura do Ar, Temperatura Resultante, Velocidade do Ar, Umidade e Níveis de PPD - predicted percentage of dissatisfied (ISO 7730)16.

\footnotetext{
${ }^{16}$ As condições de conforto resultam de uma apreciação subjectiva, pelo que os estudos de conforto térmico devem basear-se no cálculo da percentagem de indivíduos descontentes, PPD (predicted percentage of dissatisfied), conceito que foi introduzido por Fanger e que viria a ser aceito como base de regulamentação (ISO 7730, 1994) e nos trabalhos no domínio do conforto. O índice PPD representa a percentagem prevista de indivíduos que sentem desconforto térmico com o meio que os rodeia, ou seja, o número de indivíduos que irão sentir calor ou frio num determinado local.
} 

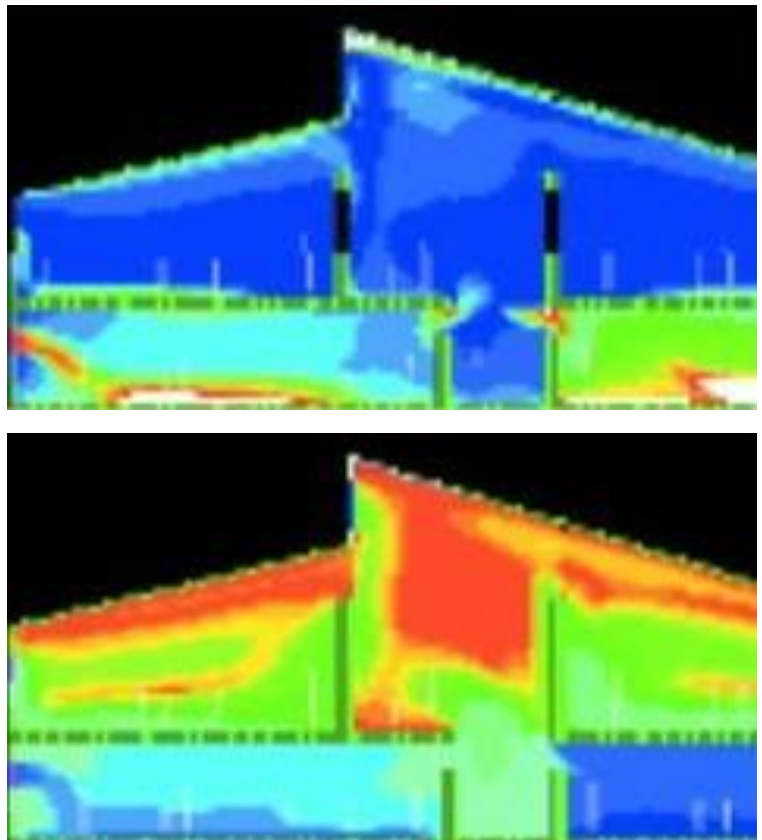

Figura 53 - Esquema de Plotagem de temperatura resultante de conforto e de resultados de PPD

O Tas Ambiens 3D Dynamic permite simulações em 3 eixos de forma dinâmica e integrada ao Tas Bulding Designer. A seguir têm-se duas figuras que ilustram a simulação de uma sala de escritório, a primeira com destaque junto a fachada e a segunda com destaque na posição do usuário. 

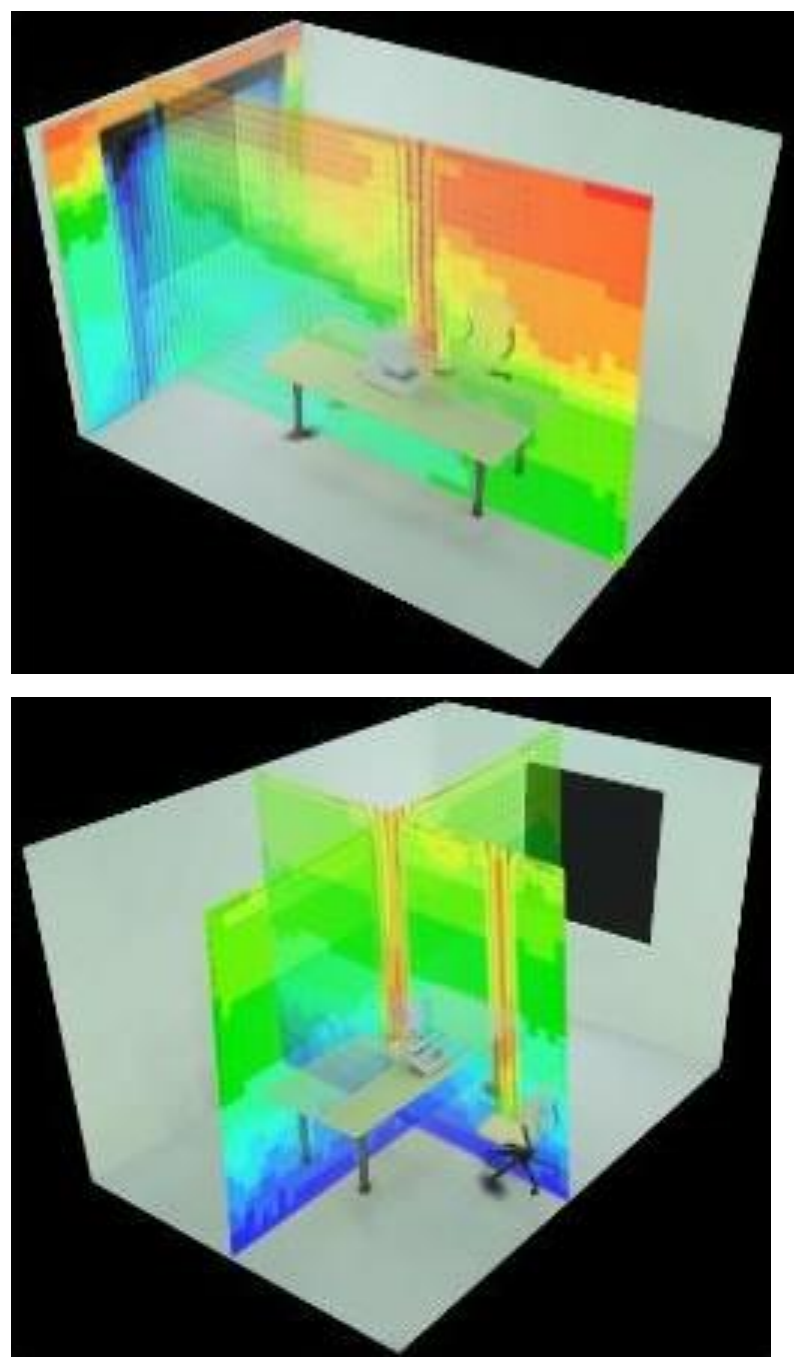

Figura 54 - Simulação de uma sala de escritório usando o CFD 3D e outra simulação para o mesmo ambiente

O software Tas foi validado pela International Energy Agency (IEA) através da comparação positiva com os dados monitorados contidos no seguinte relatório da IEA: Energy Conservation in Buildings \& Community Systems Annex 21 Subtask C Empirical Validation of Thermal Building Simulation Programs Using Test Room Data. 


\subsection{Avaliação Pós-Ocupação: o convênio OECD + USP + SEE}

Em 2005, a Diretoria para Educação da Organization for Economic Co-operation and Development (OECD) sob a coordenação de seu departamento de planejamento e projeto de edifícios escolares CELE - Centre for Effective Learning Environments, iniciou um Projeto Piloto Internacional, cujo objetivo é identificar instrumentos de aferição da qualidade de espaços escolares para que as autoridades educacionais, os responsáveis pela tomada de decisões, as comunidades escolares e outros interventores no processo de ensino-aprendizagem possam otimizar a utilização dos espaços educativos e dos investimentos que neles são efetuados.

A OECD, na área de educação escolar, é internacionamente reconhecida pela aplicação do PISA - Programa Internacional de Avaliação de Alunos, cujo objetivo é identificar até que ponto os estudantes, próximo do final da educação básica, adquiriram conhecimentos e competências essenciais para a plena participação na sociedade.

O Brasil faz parte do grupo de especialistas do Projeto Piloto desde o início dos trabalhos e foi representado pela Prof ${ }^{a}$ Sheila Walbe Ornstein, professora titular da Faculdade de Arquitetura e Urbanismo da Universidade de São Paulo, devido à sua especialização em Avaliação Pós Ocupação de Edifícios.

Foi estabelecida uma parceria entre a FAUUSP e a FDE/SEE, com a participação da Arquiteta Nanci Saraiva Moreira, da FDE, que também tem pesquisa na área de desempenho da construção escolar.

Nos primeiros anos do Projeto Piloto (2005 a 2009), foram elaborados vários documentos pela equipe de especialistas na área de educação escolar em grupo de discussão on line e realizadas 4 reuniões presenciais com o objetivo de estabelecer os quesitos para avaliação e selecionar os instrumentos adequados para aferição da qualidade de edifícios escolares em diferentes países e contextos (local, regional e/ou nacional). 
Estes estudos verificaram, entre outros aspectos, se a edificação escolar possibilita a melhoria e a eficácia educacional na promoção e aquisição de competências por meio da qualificação e da condição do edifício escolar através do conforto e segurança de seu usuário.

Os conceitos utilizados para seleção desses princípios bem como os instrumentos selecionados para sua aferição foram sistematizados em um Manual Orientador, denominado International Pilot Study on the Evaluation of Quality in Educational Spaces (EQES), disponível no site do CELE/OECD. Lançado formalmente em 2009, os instrumentos para avaliação foram aplicados, em uma primeira etapa, em 5 países: Brasil (São Paulo), México, Nova Zelândia, Portugal e Reino Unido, e tiveram como objetivo a aferição de sua eficácia.

Esta experiência mostrou a importância da Avaliação Pós-Ocupação como instrumento para retroalimentar o projeto em diversos de seus aspectos, sobretudo nas questões de Conforto Ambiental. 


\section{Projetos da FDE}

Neste capítulo são apresentados os projetos da FDE que incorporaram questões de conforto ambiental.

Ressalta-se que a maioria das consultorias refere-se a avaliações de condições de conforto acústico realizadas depois de construídas as escolas por demanda da vizinhança através do judiciário. Há ainda consultorias realizadas para desempenho do Sistema Nakamura e do Sistema construtivo metálico. Além dessas, têm-se ainda consultorias em acústica e térmica realizadas principalmente em regiões aeroportuárias.

Em item subsequente, apresenta-se um estudo de caso específico de consultoria realizada exatamente para uma Escola Estadual situada em uma região aeroportuária.

Por fim, dada a evolução das preocupações com as questões de conforto no ambiente construído, apresentam-se as primeiras consultorias realizadas visando-se a consideração integrada de diversas questões ambientais, tendo-se como objetivo atender aos requisitos da certificação Aqua.

\subsection{Projetos da FDE que incorporaram questões de conforto ambiental}

1. Sistema Nakamura

Avaliação comparativa do desempenho térmico de edificações escolares Relatório técnico No 86 592-205

Abril de 2006

Centro Tecnológico do Ambiente Construído - Lab. Conforto Ambiental - IPT

2. Sistema construtivo metálico

Síntese da avaliação dos resultados obtidos com as reformas de edificações escolares

Relatório técnico RT-93015-205

Maio de 2007

Centro Tecnológico do Ambiente Construído - Lab. Conforto Ambiental - IPT

3. Jardim Umuarama

Rua Luster, 216 - Campo Limpo

Relatório de avaliação térmica e acústica de escolas modelo em São Paulo Janeiro de 2008

Lellis Andrade Consultoria Ltda 
4. Jardim Mutinga

Rua Vitórino Caligare, s/n - Barueri

Relatório de avaliação térmica e acústica de escolas modelo em São Paulo Janeiro de 2008

Lellis Andrade Consultoria Ltda

5. EE Prof. Helios Heber Lino

Av. Montes Pirineus, 600 Vila Brasilandia - SP

Contrato no 46/1301/08/04 - R-029F/08- Agosto/2008

Relatório Técnico Conclusivo de Acústica e indicativo de medidas mitigadoras Harmonia Acústica

6. EE Prof ${ }^{a}$ Luiza Salette Junca de Almeida

Vila Brasilândia - SP

Contrato no 46/1185/08/04 - R-026D/08- Agosto/2008

Relatório Descritivo e Orientativo de Acústica

Harmonia Acústica

7. EE Vila Penteado

Av. Deputado Cantidio Sampaio, 1701 - Vila Brasilândia - SP

Relatório Técnico Conclusivo de Acústica e indicativo de medidas mitigadoras

Contrato no 46/1269/08/04 R-028C/08- Agosto/2008

Harmonia Acústica

8. EE Lauro Gomes de Almeida

Rua General Craveiro Lopes,110 Rudge Ramos São Bernardo do CampoSP

Relatório Técnico Conclusivo de Acústica e indicativo de medidas mitigadoras Contrato no46/1761/08/04- Relatório R-043B/08- Dezembro/2008

Harmonia Acústica

9. EE Lauro Gomes de Almeida

Rua General Craveiro Lopes, 110 - Rudge Ramos, São Bernardo do Campo

Conforto Térmico e Acústica Arquitetônica para atenuar problemas atuais de

Acústica existentes no prédio vizinho

Fevereiro de 2009

Roberto Starck Nogueira da Silva e Marco Antonio F. Violani

10. EE Vila Brasilândia/Elisio T. Leite

Rua ilha da juventude, s/n 02820-000 - Vila Brasilândia

Relatório técnico consolidado de consultoria de conforto acústico

Contrato 46/00093/10/04-001-001

Livre Arquitetura

Janeiro de 2010

11. EE Padre Bruno Ricco

Rua Rio Real, 379, Guarulhos

Recomendações para tratamento acústico

RT 090458-R1 
Livre Arquitetura

Janeiro de 2010

12. EE Prof. Helio Polesel

Código FDE: 01.15 .163

13. Rua Cordeiros, 20, Guarulhos, S.P.

Relatório Técnico Final Recomendações para Tratamento Acústico

Contrato № 46/1933/09/04

RT 090457 R1

Janeiro de 2010

14. EE jd. Sta. Rita II/ Pq. Souza Campos II

R. Vitorino Carmilo, 378 - Campos Elíseos - SP

Relatório técnico de consultoria de conforto acústico

RT 010465

Livre Arquitetura

Fevereiro de 2010

15. EE Santa Rita - Itaquaquecetuba

Análise do policarbonato nas aberturas

Relatório técnico de consultoria de conforto térmico

Livre Arquitetura

Fevereiro de 2010

16. EE Vila Brasilandia/Elisio T. Leite

Rua Ilha da Juventude, s/n 02820-000 Vila Brasilandia

Contrato: 46/00093/10/04-001-001

Relatório técnico de consultoria de conforto acústico

RT010470

Livre Arquitetura

Abril de 2010

17. EE Vila Brasilandia/Elisio T. Leite

Rua llha da Juventude, s/n 02820-000 Vila Brasilandia

Contrato: 46/00093/10/04-001-001

Relatório técnico de consultoria de conforto térmico

Livre Arquitetura

Julho de 2010

18. EE Padre Bruno Ricco

Rua Rio Real, 379, Guarulhos

Contrato 01.15.161

Relatório Técnico de consultoria em conforto ambiental - geotermia Green Consulting Arquitetura e Engenharia

Julho de 2010

19. EE Vila Vitória/Vida Nova

R. Vitor Modesto Bonavilla / R. Donato Maia da Silva

Projeto de Acústica 
Acústica \& Sônica

Julho de 2010

20. EE Vila Nova Jaguaré

Relatório Técnico Projeto Acústico

RT 83/10

Modal Acústica

Julho de 2010

\section{EE Bairro Luz}

Rua Afonso Pena, s/no - São Paulo

Relatório Técnico de Consultoria de Conforto Acústico

RT 010467 r6F

Agosto de 2010

22. EE Jardim Marisa

Rua 6 e rua 5, s/n - Campinas - SP

Relatório final consolidado de consultoria de acústica arquitetônica Contrato no 46/00173/10/04

Novembro de 2010

23. EE Vila Nova Jaguaré

Rua Eulo Maroni, sem número, Jaguaré, São Paulo, SP

Relatório Técnico RT 83b/10

Relatório Técnico Final de Projeto Acústico

Modal Acustica

Novembro de 2010

24. EE Jardim dos Coqueiros

Relatório técnico de consultoria de conforto térmico e iluminação

Livre Arquitetura

Fevereiro de 2011 


\subsection{Escolas em zona aeroportuária: o exemplo de Viracopos}

O aeroporto é forte indutor de crescimento urbano, e a expectativa da ampliação de Viracopos vem estimulando o crescimento populacional da região, lotando as escolas existentes.

O município incentiva a fixação das famílias, e o demonstra pela construção recente de conjuntos habitacionais, pela regularização das construções irregulares e pela implantação de serviços públicos e de infraestrutura urbana, mesmo em áreas onde o uso residencial é vetado pela lei de uso do solo, definida nessa área pela legislação aeroportuária.

Os dispositivos legais que regulam a atividade aeroportuária tratam basicamente de dois aspectos relevantes à implantação de escolas:

- Zonas de Proteção - relativas ao gabarito de altura da edificação, determinado e aprovado pelo $\operatorname{COMAR}^{17}$

- Zoneamento de Ruído - relativo ao uso do solo e ao desempenho acústico do edifício, determinado por parâmetros legais e de Normas Técnicas.

Os critérios para estabelecimento dessas Zonas estão descritos na Portaria DAC ${ }^{18}$ no 1.141/87, e quanto ao ruído, as permissões de uso são definidas em função das Áreas I, II e III geradas pelo traçado de duas curvas de nível de incômodo sonoro circundantes ao aeroporto, e assim definidas no art $3^{\circ}$ da Portaria:

- Curva de Nível de Ruído 1 - Linha traçada a partir dos pontos nos quais o nível de incômodo sonoro é igual a um valor predeterminado e especificado pelo Departamento de Aviação Civil DAC, em função da utilização prevista para o aeródromo. O nível de incômodo sonoro representado por esta curva é maior do que o representado pela Curva de nível de Ruído 2.

- Curva de Nível de Ruído 2 - Linha traçada a partir dos pontos nos quais o nível de incômodo sonoro é igual a um valor predeterminado e especificado pelo Departamento de aviação Civil -

\footnotetext{
${ }^{17}$ COMAR Comando Aéreo Regional, subordinado ao Comando da Aeronáutica

${ }^{18}$ DAC é o extinto Departamento de Aviação Civil, que pertencia ao Ministério da Aeronáutica. Com a desmilitarização dos ministérios, a Aeronáutica passou a ser uma área dentro do Ministério da Defesa, e os assuntos deste Departamento passaram à ANAC - Agência Nacional de Aviação Civil, criada em 2005 e que começou
} 
DAC, em função da utilização prevista para o aeródromo. O nível de incômodo sonoro representado por esta curva é menor do que o representado pela Curva de Nível de Ruído 1.

- Área I - Área do Plano de Zoneamento de Ruído, interior à curva de nível de ruído 1, onde o nível de incômodo sonoro é potencialmente nocivo aos circundantes, podendo ocasionar problemas fisiológicos por causa das exposições prolongadas.

- Área II - Área do Plano de Zoneamento de Ruído, compreendida entre as curvas de nível de ruído I e 2, onde são registrados níveis de incômodo sonoro moderados.

- Área III - Área do Plano de Zoneamento de Ruído, exterior à curva de ruído de nível 2, onde normalmente não são registrados níveis de incômodo sonoro significativos.

O critério adotado no Brasil e em quase todo o mundo para determinar as curvas em função do incômodo sonoro é o nível equivalente dia - noite DNL ou LDR (Day-Night equivalent sound Level), uma medida de ruído que descreve o ruído médio em 24 horas típico, e considera $10 \mathrm{~dB}(\mathrm{~A})$ a mais sobre o ruído entre 22:00 e 7:00. De acordo com este critério, as curvas 1 e 2 correspondem respectivamente a $75 \mathrm{~dB}(\mathrm{~A})$ e $65 \mathrm{~dB}(\mathrm{~A})$, portanto:

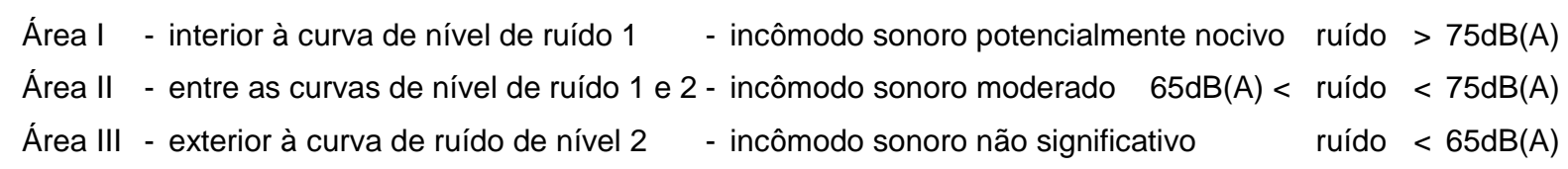

Do Art.70 da referida Portaria constam as restrições de uso para cada Área, sendo não permitindo para diversas atividades "a implantação, o uso e o desenvolvimento na Área II", por ex: residencial, de saúde, hotel, biblioteca, auditório, cinema, teatro, e escolas.

As restrições devem refletir diretamente na definição do zoneamento urbano dos municípios, como determina o Art.73:

Todo parcelamento do solo localizado em área do Plano de Zoneamento de Ruído observará as restrições estabelecidas nos Artigos 69 e 70 desta Portaria.

As escolas de que ora tratamos encontram-se todas na Área II, Área Especial Aeroportuária, para a qual o uso "escolas" não é permitido - assim como não é permitido o uso residencial - embora a população esteja lá, como representado na a seguir: 


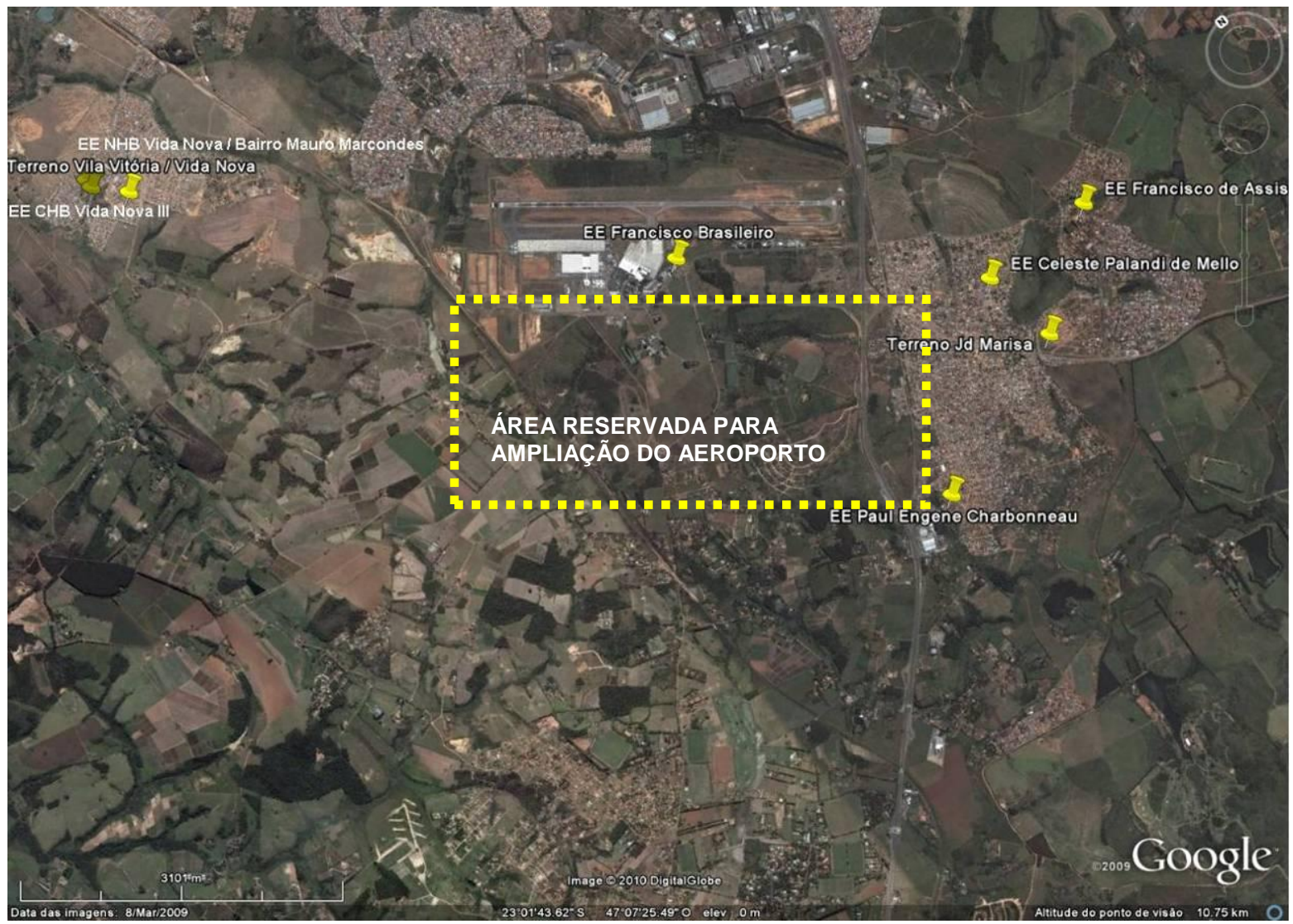

Figura 55 - Escolas estaduais existentes no entorno do Aeroporto de Viracopos, Campinas - imagem Google Earth, acesso: 2010

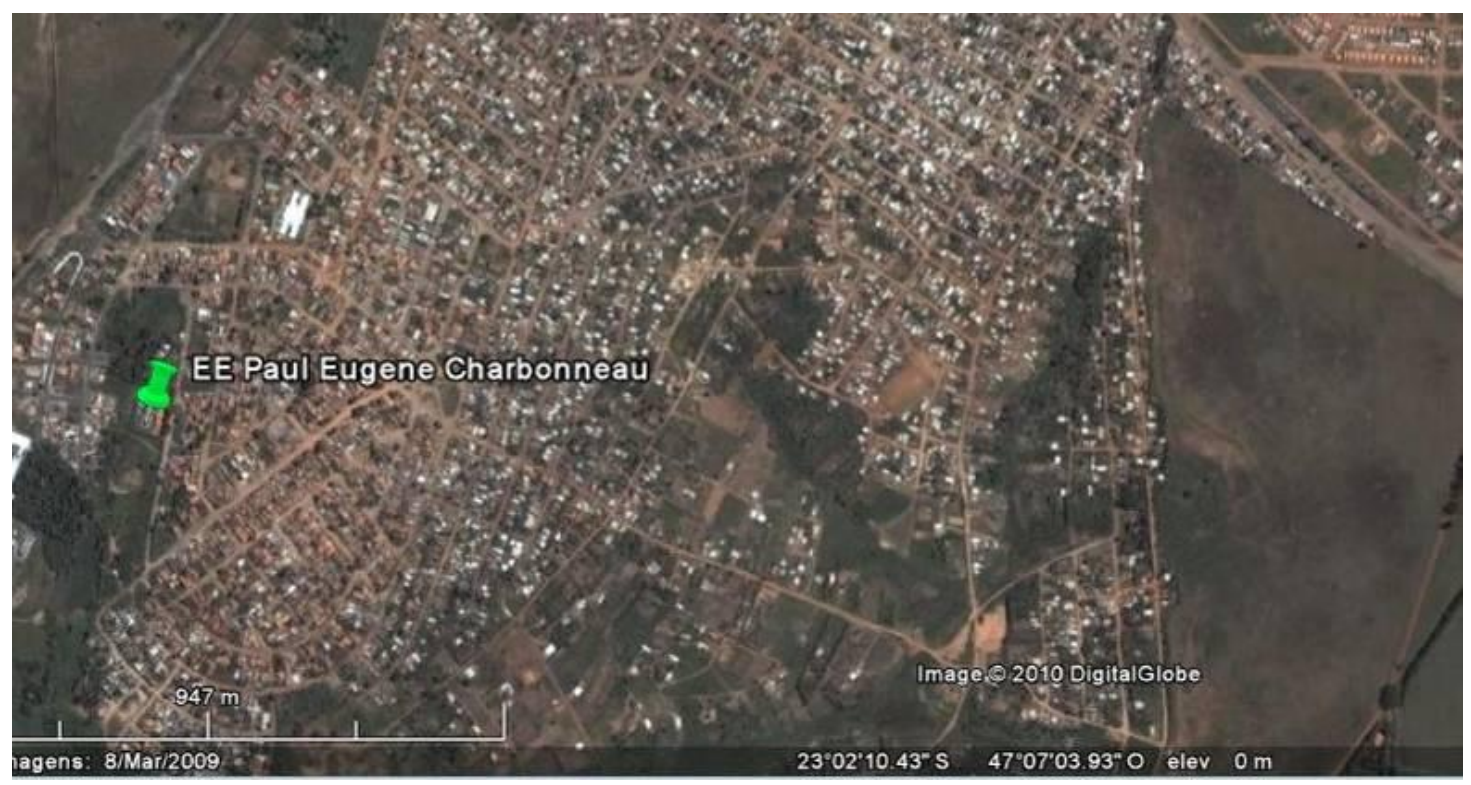

Figura 56 - Adensamento ocorrido no entorno da EE Paul Eugéne Charbonneau entre 2002 e 2009, Campinas imagem Google Earth, acesso: 2010 

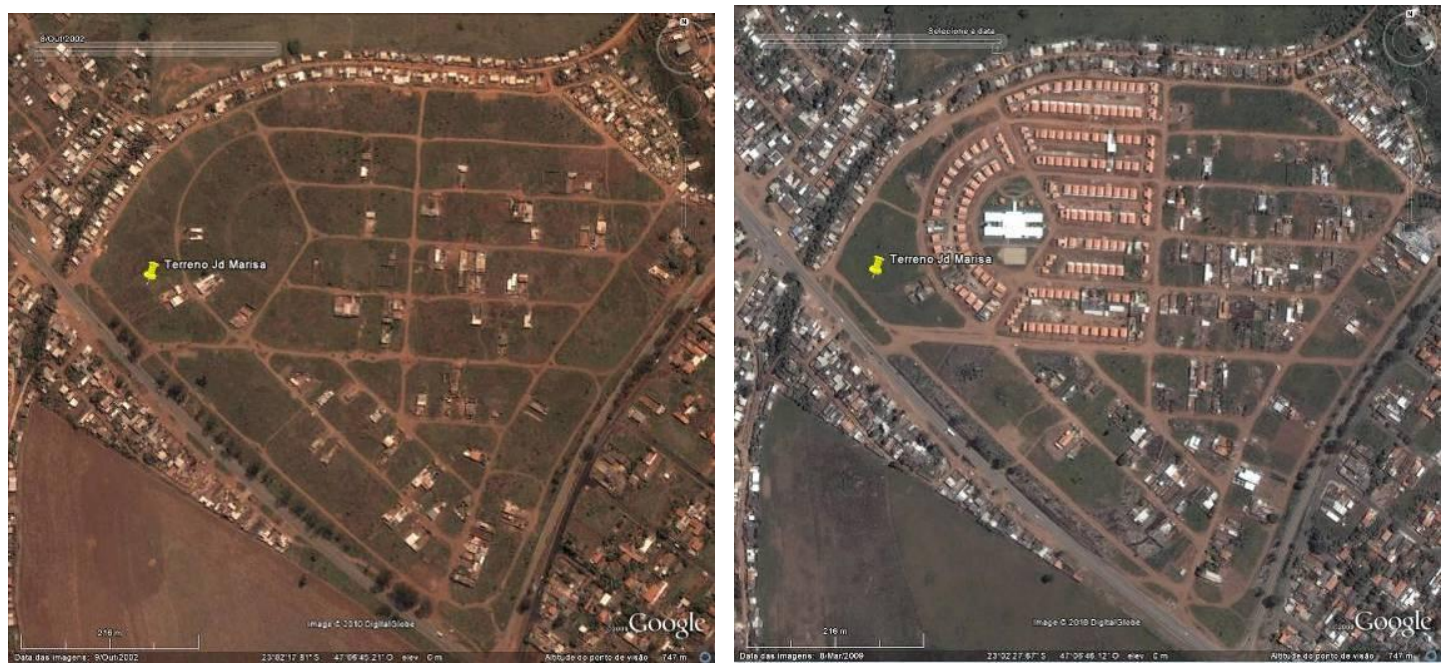

Figura 57 - Adensamento ocorrido no Jardim Marisa entre 2002 e 2009, Campinas - imagem Google Earth, acesso: 2010

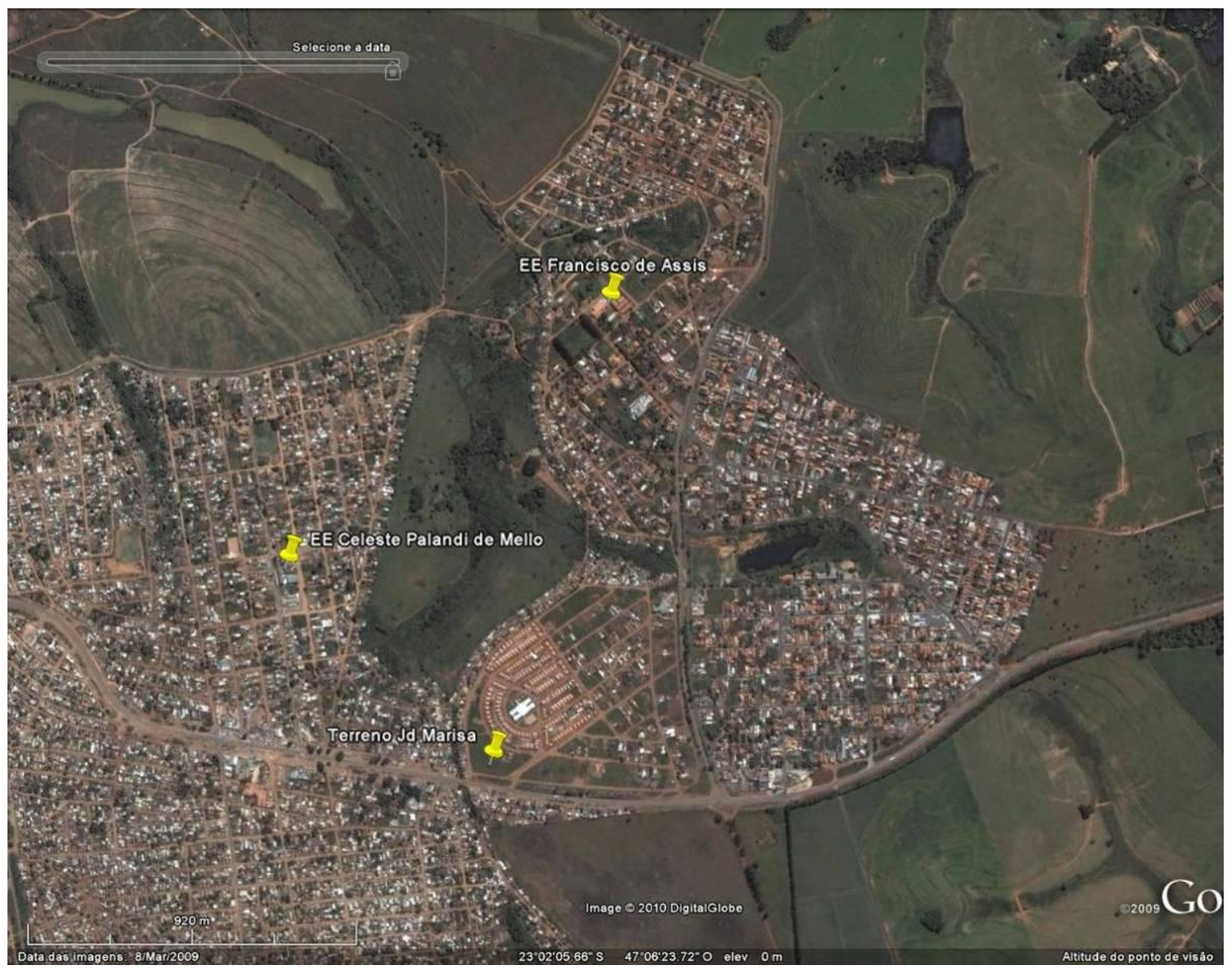

Figura 58 - Adensamento ocorrido no entorno da EE Celeste Palandi de Mello, EE Francisco de Assis e Terreno Jd Marisa entre 2002 e 2009, Campinas - imagem Google Earth, acesso: 2010

Aqui, a posição relativa às curvas de ruído, das escolas para as quais está em processo a ampliação de 50 salas de aula ( 2 obras novas e 3 ampliações de escolas existentes): 
Planta das áReAs especiais aERoportuarias - $M$ EA

PLANO ESFECIFICO UE ZONEAMENIO UL RUIDO DO ACROFORTO INTCRNACIONAL DE VIRACOPOS-CAMPINAS-SP (PFZR/SAKP) ADROVADO PELA PORTARU N' 102/OCAC, DE OS OE MARCCO DE 1999

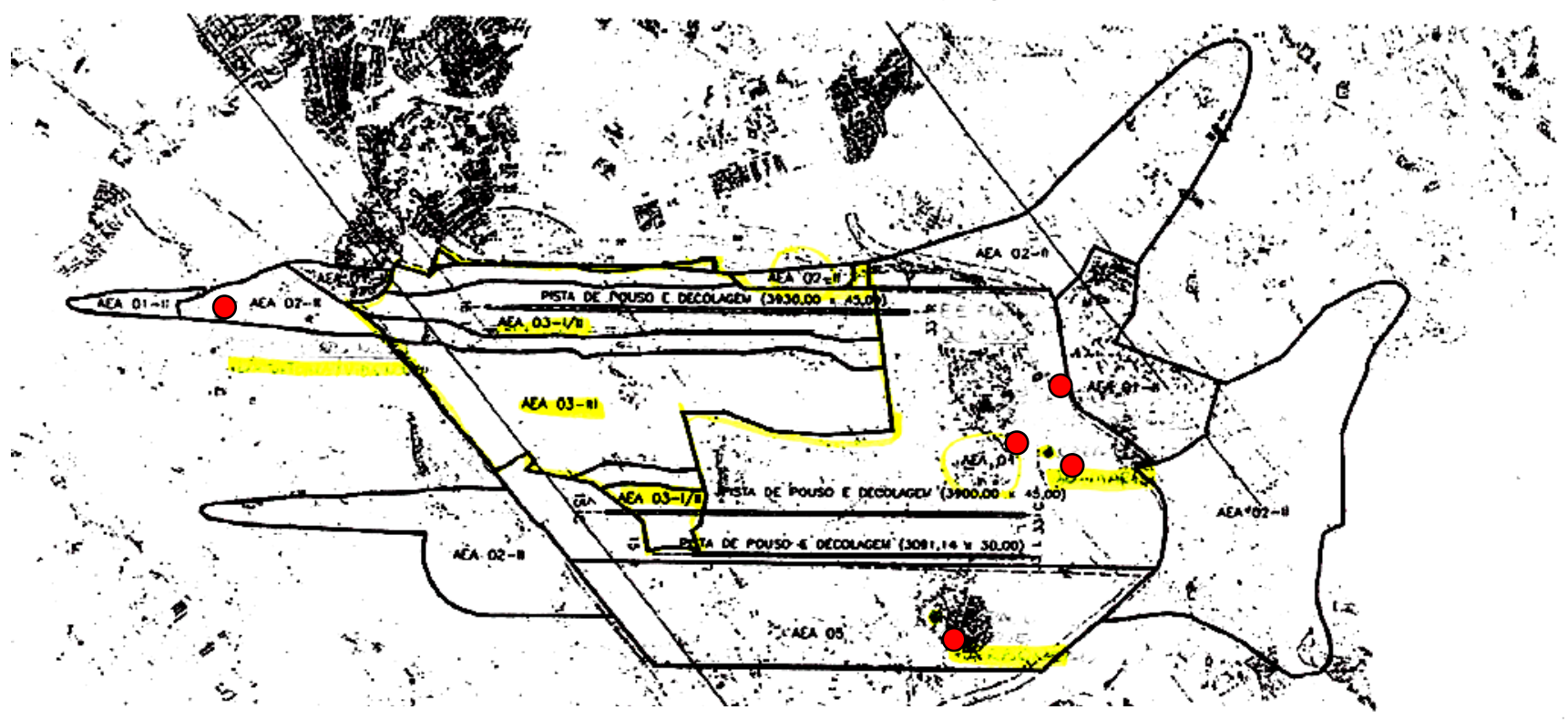

Figura 59 - Anexo II da Portaria DAC no 102/DGAC

Esta Portaria aprova o PEZR - Plano Específico de Zoneamento de Ruído para o aeroporto + previsão de ampliação. O zoneamento urbano vigente para a região de Viracopos está

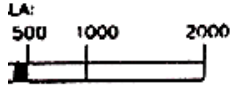
fundamentado neste Plano e também representado nesta figura. As escolas em tela estão internas à curva II de ruído (nos termos da Portaria DAC no 1.141/87), que corresponde ao contorno maior em preto em formato de dois pássaros, e pertencem a zonas restritivas aos usos escolar e residencial:

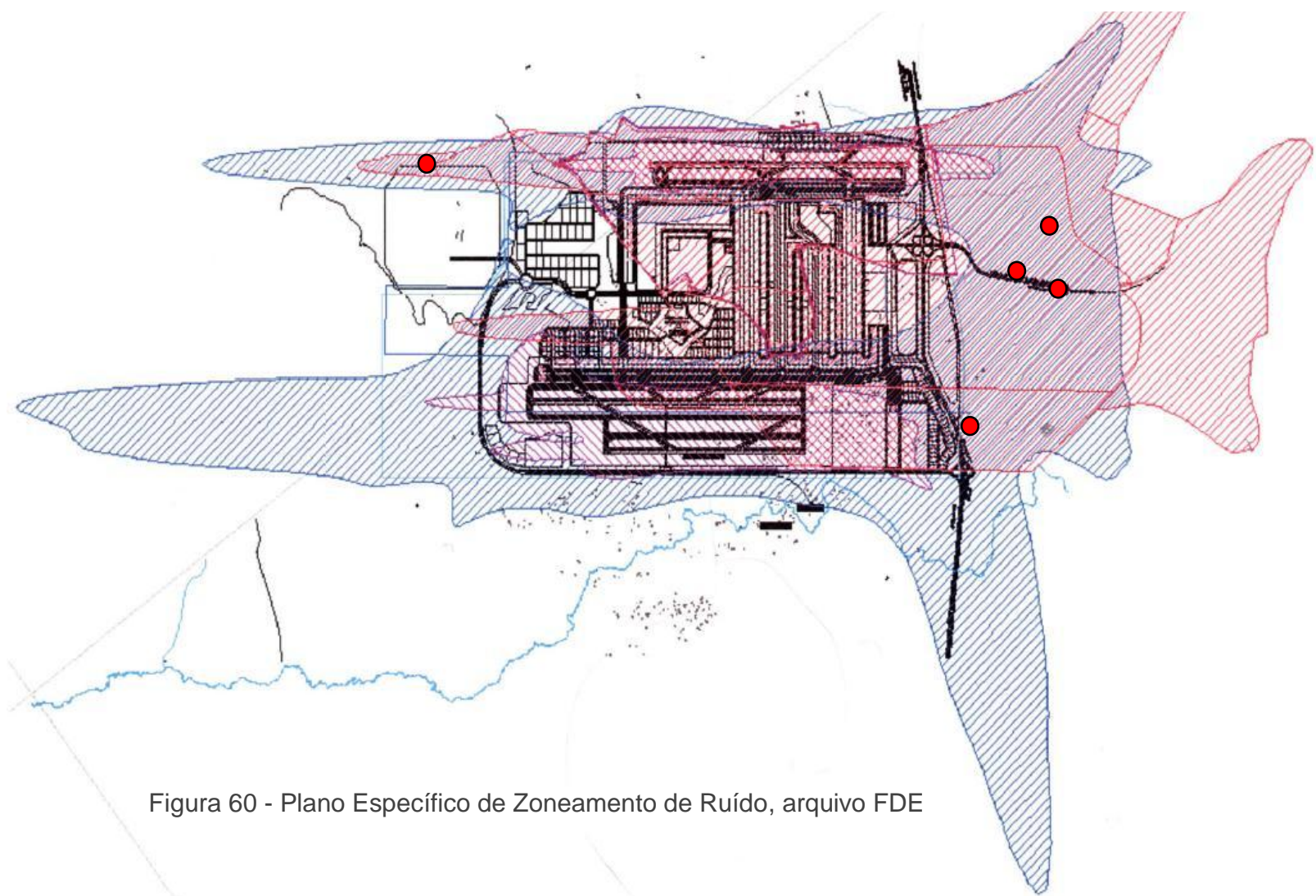

A curva de ruído II definida em 1999 e representada no contorno preto do Plano Específico de Zoneamento de Ruído da figura 60, aqui aparece representada em rosa. 
Posteriormente, em 2009, as curvas foram redefinidas e aprovadas pela ANAC através da DECISÃO oㅜ 152, DE 31 DE MARÇO DE 2009. A curva de ruído ॥ atualizada está representada em azul na figura 60 .

O zoneamento urbano ainda não foi revisto em função destas curvas. Portanto:

- o zoneamento urbano válido (1999) está representado na figura 59.

- o zoneamento de ruído válido (2009) é o representado na figura 60.

As escolas de que ora tratamos estão indicadas em vermelho nas figuras 59 e 60, ficando claro ocuparem em ambos os casos, a mesma Área II (nos termos da Portaria DAC no 1.141/87).

Consultas verbais em reuniões presenciais da FDE junto à ANAC em Brasília e INFRAERO em Viracopos resultaram na orientação de que as escolas poderiam ser construídas desde que com o tratamento acústico adequado.

Foram então providenciadas pela FDE as consultorias de conforto térmico e acústico para garantir aos projetos 0 atendimento aos parâmetros de Norma. Para todos os projetos o isolamento do ruído aeronáutico será feito pelo fechamento do vão das janelas com caixilho acústico duplo. Este fechamento irá impedir a ventilação natural, o que exige o insuflamento forçado de ar externo, previsto em sistema central, captado por ventiladores em tomada externa única e resfriado ao fluir através de tubos enterrados, pela perda de calor para o solo. Após percorrer a distância necessária para chegar à temperatura de conforto, o ar é insuflado em dutos que o distribuem aos ambientes.

Os parâmetros a seguir vêm sendo adotados:

$75 \mathrm{~dB}(\mathrm{~A})$ como referência de ruído aeroportuário a tratar (valor mais restritivo entre curvas 1 e 2); $40 \mathrm{~dB}(\mathrm{~A})$ como valor de redução de ruído $(\mathrm{RR})$.

Desta forma se pode garantir nível de pressão sonora de $35 \mathrm{~dB}(\mathrm{~A})$ para o Centro de Leitura, mais restritivo que a sala de aula, que requer $40 \mathrm{~dB}(\mathrm{~A})$, conforme os parâmetros das Normas: 
- NBR 10.152/87 - nível de pressão sonora compatível com o conforto acústico: $35 \mathrm{~dB}(\mathrm{~A})$ dentro da biblioteca;

$40 \mathrm{~dB}(\mathrm{~A})$ dentro das salas de aula.

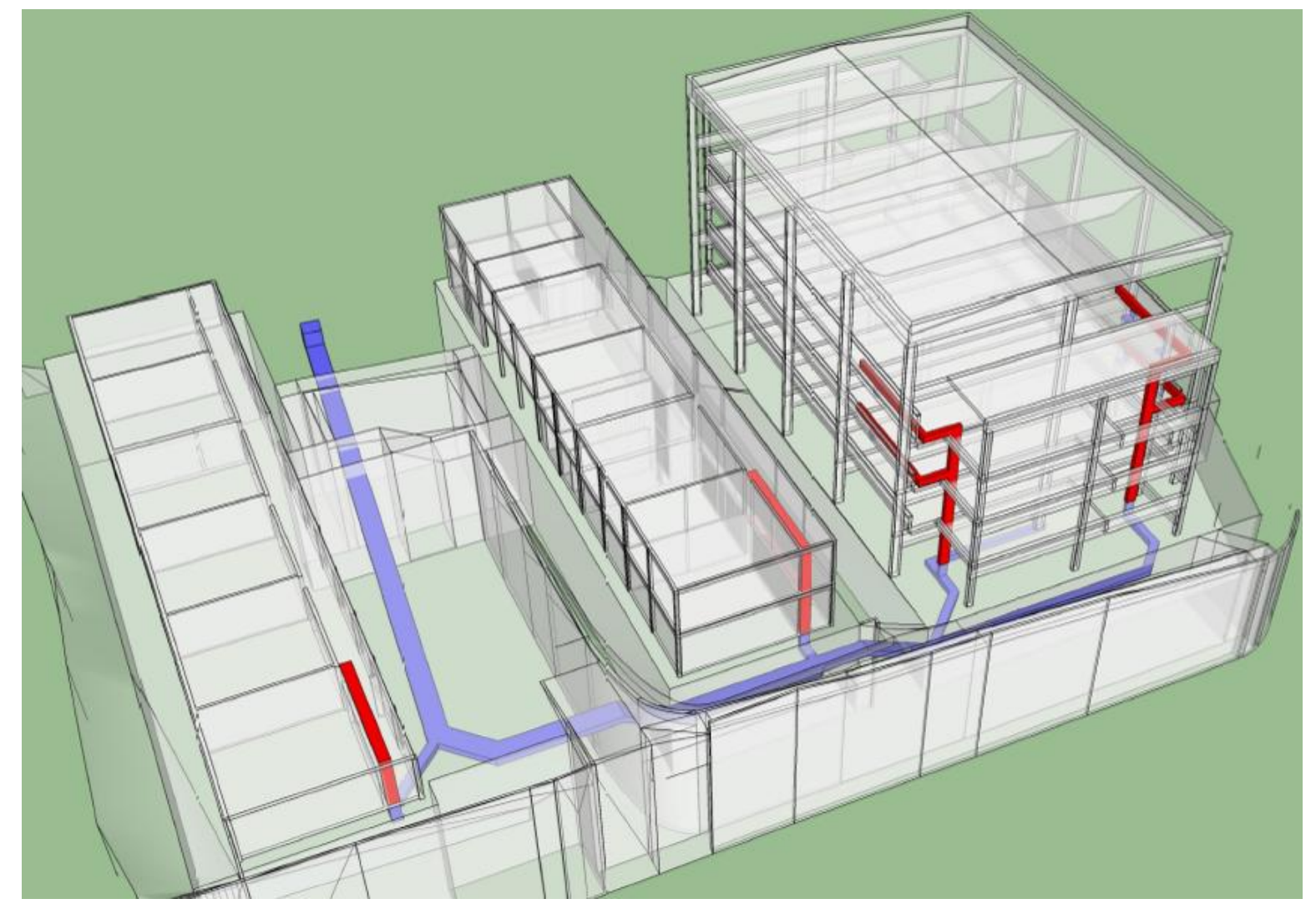

Figura 61- Esquema ilustrativo do sistema de geotermia

O esquema ilustra a tubulação enterrada (azul) através da qual o ar é resfriado pelo solo, e a tubulação de distribuição (representação parcial, em vermelho). Projeto Arqº Omar Dalank, consultoria geotérmica Engenheiro Alberto Hernandez Neto / POLI USP e Arquiteta Anarrita Bueno Buoro, para EE Bruno Ricco.

- NBR 8572/84 - valor de redução de ruído RR conforme tabela para aeroportos brasileiros da para o Aeroporto de Guarulhos (a tabela não prevê Campinas), observando-se constar do item 4.1 que: Não são objetos desta Norma a fixação dos RR para: escolas, (...) porque essas construções são mais restritivas, sob o ponto de vista acústico, que os valores apresentados na Tabela:

$35 \mathrm{~dB}(\mathrm{~A})$ a $45 \mathrm{~dB}(\mathrm{~A})$ para biblioteca, sala de música e sala de desenho;

$40 \mathrm{~dB}(\mathrm{~A})$ a $50 \mathrm{~dB}(\mathrm{~A})$ para salas de aula, laboratórios;

$45 \mathrm{~dB}(\mathrm{~A})$ a $55 \mathrm{~dB}(\mathrm{~A})$ para circulação

Com as diretrizes e pré-dimensionamento de projeto definidos, a FDE consultou a ANAC no Rio de janeiro, de quem o entendimento foi diverso em relação às consultas anteriores, contrário à construção das escolas pelo fato de estar localizada na Área II. 
Aqui se inicia o ponto nevrálgico do conflito legal. Se a ANAC tem o amparo legal da Portaria DAC 1.141/87 para não aprovar as construções escolares, teria igualmente amparo legal para aprová-las, pela faculdade que lhe atribui o parágrafo único do artigo 70:

As atividades acima referidas poderão ser, eventualmente, autorizadas pelos órgãos municipais competentes, mediante aprovação do Departamento de Aviação Civil - DAC $\left(^{*}\right)^{19}$.

Estamos diante de uma situação complexa, que foge da linearidade de construir ou não construir na área II, que põe todos atores diante de uma situação que exige a reflexão sobre tudo que está envolvido, para além das especialidades e atribuições individuais. Estar conforme ao universo da própria especialidade não significa estar conforme ao contexto mais amplo do objeto pelo qual interagem os diversos especialistas - seja ANAC, INFRAERO, FDE, SEE, Prefeitura ou a Comunidade.

E não se trata, esta expectativa por reflexão, de expectativa por flexibilização da lei, mas sim de que seja considerado outro dispositivo tão legítimo quanto foi legítimo o dispositivo que levou à negativa. Negativa esta que, neste caso, não pode basear-se simplesmente na desconformidade de uso do solo; mas, pela abertura criada no parágrafo único reproduzido anteriormente, a negativa teria que ponderar, senão a questão social do atendimento à demanda por salas, notadamente o atendimento à questão técnica da proteção acústica, com a garantia de conforto térmico. Ou seja, se a restrição ao uso do solo se faz pela questão do ruído, mitigada esta questão, e pelo poder de aprovação que lhe cabe, há que se dispor a ANAC a um estudo analítico da amplitude que o caso encerra.

A não-aprovação e portanto a não construção e ampliação daquelas escolas traz consequências que também ferem a legislação. As escolas já existentes na área restrita são insuficientes para atender a demanda que ultrapassa 10.000 alunos e que cresce dia a dia.

\footnotetext{
${ }^{19}$ DAC (*) DAC - Departamento de Aviação Civil, extinto, sendo suas funções atualmente exercidas pela ANAC.
} 
O Estado, no exercício do dever constitucional de oferecer as vagas necessárias, para acomodar a demanda crescente vem tomando as seguintes medidas:

- criação de três turnos diurnos com aulas extras aos sábados para não ferir a Lei de Diretrizes e Bases em sua determinação de carga horária mínima: LEI № 9.394, DE 20 DE DEZEMBRO DE 1996.

Lei de Diretrizes e Bases que determina:

I - a carga horária mínima anual será de oitocentas horas, distribuídas por um mínimo de duzentos dias de efetivo trabalho escolar, excluído o tempo reservado aos exames finais, quando houver;

- oferta de transporte a aproximadamente 1.250 alunos por vans para escolas distantes de sua residência, para compensar o descumprimento involuntário do ECA e da Lei Federal 11.700/2008:

LEI № 8.069, DE 13 DE JULHO DE 1990.

Dispõe sobre o Estatuto da Criança e do Adolescente e dá outras providências

Capítulo IV - Do Direito à Educação, à Cultura, ao Esporte e ao Lazer

Art. 53. A criança e o adolescente têm direito à educação, visando ao pleno desenvolvimento de sua pessoa, preparo para o exercício da cidadania e qualificação para o trabalho, assegurando-se-lhes:

V - acesso à escola pública e gratuita próxima de sua residência.

\section{Lei Federal 11.700/2008}

escola pública e gratuita, próxima da residência do aluno

- superlotação das salas, o que inclui salas ambiente transformadas em salas de aula, descumprindo o código sanitário e as normas da própria Secretaria da Educação:

DECRETO N. 12.342, de 27-09-78 CÓDIGO SANITÁRIO

CAPÍTULO VI - Edificações Destinadas a Ensino - Escolas

Artigo 102 - A área das salas de aula corresponderá no mínimo a 1,00m² por aluno lotado em carteira dupla e de $1,20 \mathrm{~m}^{2}$, quando em carteira individual.

Lembrando que além do desconforto que estas medidas causam a toda a comunidade, permanecem todos expostos ao ruído aeroportuário e aos seus efeitos na aprendizagem, seja na leitura, motivação, linguagem, aquisição da fala e memória, como mostram inúmeros estudos em todo o mundo (NUNES).

O FICAN ${ }^{20}$ Comitê Federal Interagências sobre Ruído Aeronáutico norteamericano patrocinou um estudo intitulado Relação entre a redução de ruído

\footnotetext{
${ }^{20}$ FICAN Federal Interagency Civil Aviation Noise Comitee
} 
aeronáutico nas escolas e desempenho em testes padronizados, em 2.000, para investigar a relação da redução do ruído de aeronaves dentro das salas de aula com a melhoria da pontuação nos testes de desempenho acadêmico, e assim avaliar o sucesso do isolamento sonoro da escola para redução nos níveis de ruído interno das salas de aula como alternativa ao fechamento do aeroporto.

Foram utilizados testes governamentais padronizados para garantir a uniformização da avaliação, e então foram escolhidos três aeroportos em Estados onde havia resultados anteriormente publicados e disponíveis em meio eletrônico para os últimos 10 anos. O estudo abrangeu alunos do ensino médio, ciclo II e ciclo I do ensino fundamental, além de alunos do Programa de Educação Individual, sem correspondente no Brasil. Ainda, o estudo não incluiu as escolas particulares, para as quais não há obrigatoriedade de fazer os testes.

No entorno desses três aeroportos havia um total de trinta e duas escolas públicas que sofreram redução de ruído de aeronaves durante os últimos dez anos, ou pelo fechamento do aeroporto, ou pela execução de reforma para isolamento de som.

O ruído foi considerado para os meses e horário de funcionamento da escola por um ano escolar completo. Para o cálculo de ruído nas salas de aula foram utilizadas informações de ruído do Oficial Airline Guide (OAG), com entradas em SEL e LAmax , integrados no INM versão 6.1 do Modelo FAA de integração de ruído.

Foram consideradas as dimensões e os detalhes do tipo de janela antes de depois do isolamento, estrutura das paredes, e telhado de estrutura de edifícios escolares principal, etc

Em resumo, este estudo encontrou associação significativa entre a redução de ruído e redução das taxas de insucesso, sobretudo para o Ensino Médio. Foi encontrada pouca associação para o Ensino Fundamental e pouca variação na quantidade do padrão "A" de notas, com maior variação nas médias. 
Ao final são feitas ressalvas no sentido de que o estudo deva ser revisto para validar resultados, que a amostra deva ser ampliada, e sobretudo que se realize estudos acompanhando o mesmo estudante ano a ano, ao invés de analisar médias gerais como foi o caso deste estudo.

De qualquer forma, os autores concluem pela associação significativa entre redução de ruído e diminuição nas taxas de insucesso, e que isolar o ruído apresenta resultados semelhantes ao fechamento do aeroporto.

Portanto, vê-se que estes conflitos envolvendo o aeroporto e seu entorno não são exclusividade de Viracopos, mas sim conflitos vivenciados em diversas cidades por todo o mundo, o que nos dá referências de modelos de como lidar com esta complexidade - disto que vem sendo chamado de gestão do ruído. Por exemplo, a 33 a - Assembleia da ICAO21 em Montreal, 2001, produziu a Resolução A33/7 que define o conceito de abordagem equilibrada, que consiste na conciliação das seguintes variáveis:

- redução na fonte do ruído gerado por aeronaves;

- medidas de ordenamento e gestão do território;

- procedimentos operacionais de redução do ruído;

- restrições de operação.

A legislação abre a possibilidade - e aqui entra a necessária metamorfose do próprio Direito de forma a dar conta de ser a ferramenta de conciliação - e a tecnologia permite implantar as escolas e atender a população que já está lá, sem comprometimento da saúde dos alunos.

Aeroportos urbanos do mundo todo têm escolas na zona II, e a redução na fonte do ruído vem sendo objeto de leis que obrigam à diminuição periódica da frequência de vôos em relação ao ruído que produzem, levando à descontinuidade de modelos desconformes.

21 ICAO International Civil Aviation Organization 
Os parâmetros de ruído aceitável são analisados e tomados por referência de forma local, assim como a métrica utilizada na medição.

Tabela 9: Limites de zonas de ruído aeronáutico em alguns países em

Leq, 24h.

\begin{tabular}{l|c|c|c}
\hline País & Sem Restrição & $\begin{array}{c}\text { Medidas de } \\
\text { Isolamento }\end{array}$ & $\begin{array}{c}\text { Proibição de } \\
\text { Construção de Novas } \\
\text { Residências }\end{array}$ \\
\hline ALEMANHA & $<62$ & $67-75$ & $>75$ \\
\hline AUSTRÁLIA & $<53$ & $53-58$ & $>58$ \\
\hline CANADÁ & $\leq 57$ & $60-62$ & $>68$ \\
\hline CHINA & $\leq 54$ & & $>51$ \\
\hline DINAMARCA & $\leq 51$ & $>61$ & $>72$ \\
\hline EUA & $\leq 62$ & & $>50$ \\
\hline FRANÇA & $<62$ & $62-71$ & $>62$ \\
\hline HOLANDA & $\leq 50$ & $53-60$ & $>55$ \\
\hline JAPÃO & $<54$ & $>69$ & $>62$ \\
\hline NOVA ZELÂNDIA & $\leq 52$ & $52-62$ & $>70$ \\
\hline NORUEGA & $\leq 55$ & $55-65$ & \\
\hline SUÉCIA & $<51$ & & $62-72$ \\
\hline SUIÇA & $\leq 55$ & $55-64$ & \\
\hline REINO UNIDO & & & \\
\hline
\end{tabular}

(Fonte: BRUEL \& KJAER, 2001, p. 37)

Figura 62 - Exemplo de medição: "Limites de zonas de ruído aeronáutico em alguns países"

in Percepção do ruído aeronáutico em escolas da Zona I do PEZR do Aeroporto Internacional Salgado Filho, de Maria Fernanda de Oliveira Nunes

\begin{tabular}{cccc}
\hline Horario & UA 1 hora & LAD I LAN & DNL \\
\hline 7 & 73,3 & 73,9 & 74,3 \\
\hline 8 & 76,5 & 73,9 & 74,3 \\
\hline 9 & 73,1 & 73,9 & 74,3 \\
\hline 10 & 75,2 & 73,9 & 74,3 \\
\hline 11 & 74,2 & 73,9 & 74,3 \\
\hline 12 & 73,8 & 73,9 & 74,3 \\
\hline 13 & 75,4 & 73,9 & 74,3 \\
\hline 14 & 74,5 & 73,9 & 74,3 \\
\hline 15 & 72,2 & 73,9 & 74,3 \\
\hline 16 & 71,8 & 73,9 & 74,3 \\
\hline 17 & 72,0 & 73,9 & 74,3 \\
\hline 18 & 72,6 & 73,9 & 74,3 \\
\hline 19 & 75,4 & 73,9 & 74,3 \\
\hline 20 & 73,6 & 73,9 & 74,3 \\
\hline 21 & 73,9 & 73,9 & 74,3 \\
\hline 22 & 72,0 & 73,9 & 74,3 \\
\hline 23 & 53,4 & 64,8 & 74,3 \\
\hline 24 & 0,0 & 64,8 & 74,3 \\
\hline 1 & 0,0 & 64,8 & 74,3 \\
\hline 2 & 0,0 & 64,8 & 74,3 \\
\hline 3 & 0,0 & 64,8 & 74,3 \\
\hline 4 & 0,0 & 64,8 & 74,3 \\
\hline 5 & 0,0 & 64,8 & 74,3 \\
\hline 6 & 73,4 & 64,8 & 74,3 \\
\hline & & & \\
\hline
\end{tabular}

Figura 63 - Exemplo de medição de ruído aeronáutico; fonte: INFRAERO

A FAA - Federal Aviation Administration, agência de aviação civil americana, avalia programas para isolamento de ruído como por exemplo o desenvolvido para os aeroportos de Chicago. 
Evolução da curva de ruído do aeroporto de Chicago, diminuindo significativamente desde 1979 até a previsão para 2014, em função dos programas de controle de ruído das aeronaves, rotas e frequência de vôos, posição das pistas.
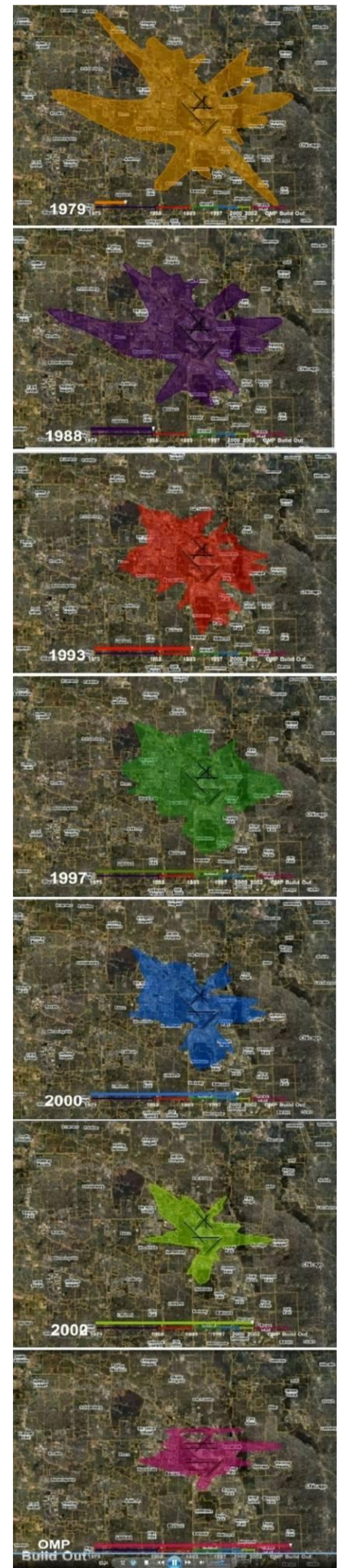


\subsection{Projetos submetidos à certificação AQUA}

O primeiro projeto de escola da FDE a ser certificado pela AQUA - Alta Qualidade Ambiental, em fase de programa, foi a EE Bairro Luz, em março de 2010, que recebeu consultoria da Inovatech Engenharia. Na sequência as escolas de Santa Rita e de Brasilândia também receberam a certificação. No momento, outras escolas estão em processo para obter o certificado.

A EE Bairro Luz foi a primeira escola pública a receber esta qualificação no Brasil. A certificação AQUA é um referencial de um sistema de construção sustentável, atestando a "Alta Qualidade Ambiental do Empreendimento", comprovada por meio de auditorias independentes realizadas pela Fundação Carlos Alberto Vanzolini, detentora do sistema de certificação.

Segundo a referida Fundação, os benefícios de um Empreendimento Certificado pelo processo AQUA são:

- qualidade e conforto ambiental;

- economias de água e energia;

- disposição ambientalmente adequada de resíduos e

- menor impacto ambiental em todas as fases da construção.

Visa preservar os recursos naturais, limitar a poluição e particularmente as emissões de gases de efeito estufa, limitar os resíduos, gerenciando os impactos sobre o ambiente exterior e criando um espaço interior sadio e confortável.

A AQUA estrutura-se em 14 categorias, ou "conjuntos de preocupações", representando os desafios ambientais a serem alcançados em um empreendimento:

1) relação do edifício com o seu entorno;

2) escolha integrada de produtos, sistemas e processos construtivos;

3) canteiro de obras com baixo impacto ambiental;

4) gestão da energia; 
5) gestão da água;

6) gestão dos resíduos de uso e operação do edifício;

7) manutenção - permanência do desempenho ambiental;

8) conforto higrotérmico;

9) conforto acústico;

10) conforto visual;

11) conforto olfativo;

12) qualidade sanitária dos ambientes;

13) qualidade sanitária do ar;

14) qualidade sanitária da água.

A Certificação AQUA é concedida ao final de cada uma das seguintes fases, mediante verificação de atendimento ao seu referencial técnico.

1) Programa: elabora-se o programa de necessidades destinado aos projetistas para orientar a concepção arquitetônica e técnica do empreendimento;

2) Concepção: elabora-se o projeto arquitetônico e definem-se as especificações técnicas para o empreendimento;

3) Realização: aplica-se o que foi definido nas fases anteriores na execução da obra.

A FDE definiu a organização, as competências, o método, os meios e a documentação necessários para alcançar seus objetivos e atender às necessidades para atingir a Certificação. Contou com a parceria da Inovatech Engenharia. Este processo experimental e piloto tem como objetivo incorporar às práticas da FDE, de forma integrada, os preceitos de sustentabilidade do edifício da escola pública. 
de

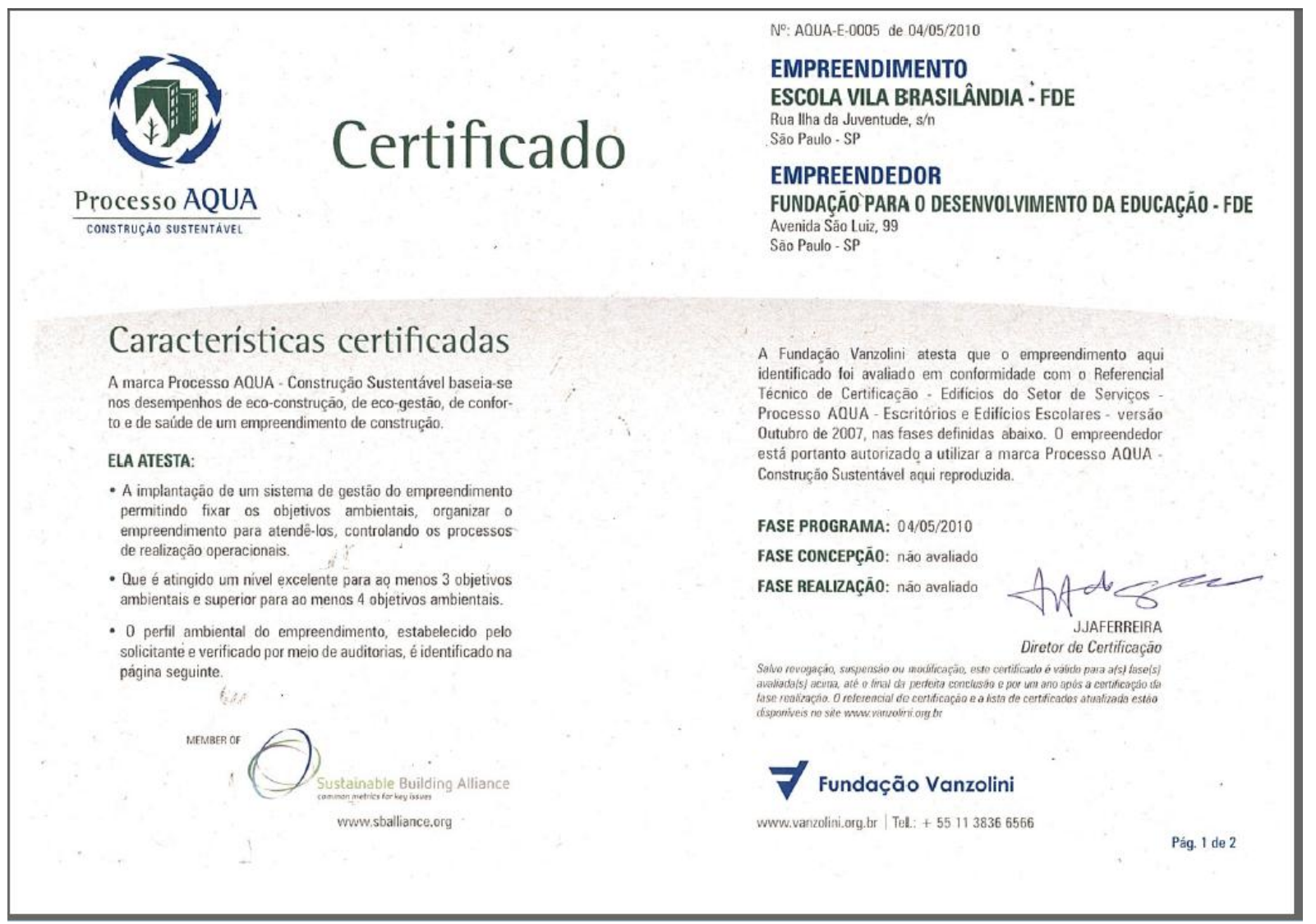

Figura 65 - Certificado de Alta Qualidade Ambiental - AQUA obtido pela FDE para a fase Programa da Escola Vila Brasilândia. Fonte: arquivos da FDE 
5. Conceitos de conforto ambiental, incorporados e a incorporar ao projeto da FDE

\subsection{Conceitos incorporados}

\section{Minuta para Contratação de Projeto com Conforto Ambiental pela FDE}

A inserção do Conforto Ambiental ao projeto exigiu a elaboração dos termos contratuais e orientações para projeto correspondentes, explicitados a seguir e reproduzidos conforme constam hoje das orientações aos analistas.

\section{Objeto do Contrato}

Elaboração de projeto executivo na área técnica de Arquitetura para construção de (característica da escola), em sistema pré-fabricado de concreto com otimização do desempenho de conforto térmico e eficiência energética, com coordenação e fornecimento dos projetos executivos nas áreas técnicas (Estrutura, Hidráulica, Elétrica).

\section{Escopo do Contrato}

O profissional consultor deverá subsidiar a elaboração do projeto em todas as suas etapas (estudo preliminar, anteprojeto e projeto executivo), visando assegurar o conforto térmico dos usuários e minimizar o consumo de energia elétrica na fase de uso da edificação, com a adoção de sistemas passivos, conformes às especificações dos Catálogos Técnicos da FDE e com baixo custo de implantação e manutenção.

Ao final do estudo preliminar e do anteprojeto o diagnóstico climático deverá ser realinhado ao produto aprovado para realimentar a etapa seguinte, com propostas coerentes às demais condicionantes.

O edifício pós-ocupado terá seu desempenho térmico e energético avaliado.

\section{Produtos:}

- parâmetros de subsídio ao projeto: 
- fornecer comparativo de desempenho das opções de orientação de fachadas, aberturas e ambientes em relação à radiação solar e materiais construtivos;

- indicar necessidade de sombreamento e apresentar soluções e especificações para elementos de controle da radiação solar direta nos ambientes.

- simular o desempenho térmico pela demonstração em maquete eletrônica 3D, a resposta dos elementos de sombreamento à radiação direta; não serão aceitas soluções de sombreamento que comprometam o conforto visual pelo contraste de luz sobre os planos de trabalho (carteira e lousa);

- demonstrar o desempenho energético pelo cálculo do consumo de energia elétrica que deverá ocorrer na fase de uso da edificação, garantindo o máximo aproveitamento da luz natural do céu visível, de forma que os elementos de controle da radiação solar direta propostos não impliquem aumento da necessidade de iluminação artificial definida no Manual de Ambientes da FDE;

- memorial de conforto térmico e eficiência energética contendo a descrição do processo de priorização de parâmetros de projeto que gerou o projeto executivo, bem como todos os produtos da consultoria (cartas solares, máscaras das obstruções, diagnóstico climático, representação gráfica dos dispositivos de controle de radiação direta, cálculo de ganhos e perdas de calor, da iluminância no plano de trabalho, da eficiência dos brises.

\section{Etapas}

- quando solicitado, realizar levantamento de campo e registrar as características intervenientes no projeto, como altura dos edifícios vizinhos e demais informações consideradas pertinentes;

- quando indisponíveis nos softwares utilizados, realizar levantamento das variáveis climáticas de temperatura, umidade relativa, radiação solar, ventos, precipitação, nebulosidade, insolação, iluminância do céu visível para o município, e registrar a fonte de obtenção e a data dos dados preferencialmente deverão atender os requisitos das Normais Climatológicas;

- apresentar:

- simulação da geometria da insolação de forma que se possa avaliar a entrada de radiação direta face às variações horárias e anuais e obstruções externas, sejam brises ou quaisquer elementos sejam edificações do entorno; 
- diagnóstico climático preliminar.

- definir parâmetros para projeto e apresentá-los para subsídio à elaboração do estudo preliminar de arquitetura, como: orientação de fachadas e ambientes em relação à radiação solar, especificação de materiais construtivos, necessidade e características de dispositivos de controle da radiação solar direta nos ambientes, soluções de sombreamento com elementos construtivos ou vegetação, etc;

- sobre o estudo preliminar aprovado pela FDE, que terá considerado em sua análise não só os parâmetros de conforto térmico mas todo o universo de parâmetros intervenientes no projeto:

- realinhar estudos e diagnóstico climático

- apresentar estimativa de consumo energético em função das especificações atuais dos Catálogos Técnicos da FDE quanto às cargas referentes à ocupação, edificação e equipamentos, demonstrando a otimização do consumo energético pela relação entre o controle da radiação solar proposto e o uso da iluminação artificial definida nos Catálogos;

- realimentar o estudo preliminar aprovado de modo a reaproximá-lo dos parâmetros iniciais, com propostas que possam interagir com as demais condicionantes no desenvolvimento do anteprojeto;

- sobre o anteprojeto aprovado pela FDE, que terá considerado em sua análise não só os parâmetros de conforto térmico mas todo o universo de parâmetros intervenientes no projeto:

- realinhar estudos e diagnóstico climático

- elaborar representação gráfica dos dispositivos de controle de radiação direta, determinar os ganhos de calor solar pela envoltória, considerando a geometria e especificações dos materiais;

- realimentar o anteprojeto aprovado de modo a reaproximá-lo dos parâmetros iniciais, com propostas que possam interagir com as demais condicionantes no desenvolvimento do projeto executivo;

- sobre o projeto executivo aprovado pela FDE, que terá considerado em sua análise não só os parâmetros de conforto térmico mas todo o universo de parâmetros intervenientes no projeto, elaborar diagnóstico climático conclusivo, determinar os ganhos de calor solar pela envoltória, considerando a geometria e especificações dos materiais;

- elaborar e apresentar resultados de simulação do desempenho térmico e luminoso bem como estimativa do consumo de energia elétrica que deverá ocorrer na fase de uso da edificação. 
- concluído o projeto executivo, a Contratada deverá produzir Memorial contendo todos os produtos da consultoria, bem como a demonstração do processo de priorização de parâmetros de projeto que gerou o produto final.

- O edifício pós-ocupado será avaliado e serão checadas as condições de conforto térmico.

\subsection{Roteiro para análise de relatórios técnicos de consultoria em conforto ambiental}
Este roteiro destina-se ao uso do analista da FDE que deve avaliar o relatório entregue pelo consultor e apresentar suas observações, e está reproduzido conforme

\subsubsection{Conforto térmico}

\section{Diretrizes}

O profissional consultor deverá subsidiar a elaboração do projeto em todas as suas etapas (estudo preliminar, anteprojeto e projeto executivo), visando assegurar o conforto térmico dos usuários e minimizar o consumo de energia elétrica na fase de uso da edificação, priorizando a adoção de sistemas passivos, conformes às especificações dos Catálogos Técnicos da FDE e com baixo custo de implantação e manutenção, considerando que o edifício terá seu desempenho térmico e energético avaliado quando ocupado. Para tanto deverá:

- evitar radiação solar direta e aproveitar a radiação indireta;

- racionalizar o uso de energia elétrica conciliando com arquitetura o aproveitamento máximo da iluminação natural, garantidos os índices de luminosidade;

- as soluções de projeto deverão ser equacionadas pelo arquiteto e o consultor em todos os seus aspectos:

- tipo de solução - brise, beiral, marquise, marquises, pérgulas, cobogós, prateleiras de luz, vegetação, etc

- tipo de material - tela, telha perfurada, siporex, elemento vazado, componentes, alvenarias, etc...

Realimentar o projeto tantas vezes quanto for necessário até chegar aos níveis de Norma, já que os parâmetros de conforto integram o processo de equacionamento de um conjunto de fatores.

Considerar as particularidades do edifício escolar:

- apresentar alternativas coerentes com a especificidade da Obra Pública e portanto considerar as questões de custo x benefício de implantação, conservação e manutenção, inclusive substituição, além da resistência ao vandalismo;

- explorar ao máximo as soluções criativas que possam ser incorporadas à Arquitetura, prescindindo de materiais sofisticados;

- focar nas carteiras e lousas como planos de trabalho a proteger da radiação direta e a iluminar ao máximo com luz natural, garantindo condições de luminosidade adequadas de 
brilho e contraste de forma que as sombras produzidas não formem desenhos regulares como bolinhas, quadradinhos, ...

- avaliar a relevância da proteção à insolação x uso do edifício (horários de aula / tipos de atividade / periodo de férias, etc);

\section{Relatório:}

O relatório deverá conter:

Mapa do Google localizando o terreno para Obras Novas;

ou

Mapa do Google localizando o terreno + escola existente para Ampliações e/ou Adequações;

Implantação geral: transportar do levantamento topográfico: norte verdadeiro / latitude / longitude;

Planta de todos os pavimentos;

Cortes longitudinais e transversais que sejam significativos para a situação estudada.

Levantamento fotográfico

\section{DADOS DO ENTORNO}

Identificar atenuantes e agravantes:

- conformação topográfica e geográfica do sítio

- edificações: altura / perímetro

- vegetação

\section{Dados climáticos}

Informar a fonte dos dados climáticos utilizados nos cálculos / simulações, por exemplo:

- carga térmica $(\mathrm{W})$

- intensidade de radiação solar $\left(\mathrm{W} / \mathrm{m}^{2}\right)$

- temperaturas: média (mensal / anual / ...) / dia típico mais quente / dia típico mais frio $\left({ }^{\circ} \mathrm{C}\right)$

- radiação solar direta e indireta / planos horizontal e vertical $\left(\mathrm{W} / \mathrm{m}^{2}\right)$

- umidade relativa UR (\%)

- ventos dominantes (observar e informar influência do microclima) $(\mathrm{km} / \mathrm{h})$

- precipitação $(\mathrm{mm} / \mathrm{t})$

- nebulosidade (0-10)

- iluminância do céu visível $\left(\mathrm{W} / \mathrm{m}^{2}\right)$

- potência de equipamentos (W)

- outras

\section{Diagnóstico climático preliminar}

relação das Normas e Legislação intervenientes método de análise e processamento dos dados climáticos em relação ao edifício modelos 2D (por ex, cartas solares) e 3D resultantes das simulações relacionadas à geometria da insolação

máscaras preliminares de obstrução externa em função das edificações existentes ganhos e perdas de calor solar pela envoltória, considerando o edifício proposto e as especificações dos materiais;

indicar software utilizado 


\section{Recomendações}

orientação de fachadas e ambientes em relação à radiação solar;

necessidade e características de dispositivos de controle da radiação solar direta nos ambientes;

especificações dos materiais construtivos: dimensões, desempenho térmico, ......;

soluções de sombreamento com elementos construtivos ou vegetação, brises / telas / marquises / beirais; horizontais / verticais; ângulo de inclinação; ....

\section{DIAGNÓSTICO CLIMÁTICO CONCLUSIVO}

Resultados de simulação do desempenho térmico e luminoso do projeto

Estimativa do consumo de energia elétrica que deverá ocorrer na fase de uso da edificação

Memória de Cálculo

Encerra todos os produtos da consultoria, bem como a demonstração do processo de priorização de parâmetros de projeto que gerou o produto final. Permite acompanhar, compreender e analisar passo a passo o trabalho realizado, ao demonstrar a eficiência e desempenho das soluções apresentadas. Consiste da descrição do processo técnico que levou aos resultados apontados, o que inclui:

métodos adotados para propor soluções;

cálculos propriamente ditos;

reprodução de imagens das simulações;

resultado das simulações que geraram alternativas e justificar alternativa adotada;

demonstração do dimensionamento dos elementos de proteção solar a partir dos estudos de insolação e iluminamento;

resultado da simulação da solução de projeto adotada demonstrando a conformidade do desempenho e eficiência;

software(s) utilizado(s);

outros.

\subsubsection{Conforto Acústico}

Mapa do google localizando o terreno (on) / terreno + escola (ampli/adeq)

Mapa do google localizando a escola e a(s) fonte(s) de ruído

Implantação geral

Planta de todos os pavimentos

Cortes longitudinais e transversais que sejam significativos para a situação estudada

No caso de zaps (zonas aeroportuárias)

Mapa das curvas de ruído i e ii * contendo:

- terreno e/ou escola

- limite da zona da Ipuos (legislação de proteção, uso e ocupação do solo = zoneamento) do município em questão

- Indicar a fonte do mapa, ex: infraero / prefeitura municipal / portaria dac / anac, com data em que foi elaborado, fonte de consulta - ex: internet, prefeitura, publicação [qual])

- Indicar a Ipuos consultada

Checar se a curva utilizada pelo profissional é a curva indicada pelo planejamento nas instruções para projeto.

Levantamento fotográfico 
Dados do entorno

Identificar atenuantes e agravantes:

- Conformação topográfica do sítio

- Edificações

- Vegetação (se significativa para atenuar sons)

Medições in loco

Ambientes que dispensam isolamento acústico externo: galpão / quadra de esportes / banheiro / depósito / cozinha / despensa / refeitório

Critérios adotados: dia da semana / horários (dia - noite) / intervalo entre medições / identificar horário de pico de ruído e relacionar ao horário de funcionamento e às atividades da escola

Tabela das medições

Memória das medições - todas as informações necessárias para seu entendimento. Exs:

Critério de escolha e representação das posições de medição em relação à fonte de ruído

Método de medição: por faixas de frequência / por nível equivalente - justificar Especificações do aparelho que deverá medir pressão sonora por faixa de frequência ("graves e agudos"). Exs:

Ruídos externos: tipos

Ruídos internos:

Sala de aula: voz humana

Quadra de esportes: bola / atividade física = impacto

Certificado de calibração do medidor de pressão sonora utilizado

Análise

Relação das normas e legislação intervenientes;

Análise dos resultados das medições;

Confrontação com as exigências das normas / legislação;

Alternativas para chegar aos níveis da norma dentro dos ambientes: quanto isolar / quanto absorver / relacionando: fonte - ambiente

Recomendações

As alternativas devem ser coerentes com a especificidade da obra pública e portanto considerar as questões de custo $\mathrm{x}$ benefício de implantação e manutenção, inclusive substituição / vandalismo.

Explorar ao máximo, soluções que possam ser incorporadas à arquitetura, propondo soluções "criativas" que prescindam de materiais sofisticados.

Realimentar o projeto tantas vezes quanto for necessário até chegar ao nível de norma.

Alternativas na forma de tabela, relacionando:

Nível medido - nível pretendido - material - solução construtiva - quanto cada material atenua, para cada combinação possível de materiais e soluções construtivas

(inserir tabela-exemplo)

Representação gráfica de todas as soluções apresentadas.

Recomendações para projeto:

Implantação mais favorável / materiais / tipologia / gabarito / vegetação (se significativa)

Quadra: não pode se tornar uma fonte de ruído para a escola e para o entorno. 
Sala de aula: isolar entrada de ruído e atenuar a reverberação

Outros

"memória de cálculo"

Permite acompanhar, compreender e analisar passo a passo o trabalho realizado. Desta forma, adicionalmente, o relatório final conterá a demonstração da eficiência e desempenho das soluções apresentadas para registrar o processo. Consiste da descrição do processo técnico que levou aos resultados apontados nos relatórios, o que inclui:

Métodos adotados para propor soluções;

Cálculos propriamente ditos;

Reprodução de imagens das simulações;

Resultado das simulações que geraram alternativas e justificar alternativa adotada;

Resultado da simulação da alternativa de projeto adotada demonstrando a conformidade do desempenho e eficiência;

Software(s) utilizado(s);

Outros.

Diretrizes mais específicas que permitam maior controle.

\subsection{Catálogos Técnicos da FDE: aspectos incorporados}

A seguir são mostradas imagens das Normas de Apresentação de Projetos, Modelo de Edital de Licitação e Catálogos Técnicos, em que há inserções relacionadas a Conforto Ambiental, demonstrando a apropriação que vem sendo feita dos conceitos, exemplos do que se fez nos últimos 3 anos.

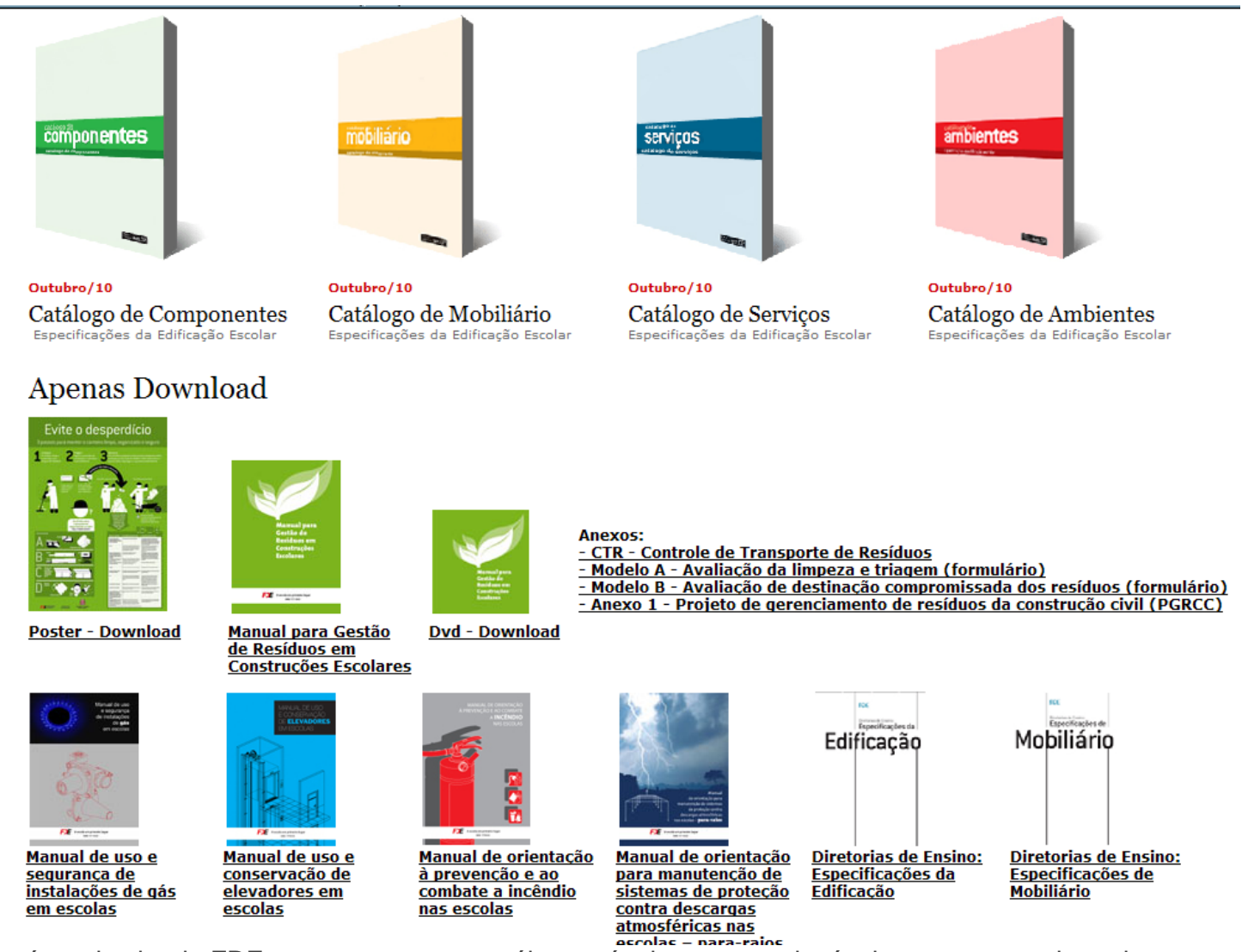

Figura 66 - área do site da FDE para acesso aos catálogos técnicos, manuais técnicos e normas de projetos 


\section{acessibilidade}

NBR 9.050 Acessibilidade a edificações, mobiliário, espaços e equipamentos urbanos: estabelece critérios e parâmetros técnicos a serem observados em projetos, construções, instalações e adaptações de edificações, mobiliário, espaços e equipamentos urbanos às condições de acessibilidade.

\section{apresentação de projetos}

NBR $\quad 6.492$ Representação de projetos de arquitetura

NBR $\quad 7.191$ Execução de desenhos para obras de concreto simples ou armado

NBR $\quad 13.531$ Elaboração de projetos de edificações Atividades técnicas

NBR $\quad 13.532$ Elaboração de projetos de edificações Arquitetura

NBR 10.151/00 Acústica: Avaliação do ruído em áreas habitadas, visando o conforto da comunidade

NBR $\quad$ 10.152/87 Níveis de ruído para conforto acústico

NBR 15.215-1 lluminação natural - Parte 1: Conceitos básicos e definições

NBR 15.215-2 Iluminação natural-Parte 2 Procedimentos de cálculo para a estimativa da disponibilidade de luz natural

NBR 15.215-3 Iluminação natural-Parte 3 Procedimento de cálculo para a determinação da iluminação natural em ambientes internos

NBR 15.215-4 Iluminação natural-Parte 4 Verificação experimental das condições de iluminação interna de edificações - Método de medição

NBR 15.220-1 Desempenho térmico de edificações - Parte 1: Definiçōes, símbolos e unidades

NBR 15.220-2 Desempenho térmico de edificações - Parte 2: Métodos de cálculo da transmitância térmica, da capacidade térmica, do atraso térmico e do fator solar de elementos e componentes de edificações (+ errata)

NBR

15.220-3 Desempenho térmico de edificações - Parte 3: Zoneamento bioclimático brasileiro e diretrizes construtivas para habitações unifamiliares de interesse social

NBR 15.220-4 Desempenho térmico de edificações - Parte 4: Medição da resistência térmica e da condutividade térmica pelo princípio da placa quente protegida

NBR 15.220-5 Desempenho térmico de edificaçōes - Parte 5: Medição da resistência térmica e da condutividade térmica pelo método fluximétrico

NBR 15.575-1 Edifícios habitacionais de até cinco pavimentos - Desempenho - Parte 1: Requisitos gerais

NBR 15.575-2 Edifícios habitacionais de até cinco pavimentos - Desempenho - Parte 2: Requisitos para os sistemas estruturais

NBR 15.575-3 Edifícios habitacionais de até cinco pavimentos - Desempenho - Parte 3 : Requisitos para os sistemas de pisos internos

NBR 15.575-4 Edifícios habitacionais de até cinco pavimentos - Desempenho - Parte 4: Sistemas de vedaçōes verticais externas e internas

NBR 15.575-5 Edifícios habitacionais de até cinco pavimentos - Desempenho - Parte 5: Requisitos para sistemas de coberturas

NBR 15.575-6 Edifícios habitacionais de até cinco pavimentos - Desempenho - Parte 6: Sistemas hidrossanitários

NBR 5.382:1985 Verificação de iluminância de interiores

NBR 5.413:1992 \|uminância de interiores

NBR 5.461:1991 Iluminação

\section{estrutura e fundações}

NBR $\quad 6118$ Projeto de estruturas de concreto: Procedimento;

NBR $\quad 6120$ Cargas para o cálculo de estruturas de edificações;

NBR $\quad 6122$ Projeto e execução de fundações: 


\begin{abstract}
Legislação Estadual
Decreto n. ${ }^{\circ} 12342$, de 27/09/78 - CÓDIGO SANITÁRIO ESTADUAL - dispõe sobre normas de saneamento básico e de saneamento das edificações, normas gerais e específicas das edificações, inclusive das edificações destinadas a ensino (prédios escolares), no âmbito do Estado de São Paulo.
\end{abstract}

Resolução SS-493, de 08/09/94 - aprova a Norma Técnica que dispõe sobre a elaboração de projetos de edificações de escolas de $1^{\circ}$ e $2^{\circ}$ graus no âmbito do Estado de São Paulo. Considerando a necessidade das edificações escolares darem atendimento às exigências mínimas de conforto, higiene, segurança, iluminação e ventilação dos ambientes, considerando a necessidade de fixar princípios de bem-estar social tantos para alunos como para trabalhadores da rede de ensino. Contém a terminologia, as condições gerais, o programa escolar, o dimensionamento dos ambientes que integram a edificação escolar.

\title{
LEGISLAÇĀO AMBIENTAL
}

Legislação Municipal

SCM - Sistema Cartográfico Metropolitano - são bases cartográficas executadas através de levantamento foto aéreo, onde estão registradas edificações existentes desde 1976, córregos, represas (com os respectivos maximorum), nascentes, curvas de nível, matas nativas, ferrovias, arruamentos e o limite das categorias de uso.

As cartas auxiliam na análise crítica do terreno ainda no estágio de sua viabilização (etapa de Estudo Preliminar), visando a identificação dos recursos naturais a menos de $30,00 \mathrm{~m}$ do lote e a definição da classe e categoria em que o mesmo está inserido.

Lei Municipal 10.365 de 22/09/1987 regulamentada pelo Decreto Municipal 26.535 de 03/08/1988 disciplinam o corte e a poda de vegetação de porte arbóreo, na Capital.

É considerada vegetação de porte arbóreo aquela composta por espécies vegetais lenhosos com diâmetro do caule à altura do peito - DAP (h aproximadamente $1,30 \mathrm{~m}$ do solo) superior a $5 \mathrm{~cm}$.

\section{Portaria 127/SMMA.G/2002}

Instrui os processos de supressão de vegetação junto à SVMA. Relaciona a documentação que deverá ser apresentada para o licenciamento ambiental.

Portaria SVMA 09/2005 - substitui a portaria 26/SVMA.G/2004.

Disciplina os critérios e procedimentos de compensação ambiental pela remoção: por corte, transplante, ou qualquer outra intervenção, de caráter excepcional, de vegetação de porte arbóreo para viabilização de projeto de edificação parcelamento do solo e obras de infra estrutura e em casos de interesse público e/ou social.

Lei Municipal $\mathrm{n}^{\circ} 13.136$ de 09/06/2001 e regulamentação Decreto 13.706 de 06/01/2004

Criação da APA Capivari Monos.

Lei Municipal n 14.459 de 03/07/2007 - Acrescenta o item 9.3 .5 à Seção 9.3 Instalações Prediais do Anexo da Lei n 11.228, de 25 de junho de 1992 (Código de Obras e Edificações)

Dispõe sobre a instalação de sistema de aquecimento de água por energia solar 
A FDE, de maneira geral, contrata projetos executivos completos para os seguintes objetos:

Obra Nova

Obra Nova projeto padrãol

Ampliação / Adequação de prédios existentes

Ampliação / Adequação em prédios de interesse histórico

Adequação à NBR9050: Acessibilidade

equipes

As equipes de trabalho consistem basicamente da seguinte formação:

Coordenador do projeto: função do arquiteto contratado em relação aos projetistas das demais áreas técnicas, que assegure a compatibilização dos projetos e o cumprimento do cronograma contratual

Coordenador da análise: função do arquiteto da FDE em relação aos analistas das demais áreas técnicas

Gestor do contrato: $\quad$ função do arquiteto da FDE coordenador da análise, no sentido de fazer cumprir o cronograma e demais termos contratuais

\section{áreas técnicas}

O projeto completo é composto pelos projetos específicos compatibilizados entre si.

Os projetos da FDE organizam-se em 4 áreas técnicas principais, complementadas por áreas técnicas a elas relacionadas:

\begin{tabular}{lcc} 
Áreas técnicas principais & código & nomenclatura digital \\
\hline Arquitetura & ARQ & A \\
Estrutura & EST & E \\
Elétrica & ELE & L \\
Hidráulica & HID & H
\end{tabular}
\begin{tabular}{lcccc} 
Áreas técnicas relacionadas & código & nomenclatura digital & área principal \\
\hline Levantamento Planialtimétrico & TOP & $T$ & (ARQ)
\end{tabular}

Avaliação Pós-Ocupação

TOP $\quad$ T (ARQ)

Conforto Ambiental Térmico

APO A

(ARQ)

Conforto Ambiental Acústico

CFT

(ARQ)

Conforto Ambiental Luminoso

CFA

Luminotécnica

CFL

LMT

Mobiliário

$M O B$

Paisagismo

Planejamento

PAI

PLA

Restauro

Terraplenagem

RES

Sondagem

Incêndio

TER

SDG

(ARQ)

(ARQ)

(ARQ)

(ARQ)

(ARQ)

(ARQ)

(ARQ)

(ARQ)

(EST)

Projeto Padrão: projeto executivo completo de prédio escolar nas áreas técnicas de arquitetura, estrutura, hidráulica
e elétrica, desenvolvido ou formatado para reimplantação em diversos terrenos. Há dois tipos de projeto padrão: bloco
único (projeto do edificio completo) e blocos componiveis (projeto de módulos de ambientes ou conjuntos de ambientes
que justapostos compõem edifícios completos). 


\section{etapas de projeto}

Para cada área técnica estão previstas etapas que deverão ser cumpridas até que seja alcançado o objetivo final do projeto completo, que é a definição de todas as informações necessárias e suficientes para a realização da obra.

As etapas de projeto e etapas complementares ao projeto podem ser as seguintes, determinadas pela FDE a cada objeto:

$\begin{array}{lc}\text { Etapas de Projeto } & \\ \text { Estudo preliminar } & \text { EP } \\ \text { Anteprojeto } & \text { AP } \\ \text { Projeto executivo } & \text { PE } \\ \text { Etapas complementares ao Projeto } & \\ \text { Auto de Vistoria do Corpo de Bombeiros } & \text { AV } \\ \text { Cadastro } & \text { CD } \\ \text { Levantamento Cadastral } & \text { LC } \\ \text { Levantamento Fotográfico } & \text { LF } \\ \text { Memorial de Cálculo } & \text { MC } \\ \text { Memorial de Restauro } & \text { MR } \\ \text { Memorial Descritivo } & \text { MD } \\ \text { Projeto de Acústica } & \text { PA } \\ \text { Pasta de Bombeiros } & \text { PB } \\ \text { Parecer de Vegetação } & \text { PV } \\ \text { Parecer Técnico de consultoria (solos, conforto ambiental) } & \text { PT } \\ \text { Projeto de Drenagem } & \text { PD } \\ \text { Relatório Técnico de vistoria } & \text { RT } \\ \text { Teste de Absorção } & \text { TA } \\ \text { Relatório de Vistoria à Obra } & \text { VO }\end{array}$

\section{fluxo de projeto}

Os projetos de Obra Nova e Ampliação e Adequação seguem de forma genérica o seguinte fluxo:

\section{Estudo Preliminar}

\section{Arquitetura}

Realização de Vistoria

Elaboração de Relatório Técnico de Vistoria / Levantamento Fotográfico

Elaboração de Estudo preliminar

Reunião de Estudo Preliminar

\section{Arquitetura + FDE}

Análises e reentregas para revisão até aprovação do Estudo Preliminar

Hidráulica + Elétrica

Realização de Vistoria
Elaboração de Relatório Técnico de Vistoria / Levantamento Fotográfico

Arquitetura Estrutura, Hidráulica e Elétrica

coordenador

EP

$\mathrm{PE}$

AV

CD

LF

$M C$

$M R$

$P A$

PB

PV

PD

RT

TA

\section{técnicos}

Arquitetura Estrutura, Hidráulica e Elétrica

coordenador + analistas FDE

Solos, Sistema Estrutural e Conforto Ambiental consultores FDE

Realização de Reunião Geral para tratar das interferências entre áreas técnicas, determinar a cota de implantação, orientação de implantação do prédio, entre outros aspectos interdisciplinares. Deverão ser apresentados os estudos aprovados com as intervenções para solução arquitetônica de todas as 
A FDE, de maneira geral, contrata projetos executivos completos para os seguintes objetos:

\section{Obra Nova}

Obra Nova projeto padrão

Ampliação / Adequação de prédios existentes

Ampliação / Adequação em prédios de interesse histórico

Adequação à NBR9050: Acessibilidade

\section{equipes}

As equipes de trabalho consistem basicamente da seguinte formação:

Coordenador do projeto: função do arquiteto contratado em relação aos projetistas das demais áreas técnicas, que assegure a compatibilização dos projetos e o cumprimento do cronograma contratual

Coordenador da análise: função do arquiteto da FDE em relação aos analistas das demais áreas técnicas

Gestor do contrato: função do arquiteto da FDE coordenador da análise, no sentido de fazer cumprir o cronograma e demais termos contratuais

\section{áreas técnicas}

O projeto completo é composto pelos projetos específicos compatibilizados entre si.

Os projetos da FDE organizam-se em 4 áreas técnicas principais, complementadas por áreas técnicas a elas relacionadas:

\begin{tabular}{lcc} 
Áreas técnicas principais & código & nomenclatura digital \\
\hline Arquitetura & ARQ & A \\
Estrutura & EST & E \\
Elétrica & ELE & L \\
Hidráulica & HID & H
\end{tabular}

\begin{tabular}{lccc} 
Áreas técnicas relacionadas & código & nomenclatura digital & área principal \\
\hline Levantamento Planialtimétrico & TOP & T & (ARQ) \\
Avaliação Pós-Ocupação & APO & A & (ARQ) \\
Conforto Ambiental Térmico & CFT & A & (ARQ) \\
Conforto Ambiental Acústico & CFA & A & (ARQ) \\
Conforto Ambiental Luminoso & CFL & A & (ARQ) \\
Luminotécnica & LMT & A & (ARQ) \\
Mobiliário & MOB & M & (ARQ) \\
Paisagismo & PAI & P & (ARQ) \\
Planejamento & PLA & U & (ARQ) \\
Restauro & RES & R & (ARQ) \\
Terraplenagem & TER & A & (ARQ) \\
Sondagem & SDG & S & (EST) \\
Incêndio & INC & I & (HID)
\end{tabular}

${ }^{1}$ Projeto Padrão: projeto executivo completo de prédio escolar nas áreas técnicas de arquitetura, estrutura, hidráulica e elétrica, desenvolvido ou formatado para reimplantação em diversos terrenos. Há dois tipos de projeto padrão: bloco único (projeto do edifício completo) e blocos componíveis (projeto de módulos de ambientes ou conjuntos de ambientes que justapostos compõem edifícios completos). 


\section{A escola como obra pública}

Projetar a escola estadual deve ter por diretriz fundamental o seu caráter de obra pública, o que implica equacionar a boa técnica à racionalização de recursos públicos e ao atendimento das solicitações e diretrizes da FDE, que por sua vez executa as políticas públicas da Secretaria de Estado da Educação.

A primeira atividade do arquiteto contratado para elaborar o projeto de uma escola estadual, será conhecer o local da implantação. Nesta visita, sobretudo, seu olhar deverá apreender a conformação física do terreno e as características do entorno, procurando vislumbrar in loco o partido que permita implantação compatível àquele terreno e por isto demande o menor movimento de terra, mas que também qualifique o tecido urbano pela inserção do edifício escolar. Pela sua escala e tipologia de referência urbana, o prédio deverá apresentar identidade de obra pública e estabelecer um diálogo respeitoso com as edificações do entorno, despertando na comunidade o senso de pertencimento.

\section{As áreas livres}

Todo o lote deverá ser considerado área de projeto, devendo, portanto, ser qualificado em toda sua extensão.

Os espaços externos e internos deverão estar integrados pela criação de relações de fluxo, seja através de aberturas, transparências, ou quaisquer possibilidades visuais ou físicas.

Uma generosa parcela da área externa deverá ser reservada para uso recreativo, na forma de pátio descoberto. Este pátio, contíguo ao pátio coberto, deverá recriar o espaço de uma pequena praça pública com bancos, árvores, mesa para xadrez ou qualquer outra possibilidade lúdica; as árvores devem possibilitar o sombreamento e ter florações diversas durante o ano, alternando as cores. Este espaço deve ser isolado do acesso administrativo, de forma que estes fluxos sejam completamente independentes, e deve ser priorizado em relação a qualquer outra área externa.

\section{O prédio}

A concepção do edifício deverá garantir o bem-estar e a segurança da criança ou do adolescente que virão a ser os principais usuários. Neste sentido o prédio escolar deve ser agradável e acolhedor; deve oferecer ambientes adequados ao desenvolvimento de atividades intelectuais, criativas, físicas e sociais.

A escola deverá ser acessível a quaisquer indivíduos, independente de restrições em sua mobilidade, em atendimento à NBR9050/2004 Acessibilidade a edificações, mobiliário, espaços e equipamentos urbanos.

A distribuição dos ambientes deverá articular três funções básicas: administrativa/de serviços, vivência e pedagógica, propiciando o encontro das pessoas e a interpenetrabilidade dos espaços, sem no entanto comprometer a privacidade das atividades, criando eixos claros de circulação que organizem o fluxo.

O edifício como um todo deverá incentivar o aluno e despertar-lhe para o aprendizado. $\bigcirc$ uso de cores estimulantes nas áreas de vivência pode contribuir para essa finalidade, assim como o uso de cores claras nos ambientes pedagógicos favorecendo a acuidade visual.

As decisões de projeto deverão dispensar manutenção a curto prazo. Os elementos construtivos, inclusive os componentes e serviços FDE, deverão ser repetidos ao máximo no sentido da racionalização da construção, evitando-se exceções e adapłações, mas ao mesmo tempo produzindo um edifício único em sua riqueza formal, funcional e espacial.

Por fim, as premissas de projeto deverão estar conciliadas aos critérios socioambientais, o que implica buscar a otimização do desempenho térmico, acústico, luminoso e energético do edifício como um dos critérios de projeto, constituindo-se o próprio edifício em modelo educativo de consciência ambiental.

\section{Ampliações e adequações}

Nas Ampliações e Adequações de prédios existentes, conciliar o atendimento destes itens às limitações da solicitação e às características do existente.

\section{Restauro}

Para prédios existentes de interesse histórico, conciliar o atendimento dos itens anteriores à recuperação dos elementos construtivos originais sempre que possível, e à elaboração de propostas de funcionamento satisfatórias. 


\section{diretrizes de projeto}

O Estudo Preliminar de Arquitetura deve mostrar graficamente o partido arquitetônico adotado em função das características específicas de cada terreno, bem como do programa estabelecido para cada escola.

Em projetos de Ampliação / Adequação, conciliar as características específicas de cada intervenção às interfaces entre os edifícios novos e existentes.

Será analisado pelos técnicos da FDE que irão verificar a conformidade do projeto às diretrizes estabelecidas nos Catálogos Técnicos, às normas técnicas e à legislação vigente, bem como para evitar custo elevado de obra e/ou manutenção.

Além das diretrizes fundamentais, o Estudo Preliminar deverá atender os seguintes itens:

\section{Edifício}

Adensar a área construída prevendo área para ampliação futura

Atentar para que a área construída se aproxime da área de programa

Considerar a previsão de ampliação futura ao locar e dimensionar escadas, rampas e elevadores, liberando a circulação para o acoplamento a novo bloco em continuidade ao existente

Evitar blocos de alturas diferentes que gerem relações visuais diretas entre ambientes internos e coberturas

Utilizar a modulação $90 \mathrm{~cm} \times 90 \mathrm{~cm}$ medidas de eixo a eixo

Optar preferencialmente por coberturas de duas águas com vigas-calhas em concreto, impermeabilizadas, conformando beirais com projeção externa aos ambientes

Não utilizar calhas centrais

Evitar lajes impermeabilizadas

Racionalizar as descidas de águas pluviais

Racionalizar a distribuição do caminhamento da tubulação de hidráulica, elétrica e incêndio, concentrando descidas e áreas molhadas, inclusive sala de uso múltiplo, em prumadas únicas ou no mesmo setor do edifício

Adotar vedos em alvenaria de blocos de concreto

Racionalizar soluções de fechamento

A circulação entre blocos de uma mesma unidade escolar deverá ser coberta

\section{Conforto ambiental e conservação de energia}

Garantir afastamentos de, no mínimo, 7,20m entre edifícios para que não sejam prejudicadas a aeração e a insolação dos ambientes de uso prolongado;

Equilibrar as perdas e ganhos de calor através da orientação adequada da edificação, do aproveitamento dos ventos dominantes para ventilação natural, do dimensionamento de vãos e vedos e da especificação dos materiais. Recomendam-se genericamente as orientações Norte-Nordeste ou Leste para ambientes pedagógicos, associadas à proteção solar adequada

Evitar radiação solar direta e aproveitar a radiação indireta, modulando-as através de brises, beirais, marquises, pérgulas horizontais, cobogós, prateleiras de luz. Demonstrar o dimensionamento destas peças a partir de estudos específicos de insolação e iluminamento.

Maximizar o uso de iluminação natural sobre a artificial

Garantir que os ruídos produzidos nos diversos ambientes, sobretudo no pátio 


\begin{tabular}{|c|c|c|c|}
\hline Código & Nome da escola & Município & \\
\hline & & ISTORIA & $\begin{array}{l}\text { DESENVOLVMENTO } \\
\text { DA EDUCAÇÁO }\end{array}$ \\
\hline
\end{tabular}

Alunos com necessidades especiais (sim ou não / quantos / quais necessidades)

Há algum acesso da escola que não seja utilizado? (sim ou não / motivo)

Inundação

Indicar perímetro da área atingida no croquis à direita

Altura

Data da última ocorrência

$N^{\circ}$ ocorrências nos últimos anos

Segurança

$\square$ Invasão

Furto ou roubo

Depredação

Conforto ambiental (problemas de conforto térmico / acústico / de iluminação, onde)

\section{Outras observações}

\begin{tabular}{|c|c|c|}
\hline Cargo funcional / Nome / órgão & & Assinatura \\
\hline Cargo funcional / Nome / órgão & & Assinatura \\
\hline Cargo funcional / Nome / órgão & & Assinatura \\
\hline Responsável pela vistoria & CREA & Assinatura \\
\hline Escritório contratado & CREA & data da vistoria \\
\hline
\end{tabular}


ANEXO - III

\section{IN STRUÇO̊̄ES PARA ELABORAÇÃO DO PROJETO: GERAIS E ESPECIFICAS}

\section{IN STRUÇÖES GERAIS}

O projeto objeto deste contrato deverá ser elaborado com vistas à obtençăo da soluçăo espacial e estetica com qualidade, durabilidade e economia da obra, apresentando conforto ambiental, facilidade de manutençáo a baixo custo, segurança dos alunos, segurança contra invasóes e limitar-se a ärea estabelecida em programa.

Além disto, devem ser considerados os seguintes aspectos:

1.1 Legislaçăo

Os trabalhos deverăo ser realizados de acordo com as normas técnicas, em estrita observáncia às legislaçóes Federal, Estadual e Municipal e a quaisquer ordens ou determinaçóes do poder público. notadamente:

- Catálogos Técnicos e Normas de Apresentaçăo de Projetos da FDE, disponibilizados no site www.fde.sp.gov.br:

- restricóes municipais, inclusive a Lei n $13.276,04$ de janeiro de 2002 para o caso das escolas no municipio de Säo Paulo, referente a reservatório para as aguas coletadas;

- Decreto Estadual 46.076/01 relativo ao sistema de proteçăo e combate a incêndio;

- NBR9050 relativa ao atendimento de pessoas portadoras de necessidades especiais, sendo que para a circulaçáo vertical dos edificios poderảo ser adotadas rampas elou elevador;

- legis laçăo ambiental no que diz respeito à área de proteçăo aos mananciais, supressăo de vegetaçăo e interferéncias em áreas de proteçào permanente.

Será responsabilidade da contratada a aprovaçăo do projeto junto ao Corpo de Bombeiros e, sempre que pertinente, junto aos örgáos determinados pela legislaçáo ambiental. Aprovacóes junto à Prefeitura Municipal teráo sua eventual exigéncia indicada no item 2. deste Anexo Ifl intitulado Instruçöes Especificas.

Todas as pranchas, relatórios, memórias, deverăo ser enviados assinados de acordo com os padróes de assinatura digital definidos pelo ITI para a ICP-Brasil. A assinatura digital do documento deve estar de acordo com o DOC-ICP-15"Assinaturas Digitais ICP-Brasil", e conforme especificaçáo do ITI presente neste documento, deve seguir padrăo CMS-CADES de assinatura.

1.2 Custo

- Sempre que possível, optar por soluçóes compactas:

- Considerar as caracterísficas do solo, fornecidas na sondagem do terreno, para o partido estrutural;

- Minimizar gastos com movimento de terra, reduzindo as áreas de intervençào, compensando os volumes de corte e aterro de forma a minimizar custos com empréstimos elou bota fora;

- Evitar ao máximo a necessidade de muros de arrimo:

- Novos componentese materiais poderăo ser propostos des de que se apresentem como solucóes económicas balizadas nos custos utilizados pela FDE;

- Pode-se optar pelo uso de divisórias leves nas áreas internas da administraçăo, permitindo flexibilidade espacial, bem como reduçäo de custo de fundaçöes;

- Pode-se optar pelo uso de instalaçóes aparentes;

- Estudar a alternativa de projeto que leve em conta a incidència de custo de cada um dos servicos a

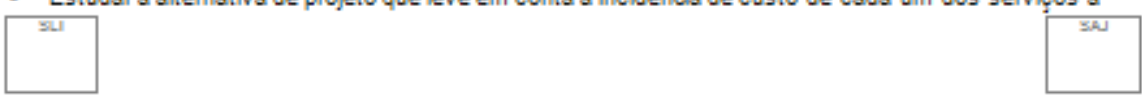

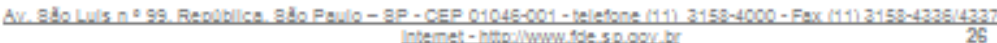

O projeto objeto deste contrato deverá ser elaborado com vistas à obtenção da solução espacial e estética com qualidade, durabilidade e economia da obra, apresentando conforto ambiental, facilidade de manutenção a baixo custo, segurança dos alunos, segurança contra invasões e limitar-se à área estabelecida em programa. 


\begin{tabular}{|l|l|l|}
\hline Edificaçãón & $\begin{array}{l}\text { Diretorias de Ensino: Especifi cações da Edifi cação" estabelece o } \\
\text { programa arquitetônico com base nas atividades efetivamente } \\
\text { desempenhadas nestes centros administrativos, resultado da tabulação de } \\
\text { dados levantados por meio de vistorias e entrevistas. São apresentadas fi } \\
\text { chas individuais de cada ambiente, nas quais estes são caracterizados, sendo } \\
\text { defi nidos layouts com indicação do mobiliário, e plantas de instalações que } \\
\text { trazem elementos de hidráulica, elétrica, iluminação, lógica e telefonia. } \\
\text { catálogo "Estas fi chas defi nem as instalações, as exigências relativas ao } \\
\text { conforto térmico, iluminação, ventilação, acabamentos e complementarmente } \\
\text { a classificação acústica de climatização dos ambientes. }\end{array}$ \\
\hline
\end{tabular}

\section{Apresentação}

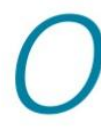

s catálogos que ora apresentamos "Diretorias de Ensino: Especificações da Edificação" e "Diretorias de Ensino: Especificações de Mobiliário", são parte do conjunto de publicações técnicas da FDE destinadas à normalização e orientação para projeto e execucão de edificios. Neste caso em especial, foram sistematizadas informações para arquitetos, projetistas e construtores visando a produção de prédios administrativos da Secretaria de Estado da Educação.

Das go Diretorias de Ensino existentes no Estado, responsáveis pela gestão de mais de 5000 unidades escolares da Rede Estadual, poucas tiveram sua edificação construida e dimensionada segundo suas funções e necessidades essenciais. Esta situação gerou na maioria dos casos, adaptações funcionais e espaciais nem sempre compativeis às inúmeras atividades ali desempenhadas, fato que se agravou com a incorporação nos últimos anos de atividades de capacitação e comunicação ligadas aos programas das "Oficinas Pedagógicas"; do "Núcleo Regional de Tecnologia Educacional - NRTE"; da "Rede do Saber", etc.

Estas duas publicações foram elaboradas com o objetivo de fornecer as informações necessárias para a concepcão de edifícios

funcionalmente adequados, que propiciem melhor eficiência na organização dos espaços, e que ao mesmo tempo atendam às normas técnicas e legislação vigente, com relação a aspectos de acessibilidade, ergonomia, segurança, entre outros.

O catálogo “Diretorias de Ensino: Especificações da Edificação” estabelece o programa arquitetônico com base nas atividades efetivamente desempenhadas nestes centros administrativos, resultado da tabulação de dados levantados por meio de vistorias e entrevistas. São apresentadas fichas individuais de cada ambiente, nas quais estes são caracterizados, sendo definidos layouts com indicação do mobiliário, e plantas de instalações que trazem elementos de hidráulica, elétrica, iluminação, lógica e telefonia. Estas fichas definem as instalações, as exigências relativas ao conforto térmico, iluminação, ventilação, acabamentos e complementarmente a classificação acústica e de climatização dos ambientes.

O catálogo "Diretorias de Ensino: Especificações de Mobiliário" define um sistema de mobiliário corporativo modular para estes prédios administrativos e suas especificações técnicas. São 52 itens que em combinacão permitem a montagem de inúmeros layouts, atendendo às diversas configurações necessárias às atividades.

Estes são apresentados por meio de fichas técnicas que contemplam sua descrição, dimensões, tolerâncias, constituintes e suas características construtivas, determinando ainda requisitos de garantia embalagem, e documentação técnica. 


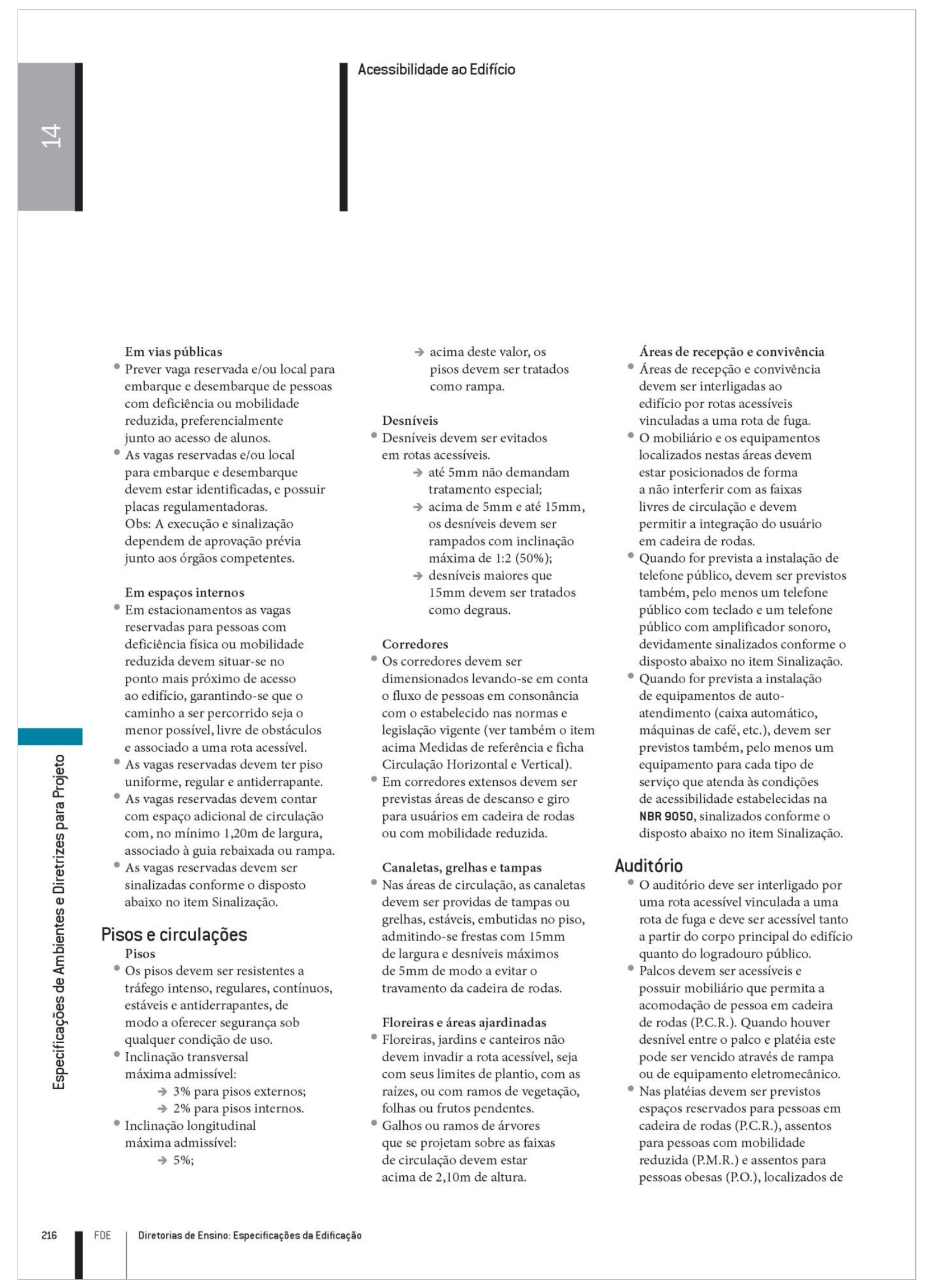




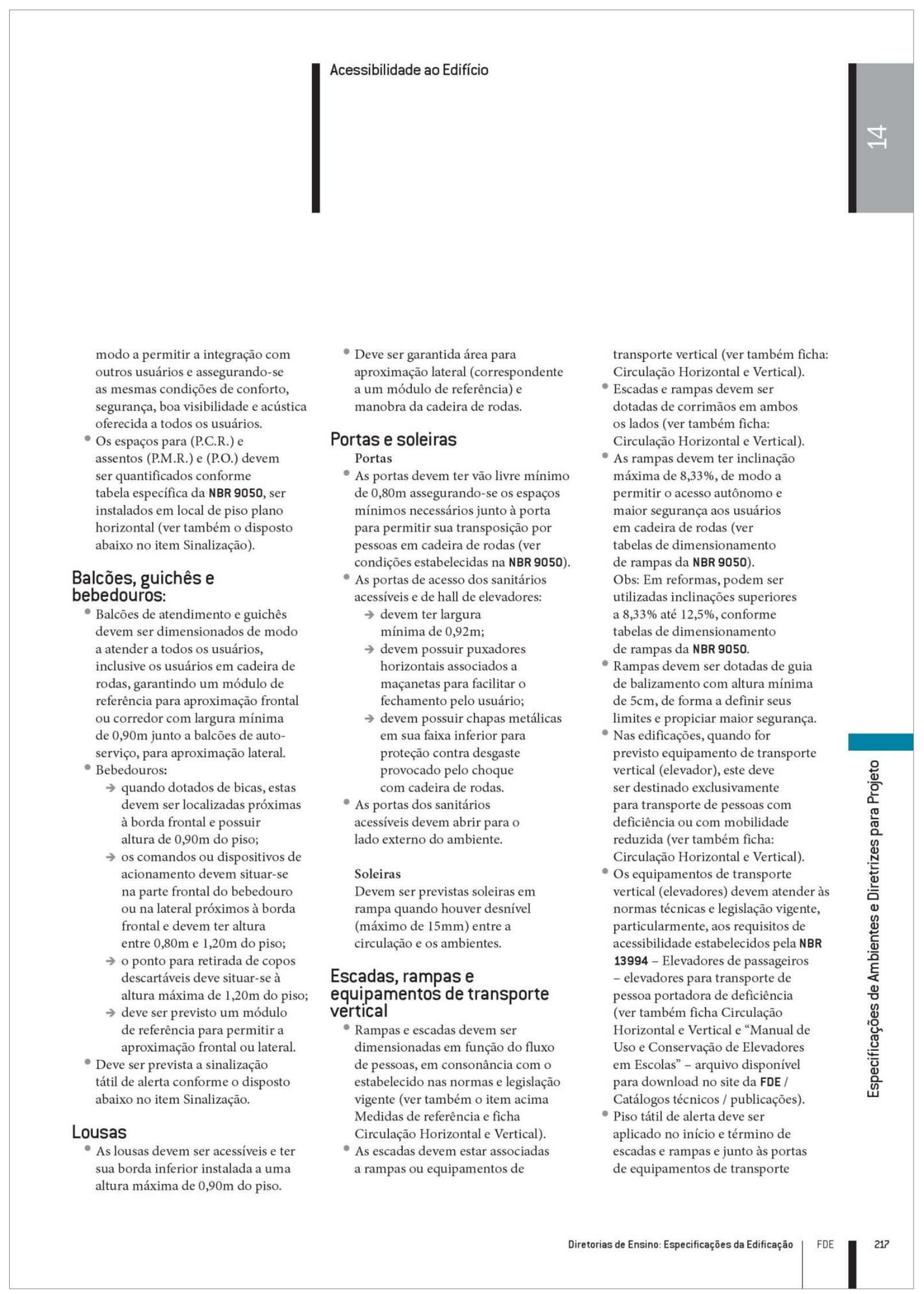

Nas plateias devem ser previstos espaços reservados para pessoas em cadeira de rodas (P.C.R.), assentos para pessoas com mobilidade reduzida (P.M.R.) e assentos para pessoas obesas (P.O.), localizados de modo a permitir a integração com outros usuários e assegurando-se as mesmas condições de conforto, segurança, boa visibilidade e acústica oferecida a todos os usuários. 


\section{Instalações Elétricas}

Diretrizes de Projeto

Os projetos de instalações elétricas devem atender às normas técnicas,

aos catálogos técnicos da FDE, e em especial às recomendações abaixo:

\section{Normas Técnicas}

\begin{tabular}{l|l}
\hline Norma & Descrição \\
\hline NBR 5410 & Instalações elétricas de baixa tensão \\
\hline NBR 5413 & Iluminância de interiores \\
\hline NBR 5598 & Eletroduto de aço-carbono e acessórios, com revestimento protetor e rosca BSP- Requisitos \\
\hline NBR 6150 & Eletroduto de PVC rígido \\
\hline NBR 6323 & Produto de aço ou ferro fundido revestido de zinco por imersão a quente \\
\hline NBR6401 & Instalações centrais de ar condicionado para conforto - Parâmetros básicos de projeto \\
\hline NBR 7285 & $\begin{array}{l}\text { Cabos de potência com isolação extrudada de polietileno termofixo (XLPE) para tensão de 0,6kV/1kV- } \\
\text { Sem cobertura - Especificação }\end{array}$ \\
\hline NBR 9050 & Acessibilidade a edificações, mobiliário, espaços e equipamentos urbanos \\
\hline NBR 9511 & Cabos elétricos - Raios mínimos de curvatura para instalação e diâmetros mínimos de núcleos de carretéis para acondicionamento \\
\hline NBR 10898 & Sistema de iluminação de emergência \\
\hline NBR 13571 & Haste de aterramento aço-cobreada e acessórios \\
\hline NBR 13897 & Duto espiralado corrugado flexível, em polietileno de alta densidade, para uso metroferroviário \\
\hline NBR 13994 & Elevadores de passageiros - Elevadores para transporte de pessoa portadora de deficiência \\
\hline NBR 14039 & Instalações elétricas de média tensão de 1,0 kV a 36,2 kV \\
\hline NBR IEC 60439-1 & $\begin{array}{l}\text { Conjuntos de manobra e controle de baixa tensão - Parte 1: Conjuntos com ensaio de tipo totalmente testados (TTA] e conjuntos com } \\
\text { ensaio de tipo parcialmente testados (PTTA) }\end{array}$ \\
\hline NBR NM 207 & Elevadores elétricos de passageiros - Requisitos de segurança para construção e instalação \\
\hline NBR NM 247-3 & $\begin{array}{l}\text { Cabos isolados com policloreto de vinila (PVC) para tensões nominais até 450/750V, inclusive - Parte 3: Condutores isolados } \\
\text { (sem cobertura) para instalações fixas (IEC 60227-3, MOD) }\end{array}$ \\
\hline NBR NM 247-2 & $\begin{array}{l}\text { Cabos isolados com policloreto de vinila (PVC) para tensões nominais até 450/750 V, inclusive - Parte 2: Métodos de ensaios } \\
\text { (IEC 60227-2, MOD) }\end{array}$ \\
\hline NBR NM 247-1 & $\begin{array}{l}\text { Cabos isolados com policloreto de vinila (PVC) para tensões nominais até 450/750 V, inclusive - Parte 1: Requisitos gerais } \\
\text { (IEC 60227-1, MOD) }\end{array}$ \\
\hline
\end{tabular}

\section{Catálogos Técnicos FDE}

Especificações da Edificação Escolar: Componentes

Especificações da Edificação Escolar: Serviços

Normas de Apresentação de Projetos de Edificações: Instalações Elétricas

Anexo nesta publicação

Anexo 1 : Simbologia - Instalações Elétricas 


\section{Climatização}

Diretrizes de Projeto

Os projetos de climatização devem atender às normas técnicas, à

legislação específica e em especial às recomendações abaixo:

\section{Legislação} PORTARIA N0 3.523 de 28/08/98 do Ministério da Saúde - Garantia de Qualidade do Ar de Interiores de Ambientes Climatizados RESOLUÇÃO RE n 9 de 16/01/2003 da ANVISA - Agência Nacional de Vigilância Sanitária

\section{Normas Técnicas}

\begin{tabular}{l|l}
\hline Norma & Descrição \\
\hline NBR 6401 & Instalações centrais de ar condicionado para conforto \\
\hline ASHRAE & "American Society of Heating, Refrigerating and Air Conditioning Engineers" \\
\hline
\end{tabular}

\section{Anexo nesta publicação}

Anexo 2: Tabela de classificação para sistemas de climatização e cargas térmicas estimadas

\section{Variáveis a serem}

\section{consideradas}

- Para o dimensionamento dos sistemas a serem adotados devem ser considerados os parâmetros constantes das fichas de ambientes no que se refere ao tamanho dos ambientes, ao tipo de uso, à taxa de ocupação, bem como à quantidade de equipamentos eletro-eletrônicos que contribuem para o ganho de calor. Estas variáveis estão sintetizadas na

coluna "Carga Térmica", do Anexo 2 .

- Em caso de centrais de processamento de dados, verificar existência de servidores com necessidade de climatização 24 horas/dia.

- Os auditórios devem possuir sistemas adequados de modo a proporcionar a renovação de ar exigida pelos órgãos de saúde e demais normas específicas de climatização.

- Deve ser observada ainda a classificação do ambiente quanto à necessidade de climatização, conforme discriminado na coluna "classificação para

climatização" do Anexo 2

\section{Variáveis adotadas para determinação das cargas} térmicas

- As cargas térmicas determinadas por ambiente foram calculadas objetivando a simplificação do projeto do sistema de climatização, porém o projetista deve avaliar a necessidade ou não de recalculáas em função de condições climáticas regionais extremas ou de outros parâmetros que sejam significativamente discrepantes dos valores adotados abaixo.

\section{Orientação}

- Norte-Sul

Obs: Adotar a condição mais desfavorável para os ambientes no que se refere ao ganho de calor por insolação direta nos vidros e paredes.

Condições externas - verão

- Temperatura de bulbo seco: $33,0^{\circ} \mathrm{C}$
- Temperatura de bulbo úmido: $27,0^{\circ} \mathrm{C}$ Obs: Considerar a máxima condição externa de temperatura de bulbo sêco e bulbo úmido.

Condições internas

Ambientes destinados à

ocupação human

$\rightarrow$ Temperatura de bulbo seco: $24,0^{\circ} \mathrm{C}$

$\rightarrow$ Umidade relativa: $50 \%$ $\pm 5 \%$ (sem controle)

Ambientes destinados a

equipamentos (racks, servidores, etc.)

$\rightarrow$ Temperatura de bulbo seco: $22,0^{\circ} \mathrm{C}$

$\rightarrow$ Umidade relativa: $50 \%$ $\pm 5 \%$ (sem controle)

Fontes internas de calo

- Iluminação: do tipo fluorescente, com taxa média de 15 watts $/ \mathrm{m}^{2}$

- Número de pessoas:

conforme ficha técnica

- Equipamentos: 300watts por estação de trabalho e 1,0Kw/rack 


\section{Referências Bibliográficas, Normas, Leis e Publicações}

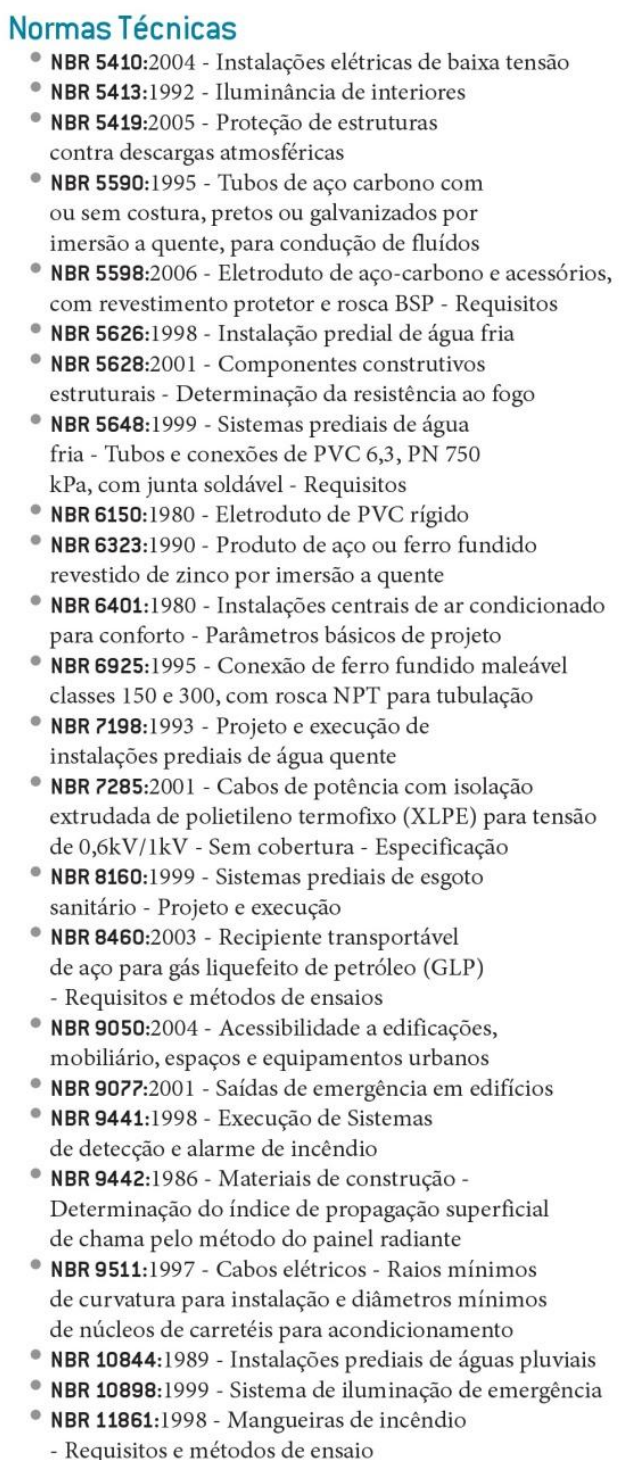

- NBR 12693:1993 - Sistema de proteção

por extintores de Incêndio

NBR 12904:1993 - Válvula de descarga

- NBR 12905:1993 - Válvula de descarga

Verificação de desempenho

- NBR 13300:1995 - Redes de telefonia internas em prédios - Terminologia

- NBR 13301:1995 - Redes de telefonia internas em prédios - Simbologia

- NBR 13434-1:2004 - Sinalização de segurança contra incêndio e pânico - Parte 1 - Princípios de projeto

- NBR 13434-2:2004 - Sinalização de segurança contra incêndio e pânico - Parte 2 - Símbolos e suas formas, dimensões e cores

- NBR 13434-3:2005 - Sinalização de segurança contra incêndio e pânico - Parte 3 - Requisitos e métodos de ensaio

- NBR 13523:2006 - Central de gás liquefeito de petróleo (GLP)

- NBR 13571:1996 - Haste de aterramento aço-cobreada e acessórios

- NBR 13714:2000 - Sistemas de hidrantes e de mangotinhos para combate a incêndio

- NBR 13726:1996 - Redes de telefonia internas em prédios - Tubulação de entrada telefônica - Projeto NBR 13727:1996 - Redes de telefonia internas em prédios - Plantas/partes componentes do projeto de tubulação telefônica

- NBR 13897:1997 - Duto espiralado corrugado flexível, em polietileno de alta densidade, para uso metroferroviário

NBR 13932:1997 - Instalações internas de gás liquefeito de petróleo (GLP) - Projeto e execução

NBR 13969:1997 - Tanques sépticos - Unidades de tratamento complementar e disposição final dos efluentes líquidos - Projeto, construção e operação

- NBR 13994:2000 - Elevadores de passageiros - Elevadores para transporte de pessoa portadora de deficiência

NBR 14039:2005 - Instalações elétricas de média tensão de $1,0 \mathrm{kV}$ a $36,2 \mathrm{kV}$

- NBR 14306:1999 - Proteção elétrica e compatibilidade eletromagnética em redes internas de telecomunicações em edificações - Projeto

- NBR 14432:2001 - Exigências de resistência ao fogo de elementos construtivos de edificações - Procedimento NBR 14570:2000 - Instalações internas para uso alternativo dos gases GN e GLP - Projeto e execução

NBR IEC 60439-1:2003 - Conjuntos de manobra e controle de baixa tensão - Parte 1 - Conjuntos com ensaio de tipo totalmente testados (TTA) e conjuntos com ensaio de tipo parcialmente testados (PTTA) 


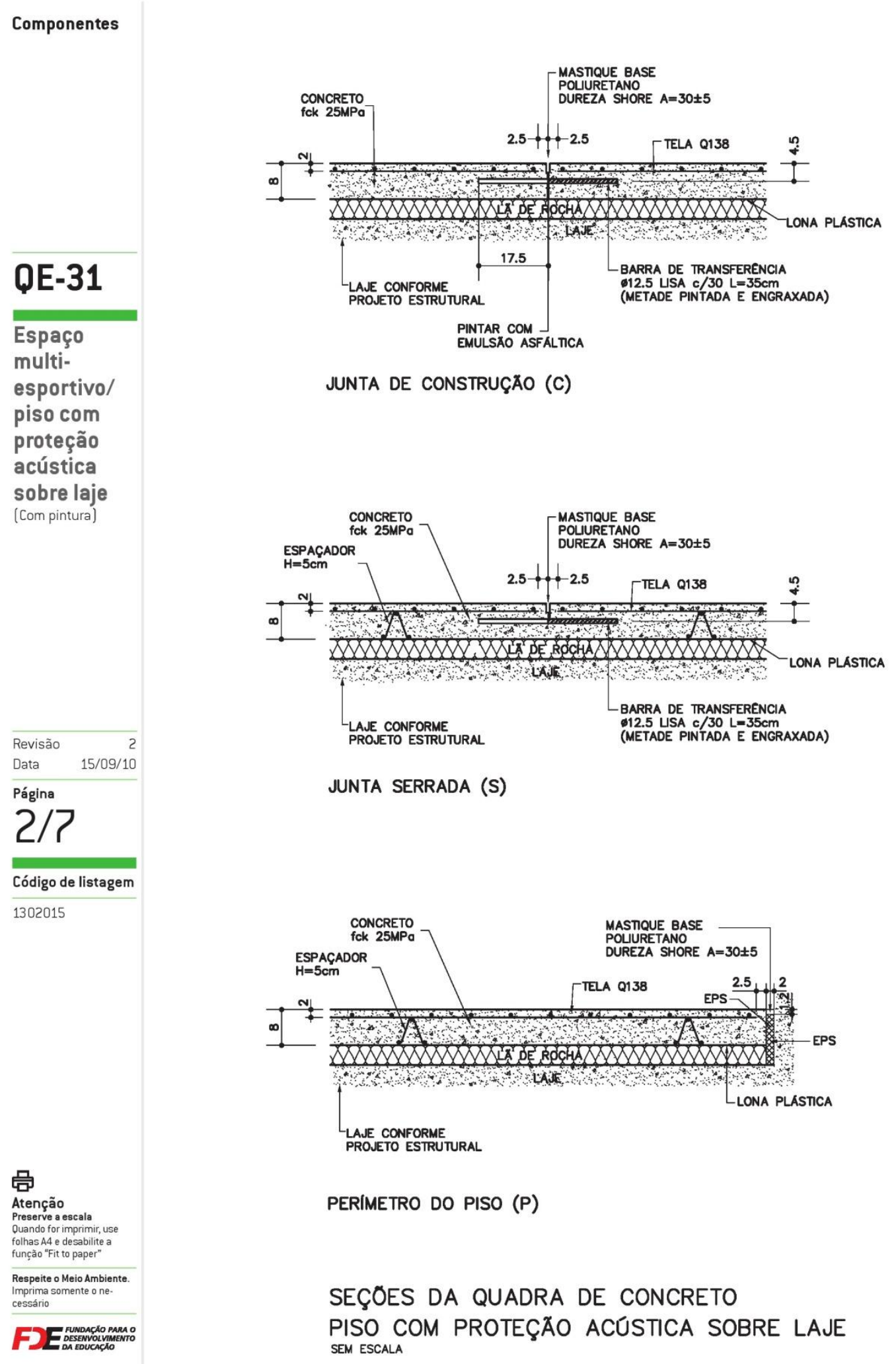




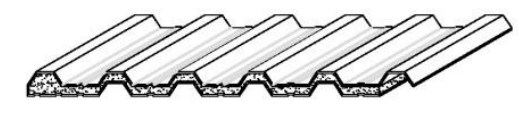

Perfil superior trapezoidal / perfil inferior trapezoidal

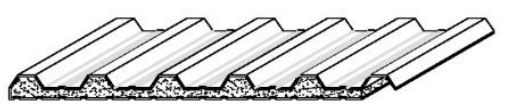

Perfil superior trapezoidal / perfil inferior nervurado

Serviços

Etapa

Coberturas

S8.23

DESCRIÇÃO

- Telhas de aço galvanizado (grau B - $260 \mathrm{~g}$ de zinco $/ \mathrm{m}^{2}$ ], tipo sanduíche com faces externas de telhas de aço (perfil superior trapezoidal / perfil inferior trapezoidal ou perfil supe rior trapezoidal / perfil inferior plano] e miolo em espuma de poliuretano expandido (injetada, auto-extinguível), bordas uniformes, permitindo encaixe com sobreposição exata, isentas de manchas e partes amassadas. Comprimentos e larguras diversas. Espessuras de 0,5mm (perfil inferior) e $0,5 \mathrm{~mm}$ (perfil superior). Espessura total da telha com isolante $=30 \mathrm{~mm}$ e $50 \mathrm{~mm}$.

- Peças complementares em aço: cumeeiras, rufos e outras, com mesmo acabamento das telhas.

- Acessórios de fixação: ganchos, parafusos auto-atarraxan tes, parafusos auto- perfurantes, com sistema de vedação, revestimento anti-corrosivos, pinos para explo-penetração com sistema de vedação, dispositivos para fixação em onda alta.

- Acessórios de vedação: fechamento de onda, fita de vedação.

\section{Protótipo comercial}

- EUCATEX:

- Perfil superior trapezoidal / perfil inferior trapezoidal L40 / $\mathrm{L} 40$ ( $\mathrm{L}=1020 \mathrm{~mm})$

- Acabamentos: natural ou pintura eletrostática poliéster em pó ou pré-pintura processo "Coil Coating"

- GPUPPOTELHAS:

- Série ACUSTIC - Linha PU

- Perfil superior trapezoidal / perfil inferior trapezoidal

- Trapézio 35 / Trapézio 35 ( L=1050mm )

- Trapézio 40 / Trapézio 40 (L=1020mm)

- Perfil superior trapezoidal / perfil inferior plano

- Trapézio 35 / Telha plana

- Trapézio 40 / Telha plana

- Acabamentos: natural ou pintura eletrostática poliéster em pó

- KOFAR:

- Perfil superior trapezoidal / perfil inferior trapezoidal

- TKM-35pp [L=1050mm $)$

- TKM-40pp ( L=980mm)

- Acabamentos: natural ou pintura eletrostática poliéster em pó

- METFORM:

- Perfil superior trapezoidal / perfil inferior trapezoidal

- MF-25/MF-25 (L=1026mm)

- MF-40/MF-40 [L=980mm ]

- MF-100 / MF-100 ( $L=750 \mathrm{~mm}$ )

- Acabamentos: natural ou pintura eletrostática poliéster

Coating"

PERFILOR:

- Perfil superior trapezoidal / perfil inferior plano

- TP33 (L=1030mm)

- Acabamentos: natural ou pré-pintura processo “Coil Coating"

\section{APLICAÇã̃o}

- Em coberturas onde haja exigência de isolamento termoacústico.

- 0 uso deve ser restrito a ambientes onde não se utilizará forro.

- Especificar em projeto os tipos de perfis para a montagem das telhas: perfil superior trapezoidal / perfil inferior trapezoidal ou perfil superior trapezoidal / perfil inferior plano.

\section{EXECUÇã̃o}

- Obedecer a inclinação do projeto com mínimo de 3\% quando houver uma peça por água e $5 \%$ quando houver mais de uma peça por água (neste caso devem ser aplicadas duas linhas de fita de vedação transversal).

- Seguir recomendações e manuais técnicos dos fabricantes, especialmente quanto aos cuidados relativos a transporte, manuseio, armazenamento, montagem e recobrimento mínimo das peças.

- A montagem das peças deve ser de baixo para cima e no sentido contrário ao dos ventos dominantes (iniciada do beiral à cumeeira).

- A embalagem de proteção deve ser verificada; telhas de aço pintadas não devem ser arrastadas; as peças devem ser armazenadas ligeiramente inclinadas e em local protegido $e$ seco; cuidado especial deve ser tomado com a pintura.

\section{FICHAS DE REFERÊNCIA}

\section{Catálogo de Serviços}

Ficha S8.01 Telha de Aço

Ficha S8.21 Telha Autoportante

Ficha S8.22 Telha de Aço Curva

\section{RECEBIMENTO}

- Verificar as condições de projeto, fornecimento e execução. Tolerância máxima quanto à inclinação: $5 \%$ do valor especificado.

- Nas linhas dos beirais não podem ser admitidos desvios ou desnivelamentos entre peças contíguas.

- Esticada uma linha entre 2 pontos quaisquer da linha de beiral ou de cumeeira, não pode haver afastamentos superiores a $2 \mathrm{~cm}$.

- PANISOL:

- Perfil superior trapezoidal / perfil inferior plano

- Isocobertura [ $L=1000 \mathrm{~mm}$ ]

- Isogrega ( $L=890 \mathrm{~mm}$ )

骨

Atenção Preserve a escala folhas A4 e de sabilite a funçăa "Fit to paper"

Respeite o Meio Ambiente Imprima somente o ne-

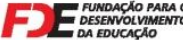




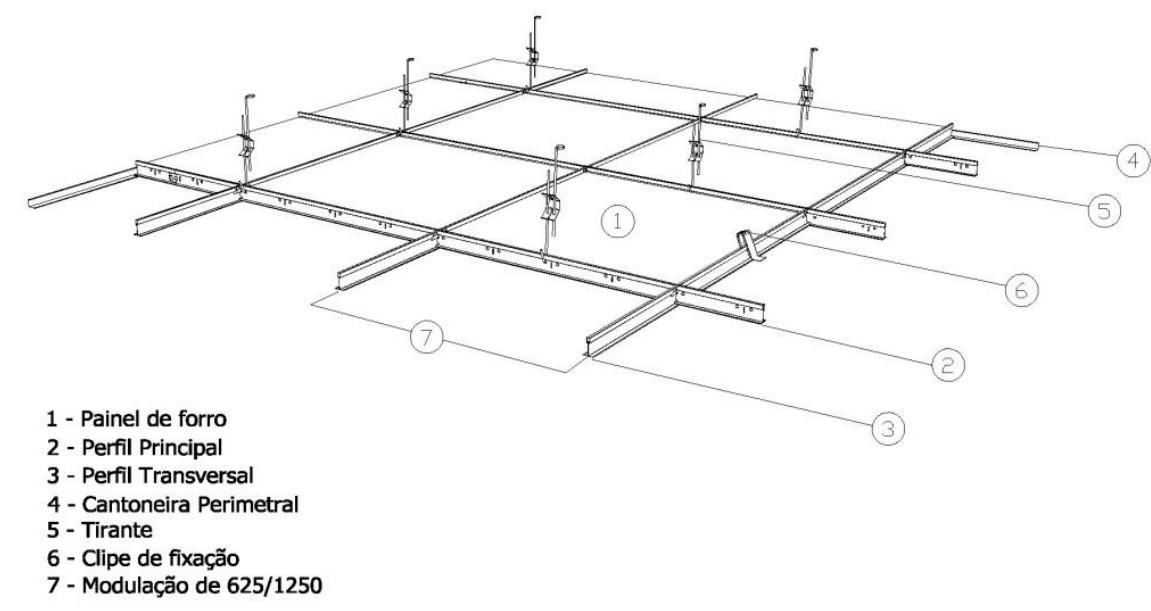

Serviços

Etapa

COBERTURA

S9.06

FORRO

ACÚSTICO

MINERAL

$625 \mathrm{~mm} \times 625 \mathrm{~mm}$ ou

$625 \mathrm{~mm} \times 1250 \mathrm{~mm}$

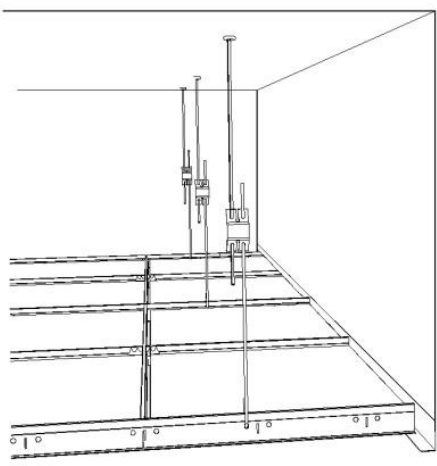

Detalhe de aplicação

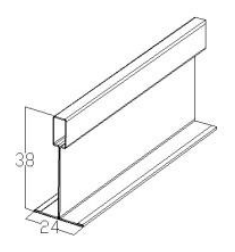

Perfil T 24/38

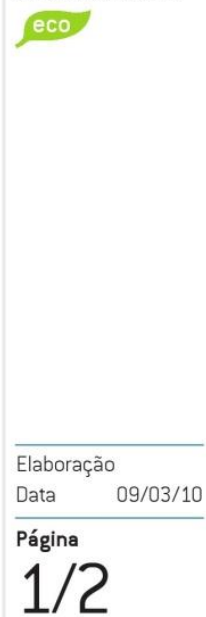

\section{DESCRIÇÃO}

- Painel de forro modular mineral biossolúvel constituído de matérias-primas não poluentes composto de lã mineral, argila e aglomerantes com acabamento pintado em branco, dotado de microperfurações destinadas à absorção acústica. - Índice de propagação de chamas: IP $\leq 25$ (NBR 9442/1988) Classe A;

- Reflexão luminosa até 90\%;

- Espessura: 13mm;

- Peso: $3,6 \mathrm{~kg} / \mathrm{m}^{2}$.

- Sistema de sustentação aparente por perfis " $T$ " invertidos $24 / 38$, com sistema de encaixe do tipo "clicado", com $38 \mathrm{~mm}$ de altura e com $24 \mathrm{~mm}$ de largura. A superfície aparente dos perfis deve ser recoberta com capa de aço galvanizado prépintada na cor branca em processo coil-coating. 0 sistema é constituído por tirantes (estrutura de sustentação metálica) além de acessórios de fixação (molas ou clipes de fixação), e arremates periféricos (cantoneiras). (Ver figuras acima)

\section{Protótipo Comercial}

- Forro acústico mineral:

- Amf Knauf Ecomin Filigran $625 \mathrm{~mm} \times 625 \mathrm{~mm} \times 13 \mathrm{~mm}$

- Amf Knauf Ecomin Filigran 625mm×1250mm×13mm

- Isolante termoacústico:

- ISOVER - ROLLISOL (LÃ DE VIDRO)

- ROCKFIBRAS Rollmax (LÃ DE ROCHA)

\section{APLICAÇÃOO}

- Em ambientes internos, protegidos da ação direta do intemperismo. Além do desempenho acústico o forro pode ter as funções de acabamento do teto e/ ou ocultamento de redes.

- Os forros minerais poderão ser instalados somente em locais que apresentem condições adequadas de ventilação e temperatura. Deverá ser previsto um sistema que promova a circulação de ar evitando formação de massas de ar quente entre a cobertura e o forro.

- Caso a temperatura do bolsão de ar forro/cobertura exceder a $30^{\circ} \mathrm{C}$, deverá ser instalado isolante térmico sobreposto do forro.

- 0 isolante a ser utilizado deverá ser ensacado e possuir $50 \mathrm{~mm}$ de espessura podendo ser de lã de vidro (densidade de $20 \mathrm{~kg} / \mathrm{m}^{3}$ ) ou de lã de rocha (densidade de $32 \mathrm{~kg} / \mathrm{m}^{3}$ ).

• Ver Serviços 10.01.059 e 10.01.061.

\section{EXECUÇÃ̃o}

- Os perfis principais (longarinas) formam modulações junto aos perfís secundários com $625 \times 625 \mathrm{~mm}$ ou $625 \times 1250 \mathrm{~mm}$ de acordo com o tamanho de forro adotado.

- As perfurações nos perfis principais estão dispostas a cada $156 \mathrm{~mm}$ em sua extensão, permitindo o encaixe dos perfis secundários (travessas).

\section{骨}

Atenção Preserve a escala
Quando forimprimir folhas A4 e desabilite a funçãa "Fit to paper"

Respeite o Meio Ambiente Imprima somente on

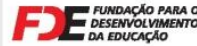




\author{
Serviços \\ Etapa \\ COBERTURA \\ S9.06 \\ FORRO \\ ACÚSTICO \\ MINERAL \\ $625 \mathrm{~mm} \times 625 \mathrm{~mm}$ ou \\ $625 \mathrm{~mm} \times 1250 \mathrm{~mm}$ \\ eco \\ Elaboração \\ Data 09/03/10

Página \\ 骨 \\ Atenção \\ Preserve a escala \\ folhas A4 e desabilite a \\ funçăo "Fit to paper" \\ Respeite o Meio Ambiente. \\ mprima somente on

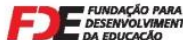 \\ - Os pendurais devem ser constituídos por perfis rígidos com \\ resistência adequada para sustentar o sistema. Devem ser \\ fixados à estrutura existente, de acordo com suas caracte- \\ risticas: \\ - a) Laje ou viga de concreto: utilizar bucha metálica \\ expansível a ser dimensionada de acordo com a carga total \\ do forro; \\ - b) Vigas de aço: fixar os tirantes às abas da viga metálica \\ desde que autorizado pelo responsável técnico; \\ - c) Concreto Celular leve: recomenda-se a utilização de uma \\ estrutura auxiliar independente para o forro; \\ -d) Vigas de madeira: a ser detalhada pelo responsável \\ técnico da cobertura. \\ - As placas de forro mineral devem ser fixadas à estrutura \\ por meio de clipes de fixação. Utilizar 04 clipes por módulo \\ de forro. \\ - A instalação de luminárias não deve comprometer o \\ desempenho do forro. As luminárias modulares podem ser \\ instaladas e apoiadas na grade estrutural do sistema do \\ fabricante, desde que seu peso não comprometa ou flexione \\ a estrutura. Se o peso incidente for maior que o previsto \\ (acima de $5 \mathrm{~kg}$ / Luminária), recomenda-se utilização de um \\ atirantamento de apoio independente para as luminárias.

\section{FICHAS DE REFERÊNCIA} \\ Catálogo de Componentes \\ Ficha IL-60 Luminária de Sobrepor com Refletor e Aletas \\ Lâmpadas Fluorescentes (2x32W) \\ Ficha IL-61 Luminária de Embutir com Refletor e Aletas \\ - Lâmpadas Fluorescentes (2x32W) \\ Ficha IL-62 Luminária de Sobrepor com Refletor e Aletas \\ - Lâmpadas Fluorescentes (4X16W) \\ Ficha IL-63 Luminária de Embutir com Refletor e Aletas \\ - Lâmpadas Fluorescentes (4×16W)

\section{RECEBIMENTO} \\ - Atendidas as condições de fornecimento e execução, os \\ forros poderão ser recebidos se a aparência final do conjunto \\ for homogênea e plana. Verificar ausência de emendas e \\ perfeito nivelamento. \\ - Aferir especificações do produto (dimensionamento, espes- \\ suras de parede das peças, etc) e componentes (acessórios). \\ - Verificar identificação do produto / fabricante no verso do \\ painel. \\ - Deverá ser feita inspeção visual, consistindo na verificação \\ de fissuras, trincas, deformações ou superfícies irregulares. \\ - Verificar qualidade dos acabamentos nos encontros do forro \\ com as paredes do ambiente. \\ SERVIÇOS \\ 10.01 \\ FORRO \\ 10.01.013 FORRO DE PLACA MINERAL (625×625×13)MM \\ INCL PERFIS FORN/INST. \\ 10.01.014 FORRO DE PLACA MINERAL $(625 \times 1250 \times 13)$ MM \\ INCL PERFIS FORN/INST. \\ 10.01.059 ISOLAÇ̃̃O TERMOACÚSTICA - LA DE VIDRO E=2" \\ 10.01.061 ISOLAÇÃO TERMOACÚSTICA - LA DE ROCHA \\ $\mathrm{E}=2 "$

\section{SERVIÇOS INCLUÍDOS NOS PREÇOS} \\ - Fornecimento e instalação de forro modulado \\ $625 \times 625 \times 13 \mathrm{~mm}$ ou $625 \times 1250 \times 13 \mathrm{~mm}$, incluindo acessórios \\ de fixação.

\section{CRITÉRIOS DE MEDIÇÃO} \\ $10.01 .013 \quad 10.01 .014$ \\ - $\mathrm{m}^{2}$ - por $\mathrm{m}^{2}$ de projeção horizontal de cobertura executada.
}

\section{NORMAS}

- NBR 9442/1988 - Materiais de construção - Determinação do índice de propagação superficial de chama pelo método do painel radiante.

- IS0 11654:1997 - Acoustics - Sound absorbers for use in

buildings - Rating of sound absorption.

- ASTM C 423-02a - Standard test method for sound absorp tion and sound absorption coefficients by the reverberation room method.

- DIN 52612-2 - Tesing of thermal insulating materials; determination of thermal conductivity by means of the guarded hot plate apparatus; conversion of the measured values for building applications 


\subsection{Catálogos Técnicos da FDE: aspectos a incorporar}

A todas as fichas dos Catálogos Técnicos de Componentes, Serviços e Ambientes em que for pertinente, deverão ser incorporados parâmetros de Conforto Ambiental ao lado dos parâmetros relacionados a outros aspectos que delas já constam, como se pode ver no exemplo da ficha SALA DE AULA do Caderno de Ambientes, composta de 6 páginas aqui reproduzidas a partir da folha seguinte. Há fichas como estas para cada um dos 27 ambientes escolares.

A leitura das informações não é clara nesta reprodução, mas o principal objetivo e demonstrar a riqueza de detalhes com que cada ambiente, assim como cada componente e cada serviço é descrita, e assim demonstra-se a importância de que sejam especificados para cada um destes itens as diretrizes de Conforto Ambiental.

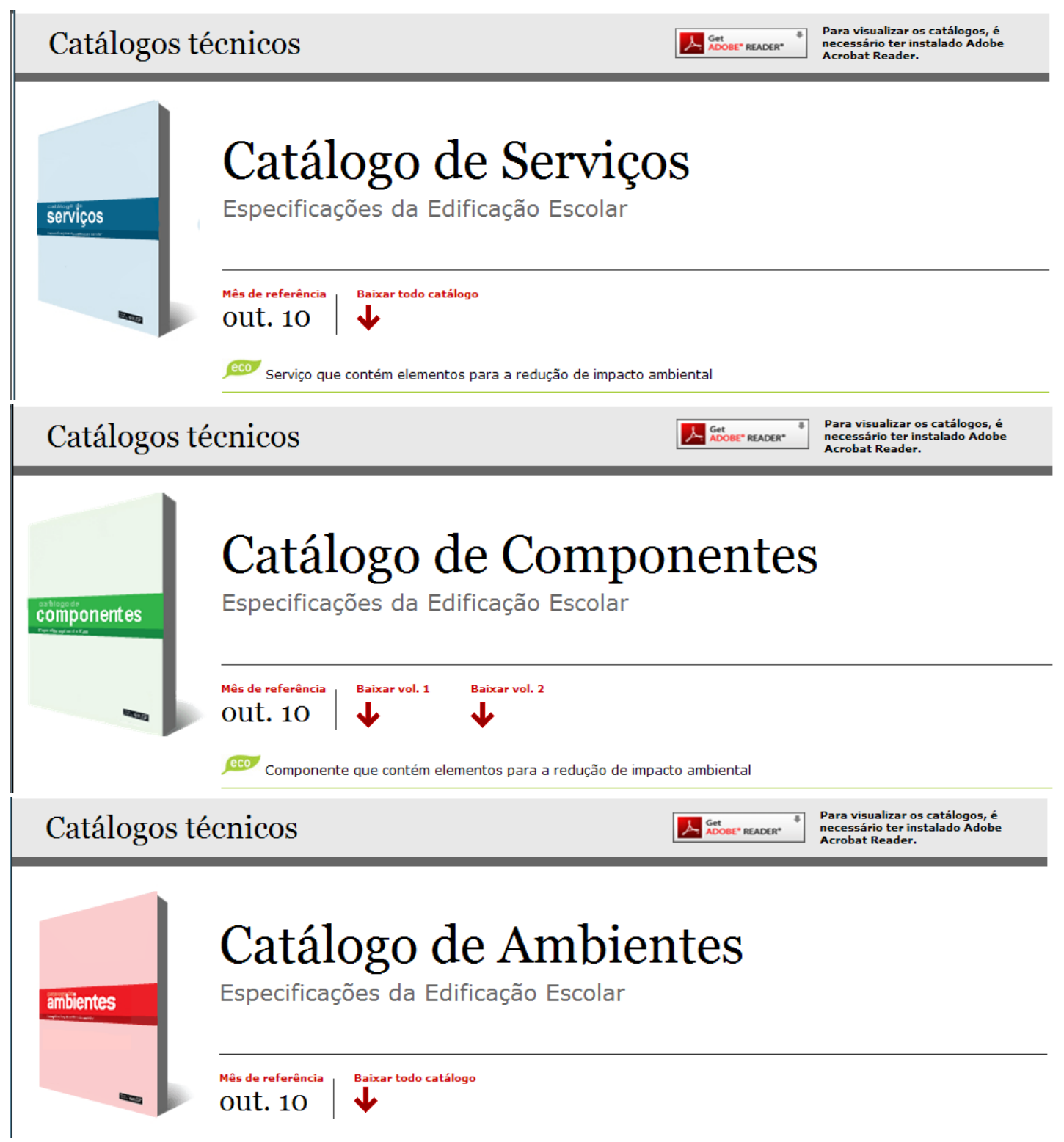




\section{Sala de Aula}

\begin{tabular}{ll}
\hline Conjunto funcional & Pedagógico \\
Programa arquitetônico & Ciclo I- Cíclo II - Ensino Médio \\
Módulo básico & M1 - M2 - M3 - M4 - M5 - M6 \\
Data & Junho/2010
\end{tabular}

\section{Layout}

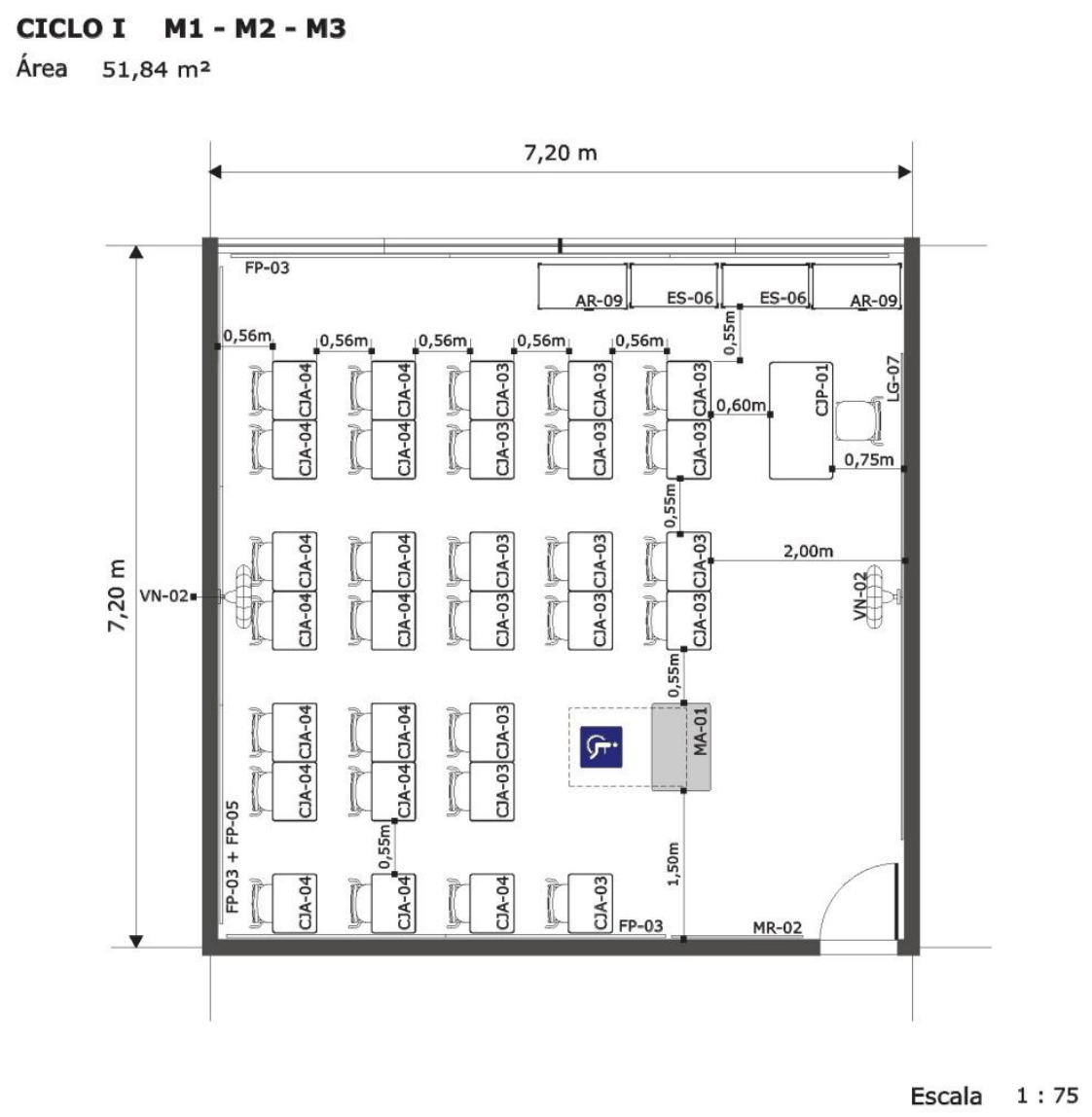

\begin{tabular}{l|l} 
吕 Atenção & \\
Preserve a escala: Ouando for imprimir, use & Respeite o Meio Ambiente.
\end{tabular} 


\begin{tabular}{lll} 
Sala de Aula & \\
$\begin{array}{lll}\text { Conjunto funcional } \\
\text { Programa arquitetônico } \\
\text { Módulo básico } \\
\text { Data }\end{array}$ & $\begin{array}{l}\text { Pedagógico } \\
\text { Ciclol-Ciclo II-Ensino Médio } \\
\text { M1-M2-M3-M4-M5-M6 } \\
\text { Junho/2010 }\end{array}$ & $2 / 6$ \\
\hline & Página
\end{tabular}

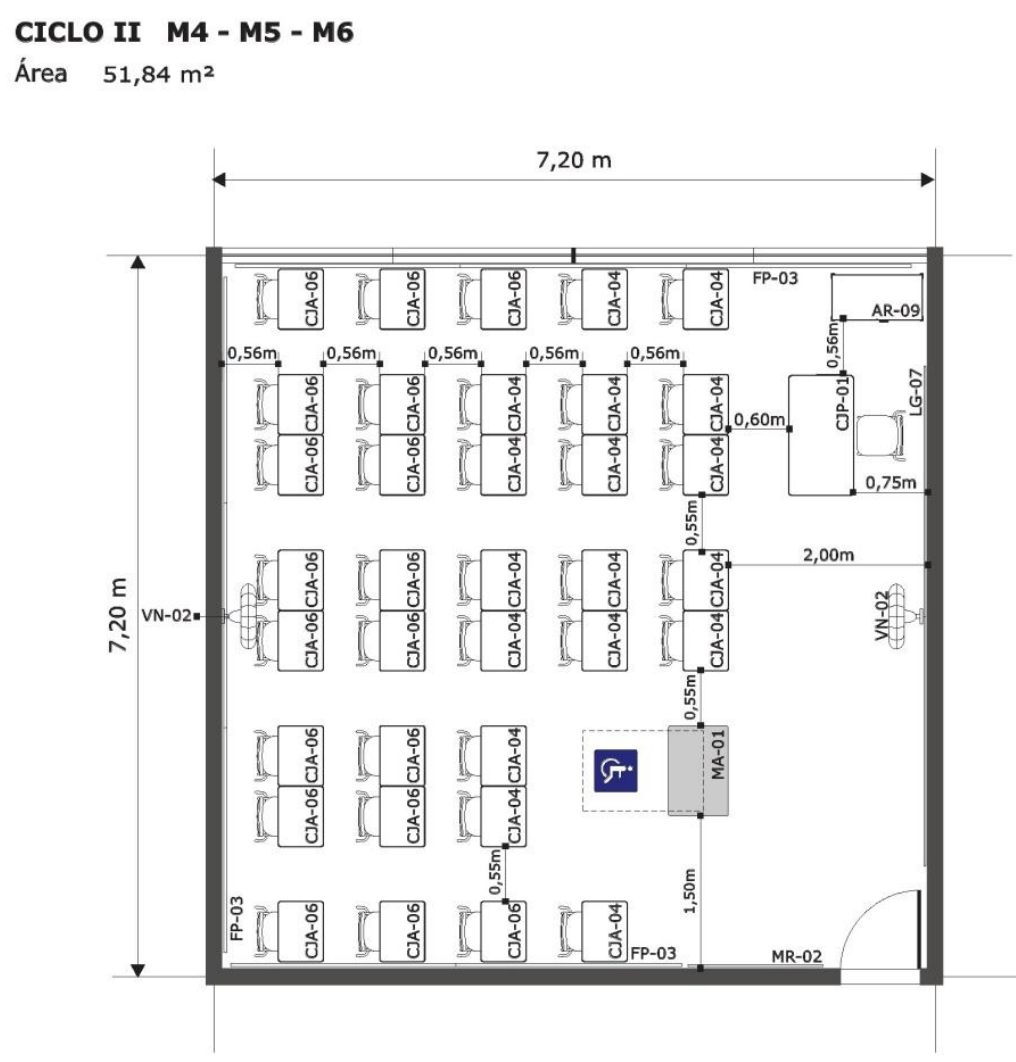

Escala $1: 75$ 


\section{Sala de Aula}

\begin{tabular}{ll}
\hline Conjunto funcional & Pedagógico \\
Programa arquitetônico & Ciclo I-Ciclo II - Ensino Médio \\
Módulo básico & M1 - M2 - M3 - M4 - M5 - M6 \\
Data & Junho/2010
\end{tabular}

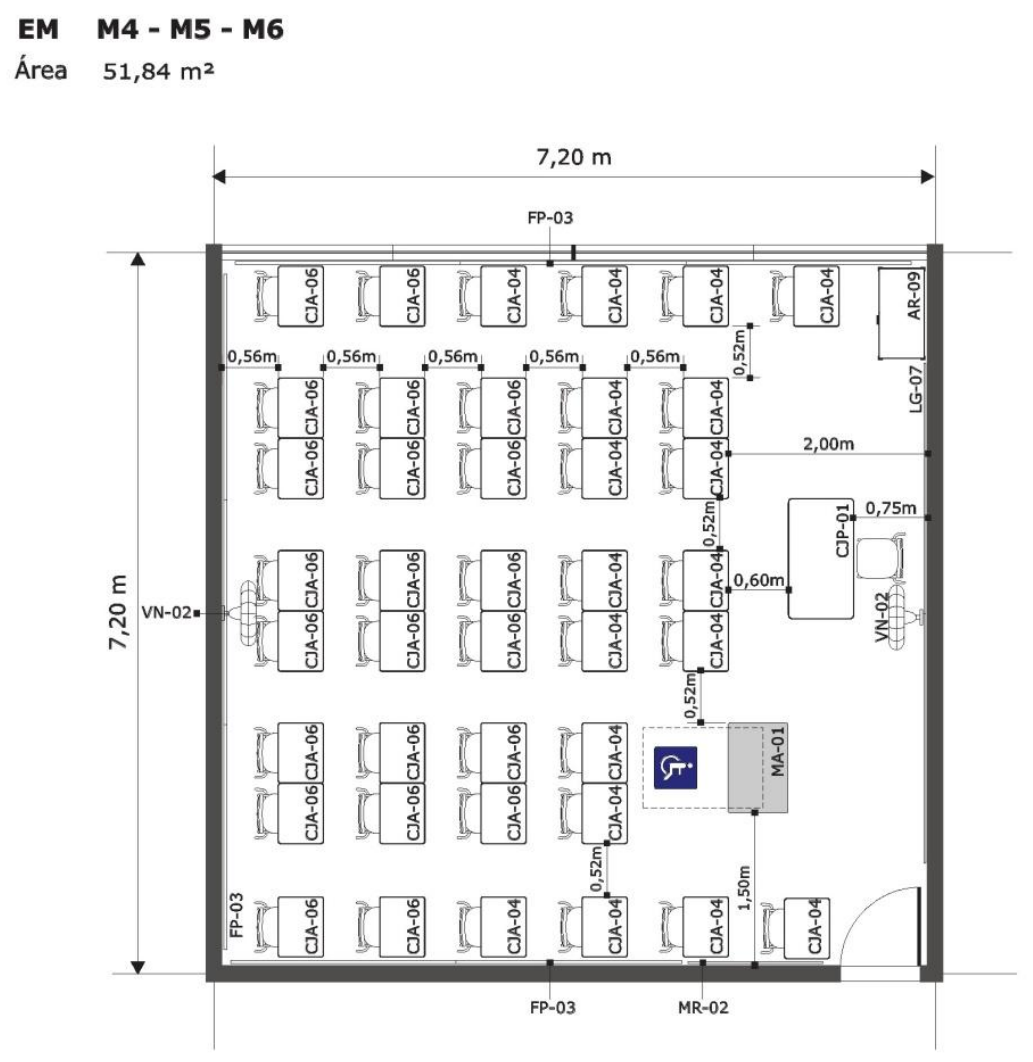

Escala $1: 75$ 


\begin{tabular}{|c|c|c|c|}
\hline \multirow[t]{2}{*}{ Ambientes } & \multicolumn{3}{|l|}{ Sala de Aula } \\
\hline & $\begin{array}{l}\text { Conjunto funcional } \\
\text { Programa arquitetônico } \\
\text { Módulo básico } \\
\text { Data }\end{array}$ & $\begin{array}{l}\text { Pedagógico } \\
\text { Ciclo I-Ciclo II - Ensino Médio } \\
\text { M1 - M2 - M3 - M4 - M5 - M6 } \\
\text { Junho/2010 }\end{array}$ & Página \\
\hline
\end{tabular}

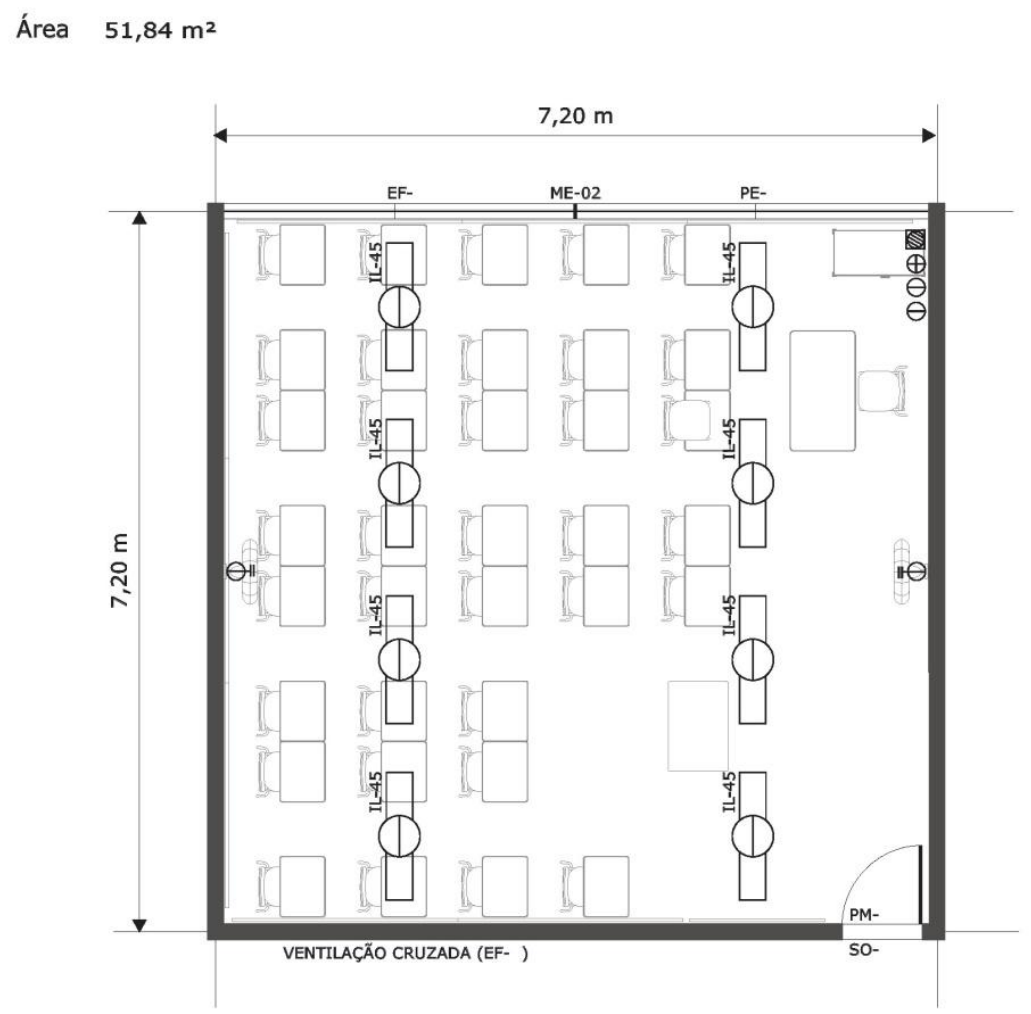

Escala $1: 75$

Simbologia

Ponto de lógica

Ponto para equipamento de comunicação interna

Tomada padrão NBR 14.136 2P+T baixa, 10A / 110V

Tomada padrão NBR 14.136 2P+T alta, 10A / 110V 
Sala de Aula

Conjunto funcional

Programa arquitetônico

Módulo básico

Data

\section{Pedagógico}

Ciclo I-Ciclo II - Ensino Médio

M1 - M2 - M3 - M4 - M5 - M6

Junho/2010
Página

$5 / 6$

$08 \mathrm{~A}$

\section{Especificações}

\section{CARACTERIZAÇÃO DO AMBIENTE}

-Ambiente onde se desenvolvem as atividades de ensino e aprendizagem.

\section{DIRETRIZES PARA PROJETO}

- Prever espaço para a distribuição e instalação de itens de Mobiliário e Equipamentos conforme tabelas - ver item 'MOBILIÁRIO E EQUIPAMENTOS' e item 'NOTAA SER INSERIDA EM PROJETO'.

- Prever sinalização do ambiente.

\section{EXIGÊNCIAS AMBIENTAIS}

- Pé direito mínimo: $3,00 \mathrm{~m}$.

- Área de iluminação natural mínima: 1/5 da área do piso.

- Área de ventilação natural mínima: $1 / 10$ da área de piso.

- A profundidade do ambiente em relação ao posicionamento dos caixilhos não poderá ser superior a três vezes seu pé direito, incluída na profundidade a projeção de saliências ou cobertura.

- Laje obrigatória.

- lluminação fluorescente.

- Nível mínimo de iluminamento: 300 lux.

- A critério da gerência de projetos, adotar circuitos alternados para iluminação do ambiente, visando melhor aproveitamento da luz natural e melho adequação às atividades didáticas.

- Carga acidental a ser prevista: $300 \mathrm{kgf} / \mathrm{m}^{2}$.

- Classificação acústica: resguardado.

- lluminação natural unilateral preferencialmente à esquerda da lousa

(vista de frente) sendo admitida a iluminação zenital, quando solucionado ofuscamento.

- Ventilação cruzada obrigatória através de caixilhos situados na parede oposta à das janelas.

- Parede com acabamento impermeável.

- Piso impermeável, de fácil higienização e resistente a tráfego intenso.

\section{INSTALAÇõES}

- 2 tomadas padrão NBR $14.1362 \mathrm{P}+\mathrm{T}$ alta, 10A / 110V ou de acordo com a tensão local ( $h=2,20 \mathrm{~m}$ do piso).

- 2 tomadas padrão NBR 14.136 2P+T baixa, 10A / 110V ou de acordo com a tensão local ( $h=0,30 \mathrm{~m}$ do piso), sendo 1 tomada de uso geral e 1 tomada para informática.

- 8 luminárias / lâmpadas fluorescentes / 2 x 32W (IL-45).

- 1 ponto para equipamento de comunicação interna - tubulação seca

( $h=2,20 \mathrm{~m}$ do piso).

- 1 ponto de lógica - tubulação seca ( $h=0,50 \mathrm{~m}$ do piso).

\section{COMPONENTES A SEREM INDICADOS EM PROJETO}

$\begin{array}{ll}\text { EF- } & \text { esquadria de ferro / ventilação cruzada - a especificar } \\ \text { EF- } & \text { esquadria de ferro a especificar } \\ \text { IL-45 } & \text { luminária aberta com refletor para lâmpada fluorescente - } 2 \times 32 W \\ \text { ME-02 } & \text { montante estrutural para esquadrias } \\ \text { PE- } & \text { peitoril a especificar } \\ \text { PM- } & \text { porta a especificar }(L=82 \mathrm{~cm} \text { ) } \\ \text { RS- } & \text { sinalização a especificar } \\ \text { SO- } & \text { soleira rampada a especificar }\end{array}$

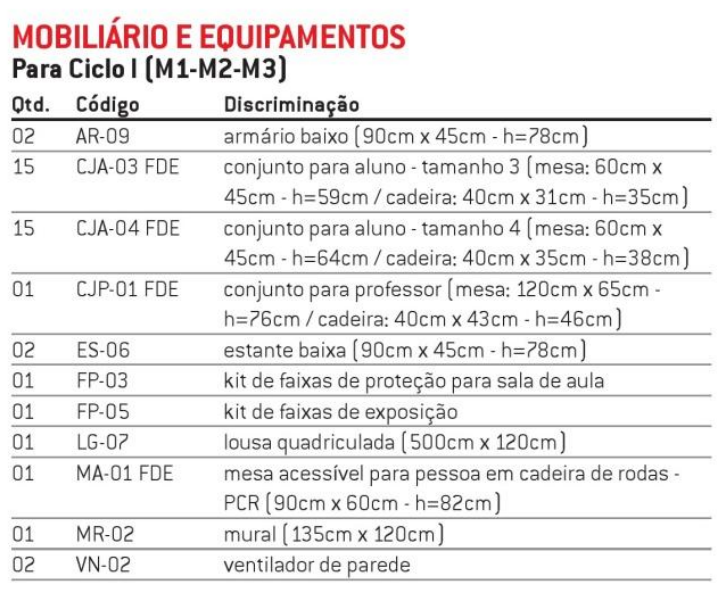

\section{Para Ciclo II (M4-M5-M6)}

Otd. Código Discriminação

01 AR-09 armário baixo $(90 \mathrm{~cm} \times 45 \mathrm{~cm}-\mathrm{h}=78 \mathrm{~cm})$

17 CJA-04 FDE conjunto para aluno - tamanho 4 (mesa: $60 \mathrm{~cm} x$ $45 \mathrm{~cm}-\mathrm{h}=64 \mathrm{~cm} /$ cadeira: $40 \mathrm{~cm} \times 35 \mathrm{~cm}-\mathrm{h}=38 \mathrm{~cm}$ )

18 CJA-06 FDE conjunto para aluno - tamanho 6 (mesa: $60 \mathrm{~cm} x$

$45 \mathrm{~cm}-\mathrm{h}=76 \mathrm{~cm} /$ cadeira: $40 \mathrm{~cm} \times 43 \mathrm{~cm}-\mathrm{h}=46 \mathrm{~cm}$ )

01 CJP-01 FDE conjunto para professor (mesa: $120 \mathrm{~cm} \times 65 \mathrm{~cm}$ $h=76 \mathrm{~cm} /$ cadeira: $40 \mathrm{~cm} \times 43 \mathrm{~cm}-\mathrm{h}=46 \mathrm{~cm}$ )

\begin{tabular}{lll}
\hline 01 & FP-03 & kit de faixas de proteção para sala de aula \\
\hline 01 & LG-07 & lousa quadriculada $[500 \mathrm{~cm} \times 120 \mathrm{~cm})$ \\
\hline 01 & MA-01 FDE & $\begin{array}{l}\text { mesa acessivel para pessoa em cadeira de rodas - } \\
\text { PCR }(90 \mathrm{~cm} \times 60 \mathrm{~cm} \cdot \mathrm{h}=82 \mathrm{~cm})\end{array}$ \\
\hline 01 & MR-02 & mural $(135 \mathrm{~cm} \times 120 \mathrm{~cm})$ \\
\hline 02 & VN-02 & ventilador de parede \\
\hline
\end{tabular}

Para Ensino Médio (M4-M5-M6)

\begin{tabular}{|c|c|c|}
\hline Qtd. & Código & Discriminação \\
\hline 01 & AR-09 & armário baixo $(90 \mathrm{~cm} \times 45 \mathrm{~cm}-\mathrm{h}=78 \mathrm{~cm})$ \\
\hline 18 & CJA-04 FDE & $\begin{array}{l}\text { conjunto para aluno - tamanho } 4 \text { (mesa: } 60 \mathrm{~cm} \times \\
45 \mathrm{~cm}-\mathrm{h}=64 \mathrm{~cm} / \text { cadeira: } 40 \mathrm{~cm} \times 35 \mathrm{~cm}-\mathrm{h}=38 \mathrm{~cm} \text { ) }\end{array}$ \\
\hline 22 & CJA-06 FDE & $\begin{array}{l}\text { conjunto para aluno - tamanho } 6 \text { (mesa: } 60 \mathrm{~cm} \times \\
45 \mathrm{~cm}-\mathrm{h}=76 \mathrm{~cm} / \text { cadeira: } 40 \mathrm{~cm} \times 43 \mathrm{~cm}-\mathrm{h}=46 \mathrm{~cm} \text { ) }\end{array}$ \\
\hline 01 & CJP-01 FDE & $\begin{array}{l}\text { conjunto para professor (mesa: } 120 \mathrm{~cm} \times 65 \mathrm{~cm} \text { - } \\
\mathrm{h}=76 \mathrm{~cm} / \text { cadeira: } 40 \mathrm{~cm} \times 43 \mathrm{~cm}-\mathrm{h}=46 \mathrm{~cm} \text { ) }\end{array}$ \\
\hline 01 & FP-03 & kit de faixas de proteção para sala de aula \\
\hline 01 & LG-0? & lousa quadriculada $[500 \mathrm{~cm} \times 120 \mathrm{~cm}$ ) \\
\hline 01 & MA-01 FDE & $\begin{array}{l}\text { mesa acessivel para pessoa em cadeira de rodas - } \\
\text { PCR }[90 \mathrm{~cm} \times 60 \mathrm{~cm}-\mathrm{h}=82 \mathrm{~cm}]\end{array}$ \\
\hline 01 & MR-02 & mural $(135 \mathrm{~cm} \times 120 \mathrm{~cm})$ \\
\hline 02 & VN-02 & ventilador de parede \\
\hline
\end{tabular}




\section{Especificações}

NOTA A SER INSERIDA EM PROJETO

- Itens de mobiliário a instalar:

Qtd. Código Discriminação

\begin{tabular}{lll}
\hline 01 & FP-03 & kit de faixas de proteção para sala de aula \\
\hline 01 & FP-05 & kit de faixas de exposição (somente para Ciclo I) \\
\hline 01 & LG-0? & lousa quadriculada \\
\hline 01 & MR-02 & mural \\
\hline 02 & VN-02 & ventilador de parede \\
\hline 0
\end{tabular}

Obs:

Mobiliário e equipamentos listados acima deverão ser retirados pela

Construtora no DME (Departamento de Mobiliário Escolar) e instalados;

- Orientações para instalação conforme instruções constantes na ficha de mobiliário correspondente ou "Anexo". 


\section{CONSIDERAÇÕES FINAIS}

O conhecimento de Conforto Ambiental - através dos quais é possível mensurar e aplicar ao projeto, condicionantes da física das construções que interferem diretamente no bem estar térmico, acústico, luminoso e ergonômico de seus usuários - está disponível à formação do arquiteto, de forma sistemática, desde meados do século XX.

No entanto, sua aplicação não ocorre da maneira como seria esperado. Avaliações pós-ocupação bem como o retorno dos usuários que nos chegam por diversos meios, dão conta de que nossos ambientes escolares apresentam-se desconfortáveis térmica e acusticamente numa proporção que não conhecemos qual é em relação ao total de escolas da rede, mas que independente disto, não deveria ocorrer.

Estabelecido o panorama atual das questões de conforto ambiental no projeto de escolas estaduais, e impulsionados pelas certificações que vêm gerando demandas de projeto relacionadas ao conforto, fica estabelecida a base para a formulação de diretrizes e sistematização de instrumentos de definição e avaliação de parâmetros para projeto a serem incorporados.

Estes instrumentos, como as Normas Técnicas, os softwares e as Avaliações PósOcupação empreendidas e por empreender vêm de encontro à necessidade, à premência, à pertinência, à possibilidade e à viabilidade de, enfim, projetar a escola estadual paulista sob a lente do conforto ambiental. 


\section{REFERÊCIAS BIBLIOGRÁFICAS}

AKUTSU, M. Recursos para previsão do desempenho térmico de uma edificação. In: USP, E. P. Anais do Simpósio Nacional de Conservação de Energia nas Edificações USP 1989. [S.I.]: Escola Politécnica da USP, 1989. p. 109-125.

AKUTSU, M.; VITTORINO, F. Tratamento de dados climáticos para a avaliação do desempenho térmico de edificações: manual de procedimentos para avaliação. IPT. São Paulo. 1988. Relatório interno IPT.

AKUTSU, M.; VITTORINO, F.; KANACIRO, C. Tratamento estatístico de dados climáticos para a definição dos períodos de verão e inverno. Anais do Encontro Nacional de Conforto no ambiente construído - ANTAC, ABERGO, SOBRAC Florianópolis, 1993. Florianópolis: [s.n.]. 1993.

ALLUCI, M. P. Dados Climáticos, Diagrama Bioclimático, Balanço Térmico, Classificação Climática, Zona de Conforto, Geometria Ótima. São Paulo: FAUUSP, 1998. (Apostila da disciplina AUT 815 - Projeto Arquitetônico: Critérios para Adequação Climática das Edificações).

ALUCCI, M. P. Conforto térmico, conforto luminoso e conservação de energia elétrica: procedimentos para desenvolvimento e avaliação de projetos. São Paulo: FAUUSP, 1993. (Tese de doutoramento em arquitetura).

ALUCCI, M. P. Conservação de Energia Elétrica nas Edificações. São Paulo: FAUUSP, 1997. (Apostila da disciplina AUT 815 - Projeto Arquitetônico: Critérios para Adequação Climática das Edificações).

ANDRADE, M. R. D.; VIANNA, N. S. Procedimentos metodológicos para aplicação pós-ocupação em conjuntos habitacionais para a população de baixa renda: do desenho urbano à unidade habitacional. In: ABIKO, A. K.; ORNSTEIN, S. W. Inserção Urbana e Avaliação Pós-Ocupação (APO) da Habitação de Interesse Social. São Paulo: FAUUSP, v. 1, 2002. Cap. 8, p. 210-241.

BAPTISTA, G. M. D. M. Ilhas urbanas de calor. Scientific American Brasil, São Paulo, p. 24-30, 2010.

BARING, J. G. D. A. Contribuições para a correta resolução acústica dos edifícios. São Paulo: FAUUSP, 1981. Dissertação de mestrado.

BARING, J. G. D. A. O desempenho acústico de caixilhos de fachada no contexto do controle da poluição sonora urbana. São Paulo: FAUUSP, 1989. Tese de doutorado.

BARING, J. G. D. A. Acústica de Janelas in Manual Técnico de Caixilhos e Fachadas. São Paulo: Pini, 1991. 
BEHLING, S.; BEHLING, S. Sol Power - La evolución de la arquitectura sostenible. Barcelona: Gustavo Gili, 2002.

BENCOSTTA (ORG), M. L. A. História da educação, arquitetura e espaço escolar. São Paulo: Cortez Editora, 2005.

BIDERMAN (ORG) [ET AL], R. Guia de compras públicas sustentáveis: uso do poder de compra do governo para a promoção de desenvolvimento sustentável. Rio de Janeiro: Editora FGV, 2006.

BISTAFA, S. R. Acústica aplicada ao controle do ruíd. São Paulo: Blücher, 2006.

BROWN, G. Z.; DEKAY, M. Sol, vento \& luz - estratégias para o projeto de arquitetura. 2ª ${ }^{a}$ ed. Porto Alegre: Bookman, 2004.

BUITONI, C. S. Mayumi Watanabe Souza Lima: a construção do espaço para a educação. São Paulo: [s.n.], 2009. Dissertação de Mestrado / FAU USP.

BUTTI, K.; PERLIN, J. Un hilo dorado - 2.500 años de arquitectura y tecnologia sola. Madrid: Hermann Blume, 1985.

CAMPILONGO, C. F. Política, Sistema Jurídico e Decisão Judicial. São Paulo: Max Limonad, 2002.

CAMPOS, C. D. São Paulo pela Lente da Higiene - As propostas de Geraldo Horácio de Paula Souza para a cidade (1925-1945). São Carlos: RiMa, 2002. ISBN 85-86552-28-3.

CAVALEIRO E SILVA, A.; MALATO, J. Geometria da insolação dos edifícios. Lisboa: Laboratório Nacional de Engenharia Civil, 1969.

CHICHIERCHIO, L. C. Desempenho térmico das construções. São Paulo: FAUUSP, 1981.

CHTOL, T. M.; EVSTRÁTOV, G. I. Construção de edifícios e obras públicas em climas quentes. Tradução de Anatóli Kutchumov. Moscou: Mir Moscovo, 1987.

CONESP. Edificação e seus elementos construtivos - Especificações da edificação escolar. 2ª . ed. São Paulo: FDE, 1988.

CORBELLA, O.; YANNAS, S. Em busca de uma Arquitetura Sustentável para os Trópicos. Rio de Janeiro: Revan, 2003. ISBN 85-7106-268-4.

CORREAA, M. E. P.; MELLO, M. G. D.; NEVES, H. M. V. Arquitetura Escolar Paulista 1890 - 1920. São Paulo: FDE, 1991.

CORREA, M. E. P.; MELLO, M. G. D.; NEVES, H. M. V. Arquitetura escolar paulista 1890-1920. São Paulo: FDE Fundação para o Desenvolvimento da Educação, 1991. 
COSTA, E. C. D. Arquitetura ecológica - condicionamento térmico natural. São Paulo: Edgar Blücher, 1982.

CREMONESI, J. F. Planejamento e utilização do entorno de vias expressas em função do nível de ruído. São Paulo: FAUUSP, 1974.

CUNHA (ORG), E. G. D. Elementos de arquitetura de climatização natural: método projetual buscando a eficiência nas edificações. Porto Alegre: Masquatro, 2006. ISBN 85-99897-03-9.

CUNHA, J. R. A. D.; ESTEVES, R. G. Manual prático do mobiliário escolar. São Paulo: ABIME, 2001.

DEL CARLO (COORD), U.; VILELA (ELAB), M. M. Projeto EMA - XXI energia e meio ambiente para o século XXI. São Paulo: IEE USP, 1997.

DEL CARLO, U. Ruído urbano. São Paulo: FAUUSP, 1989. Tese de livre-docência.

ENERGIA SOLAR PASSIVA - PRINCÍPIOS BÁSICOS, C. T. [S.I.]: TEIXEIRA, Artur Pedro. Coleção "Formação profissional"; Lisboa: Plátano Editora, s.d..

ENGE, R. B. Planejamento da rede física escolar. São Paulo: [s.n.], 2007. Dissertação de Mestrado FAU USP.

ETCHEBÈHÉRE JÚNIOR, L.; MAZZALI, L.; VIÉGAS, R. F. Educação e filantropia na cidade de São Paulo, no final do século XIX e primeiras décadas do século XX. História da Educação, Pelotas, n. 22, p. 155-181, Mai/Ago 2007. ISSN 1414-3518.

FDE. Arquitetura Escolar e Política Educacional. São Paulo: FDE, 1998.

FDE. FDE Relatório de Atividades 2007 | 2010. São Paulo: FDE, 2010.

FERREIRA, A. D. F.; CORRÊA, M. E. P.; MELLO, M. G. D. Arquitetura Escolar Paulista - Restauro. São Paulo: FDE, 1998.

FERREIRA, A. D. F.; MELLO, M. G. D. Arquitetura escolar paulista - anos 1950 1960. São Paulo: FDE, 2006.

FERREIRA, A. D. F.; MELLO, M. G. D. Arquitetura Escolar Paulista - estruturas pré-fabricadas. São Paulo: FDE, 2006.

FICHER, S. Os arquitetos da Poli. São Paulo: EDUSP, 2005.

FROTA, A. B. Geometria da Insolação. São Paulo: Geros, 2004. ISBN 85-9021933-X.

FROTA, A. B.; SCHIFFER, S. R. Manual de Conforto Térmico. 2ª ed. São Paulo: Studio Nobel, 1995. ISBN 85-85445-39-4.

GAMA, R. Glossário. São Paulo: FAUUSP, 1982. 
GIVONI, B. Man, climate and architecture. London: Appley Science Pub, 1976.

GONDRA, J. G. Entre o cura e o médico: higiene, docência e escolarização no Brasil Imperial. História da Educação, Pelotas, n. 22, p. 183-204, Mai/Ago 2007. ISSN 1414-3518.

GREGORY, R. L. Olho e Cérebro. Rio de Janeiro: Zahar, 1979. ISBN 0691024561.

HADLICH, F. As escolas do Ipesp: projetos de edifícios escolares produzidos para o Instituto de Previdência do Estado de São Paulo de 1959 - 1962. São Paulo: [s.n.], 2009. Dissertação de Mestrado FAU USP.

HARVEY, D. O trabalho, o capital e o conflito de classes em torno do ambiente construído nas sociedades capitalistas avançadas. Espaço e Debates. Revista Espaço e Debates, v. 6, p. 6-34, 1982.

JORGE, L. A. O desenho da janela. São Paulo: Annablume, 1995.

LADURIE, E. L. R. Historia del clima desde el año mil. México, DF: Fondo de cultura económica, 1991. ISBN 968-16-3262-1. (Título original: Histoire du climat depuis l'an mil. Flammarion: París, 1983).

LAMBERTS, R. et al. Eficiência energética em edificações: estado da arte. Rio de Janeiro: Eletrobrás, CEPEL, 1996.

LEMOS, C. A. C. Ramos de Azevedo e seu escritório. São Paulo: PINI, 1993.

LIMA (COORD), M. W. D. S. Avaliação pós-ocupação em conforto ambiental em escolas estaduais de $1^{\circ}$ grau no Estado de São Paulo. CONESP FDE. São Paulo. 1988.

LIMA, M. W. D. S. Arquitetura e educação. São Paulo: Studio Nobel, 1995.

LIMA, M. W. D. S. Caderno de Avaliação do conforto ambiental das escolas de 1ำ grau da rede estadual de São Paulo: Recomendações para novas especificações. [S.I.].

MALATO, A. C.; MALATO, J. J. Geometria da insolação de edifícios. Lisbota: LNEC, 1969.

MARCILIO, M. L. O bê-á-bá no caos.

MASCARÓ, L. R. D. Ambiência urbana = Urban environment. 2ª . ed. Porto Alegre: +4, 2004. ISBN 85-241-0517-8.

MOREIRA, N. S. Construção escolar - desenvolvimento, políticas e propostas para a escola rural visando a democratização do campo. São Paulo: [s.n.], 2000. Dissertação de Mestrado FAU USP. 
MOREIRA, N. S. Espaços educativos para a escola de ensino médio, proposta para as escolas do Estado de São Paulo. São Paulo: [s.n.], 2006. Tese de Doutorado FAU USP.

MOREIRA, N. S.; ORNSTEIN, S. W. Acessibilidade na Rede Física de Escolas Públicas do Estado de São Paulo: Condições Atuais e Desafios Futuros. São Paulo: Anablume, 2010.

MOREIRA, V. D. A. Iluminação \& Fotometria. 2ª . ed. São Paulo: Edgard Blücher, 1982.

NORMAIS Climatológicas. Brasília: Departamento Nacional de Meteorologia da Secretaria Nacional de Irrigação do Ministério da Agricultura e Reforma Agrária, 1992.

OLGYAY, V.; OLGYAY, A. Arquitectura y clima, Barcelona, 1998.

OLIVEIRA, F. V. D. Arquitetura escolar paulista nos anos 30. São Paulo: [s.n.], 2007. Dissertação de Mestrado FAU USP.

ORNSTEIN, S. W. et al. Improving the quality of school facilities through building performance assessment. Journal of Educational Administration, California, v. 47, p. 350-367, 2009. ISSN 978-1-84855-712-3.

ORNSTEIN, S. W.; BORELLI NETO, J. O desempenho dos edifícios da rede estadual de ensino - $O$ caso da Grande São Paulo - Avaliação técnica: primeiros resultados. São Paulo: FAUUSP, 1993.

PRADO, L. C. D. Acústica arquitetônica. São Paulo: FAUUSP, 1962.

RIVERO, R. Arquitetura e clima: Acondicionamento térmico natural. Porto Alegre: D.C. Luzzatto Editores, Ed. da Universidade, UFRGS, 1985.

RIVERO, R. Arquitetura e clima: acondicionamento térmico natural. Porto Alegre: Editora da Universidade UFRGS, 1985.

ROGERS, R.; GUMUCHDJIAN, P. Cidades para um pequeno planeta. Amadora: Gustavo Gili, 2001.

RORIZ, M. Luz do Sol. Radiação Solar e lluminação (software). São Carlos: [s.n.], 1995.

SAIA, L. Morada Paulista. 2ª ed. São Paulo: Perspectiva, 1978. ISBN 8527306050. (Coleção Debates).

SANOFF, H. School Design. New York: Van Nostrand Reinhold, 1994.

SCARAZZATO, P. S. A Luz Natural na Tecnologia da Arquitetura e do Urbanismo em Regiões Tropicais e Subtropicais Úmidas. Catálogos Técnicos AUT, São Paulo, v. 1, p. 23-35, 1996. 
SCHMIDT (ORG), R. F. Fisiologia Sensorial. 3ª ed. São Paulo: EPUSP, 1980. ISBN 3-540-40053-2. (Coleção "Ciências Médicas) (Título original: Grundriß der Sinnesphysiologie. Heidelberg: Springer-Verlag Berlin, 1977).

SCHWARCZ, L. M. As Barbas do Imperador - D Pedro II, um Monarca nos Trópicos. 2ª . ed. São Paulo: Companhia das Letras, 2006. ISBN 85-7164-837-9.

SEGAWA, H. Clave de sol: notas sobre a história do conforto ambiental. Revista da ANTAC - Ambiente Construído, Porto Alegre, v. 3, n. 2, p. 37-46, 2003.

SIGNORINI, M. M. Metrologia. São Paulo: FAUUSP, 1986. Trabalho Programado.

TEIXEIRA, A. P. Energia solar passiva: princípios básicos, cálculos, tabelas. Lisboa: Plátano, s/d.

TOLEDO, B. L. D. Prestes Maia e as origens do urbanismo moderno em São Paulo. São Paulo: Empresa das Artes, 1996.

VARGAS, M. Metodologia da pesquisa tecnológica. Rio de Janeiro: Globo, 1985.

VERNIER, J. O meio ambiente. Campinas: Papirus, 1994.

VIANNA, N. S.; GONÇALVES, J. C. S. Iluminação e Arquitetura. São Paulo: Virtus, 2001.

VITRUVIUS. Tratado de Arquitetura. Tradução de M. Justino Maciel. São Paulo: Martins Fontes, 2007. ISBN 978-85-7707-003-9. (original em latim c. 27 AC) (Coleção Todas as Artes).

WOLFF, S. F. S. Escolas para a República: Os Primeiros Passos da Arquitetura das Escolas Públicas Paulistas. São Paulo: EDUSP, 2010.

Catálogos técnicos da FDE: http://catalogotecnico.fde.sp.gov.br 